\title{
Algoritmos Evolutivos Multi-Objetivo para Reconfiguração de Redes em Sistemas de Distribuição de Energia Elétrica ${ }^{1}$.
}

Tese apresentada à Escola de Engenharia de São Carlos da Universidade de São Paulo, como parte dos requisitos para obtenção do título de Doutor em Ciências pelo Programa de Engenharia Elétrica.

Área de concentração: Sistemas Elétricos de Potência

Orientador: Prof. Dr. João Bosco Augusto London Junior Co-Orientador: Prof. Dr. Alexandre Cláudio Botazzo Delbem

\section{São Carlos}

2013

\footnotetext{
${ }^{1}$ Trata-se da versão corrigida da tese. A versão original se encontra disponível na EESC/USP que aloja o Programa de Pós-Graduação de Engenharia Elétrica.
} 

AUTORIZO A REPRODUÇÃO TOTAL OU PARCIAL DESTE TRABALHO, POR QUALQUER MEIO CONVENCIONAL OU ELETRÔNICO, PARA FINS DE ESTUDO E PESQUISA, DESDE QUE CITADA A FONTE.

Sanches, Danilo Sipoli

Algoritmos evolutivos multi-objetivo para

S211a reconfiguração de redes em sistemas de distribuiçăo de energia elétrica / Danilo Sipoli Sanches; orientador João Bosco Augusto London Junior; coorientador Alexandre Cláudio Botazzo Delbem. São Carlos, 2013.

Tese (Doutorado) - Programa de Pós-Graduação em Engenharia Elétrica e Área de Concentração em Sistemas Elétricos de Potência -- Escola de Engenharia de São Carlos da Universidade de Săo Paulo, 2013.

1. Algoritmos evolutivos multi-objetivo. 2 . Representaçằ nó-profundidade. 3. Reconfiguraçăo de redes. 4. Sistemas de distribuiçăo de grande porte. I. Título. 

FOLHA DE JULGAMENTO

Candidato: Bacharel DANILO SIPOLI SANCHES.

Título da tese: "Algoritmos evolutivos multi-objetivo para reconfiguração de redes em sistemas de distribuição de energia elétrica".

Data da defesa: 14/01/2013

\section{Comissão Julgadora:}

Resultado:

Prof. Associado João Bosco Augusto London Júnior (Orientador) Aprovado (Escola de Engenharia de São Carlos/EESC)

Prof. Dr. José Roberto Sanches Mantovani (Universidade Estadual Paulista "Júlio de Mesquita Filho"/UNESP-campus Ilha Solteira)

Prof. Dr. Oriane Magela Neto

(Universidade Federal de Minas Gerais/UFMG)

Prof. Dr. Cláudio Fabiano Motta Toledo

Aprovado

(Instituto de Ciências Matemáticas e de Computação/USP)

Prof ${ }^{a}$. Dra. Telma Woerle de Lima Soares

Aprovado

(Universidade Federal de Goiás/UFG)

Coordenador do Programa de Pós-Graduação em Engenharia Elétrica e Presidente da Comissão de Pós-Graduação:

Prof. Titular Denis Vinicius Coury 


\section{Dedicatória}

Aos meus pais, Nelson e Márcia, ao meu irmão Murilo, à minha namorada Fernanda e a todos os que acreditaram na realização desse trabalho. 



\section{Agradecimentos}

À Deus, primeiramente, pela minha existência e por iluminar os meus caminhos.

Ao meu orientador professor João Bosco Augusto London Jr., pela orientação, confiança e paciência com que me atendeu ao londo de toda a caminhada, e por acreditar em mim no desenvolvimento desta tese. Agradeço também pelas críticas construtivas e revisão de artigos científicos.

Ao meu co-orientador professor Alexandre Cláudio Botazzo Delbem, pelas inúmeras colaborações e ensinamentos, e pelo tempo generosamente dedicado ao longo de todo o doutorado. Agradeço também pelo total incentivo e motivação à pesquisa.

Aos amigos do LACOSEP (Laboratório de Análise Computacional em Sistemas Elétricos de Potência) pelas constantes colaborações e discussões, e principalmente, pela amizade.

Aos amigos das reuniões de quarta-feira, Raphael, Fernando, Guilherme e Rogério, pelo companheirismo, cachaça e amizade.

Aos funcionários do Departamento de Engenharia Elétrica: Marisa, Jussara, Verinha e Odair, que me auxiliaram ao longo desses anos.

Aos amigos conquistados durante todo o tempo de trabalho em São Carlos.

À Coordenação de Aperfeiçoamento de Pessoal de Nível Superior (CAPES), pela concessão da bolsa de doutorado.

À Escola de Engenharia de São Carlos (EESC/USP) por todo suporte necessário para o desenvolvimento desta tese.

Aos meus pais, Nelson e Márcia, e meu irmão, Murilo, pela ajuda e conselhos em todos momentos.

À Fernanda, pela constante ajuda, incentivo e carinho nos momentos difíceis. 

"É melhor tentar e falhar, que preocupar-se e ver a vida passar.

É melhor tentar, ainda que em vão que sentar-se, fazendo nada até o final.

Eu prefiro na chuva caminhar, que em dias frios em casa me esconder.

Prefiro ser feliz embora louco, que em conformidade viver."

Martin Luther King 



\section{Sumário}

Lista de Abreviaturas e Siglas $\quad$ xiii

Lista de Figuras $\quad$ Xv

Lista de Tabelas $\quad$ xvii

Lista de Algoritmos $\quad$ xix

Resumo $\quad$ xxi

Abstract $\quad$ xxiii

1 Introdução 1

1.1 Introdução . . . . . . . . . . . . . . . . . . . . . . 1

1.2 Sistemas Elétricos de Potência . . . . . . . . . . . . . . . . . 2

1.2.1 Sistema de Distribuição de Energia . . . . . . . . . . . . . . . . 3

1.3 Apresentação do Problema . . . . . . . . . . . . . . . . . . . . . . 4

1.4 Reconfiguração de Redes . . . . . . . . . . . . . . . . . . . . 5

1.4.1 Redução de Perdas em Sistemas de Distribuição Radiais . . . . . . 5

1.4.2 Restabelecimento de Energia em Sistemas de Distribuição Radiais . 6

1.5 Metodologias para Abordagem dos Problemas . . . . . . . . . . . . . . 7

1.6 Objetivo . . . . . . . . . . . . . . . . . . 8

1.7 Organização do Trabalho . . . . . . . . . . . . . . . . . . 9

2 Reconfiguração de Redes em Sistemas de Distribuição 11

2.1 Introdução . . . . . . . . . . . . . . . . . . . . . . . . . 11

2.2 Revisão Bibliográfica . . . . . . . . . . . . . . . . . . . 11

2.2.1 Restabelecimento de Energia em Sistemas de Distribuição Radiais . 11

2.2.2 Redução de Perdas em Sistemas de Distribuição Radiais . . . . . . 16

2.2.3 Metodologias baeseadas em AEs . . . . . . . . . . . . . . 18

2.3 Representação de um Sistema de Distribuição através de Grafos . . . . . . 19

2.4 Formulação Matemática . . . . . . . . . . . . . . . . . . . . . . . . 22

2.5 Fluxo de Carga para SDRs . . . . . . . . . . . . . . . . . 25 
2.5.1 Método de Varredura Direta/Inversa . . . . . . . . . . . . . . . 26

2.5.1.1 Método de Soma de Correntes . . . . . . . . . . . . . . . 27

2.5.1.2 Método de Soma de Potências . . . . . . . . . . . . . . . 28

2.6 Modelagem da Carga . . . . . . . . . . . . . . . . . . . . . 30

2.6.1 Carga de impedância constante com a tensão . . . . . . . . . . . . . 31

2.6.2 Carga de potência constante com a tensão . . . . . . . . . . . . . . 31

2.6.3 Carga de corrente constante com a tensão . . . . . . . . . . . . 32

2.7 Cálculo do número de manobras . . . . . . . . . . . . . . . . . . . . 33

2.8 Conclusões . . . . . . . . . . . . . . . . . . . . . . . . . 35

3 Representação Nó-Profundidade $\quad 37$

3.1 Introdução . . . . . . . . . . . . . . . . . . . . . . . 37

3.2 Representação Nó-Profundidade . . . . . . . . . . . . . . . . . . . . . . 37

3.2 .1 Operadores da RNP . . . . . . . . . . . . . . . . . . . . . 38

3.2.1.1 Operador PAO . . . . . . . . . . . . . . . 39

3.2.1.2 Operador CAO . . . . . . . . . . . . . . 39

3.2.2 Determinação dos nós (vértices) $p, r$ e $a \ldots \ldots$. . . . . . . . 41

3.2.3 Localização de um nó (vértice) na RNP . . . . . . . . . . . . . . . . 41

3.3 Conclusões . . . . . . . . . . . . . . . . . . . . . . . 43

4 Algoritmos Evolutivos para Otimização Multi-Objetivo 45

4.1 Introdução . . . . . . . . . . . . . . . . . . . . . . . . . . 45

4.2 Algoritmos Evolutivos . . . . . . . . . . . . . . . . . . . . 45

4.2.1 Evolução Diferencial . . . . . . . . . . . . . . . . . . . . . . 47

4.2.1.1 Funcionamento . . . . . . . . . . . . . . . . . . 47

4.3 Problemas de Otimização Multi-Objetivo . . . . . . . . . . . . . . . . . . . 49

4.3.1 Conceitos Básicos . . . . . . . . . . . . . . . . . 50

4.3.2 Diferenças entre Otimização Mono-Objetivo e Multi-Objetivo . . 51

4.4 Algoritmos Evolutivos para Otimização Multi-Objetivo . . . . . . . . . . . 52

4.4.1 NSGA-II: Elitist Non-Dominanted Sorting Genetic Algorithm . . . 52

4.4.2 SPEA2: Strength Pareto Evolutionary Algorithm . . . . . . . . . 55

4.4.2.1 Seleção e truncamento . . . . . . . . . . . . . . 57

4.4.3 Algoritmo Evolutivo Multi-Objetivo em Tabelas . . . . . . . . . . . 58

4.5 Métricas de desempenho . . . . . . . . . . . . . . . . . . . . . . 59

4.6 Conclusões . . . . . . . . . . . . . . . . . . . . . . . . 60

5 AEMO para Reconfiguração de Redes em SDR 61

5.1 Introdução . . . . . . . . . . . . . . . . . . . . . . . . . . 61

5.2 Extensão da RNP para fluxo de carga . . . . . . . . . . . . . . . . . 61

5.2.1 Método de Soma de Correntes com RNP . . . . . . . . . . . . . . 64 
5.3 AEMT com o uso da RNP . . . . . . . . . . . . . . . . . 66

5.3.1 Resultados Obtidos com o AEMT . . . . . . . . . . . . . 67

5.4 NSNP - NSGA-II com o uso da RNP . . . . . . . . . . . . . . . . . . . 69

5.4 .1 Formulação Matemática . . . . . . . . . . . . . . 70

5.4 .2 NSNP - Pseudocódigo . . . . . . . . . . . . . . 71

5.4.3 Resultados Obtidos com o NSNP . . . . . . . . . . . . . . . 71

5.5 Conclusões . . . . . . . . . . . . . . . . . . . . . . 72

6 Metodologias Propostas $\quad 73$

6.1 Introdução . . . . . . . . . . . . . . . . . . . . . . . . . . . 73

6.2 AEMT com Soluções Não Dominadas e Strength Pareto . . . . . . . . . . . 73

6.3 Evolução Diferencial Multi-Objetivo em Tabelas . . . . . . . . . . . . . 77

6.3.1 Operador de Recombinação baseado no Histórico Evolutivo . . . . . 77 6.3.1.1 Exemplo Ilustrativo . . . . . . . . . . . . . . . . . . . 79

6.3.2 Mutação Diferencial por Lista de Movimentos . . . . . . . . . . . . 81 6.3.2.1 Exemplo Ilustrativo . . . . . . . . . . . . . . . 83

6.3.3 Funcionamento . . . . . . . . . . . . . . . 86

6.4 Conclusões . . . . . . . . . . . . . . . . . . . . . . . . . 90

7 Resultados Experimentais $\quad 91$

7.1 Simulações para o problema de Restabelecimento de Energia . . . . . . . . 92

7.1.1 Simulações para falta única . . . . . . . . . . . . . . . . . 93

7.1.1.1 Subpopulações de pares de manobras e heurística . . . . . 98

7.1.2 Simulações com múltiplas faltas . . . . . . . . . . . . . . . . . 103

7.2 Simulações para o problema de Redução de Perdas Ôhmicas . . . . . . . . 106

7.3 Conclusões . . . . . . . . . . . . . . . . . . . . . . 111

8 Conclusões e Trabalhos Futuros $\quad 113$

8.1 Conclusões . . . . . . . . . . . . . . . . . . . . . . . . . 113

8.2 Perspectivas Futuras . . . . . . . . . . . . . . . . . . . 115

9 Publicações Originadas desta Pesquisa $\quad 117$

9.1 Artigos Submetidos . . . . . . . . . . . . . . . . . 117

9.2 Artigos Aceitos para Publicação . . . . . . . . . . . . . . . . . . . 117

9.3 Artigos Publicados . . . . . . . . . . . . . . . . 118

$\begin{array}{ll}\text { Referências Bibliográficas } & 119\end{array}$ 



\section{Lista de Abreviaturas e Siglas}

\begin{tabular}{|c|c|}
\hline$A C G$ & Ancestral Comum Geral. \\
\hline$A E$ & Algoritmo Evolutivo. \\
\hline$A E M O$ & Algoritmo Evolutivo Multi-Objetivo. \\
\hline$A E M T$ & Algoritmo Evolutivo Multi-Objetivo em Tabelas. \\
\hline$A E M T-S P$ & Algoritmo Evolutivo Multi-Objetivo em Tabelas com Soluções Não \\
\hline & Dominadas e Strength Pareto. \\
\hline$A G$ & Algoritmo Genético. \\
\hline$B T$ & Busca Tabu. \\
\hline$B T R$ & Busca Tabu Reativa. \\
\hline$C A O$ & Change Ancestor Operator. \\
\hline$D E$ & Differential Evolution. \\
\hline$E D M T$ & Evolução Diferencial Multi-Objetivo em Tabelas. \\
\hline$E E$ & Estratégia Evolutiva. \\
\hline$E H R$ & Evolutionary History Recombination. \\
\hline$H V$ & Hipervolume. \\
\hline MOOP & Multi-Objective Optimization Problem. \\
\hline$M P F$ & Modelo Pai-Filho. \\
\hline$N A$ & Normalmente Aberto. \\
\hline$N F$ & Normalmente Fechado. \\
\hline$N S G A-I I$ & Non-Dominated Sorting Genetic Algorithm-II. \\
\hline$N S N P$ & NSGA-II com RNP. \\
\hline$P A O$ & Preserve Ancestor Operator. \\
\hline$R C G$ & Representação por Cadeia de Grafos. \\
\hline$R N P$ & Representação Nó-Profundidade. \\
\hline$S A$ & Simulated Annealing. \\
\hline$S D R$ & Sistema de Distribuição Radial. \\
\hline$S D R-S C$ & Sistema de Distribuição Radial real da cidade de São Carlos. \\
\hline$S E P$ & Sistema Elétrico de Potência. \\
\hline$S P E A 2$ & Strength Pareto Evolutionary Algorithm. \\
\hline
\end{tabular}





\section{Lista de Figuras}

1.1 Sistemas Elétricos de Potência (adaptado de (GARCIA, 2005)) . . . . . . . 2

1.2 Ilustração de um sistema de distribuição (adaptado de (GARCIA, 2005)). . 3

2.1 Exemplo de um grafo. . . . . . . . . . . . . . . . . . . . . 20

2.2 Exemplo de um Sistema de Distribuição Radial. . . . . . . . . . . . . . . . 21

2.3 Exemplo de um SDR representado por um grafo. . . . . . . . . . . . . 26

2.4 Passo backward sweep. . . . . . . . . . . . . . . . . . . . . . 28

2.5 Alimentador de uma rede de distribuição. . . . . . . . . . . . . . . . . . . . 29

2.6 Sistema de Distribuição Radial com duas barras. . . . . . . . . . . . . . . . 31

2.7 Operações de manobras necessárias para isolar o setor em falta. . . . . . . 34

3.1 Exemplo de um grafo e sua RNP . . . . . . . . . . . . . . . 38

3.2 Ilustração dos passos do operador PAO . . . . . . . . . . . . . . . . 40

3.3 Ilustração dos passos do operador CAO. . . . . . . . . . . . . . . . . . 42

4.1 Processo para gerar um vetor modificado $v_{i}^{G+1}$ de uma função bidimensional. 48

4.2 Curva Conforto X Custo do automóvel. . . . . . . . . . . . . . . . . . . . 50

4.3 Ordenação por não dominância $($ Deb, 2001) . . . . . . . . . . . . . . . . 53

4.4 Esquema para uma iteração do NSGA-II (Deb, 2001) . . . . . . . . . . . . 56

4.5 Algoritmo de Corte no modelo SPEA2 (ZITZLER et al., 2001). . . . . . . 58

5.1 SDR com dois alimentadores. . . . . . . . . . . . . . . . . 62

5.2 Agrupamento das linhas e barras em setores. . . . . . . . . . . . . . . . 62

5.3 Grafo representando setores do SDR da Figura 5.2. . . . . . . . . . . . . 62

5.4 Árvore do setor D, com os nós adjacentes aos setores B e H. . . . . . . . . 63

6.1 Fronteiras de pareto obtidas através das tabelas $F_{1}, F_{2}$ e $F_{3} \ldots \ldots$. . . . 75

6.2 Histórico de aplicações dos operadores PAO e CAO . . . . . . . . . . . . . 78

6.3 SDR com três alimentadores modelados por um grafo com três árvores. . . 79

6.4 RNP dos três alimentadores da Figura 6.3. . . . . . . . . . . . . . . 79

6.5 Inidivíduo gerado com o operador PAO na configuração da Figura 6.3. . . . 80

6.6 Inidivíduo gerado com o operador CAO na configuração da Figura 6.3. . 80 
6.7 Ancestral comum dos indivíduos das Figuras 6.5 e 6.6 . . . . . . . . . 81

6.8 Novo indivíduo gerado pelo operador EHR. . . . . . . . . . . . . . . 81

6.9 Lista de movimentos de $X_{2}$ até $Y_{2} \ldots \ldots \ldots \ldots$. . . . . . . 83

6.10 Indivíduo $X_{\alpha}$ selecionado aleatoriamente na população. . . . . . . . . . . . 84

6.11 Indivíduo $X_{\beta}$ selecionado aleatoriamente na população. . . . . . . . . . . . 84

6.12 Indivíduo $X_{\gamma}$ selecionado aleatoriamente na população. . . . . . . . . . . . 84

6.13 Lista de Movimentos $M_{A C \beta} \ldots \ldots \ldots$. . . . . . . . . . . 85

6.14 Lista de Movimentos $M_{A C \gamma} \ldots \ldots \ldots$. . . . . . . . . . 85

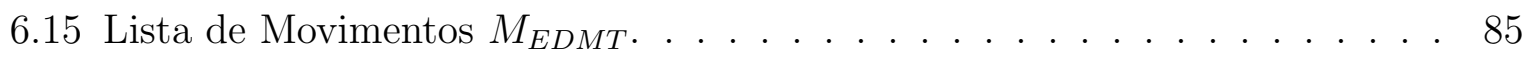

6.16 Lista de Movimentos $M_{E D M T}^{\prime} \ldots \ldots \ldots \ldots$. . . . . . . . . 85

6.17 Vetor modificado $v^{i}$ resultante. . . . . . . . . . . . . . . . 86

6.18 Indivíduos $X_{4}, Y_{5}, K_{2}$ e $W_{2}$ selecionados aleatoriamente da população. . . . 87

6.19 Mutação Diferencial. . . . . . . . . . . . . . . . . . . . 87

6.20 Cruzamento entre os indivíduos ancestrais de $X_{4}$ e $Y_{6}$ até o ACG. . . . . . 88

7.1 Fronteiras de Pareto obtidas para o sistema 1. . . . . . . . . . . . . 96

7.2 Fronteiras de Pareto obtidas para o sistema 2. . . . . . . . . . . . . 96

7.3 Fronteiras de Pareto obtidas para o sistema 3. . . . . . . . . . . . . 97

7.4 Fronteiras de Pareto obtidas para o sistema 4. . . . . . . . . . . . . . . . . 97

7.5 Fronteiras de Pareto obtidas para o sistema 1. . . . . . . . . . . . . . . 101

7.6 Fronteiras de Pareto obtidas para o sistema 2. . . . . . . . . . . . . . . . 102

7.7 Fronteiras de Pareto obtidas para o sistema 3. . . . . . . . . . . . . 102

7.8 Fronteiras de Pareto obtidas para o sistema 4. . . . . . . . . . . . . 103

7.9 Fronteiras de Pareto obtidas para múltiplas faltas. . . . . . . . . . . . . 105

7.10 Fronteiras de Pareto obtidas para o sistema 1. . . . . . . . . . . . . . . . 109

7.11 Fronteiras de Pareto obtidas para o sistema 2. . . . . . . . . . . . . . 110

7.12 Fronteiras de Pareto obtidas para o sistema 3. . . . . . . . . . . . . . . . 110

7.13 Fronteiras de Pareto obtidas para o sistema 4. . . . . . . . . . . . 111 


\section{Lista de Tabelas}

2.1 Grau de cada um dos nós do grafo da figura 2.1. . . . . . . . . . . . 20

2.2 Manobras de chaves - caso 1. . . . . . . . . . . . . . . . . . . 34

2.3 Manobras de chaves - caso 2. . . . . . . . . . . . . . . . . . 35

2.4 Manobras de chaves - caso 3. . . . . . . . . . . . . . . . . . 35

7.1 Características da $1^{a}$ configuração factível para os sistemas 1, 2, 3 e 4. . . 93

7.2 Número de manobras obtidas para os Sistemas 1, 2, 3 e 4. . . . . . . . . . 94

7.3 Simulações para uma falta no Sistema 1. . . . . . . . . . . . . . . . 95

7.4 Simulações para uma falta no Sistema 2. . . . . . . . . . . . . . . . 95

7.5 Simulações para uma falta no Sistema 3. . . . . . . . . . . . . . . . 95

7.6 Simulações para uma falta no Sistema 4. . . . . . . . . . . . . . . . . 95

7.7 Valores obtidos de hipervolume para as três metodologias. . . . . . . . . . . 98

7.8 Número de manobras obtidas com o uso da heurística. . . . . . . . . . . . . . 99

7.9 Simulações com heurística para uma falta no Sistema 1. . . . . . . . . . . . 100

7.10 Simulações com heurística para uma falta no Sistema 2. . . . . . . . . . . . 100

7.11 Simulações com heurística para uma falta no Sistema 3. . . . . . . . . . . . 100

7.12 Simulações com heurística para uma falta no Sistema 4. . . . . . . . . . . . 101

7.13 Valores obtidos de hipervolume para as três metodologias. . . . . . . . . . . 103

7.14 Características da $1^{a}$ configuração factível encontrada para múltiplas faltas. 104

7.15 Número de manobras obtidas para o problema de múltiplas faltas. . . . . . 104

7.16 Valores obtidos de hipervolume para o sistema 4 com múltiplas faltas. . . . 105

7.17 Valores da topologia inicial dos Sistemas 1, 2, 3 e 4. . . . . . . . . . . . . 106

7.18 Simulações para redução de perdas ôhmicas nos Sistemas 1, 2, 3 e 4. . . . 107

7.19 Resultados das simulações para o Sistema 1. . . . . . . . . . . . . . . 108

7.20 Resultados das simulações para o Sistema 2. . . . . . . . . . . . . . . . . . 108

7.21 Resultados das simulações para o Sistema 3. . . . . . . . . . . . . . . . . . 108

7.22 Resultados das simulações para o Sistema 4. . . . . . . . . . . . . . . . 108

7.23 Valores obtidos de hipervolume. . . . . . . . . . . . . . . . . . . 109 



\section{Lista de Algoritmos}

1 Determinação dos vértices $p, r$ e $a \ldots \ldots$. . . . . . . . . . . . 41

2 Algoritmo Evolutivo. . . . . . . . . . . . . . . . . . 46

3 Ordenação por não-dominância . . . . . . . . . . . . . . . . . . . . . . 54

4 Cálculo da distância de multidão. . . . . . . . . . . . . . . . . . . 54

5 NSGA-II. . . . . . . . . . . . . . . . . . . . 55

6 Subrotina CORRENTES. . . . . . . . . . . . . . . . . 65

$7 \quad$ Subrotina TENSÕES. . . . . . . . . . . . . . . . . 65

8 Fluxo de carga. . . . . . . . . . . . . . . . . 66

9 Algoritmo Evolutivo Multi-Objetivo em Tabelas. . . . . . . . . . . . . . . . 68

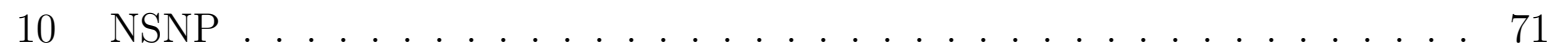

11 AEMT com Soluções Não Dominadas e Strength Pareto. . . . . . . . . . . . 76

12 Pseudocódigo do EHR. . . . . . . . . . . . . . . . . . . 79

13 Evolução Diferencial Multi-Objetivo em Tabelas. . . . . . . . . . . . . . 89 



\section{Resumo}

SANCHES, D. S. (2013). Algoritmos Evolutivos Multi-Objetivo para Reconfiguração de Redes em Sistemas de Distribuição de Energia Elétrica. 2013, 152 f. Tese (Doutorado) - Escola de Engenharia de São Carlos, Universidade de São Paulo, São Carlos, 2013.

Encontrar a configuração de mínimas perdas ôhmicas ou que forneça um adequado plano de restabelecimento após a ocorrência de faltas permanentes são problemas de natureza combinatorial, com múltiplos objetivos e restrições, que envolvem funções cujas características, em geral, dificultam o uso de técnicas de programação matemática. Algoritmos Evolutivos têm apresentado resultados animadores para esses problemas, especialmente quando aplicados em sistemas de dstribuição de grande porte. Neste trabalho são propostas duas novas metodologias, baseadas em Algoritmos Evolutivos Multi-Objetivo, para reconfiguração de redes em sistemas de distribuição, que podem ser aplicadas para o tratamento dos problemas de redução de perdas ôhmicas e restabelecimento de energia em sistemas de grande porte (com milhares de barras, linhas e chaves). Para o desenvolvimento dessas metodologias, foi utilizado uma estrutura de dados para manipular grafos produzindo exclusivamente configurações radiais e conexas, chamada Representação Nóprofundidade. As metodologias propostas foram testadas para diversos sistemas, dentre os quais destaca-se um com 30.880 barras, tendo sido satisfatórios os resultados obtidos. Para o problema de restabelecimento de energia foram testados falta única e múltiplas faltas.

Palavras-Chave: Algoritmos Evolutivos Multi-Objetivo, Representação Nóprofundidade, Reconfiguração de Redes, Sistema de Distribuição de grande porte. 



\section{Abstract}

SANCHES, D. S. (2013). Multi-Objective Evolutionary Algorithm for Network Reconfiguration in Distribution Systems. 2013, 152 f. Tese (Doutorado) - Escola de Engenharia de São Carlos, Universidade de São Paulo, São Carlos, 2013.

Find the distribution system configuration of minimum power losses or that provides an adequate service restoration plan is a combinatorial, multi-objective and multi constraint problems, which involves functions whose characteristics, in general, difficult the use of mathematical programming techniques. Evolutionary Algorithms have shown relevant results for these problems, especially for Large-Scale Distribution Systems. This work proposes two methodologies for network reconfiguration based on Multi-Objective Evolutionary Algorithms, which can be applied to treat the problems of power loss reduction and service restoration in large scale distribution systems (with thousands of buses, lines and switches). In order to develop these methodologies, it was used a data structure to manipulate graphs producing exclusively radial and connected connections, called Node Depth Encoding. The proposed methodologies were successfully tested in several distribution systems, among them one with 30,880 buses. The problem of service restoration is analyzed considering cases of single and multiple faults.

Keywords: Multi-Objective Evolutionary Algorithms, Node-depth Encoding, Network Reconfiguration, Large-scale Distribution System. 



\section{Capítulo 1}

\section{Introdução}

\subsection{Introdução}

A energia elétrica não é armazenável em larga escala. Portanto, a sua produção deve ser praticamente simultânea ao seu consumo. As etapas que envolvem desde a conversão de outras fontes de energia em energia elétrica até seu consumo final é denominado sistema de energia elétrica (ou sistema elétrico de potência).

Durante os últimos anos, o setor elétrico brasileiro têm sido alvo de significativas mudanças nas regulamentações, com o objetivo de melhorar cada vez mais a qualidade, continuidade e confiabilidade do abastecimento de energia elétrica. Por outro lado, questões financeiras, limitadoras da capacidade de investimento das empresas, estão cada vez mais presentes no contexto dos projetos de planejamento de sistemas de energia. Como consequência, observa-se no atual cenário das empresas que atuam no setor de distribuição de energia elétrica uma crescente necessidade de uso de sistemas computacionais para apoio às atividades de planejamento e operação das suas redes elétricas. As atividades dos engenheiros e operadores de sistemas de distribuição de energia têm necessitado de ferramentas computacionais que garantam agilidade e flexibilidade no projeto e operação destas redes (FERREIRA, 2010).

Este capítulo inicia-se com uma apresentação resumida da estrutura dos sistemas elétricos de potência no Brasil, ilustrando com maiores detalhes os sistemas de distribuição de energia elétrica. Em seguida, são introduzidos os problemas de redução de perdas e de restabelecimento de energia elétrica em sistemas de distribuição, analisando então a solução destes problemas através do processo de reconfiguração de redes, que é o foco deste trabalho. Nas últimas seções deste capítulo, encontram-se os objetivos deste trabalho e a organização dos demais capítulos. 


\subsection{Sistemas Elétricos de Potência}

A eletricidade é responsável por grande parte da energia consumida no Brasil, representando cerca de $17 \%$ do consumo energético final do país, ficando atrás apenas do óleo diesel (QUEIROZ, 2010). A figura 1.1 ilustra uma representação clássica da divisão dos sistemas elétricos de potência (SEP).

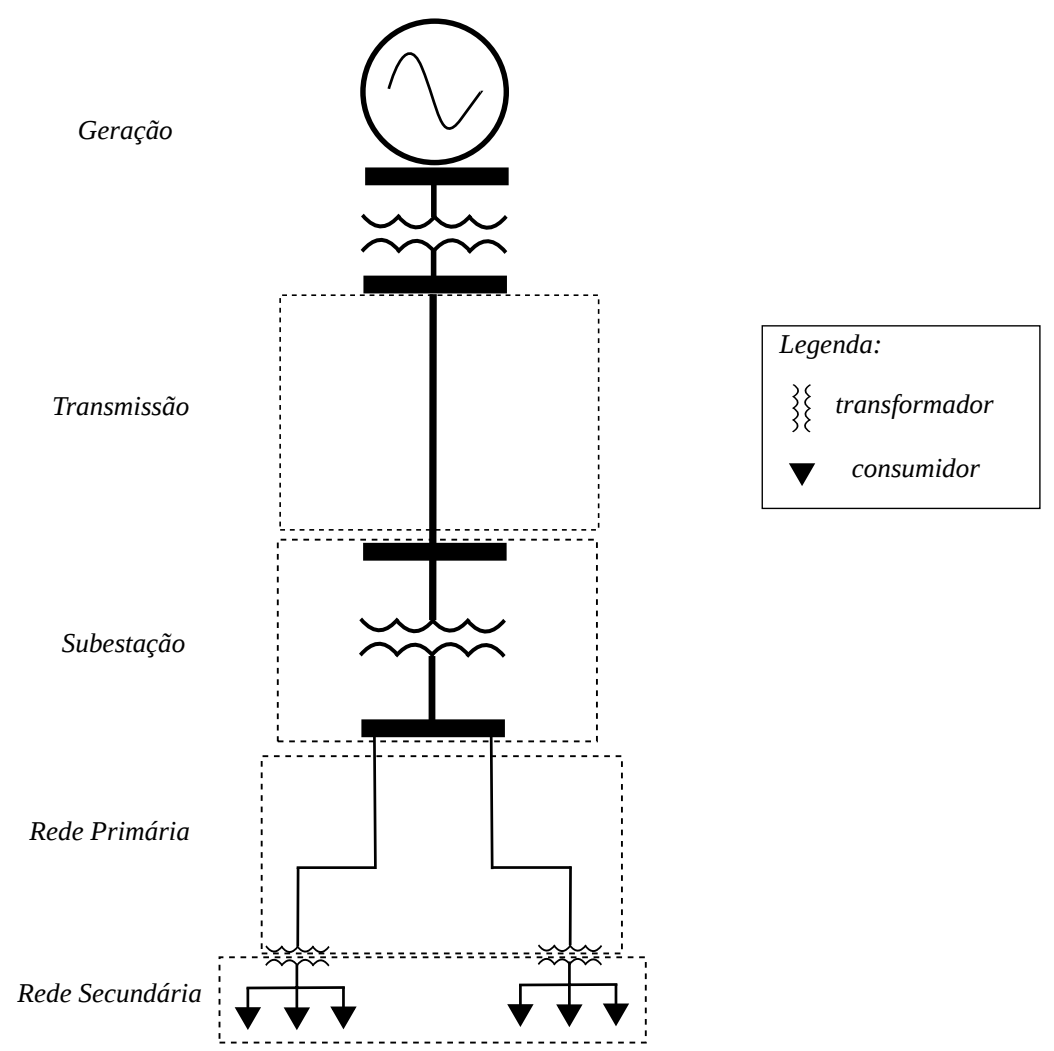

Figura 1.1: Sistemas Elétricos de Potência (adaptado de (GARCIA, 2005))

Conforme ilustrado na figura 1.1, os SEP podem ser subdivididos em (KAGAN; OLIVEIRA; ROBBA, 2005):

- Sistema de geração: composto pelas usinas de geração de energia elétrica, que geram a energia elétrica a partir da conversão eletromecânica de energia. A fonte primária de energia pode ser a água, o carvão, o óleo, a fissão nuclear, etc;

- Sistema de transmissão: composto basicamente por linhas de transmissão e transformadores reguladores, que conectam os pontos de geração aos pontos de consumo (até as subestações de distribuição);

- Sistema de distribuição: composto por subestações abaixadoras e circuitos elétricos (chamados alimentadores). É responsável pelo fornecimento de energia às áreas urbanas, rurais ou grandes empresas consumidoras. 


\subsubsection{Sistema de Distribuição de Energia}

O sistema de distribuição é a parte da rede elétrica que está localizada entre as subestações de distribuição e os consumidores, sejam eles alimentados em média tensão ou em baixa tensão. A partir desta definição considera-se que o sistema de distribuição é composto pelas subestações de distribuição, alimentadores e ramais laterais primários, transformadores abaixadores de média tensão para baixa tensão, geradores distribuídos com seus respectivos sistemas de controle, sistema de proteção e circuitos secundários (PEREIRA, 2009). A figura 1.2 ilustra um sistema de distribuição.

Portanto, o sistema de distribuição de energia elétrica pode ser dividido em:

- Sistema (ou rede) de Distribuição Primária (ou Distribuição de Média Tensão): opera geralmente em redes radiais aéreas na tensão de $13,8 \mathrm{kV}$. É projetado com possibilidade de transferência de blocos de cargas entre circuitos para o atendimento da operação em condições de contingências ou para manutenção preventiva e/ou corretiva. Esse sistema atende aos consumidores primários (industriais de médio porte, conjuntos comerciais, hospitais, shopping centers, instalações de iluminação pública, etc) e aos transformadores de distribuição que, por sua vez, suprem os sistemas de distribuição secundária ou de baixa tensão;

- Sistema (ou rede) de Distribuição Secundária (ou Distribuição de Baixa Tensão): opera geralmente em redes radiais ou em malha com tensões de 220/127V ou 380/220V. Atende aos consumidores de baixa tensão, pequenos comércios e indústrias e, principalmente, os consumidores domésticos. Essa parte do sistema de distribuição usualmente não conta com recurso para o atendimento de contingências.

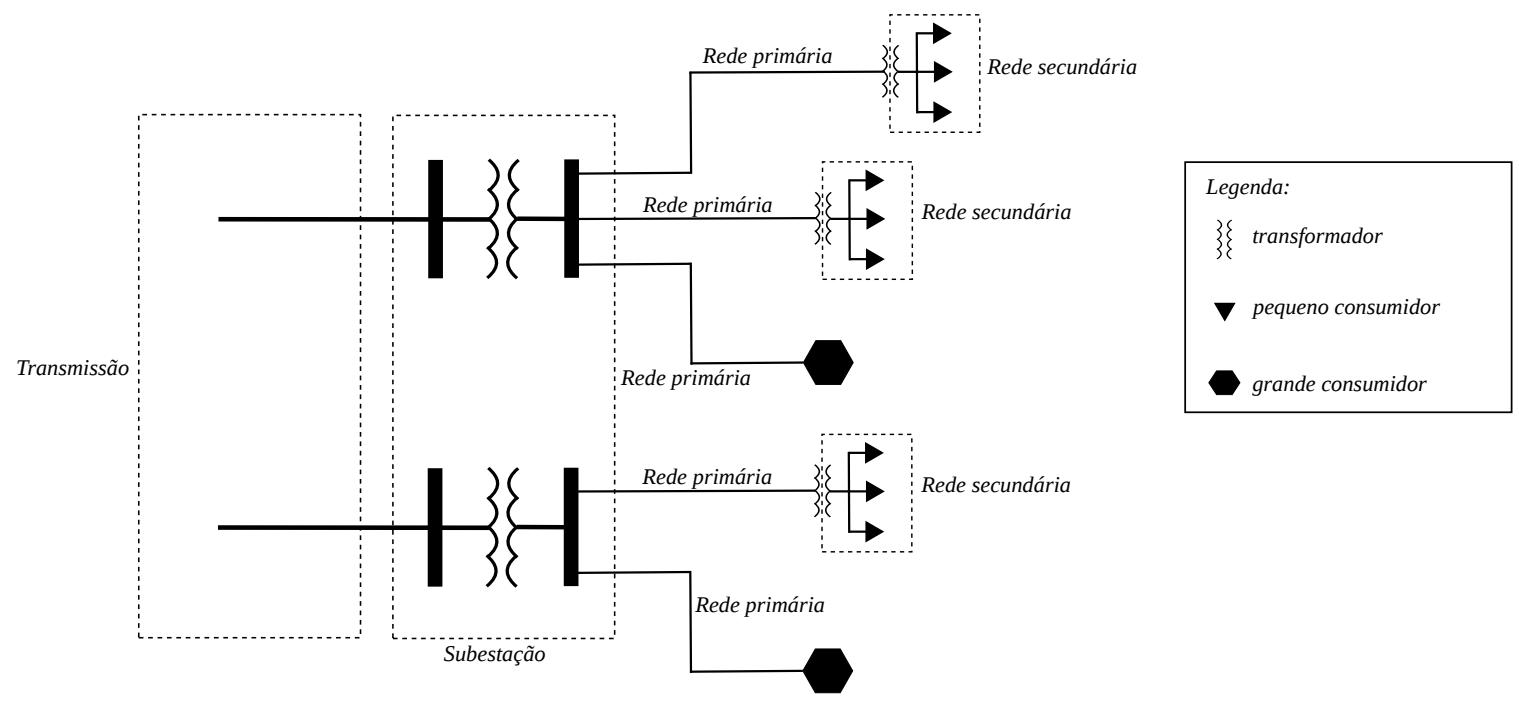

Figura 1.2: Ilustração de um sistema de distribuição (adaptado de (GARCIA, 2005)). 


\subsection{Apresentação do Problema}

Os sistemas de distribuição de energia elétrica devem operar de forma confiável e econômica, respeitando tanto as restrições de carga como as restrições operacionais. O primeiro tipo de restrição está relacionado com o suprimento da demanda total dos consumidores alimentados pelo sistema, enquanto que o segundo estabelece os limites de tensão e corrente para garantir que as linhas e os equipamentos instalados operem de forma segura e eficiente.

Operando em regime permanente, é desejável aumentar a eficiência e diminuir o custo operacional. Uma das formas de se obter este resultado é através da operação do sistema no estado de mínimas perdas. Neste estado, o sistema de distribuição apresenta um melhor perfil de tensão ao longo dos alimentadores, caracterizado por uma melhor distribuição do fluxo de potência nas linhas, o que influencia diretamente no aumento da vida útil dos equipamentos instalados na rede.

Assim como em outras cadeias produtivas, os SEP possuem perdas em cada uma de suas etapas. As perdas de energia elétrica são usualmente classificadas de acordo com a origem. As perdas pelo processo físico do transporte (condução e transformação) da energia elétrica são classificadas como perdas técnicas, enquanto que as demais perdas, como problemas na medição, erros em medições por estimativa, fraudes e furtos de energia elétrica, são classificadas como perdas não técnicas (QUEIROZ, 2010).

Outro aspecto de grande importância está relacionado com a continuidade do fornecimento de energia aos consumidores, que é fundamental para o bem estar da sociedade moderna. Entretanto, quando acontecem eventos que provocam o isolamento de partes do sistema, em função de uma dada situação de contingência ou da necessidade de manutenção programada, a consequência é o desabastecimento de um certo número de consumidores. Neste caso, a configuração das chaves de manobra instaladas na rede deve ser modificada com o objetivo de isolar o trecho sujeito à situação de contingência ou alvo da manutenção programada.

Uma vez realizado este isolamento, pela característica radial normalmente utilizada no sistema de distribuição, trechos à jusante do isolado também deixam de ser atendidos. Desta forma, uma reconfiguração da rede pode ser executada visando a melhora de indicadores, tais como número de consumidores atendidos, perfil de tensão, perda de energia nos condutores, balanceamento da carga entre alimentadores e outros (FERREIRA, 2010).

Este trabalho trata do problema de reconfiguração de redes em sistemas de distribuição radiais de grande porte. 


\subsection{Reconfiguração de Redes}

As interrupções no fornecimento de energia nos Sistemas de Distribuição Radiais (SDRs) são inevitáveis, isto em virtude da execução de obras de expansão, intervenções de manutenção preventiva em componentes da rede ou pela atuação de um dispositivo de proteção em decorrência de faltas permanentes. Desta forma, o agrupamento de vários pontos de carga em blocos separados por chaves, que operam no estado Normalmente Aberto (NA) e Normalmente Fechado (NF), foi uma solução encontrada para melhorar a confiabilidade dos SDRs sem incorrer em gastos excessivos. Esses blocos de carga são chamados de setores. Assim, a partir da reconfiguração da rede, isto é, da operação de chaves, é possível a troca de carga entre os alimentadores em caso de interrupção em algum ponto da rede. Nessas situações, torna-se necessário um plano de restabelecimento de energia, que consiste, basicamente, em determinar um conjunto de manobras de chaves para restringir as interrupções à menor parte possível do sistema.

Vale destacar ainda que em condições normais de operação, pode-se utilizar a reconfiguração de redes, através da manobra de chaves NA e NF, para reduzir as perdas totais por efeito joule (GOMES et al., 2005); (SARFI; SALAMA; CHIKHANI, 1995) e/ou para balanceamento de carga entre os alimentadores (CHEN et al., 2000), aliviando os alimentadores que estão com carregamento crítico. Dessa forma, a reconfiguração permite a redução de queda de tensão (MANTOVANI; CASARI; ROMERO, 2000) e alívio de trechos da rede com sobrecarga (STROGATZ, 2001) (corrente elétrica em níveis acima do suportado pelos cabos). A reconfiguração de redes pode ser aplicada, ainda, para o planejamento da expansão de SDRs, definindo a topologia em que o sistema irá operar no futuro (KAGAN, 1999).

Face ao exposto, reconfiguração de redes pode ser aplicada para tratamento de diversos problemas relacionados com a operação e planejamento de SDRs. Este trabalho abordará especificamente os problemas de restabelecimento de energia e redução de perdas, que serão discutidos com mais detalhes nas próximas seções.

\subsubsection{Redução de Perdas em Sistemas de Distribuição Radiais}

O problema de redução de perdas através da reconfiguração de redes foi primeiramente abordado por MERLIN; BACK (1975) e vem sendo bastante estudado desde então. A possibilidade de reconfiguração das redes de distribuição através da modificação do estado das chaves seccionadoras proporciona uma grande quantidade de configurações possíveis. Além de possibilitar a solução de problemas técnicos da operação de SDRs, realizar operações de chaveamento não é muito oneroso para as distribuidoras. Normalmente, os custos das operações de manobra se resumem a custos operacionais com o deslocamento de equipes, sendo que, em alguns casos, as chaves podem ser manobradas por comandos remotos. 
Vale destacar que, cada configuração apresenta um montante de perdas elétricas definidas pelos fluxos de potência e perfis de tensão ao longo da rede. O problema de minimização de perdas a partir do processo de reconfiguração de rede consiste em encontrar a configuração que apresenta a menor quantidade de perdas elétricas satisfazendo as restrições de queda de tensão, capacidade de fluxo nas linhas, carregamento das subestações, radialidade e atendimento das cargas (COSTA, 1999).

Entretanto, chaveamentos causam perturbações transitórias indesejáveis e diminuição do tempo útil das chaves. Por isso, os centros de operações de distribuição são normalmente reticentes em relação à manobras freqüentes. Portanto, metodologias que contemplem alternativas de compromisso entre reduções de perdas e riscos de manobras são promissoras (BUENO, 2005).

\subsubsection{Restabelecimento de Energia em Sistemas de Distribuição Radiais}

Depois de o setor em falta ter sido identificado e isolado, torna-se necessário a obtenção de um plano apropriado para restabelecimento da energia para as áreas sem falta que ficaram sem energia em função da atuação da proteção. Um plano de restabelecimento de energia adequado tem como principais necessidades práticas:

- Ser encontrado em um curto intervalo de tempo (tempo-real);

- O número de manobras deve ser mínimo;

- Reduzido número de consumidores interrompidos;

- Nenhum componente sobrecarregado;

- A estrutura radial (sem formar anéis) do sistema deve ser mantida;

- Reduzir o total de perdas resistivas;

- Reduzir quedas de tensão.

Face ao exposto, o restabelecimento de energia é um problema com múltiplos objetivos, alguns conflitantes. Naturalmente, outros objetivos, além dos supracitados, podem ser considerados na formulação do problema.

\footnotetext{
1 Busca-se um reduzido número de manobras (ou chaveamentos) basicamente por dois motivos: a operação frequente das chaves reduz a expectativa de vida destas; quanto mais manobras, maior o tempo para implementar o plano (as chaves são em geral operadas manualmente).
} 


\subsection{Metodologias para Abordagem dos Problemas}

Encontrar a configuração de mínimas perdas ou que forneça um adequado plano de restabelecimento é um problema de natureza combinatorial, onde o esforço de cálculo requerido para se garantir o ótimo global por enumeração exaustiva de todas as soluções possíveis é inviável para redes de grande porte.

Ante o exposto, as técnicas de programação matemática não são utilizadas nos problemas de reconfiguração de redes em SDR de grande porte. Algoritmos Evolutivos (AEs) são uma técnica alternativa que têm se mostrado capaz de lidar com esses problemas, porém produzem muitas configurações não factíveis quando aplicados em SDR de tamanho real (SANTOS, 2009). Vale destacar que no contexto deste trabalho configurações factíveis são configurações radiais que permitem o fornecimento de energia elétrica para todo o sistema ${ }^{2}$.

O desempenho de um AE convencional ${ }^{3}$, para reconfiguração de redes em SDR, é afetado principalmente pelos seguintes fatores:

1. A estrutura de dados adotada: reconfiguração de redes via AEs requer um algoritmo de busca em grafo. Assim, o desempenho dos AEs torna-se fortemente afetado pela forma com que as árvores de grafo são computacionalmente representadas. Importa lembrar que no problema em pauta as árvores do grafo representam os alimentadores dos SDRs;

2. Os operadores genéticos adotados, que podem produzir muitas configurações não factíveis; e

3. A conversão de um problema multi-objetivo em um mono-objetivo através da utilização de fatores de ponderação.

Buscando melhorar o desempenho dos AEs aplicados em problemas de reconfiguração de redes em SDR, os métodos propostos em (MANSOUR et al., 2009) e (SANTOS et al., 2010) usam uma nova estrutura de dados, denominada Representação Nó-Profundidade (RNP), e seus operadores genéticos.

A RNP melhora o desempenho dos AEs devido às suas seguintes propriedades (MANSOUR et al., 2009); (SANTOS et al., 2010): (i) A RNP e seus operadores produzem exclusivamente configurações factíveis; (ii) Em comparação com outras estruturas de dados, a RNP pode gerar mais configurações factíveis, num mesmo período de tempo, tendo em vista que a mesma apresenta uma complexidade computacional de ordem $O \sqrt{n_{s}}$ (SANTOS, 2009), onde $n_{s}$ é o número de vértices no grafo (ou setores do sistema); (iii)

\footnotetext{
${ }^{2} \mathrm{O}$ termo "todo o sistema" significa todas as partes ligadas do sistema, pois, em algumas situações não é possível conectar uma área fora de serviço em razão da falta de chaves.

3 AEs convencionais são aqueles que convertem um problema de otimização multi-objetivo em um problema mono-objetivo através da utilização de uma função agregação e de fatores de ponderação.
} 
Cada configuração gerada pela RNP e seus operadores possui todos os nós ordenados de acordo com uma relação conhecida como Modelo Pai-Filho (MPF), possibilitando, assim, a execução de um algoritmo de fluxo de carga de varredura direta/inversa de forma mais eficiente. Trabalhando com outras estruturas de dados e operadores, antes de aplicar um fluxo de potência de varredura direta/inversa é necessário executar um algoritmo de ordenação, toda vez que uma nova configuração for gerada, para organizar os nós de acordo com o MPF. Importa destacar que o estudo de fluxo de carga é necessário para avaliar a qualidade de cada configuração gerada por um AE na busca da solução mais adequada para o problema de reconfiguração de redes em análise.

Além de fazerem uso da RNP, os métodos propostos por MANSOUR et al. (2009) e SANTOS et al. (2010) fazem uso de AEs Multi-Objetivos (AEMOs).

O método proposto em (MANSOUR et al., 2009) baseia-se na combinação da RNP com uma versão modificada de um dos principais AEMOs da literatura denominado NSGA-II (do inglês, Elitist Non-Dominated Sorting Genetic Algorithm). Por outro lado, o método proposto em (SANTOS et al., 2010) faz uso da RNP em conjunto com um AEMO que trabalha em paralelo com várias subpopulações armazenadas em tabelas. Dessa forma, as melhores configurações do SDR, para cada característica do problema em análise (número de manobras, perdas resistivas, queda de tensão, carregamento da rede e carregamento da subestação), são armazenadas em suas respectivas subpopulações. Torna-se possível, então, encontrar de forma eficiente soluções pertencentes ao chamado conjunto de Pareto, que consiste das configurações que não são dominadas por solução alguma (DEB, 2001).

Desde ponto em diante, o método proposto em (SANTOS et al., 2010) será chamado simplesmente de AEMT (AE baseado no Método de Tabelas); já o método proposto em (MANSOUR et al., 2009) será chamado de NSNP (NSGA-II com RNP).

A eficiência dos métodos AEMT e NSNP foi comprovada através de diversas simulações computacionais realizadas em sistemas teste da literatura e no SDR da cidade de São Carlos, São Paulo, em operação em 1994, que possui 3.860 barras, 635 chaves, 3 subestações com dois transformadores com potência de 50MVA e um transformador de 25MVA e 23 alimentadores.

\subsection{Objetivo}

O principal objetivo deste trabalho é desenvolver duas novas metodologias para reconfiguração de redes em SDR, que possam ser aplicadas para o tratamento dos problemas de redução de perdas e restabelecimento de energia em SDR de grande porte (com milhares de barras, linhas e chaves), sem a exigência de simplificação alguma, seja na modelagem do problema seja na quantidade de equipamentos da rede elétrica a serem considerados. Entretanto, as duas novas metodologias não levam em consideração aspectos práticos como: 
sequência dos chaveamentos, consumidores prioritários, priorização de chaves automáticas e considerar vários níveis de carregamento do sistema.

Com isso, o foco de análise das metodologias será nos seguintes aspectos: obtenção de uma ferramenta que disponibilize adequados planos de reconfiguração de redes, seja eficiente para sistemas de pequeno e grande porte e forneça boas soluções para o problema de restabeleciemnto de energia com única e múltiplas faltas. Dessa forma, propõe-se:

1. Integrar as características dos métodos NSGA-II e SPEA2 no método AEMT, para obtenção de uma metodologia mais eficiente para tratamento de problemas de reconfiguração de redes em SDRs de grande porte;

2. Desenvolvimento de uma nova metodologia baseada no algoritmo de Evolução Diferencial (DE, do inglês Diffential Evolution) (STORN; PRICE, 1997). Com isso, o objetivo desta nova metodologia é aumentar a eficiência de busca por melhores soluções quando comparado com o AEMT, uma vez que o DE é a abordagem evolutiva de maior destaque atualmente devido as suas características e aos bons resultados obtidos;

3. Desenvolver uma herística que priorize as manobras entre os alimentadores com maior queda de tensão e maior carregamento da rede.

\subsection{Organização do Trabalho}

Os próximos Capítulos desta Tese estão organizados da seguinte forma:

- O Capítulo 2 revisa os principais trabalhos desenvolvidos para tratamento dos problemas de reconfiguração de redes em restabelecimento de energia e redução de perdas, bem como os principais métodos para cálculo de fluxo de carga em SDRs, que são de suma importância para a solução desses problemas de reconfiguração de redes. São apresentados também os conceitos básicos da teoria de grafos e uma formulação geral para problemas de reconfiguração de redes em SDRs.

- O Capítulo 3 apresenta a estrutura de dados denominada Representção NóProfundidade (RNP), que será utilizada para o desenvolvimento das metodologias propostas;

- O Capítulo 4 introduz conceitos de algoritmos evolutivos, com destaque para a evolução diferencial, seguido por conceitos de otimização multi-objetivo, descrevendo as técnicas tradicionais para resolver problemas de otimização multi-objetivo;

- O Capítulo 5 apresenta as metodologias desenvolvidas por MANSOUR et al. (2009) e SANTOS et al. (2010). 
- O Capítulo 6 apresenta as duas metodologias propostas neste trabalho.

- O Capítulo 7 apresenta testes comprobatórios da eficiência das metodologias propostas, juntamente com a análise dos resultados;

- O Capítulo 8 apresenta as conclusões do trabalho e as perspectivas futuras; e

- O Capítulo 9 apresenta as publicações originadas desta pesquisa. 


\section{Capítulo 2}

\section{Reconfiguração de Redes em Sistemas de Distribuição}

\subsection{Introdução}

Na próxima seção deste capítulo será apresentada uma revisão bibliográfica, destacando alguns dos principais trabalhos tratando dos problemas de reconfiguração de redes em SDRs que serão abordados neste trabalho, isto é, dos problemas de restabelecimento de energia em situações de faltas permanentes e redução de perdas ôhmicas. Em seguida, apresentar-se-á uma formulação matemática geral, bem como procedimentos e metodologias empregadas para solução desses problemas através da utilização de AEs, uma vez que esses algoritmos serão utilizados para desenvolvimento das metodologias propostas neste trabalho.

\subsection{Revisão Bibliográfica}

Diversos trabalhos foram desenvolvidas para tratar os problemas de redução de perdas e restabelecimento de energia através da reconfiguração de redes em SDRs. Alguns destes trabalhos serão brevemente apresentados a seguir.

\subsubsection{Restabelecimento de Energia em Sistemas de Distribuição Radiais}

Desde a década de 80, diversos estudos foram realizados sobre o problema de restabelecimento de energia em sistemas de distribuição após a ocorrência de faltas permanentes. Em (AOKI et al., 1989) é proposto um método gradiente dual efetivo para o problema de restabelecimento de energia. O método tem como objetivo restabelecer rapidamente as cargas desenergizadas no sistema de distribuição usando chaves seccionadoras. A restau- 
ração de serviço envolve a energização das cargas na parte isolada da rede, transferindo-as para alimentadores adjacentes por meio de manobras das chaves seccionadoras NA e NF. O Funcionamento do método é definido da seguinte maneira: primeiro transferem-se todas as cargas desenergizadas para alimentadores adjacentes (ou alimentadores de apoio). O próximo passo, chamado de estágios de apoio, os alimentadores de apoio que possuem violações de restrição devido as cargas extras transferidas, são definidos como alimentadores de violação, e as cargas extras são transferidas para outros alimentadores, eliminando as violações de restrição. Consideram-se as seguintes restrições operacionais: limite de fluxo nas linhas, queda de tensão adequada nos nós consumidores, capacidade dos alimentadores e radialidade. A função objetivo utilizada procura restaurar o maior número de cargas desenergizadas quanto possível. Os resultados computacionais obtidos demonstraram a rapidez e eficiência do método em evitar operações de chaveamento desnecessárias.

Em (MORELATO; MONTICELLI, 1989) é proposto um método para a resolução do problema de restabelecimento de energia através de uma busca heurística que percorre uma árvore de decisão binária, onde conhecimento específico é utilizado como guia na busca. O estado de cada chave pode ser aberto (0) ou fechado (1). A cada nível da árvore define-se uma variável de decisão, sendo que os estados determinam o caminho até as folhas. A busca heurística utilizada compreende uma busca em profundidade que testa a factibilidade de cada solução encontrada. Caso não seja factível, um backtrack é iniciado em busca de outra solução. Os resultados obtidos para uma rede de 20 nós consumidores, 33 chaves e 4 alimentadores indicam o potencial da técnica proposta.

Em (SHIRMOHAMMADI, 1992) regras heurísticas são utilizadas para determinar o número mínimo de manipulações de chaves para restabelecer a energia em uma área afetada por uma falta. O procedimento baseia-se primeiro na criação de uma rede malhada, por meio do fechamento de todas as chaves. A seguir executa-se um fluxo de carga para redes desse tipo, classificando as chaves quanto ao fluxo de potência que as atravessa. Busca-se então abrir a chave que apresenta o menor fluxo, repetindo-se esse procedimento até encontrar uma rede radial.

O trabalho de (FUKUYAMA; CHIANG; MIU, 1996) trata do problema de restabelecimento de energia com o uso de um algoritmo genético paralelo. Neste trabalho as restrições operacionais consideradas foram: limite de capacidade dos alimentadores, de queda de tensão e de fluxo nas linhas, que foram tratadas através de fatores de penalidades na função de avaliação dos indivíduos. Um operador de reparação também foi proposto, para situações nas quais um indivíduo gerado não corresponde a uma rede radial. Os resultados apresentados indicam a eficiência do método quanto a redução do tempo computacional gasto em relação ao tamanho da rede de distribuição utilizada.

Em (AUGUGLIARO; DUSONCHET; SANSEVERINO, 2000) foram utilizadas Estratégias Evolutivas (EE), com uma definição fuzzy de múltiplos objetivos que compõem um problema de restabelecimento de energia em SDRs, tais objetivos sendo conflitantes. 
Foi considerado a possibilidade de controle remoto das chaves, de bancos de capacitores e conexões de cargas. Desta forma, após a ocorrência de uma falta permanente, torna-se possível executar remotamente ações para restabelecer energia nas áreas afetadas. $\mathrm{Na}$ formulação do problema duas funções foram consideradas como principais: minimização de perdas resistivas e a maximização da quantidade de cargas a ser restabelecida. As configurações geradas são avaliadas através de conjuntos fuzzy. Como restrições foram consideradas: a permanência da estrutura radial, carregamento nos transformadores, carregamento das linhas e queda de tensão nas barras. Testes foram realizados em um SDR inicialmente malhado contendo 98 setores, 81 barras de carga e 24 bancos de capacitores. Considerou-se apenas a ocorrência de uma única falta permanente.

TOUNE et al. (2002) realizaram um estudo comparativo de 4 algoritmos heurísticos utilizados para restabelecimento de energia em SDRs. Os algoritmos estudados foram: Busca Tabu (BT), Busca Tabu Reativa (BTR), Simulated Anneling (SA) e AEs. O estudo foi realizado considerando o objetivo de encontrar, após a ocorrência de uma falta, planos de restabelecimento de energia que sejam capazes de minimizar o número de consumidores sem energia. Como restrições foram consideradas: manter a estrutura radial, queda de tensão, carregamento nos transformadores e carregamento nas linhas. Apresentou-se a formulação matemática de cada um dos algoritmos e foram realizadas comparações qualitativas e quantitativas entres os mesmos. Realizaram-se testes em um SDR contendo 3 alimentadores e 60 barras.

Em (SHIN et al., 2004) foi utilizada uma abordagem híbrida, combinando AEs e BTs, para resolver o problema de restabelecimento de energia e reconfiguração ótima de redes em SDR. No referido trabalho uma configuração é dita ótima se o plano de restabelecimento minimiza as perdas e atende às restrições operacionais do sistema, mantendo a rede radial. O algoritmo proposto procura utilizar as propriedades que os AEs e BTs têm de melhor, dando origem ao método denominado AG-Tabu. Na formulação do problema foram avaliados o custo das perdas resistivas e o custo total após a interrupção e reconexão do sistema devido a ocorrência de uma falta. A função objetivo utilizada avalia o custo de perdas ôhmicas e o custo total após a interrupção e reconexão do sistema devido a ocorrência de uma falta. Apesar da busca por um indivíduo com menor número de chaves alteradas estar implícita, o que consta na função objetivo é o custo para reduzir as perdas ou o custo total para proceder a alteração na topologia. Como restrições foram consideradas: carregamento nos transformadores, carregamento nas linhas e manutenção da estrutura radial. Testes foram realizados em um SDR com 7 alimentadores e 38 barras, com a ocorrência de uma única falta.

Em (HONG; HO, 2005) é proposto um método baseado em algoritmos genéticos (AGs) para determinar a configuração da rede de distribuição. O método proposto, formulado como um problema fuzzy multi-objetivo, leva em consideração a condição normal de operação e contingências. Os estados das chaves são considerados como medidas de prevenção 
para múltiplas faltas. Já a codificação dos cromossomos é baseada no número Prufer, que garante que a configuração do sistema seja sempre radial. Os resultados das simulações para dois diferentes sistemas de ditribuição, mostram a eficiência do método proposto.

Em (DELBEM; CARVALHO; BRETAS, 2005) é proposto uma nova codificação para SDRs baseada em Cadeia de Grafos, de modo a melhorar o desempenho dos AEs para tratamento de de problemas de reconfiguração de redes. A partir dessa codificação foram desenvolvidos operadores de reprodução não convencionais, que possibilita a geração de configurações factíveis, a partir de uma configuração factível já existente. Utilizando conceitos de grafos e, partindo do princípio que uma árvore de grafo pode ser representada por cadeias conectando a raiz às folhas, o conjunto de todas essas cadeias armazenadas adequadamente representa um alimentador de um SDR. Portanto, o conjunto de todos os alimentadores representa um sistema completo. A técnica proposta pode lidar com o problema multi-objetivo, utilizando sub-populações, semelhante à técnica empregada em (R. BENAYOUN J. DE MONTGOLFIER; LARITCHEV, 1971). Testes foram realizados em um SDR de grande porte, composto de 1471 barras, 249 chaves, 3 subestações e 23 alimentadores. Como restrições foram consideradas: queda de tensão, carregamento nas linhas e carregamento nos transformadores. A estrutura radial do SDR é sempre uma condição satisfeita no problema, pois os operadores de reprodução propostos geram apenas configurações factíveis. O artigo trata de uma falta por vez. Foram consideradas faltas em setores críticos da rede, por exemplo, que isolem todo um alimentador. Vale destacar que a técnica foi aplicada ao problema de reconfiguração de SDR, sendo testada em restabelecimento de energia, redução de perdas resistivas e planejamento de SDR.

Em (INAGAKI; NAKAJIMA; HASEYAMA, 2006) utilizou-se uma abordagem multiobjetivo baseada na obtenção de soluções pertencentes ao conjunto de Pareto. Para encontrar essas soluções são utilizados AEs. Desta forma, um número maior de configurações é disponibilizado para o operador decidir qual se adapta melhor ao problema. Uma combinação de AEs e SA é realizada com o objetivo de melhorar a precisão das soluções. $\mathrm{Na}$ formulação do problema foram considerados dois objetivos: reduzir a área fora de serviço após uma falta e o número de operações (ou manobras) de chaveamento. Os objetivos também priorizam consumidores como hospitais, shopping centers, etc; Como configurações infactíveis podem ser geradas durante as avaliações do algoritmo proposto, uma rotina para verificar e corrigir tais infactibilidades é aplicada. Testes foram realizados em um SDR com 4 transformadores, 6 alimentadores e 78 barras de carga. Apenas a ocorrência de uma única falta permanente foi abordada nos testes.

Em (KUMAR; DAS; SHARMA, 2008) foi desenvolvido um algoritmo para restabelecimento de energia em SDR, baseado no AEMO proposto por DEB et al. (2002), denominado NSGA-II. Modificações no NSGA-II foram realizadas para melhorar o desempenho computacional do mesmo. Os resultados obtidos pelo método proposto, denominado NSGA-II avançado, foram comparados com os resultados obtidos pelo NSGA-II proposto 
por DEB et al. (2002) e por um AE mono-objetivo. O NSGA-II avançado conseguiu obter os mesmos resultados encontrados pelas outras técnicas, porém com um tempo computacional menor. Isso deve-se à implementação do NSGA-II utilizando a estrutura de dados apresentada em (JENSEN, 2003). Na formulação do problema foram considerados os seguintes objetivos: reduzir a área fora de serviço, minimização do número de manobras (tanto para chaves remotamente controladas, quanto para chaves manualmente controladas) e minimizar as perdas resistivas. Testes foram realizados em quatro SDRs, todos de pequeno porte.

Em (GARCIA; FRANCA, 2008) propõe-se uma busca local baseada em uma heurística multio-bjetivo para o problema de restabelecimento de energia. O método de busca heurística multi-objetivo proposto é utilizado para explorar o espaço de soluções do problema de restabelecimento de energia, representado por todas as configurações da rede pós falta. Este é um método baseado na vizinhança que sistematicamente gera novas soluções a partir da transformação de outras soluções. As soluções geradas, chamadas de soluções vizinhas, são obtidas a partir de um mecanismo específico de geração de soluções. A minimização de dois objetivos conflitantes foram considerados: a carga não fornecida e o número de operações de chaveamento. Experimentos computacionais com três diferentes sistemas de distribuição apresentaram a flexibilidade e a eficiência do método proposto.

Em (KLEINBERG; MIU; CHIANG, 2009) é proposto um novo algoritmo heurístico que incorpora um esquema de corte de cargas para a resolução do problema de restabelecimento de energia em sistemas de distribuição. O algoritmo proposto baseia-se na ordenação dos índices das chaves para eliminar soluções infactíveis, identificando ao mesmo tempo conjuntos com soluções "ótimas". Um exemplo numérico é apresentado para ilustrar o funcionamento do algoritmo proposto.

Em (DIMITRIJEVIC; RAJAKOVIC, 2011) é proposto uma nova abordagem heurística baseada no algoritmo de Prim (CORMEN, 2002) para o tratamento do problema de restabelecimento de energia em redes de distribuição. Para tanto, consideram-se, como objetivos, a minimização do número de consumidores sem energia e a redução do número de operações de manobras. A abordagem proposta, baseia-se no fato de que a maior parte dos equipamentos de manobras em uma área desenergizada, permanecem no mesmo estado (aberto ou fechado) em que encontravam-se antes da falta. Com isso, durante o processo de restabelecimento, os ramos que possuem chaves no estado NF e/ou chaves controladas remotamentes, são priorizadas para aceitar as cargas dos ramos que possuem chaves no estado NA. Com isso, a partir da priorização de chaves, espera-se obter uma influência direta na redução do número de operações de manobras. Os resultados obtidos, a partir de experimentos computacionais com um sistema de distribuição composto por 468 barras e 608 ramos, indicaram boa qualidade de soluções. 


\subsubsection{Redução de Perdas em Sistemas de Distribuição Radiais}

Conforme mencionado anteriormente em (MERLIN; BACK, 1975), foi desenvolvido um dos primeiros trabalhos relacionado ao problema de redução de perdas a partir do processo de reconfiguração de redes. Foram desenvolvidos dois diferentes métodos de resolução. O primeiro é um método heurístico, conhecido como abertura sequencial de chaves, onde parte-se de uma rede em que todas as chaves se encontram fechadas e através de uma heurística baseada nos fluxos dos ramos, abre-se as chaves até alcançar uma configuração radial. O segundo método é uma abordagem exata que encontra a configuração ótima de mínimas perdas através da técnica de programação inteira branch-and-bound. Segundo os autores, a aplicação do segundo método é viável apenas em redes de pequeno porte.

SHIRMOHAMMADI; HONG (1989) modificaram a heurística de MERLIN; BACK (1975), incluindo, na formulação do problema, os limites de tensão nos barramentos e de corrente nas linhas. Também apresentaram um modelo de cálculo de fluxo de carga para redes radiais, válido também para redes fracamente malhadas.

CIVANLAR et al. (1988) apresentaram uma nova heurística para reconfiguração de redes, conhecida como troca de ramos (do inglês branch-exchange), onde a cada etapa realiza-se uma permutação de estados entre pares de chaves, uma aberta e outra fechada, objetivando redução de perdas. BARAN; WU (1989a) aperfeiçoaram a abordagem de CIVANLAR et al. (1988), propondo dois novos métodos para o cálculo de fluxo de carga para redes radiais.

Em (NARA et al., 1992) é proposto um dos primeiros métodos baseado em AEs aplicado ao problema de reconfiguração de redes em sistemas de ditribuição. Neste trabalho é proposto uma representação binária para os cromossomos que representam os estados das chaves seccionadoras ( 1 - chave fechada e 0 - chave aberta). Testes foram realizados em dois tipos de sistemas de distribuição e comparados com a abordagem proposta por AOKI et al. (1990), comprovando que os métodos baseados em AEs apresentam um melhor desempenho. KASHEM; GANAPATHY; JASMON (2001) também seguem a linha de troca de ramos para reduzir perdas, desenvolvendo uma análise da circunferência de perdas para determinar a troca mais adequada, originalmente proposta por BARAN; WU (1989b). A técnica, denominada de metodologia geométrica pelos autores, é testada em uma rede de 69 barras e comparada com a metodologia de BARAN; WU (1989b). Obtêmse as mesmas soluções, porém, executando menor quantidade de cálculos de fluxos de carga. Consequentemente, alcançam os resultados com menores tempos computacionais.

Em (J.Z.; ZHU, 2002) é proposto um AE para minimização de perdas resistivas em SDR. O mesmo é denominado AE refinado, devido àlgumas alterações na codificação do cromossomo da abordagem proposto por NARA et al. (1992). Neste trabalho, um cromossomo é representado por uma string contendo somente o número de chaves seccionadoras 
NA representada por números binários. Uma análise dos algoritmos das duas abordagens foi realizado, indicando que a complexidade do método proposto por NARA et al. (1992) aumenta com o número de chaves do sistema enquanto que a do $\mathrm{AE}$ refinado proposto por J.Z.; ZHU (2002) aumenta com a quantidade de chaves seccionadoras NA em uma configuração factível.

Em (HSIAO, 2004) é proposto um AE multi-objetivo para reconfiguração de redes em sistemas de distribuição. Os múltiplos objetivos considerados foram: minimizar as perdas de energia, garantir a qualidade da tensão, garantia de confiabilidade de serviço e minimização de manobras. Geralmente, os atributos destes quatro objetivos acima são diferentes e alguns podem ser conflitantes. Por isso, para auxiliar na qualidade das soluções, é proposto um algoritmo interativo fuzzy. Um sistema da Tai-Power Company foi utilizada para avaliar a metodologia. VENKATESH et al. (2004) propõem reduzir perdas e melhorar os níveis de tensões em sistemas de distribuição, também utilizando lógica fuzzy e computação evolutiva. A metodologia proposta é avaliada com testes em uma rede pequena, adotada anteriormente por BARAN e WU (1989).

VITORINO; JORGE; NEVES (2009) propõe um novo método baseado em AG para melhorar a confiabilidade e minimizar as perdas em SDRs. A metodologia é baseada na simulação de Monte Carlo e em dados históricos da rede. O método analisa o SDR em duas perspectivas. A primeira perspectiva considera que não há nenhum investimento na rede, considerando apenas as chaves seccionadoras já existentes, e uma segunda perspectiva que define quais os ramos a serem equipados com novas chaves seccionadoras. O número máximo de chaves que podem ser colocados na rede e os ramos candidatos são definidos por um agente de decisão. A eficácia do método é demonstrada através da análise de um sistema de distribuição de 69 barras.

WU; TSAI (2011) propuseram uma abordagem eficaz baseada na otimização por enxame de partículas, com codificação inteira para determinar bons esquemas de operações de manobras para reconfiguração de redes. A abordagem proposta é capaz de melhorar a eficiência da busca para problemas de reconfiguração de redes, considerando o histórico de soluções ótimas locais na geração de novas partículas. As soluções ótimas locais encontradas durante o processo de evolução são usadas quando novas partículas são geradas. Três diferentes sistemas de distribuição foram usados neste trabalho, para verificar e validar a eficiência do método proposto. Resultados das simulações mostram que o método proposto pode encontrar soluções para os problemas de redução de perdas, em sistemas de distribuição, de forma mais eficiente computacionalmente quando comparado com otimização por enxame de partículas discreto, otimização por enxame de partículas com codificação binária e AGs.

RAO et al. (2012) propõem um novo método para tratar do problema de reconfiguração de redes considerando geração distribuída. Os objetivos do trabalho são: minimização das perdas ôhmicas e melhora do pefil de tensão no sistema de distribuição. Para 
tanto, uma meta-heurístca denominada Algoritmo de Busca Harmônica é utilizada para o auxiliar no processo de reconfiguração de redes e identificação de alocações ótimas de geração distribuída no sistema de distribuição. As restrições de máxima queda de tensão e carregamento da rede são incluídos na avaliação da função objetivo. O método proposto foi avaliado para sistemas de distribuição com 33 e 69 barras, apresentando bons resultados para redução de perdas e alocação ótima de geração distribuída.

\subsubsection{Metodologias baeseadas em AEs}

Conforme apresentado nas seções anteriores, os métodos mais recentes, desenvolvidos para tratamento dos problemas de reconfiguração de redes restabelecimento de energia e redução de perdas ôhmicas, baseiam-se em AEs. No capítulo 4 os AEs serão apresentados com mais detalhes, mas para possibilitar o entendimento das demais seções deste capítulo, importa destacar algumas definições básicas sobre AEs. AEs são métodos de otimização inspirados nos princípios da Seleção Natural (Teoria de Darwin), que utilizam técnicas e conceitos da genética. O princípio básico dos AEs é o seguinte: dada uma população inicial de indivíduos (isto é, um conjunto de soluções), pressões do ambiente desencadeiam um processo de seleção natural (ou seja, um processo que privilegia as melhores soluções até então encontradas), causando um incremento na adequação dos indivíduos (soluções). Dessa forma, dada uma função a ser otimizada (seja maximizada ou minimizada), gera-se aleatoriamente um conjunto de soluções (uma população), isto é, elementos pertencentes ao domínio da função. Em seguida, aplicando a função a ser otimizada, verifica-se a qualidade das soluções geradas, atribuindo-lhes um valor que mede sua adequação ao problema, chamado fitness ou aptidão. Com base no fitness, algumas das melhores soluções são selecionadas para darem origem a um novo conjunto de soluções (uma nova geração), através da aplicação de operadores genéticos (recombinação e/ou mutação).

A recombinação é um operador genético aplicado em duas ou mais soluções (chamadas pais) resultando em duas ou mais novas soluções (chamadas descendentes ou filhos). A mutação é aplicada em uma única solução a fim de gerar outra. Ao final desse processo, as novas soluções (descendentes) competem com as soluções da geração anterior, com base no fitness, para assumir um lugar na nova população. Esse processo é iterativo até que se encontre uma solução que seja suficientemente qualificada ou até que um número máximo de iterações (gerações) seja atingido. No contexto de reconfiguração de redes em SDRs, os indivíduos (ou soluções) representam configurações dos SDRs. Dessa forma, através da abertura e fechamento de chaves seccionadoras obtém-se uma população inicial de configurações. Em seguida, realiza-se uma análise, de cada configuração gerada, para verificar a sua factibilidade e adequação ao problema (o fitness da solução). Para ser factível uma solução (ou configuração) deve atender às restrições técnicas do problema, como, por exemplo, a característica radial da rede e os limites operacionais dos equipamentos. Defini-se 
a adequação (ou fitness) de cada configuração, em função dos objetivos a serem minimizados ou maximizados (como, por exemplo, número de consumidores sem energia, número de manobras necessárias para implantação de cada configuração gerada e perdas ôhmicas). As melhores configurações (ou soluções) são então selecionadas para darem origem a um novo conjunto de configurações, através da aplicação de operadores genéticos. Tais operadores realizam basicamente alterações nos estados das chaves seccionadoras gerando novas configurações a partir das configurações geradas anteriormente.

Para avaliar a factibilidade e o fitness de cada configuração gerada por um AE é necessária a execução de um fluxo de carga e de metodologias eficientes para contagem do número de manobras necessárias para implantação de cada configuração. Dessa forma, haja vista a necessidade de avaliação de uma grande quantidade de configurações, tornase necessário a utilização de estruturas de dados eficientes computacionalmente, para representação da topologia elétrica dos SDRs, que possibilitem o desenvolvimento e/ou aplicação de operadores genéticos que gerem exclusivamente configurações radiais, bem como de eficientes algoritmos para cálculo de fluxo de carga. Em razão dessas necessidades, apesar dos métodos baseadas em AEs terem apresentado resultados animadores, para tratamento de problemas de reconfiguração de redes, a maioria desses métodos podem ser aplicados apenas em SDRs de pequeno porte, ou, em modelos simplificados de SDRs de grande porte (que não consideram todas as chaves e/ou barras desses sistemas).

Conforme discutido na seção 1.5, do capítulo 1, para superar a limitação dos métodos baseados em AEs, os métodos NSNP e AEMT, propostos respectivamente em (MANSOUR et al., 2009) e (SANTOS et al., 2010), fazem uso da estrutura de dados RNP em conjunto com AEMOs. Essas metodologias possibilitam o tratamento de problemas de reconfiguração de redes em SDRs de grande porte, sem a exigência de simplificação alguma, considerando todas as chaves e barras desses sistemas. Entretanto, a qualidade dos resultados obtidos por esses métodos, para SDRs de grande porte, não é a mesma em relação aos obtidos para SDRs de pequeno porte. Além disso, a qualidade dos resultados obtidos não se mantém quando tais métodos são aplicados para tratamento do problema de restabelecimento de energia no caso de múltiplas faltas. Para desenvolvimento das duas metodologias propostas neste trabalho, utilizar-se- ão AEMO e a estrutura de dados RNP. Dessa forma, as próximas seções deste capítulo apresentarão questões relativas ao problema de reconfiguração de redes com enfoque na aplicação de AEMO e RNP.

\subsection{Representação de um Sistema de Distribuição através de Grafos}

Uma diversidade de problemas pode ser representada por meio de diagramas que consistem em um conjunto de pontos e linhas que conectam alguns desses pontos. Um exemplo 
conveniente são as redes elétricas, as quais, basicamente, consistem de um conjunto de barras e de ramos que as interconectam, onde cada barra pode ser representada por um ponto e as conexões entre as mesmas podem ser representadas por linhas. A abstração matemática de problemas desse tipo dá lugar ao conceito de grafo.

Um grafo $G$ consiste de um conjunto finito $N(G)$ de elementos, chamados nós, e um conjunto finito $E(G)$ de pares de nós não-ordenados, chamados arestas. Um grafo é simbolicamente representado por $G=(N, E)$. Se $V$ e $W$ são dois nós de um grafo, e se o par $V, W$ é uma aresta denotada por e, diz-se que $e$ conecta $V$ e $W$, como pode ser visto na Figura 2.1. Neste caso, a aresta $e$ é dita incidente aos nós $V$ e $W$.

A ordem de um grafo $G$ é dada pelo número de elementos do conjunto finito $N(G)$, ou seja, pelo número de nós de $G$. O tamanho de um grafo $G$ é dado pelo seu número de arestas, isto é, pelo número de elementos do conjunto finito $N(E)$. Assim, a ordem do grafo da Figura 2.1 é 5 e seu tamanho também é 5 . O grau de um nó é dado pelo número de arestas que lhe são incidentes. A Tabela 2.1 apresenta o grau de cada nó do grafo da Figura 2.1.

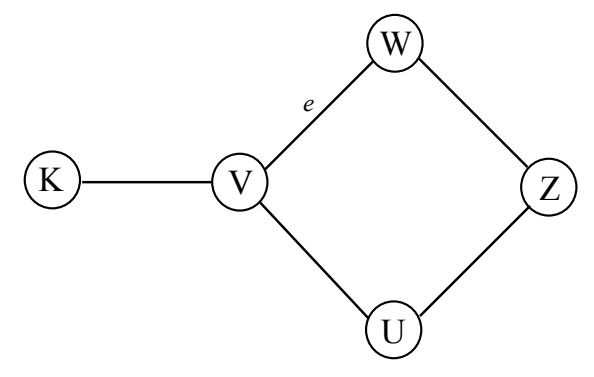

Figura 2.1: Exemplo de um grafo.

Tabela 2.1: Grau de cada um dos nós do grafo da figura 2.1.

\begin{tabular}{|c||c|}
\hline \hline Nó & Grau \\
\hline \hline $\mathrm{K}$ & 1 \\
$\mathrm{~W}$ & 2 \\
$\mathrm{U}$ & 2 \\
$\mathrm{~V}$ & 3 \\
$\mathrm{Z}$ & 2 \\
\hline \hline
\end{tabular}

Dado um grafo $G$, uma sequência de arestas $\left\{s_{0}, s_{1}\right\},\left\{s_{1}, s_{2}\right\}, \ldots,\left\{s_{m-2}, s_{m-1}\right\}$, $\left\{s_{m-1}, s_{m}\right\}$, em que todas as arestas são distintas, é chamada de caminho, isto é, um caminho é uma sequência de nós, tal que de cada um dos nós exista uma única aresta distinta para o nó seguinte. Alem disso, se os nós $s_{0}, s_{1}, s_{2}, \ldots, s_{m-1}$ e $s_{m}$ são distintos, então o caminho é chamado de cadeia ou caminho simples. O comprimento do caminho é o número de arestas que o caminho usa. Se somente os nós $s_{0}$ e $s_{m}$ são iguais, o caminho é chamado de ciclo.

Da Figura 2.1, tem-se: 
- Exemplo de um caminho: $\{K, V\},\{V, W\},\{W, Z\}$ e $\{Z, U\}$;

- Exemplo de um ciclo: $\{V, W\},\{W, Z\},\{Z, U\}$ e $\{U, V\}$;

Um par de nós de um grafo é um par conexo, se existir um caminho entre esses nós. Um grafo $G$ é um grafo conexo, se todo par de nós em $G$ é um par conexo.

Diz-se que $H$ é um subgrafo conexo máximo de um grafo $G$, se um único subgrafo conexo contendo $H$ é o próprio $H$. Um subgrafo conexo $H$ máximo também é chamado de componente. Um grafo $G$ é conexo se o número de seus componentes for igual a um.

Um grafo acíclico é um grafo sem ciclos. Uma árvore é um grafo acíclico conexo. Uma floresta é um grafo formado por um conjunto de árvores. Logo cada componente de uma floresta é uma árvore. Quando uma floresta tem apenas uma árvore, ela é uma floresta conexa. Assim, uma árvore é uma floresta conexa.

Geralmente, chama-se um dos nós de uma árvore de nó raiz. Este é tomado como uma referência e pode ter grau maior ou igual a um. Nós que possuem grau um são chamados de nós terminais, exceto se for o nó raiz. Uma árvore geradora (spanning tree) de um grafo $G$ é qualquer subárvore de $G$ que contenha todos os nós de $G$.

Para abordagens de problemas de reconfiguração de redes em sistemas de distribuição, os principais componentes a serem representados são: chaves, blocos de carga, linhas e subestações. A Figura 2.2 ilustra a topologia elétrica de uma rede de distribuição possuindo 2 subestações e 4 alimentadores, destacando os componentes supracitados. Cada barra (nó) do sistema representa um bloco de carga e as arestas interligando as barras são chaves seccionadoras. As arestas em linha cheia representam as chaves NF, enquanto as arestas em linha tracejada representam as chaves NA. A rede da Figura 2.2 pode ser representada por um modelo de grafos (AHUJA R.; ORLIN, 1993). Essa representação é conveniente por dois aspectos: pela abstração intuitiva da rede e pela possibilidade de implementar algoritmos eficientes utilizando resultados e estruturas de dados da área de grafos.

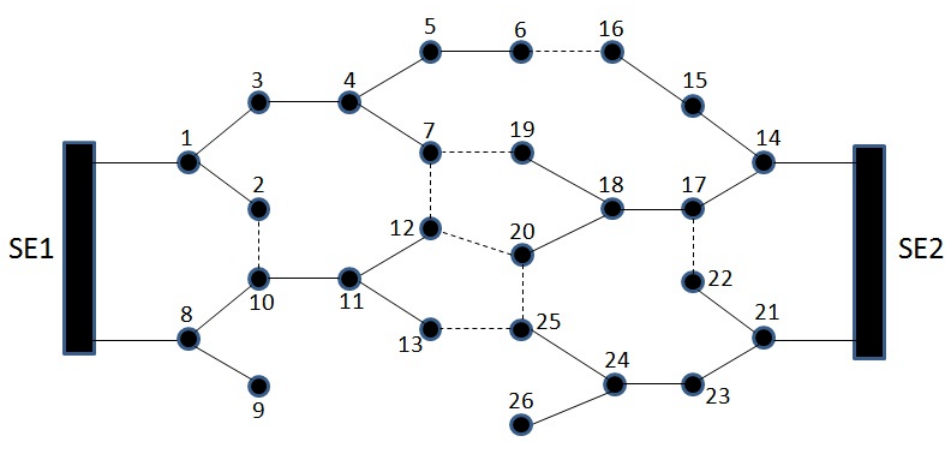

Figura 2.2: Exemplo de um Sistema de Distribuição Radial. 


\subsection{Formulação Matemática}

Nesta seção será apresentada uma formulação geral, para tratamento dos problemas de reconfiguração de redes restabelecimento de energia e redução de perdas ôhmicas. Para isso, considerar-se-ão, ao mesmo tempo, todos os objetivos e restrições desses problemas.

O problema de redução de perdas consiste, basicamente, em encontrar uma configuração radial que minimiza as perdas sem violar as restrições operacionais do sistema (queda de tensão e carregamento da rede e das subestações). Por outro lado, o problema de restauração de energia envolve a obtenção de uma configuração radial, que minimiza as áreas fora de serviço e o número de chaveamentos necessários para sua implantação, sem violar as restrições operacionais do sistema.

Portanto, o problema geral de reconfiguração de redes em SDR pode ser formulado como segue (DELBEM; CARVALHO; BRETAS, 2005):

$$
\begin{array}{ll}
\text { Min. } & E(F) \\
\text { s.a. : } & H(F)=0 \\
& I(F) \leq 0 \\
& F \text { ser uma floresta, }
\end{array}
$$

onde:

- F - floresta que correspondente a uma configuração do sistema, onde cada árvore corresponde a um alimentador ligado a uma subestação;

- $E(F)$ - função objetivo;

- $H(F)$ - restrições de igualdade representando as equações de fluxo de carga;

- $I(F)$ - restrições de desigualdade representando as restrições operacionais do sistema.

A função $E(F)$ contém, em geral, os seguintes componentes:

- $\phi(F)$ - quantidade de cargas fora de serviço para uma configuração radial da rede (uma floresta F);

- $\varphi(F)$ - perdas resistivas no sistema para $F$;

- $\psi\left(F, F^{0}\right)$ - número de operações de chaveamento para obter uma dada configuração $F$, a partir da configuração original $F^{0}$ (no caso de restabelecimento de enrgia, $F^{0}$ é a configuração com o setor em falta isolado).

As restrições de igualdade correspondem às equações de fluxo de carga. Um sistema linear do tipo $A x=b$ pode representá-las, onde: 
- $A$ - matriz de incidência de $F$;

- $x$ - vetor de correntes de linha;

- $b$ - vetor com as injeções de correntes nas barras de carga $(b i \leq 0)$ ou injeções de correntes nas subestações $\left(b_{i}>0\right)$.

As restrições operacionais de $I(F)$ para problemas de reconfiguração de redes em SDRs geralmente incluem:

- Um limitante superior de corrente $\bar{x}_{j}$ para cada corrente de linha $x_{j}$. A maior taxa $x_{j} / \bar{x}_{j}$ é denominada carregamento da rede para a configura $F$, que será representada por $X(F)$;

- A máxima injeção de corrente $\bar{b}_{i}$ possível para cada subestação $i$, onde a maior taxa $b_{i} / \bar{b}_{i}$ é denominada carregamento da subestação da configuração $F$, representada por $B(F)$;

- Um limitante inferior para a tensão no nó $\underline{v}$. Seja $v_{i}$ a tensão na barra $i$ e $v_{b}$ a tensão base do sistema; a menor taxa $v_{i} / v_{b}$ é denominada maior queda de tensão da rede na configuração $F$, representada por $V(F)$. O vetor de tensão $v$ é dado por $Y v=b$, onde $Y$ é a matriz de admitância nodal $\left(Y=A Y_{x} A^{T}\right.$, com $Y_{x}$ sendo a matriz de admitância diagonal).

A função objetivo para problemas envolvendo reconfiguração de SDRs geralmente é não linear, descontínua e com vários ótimos locais, dificultando a utilização de Programação Matemática. Quando os AEs são empregados para resolução desse tipo de problema, algumas modificações são realizadas na formulação apresentada na expressão 2.1. São inseridos fatores de penalidades (GOLDBERG, 1989) a fim de penalizar as configurações da rede que violarem as restrições operacionais $I(F)$. Assim, o problema pode ser reformulado como segue:

$$
\begin{array}{ll}
\text { Min. } & E(F)+|\Omega I(F)| \\
\text { s.a.: } & H(F)=0 \\
& F \text { é uma floresta, }
\end{array}
$$

onde $\Omega$ é uma matriz diagonal com os seguintes elementos:

$$
\mathrm{w}_{11}=\left\{\begin{array}{l}
w_{x}, \text { se, pelo menos para um } j, x_{j}>\bar{x}_{j} \\
0, \text { caso contrário; }
\end{array}\right.
$$




$$
\begin{aligned}
& \mathrm{w}_{22}=\left\{\begin{array}{l}
w_{s}, \text { se, pelo menos para um } i, b_{i}>\bar{b}_{i} \\
0, \text { caso contrário; }
\end{array}\right. \\
& \mathrm{w}_{33}=\left\{\begin{array}{l}
w_{v}, \text { se, pelo menos para um } i, v_{i}<\underline{v} \\
0, \text { caso contrário. }
\end{array}\right.
\end{aligned}
$$

Os pesos $w_{x}, w_{s}$ e $w_{v}$ são valores positivos e $|$.$| é a norma infinita usual$ (GRADSHTEYN; RYZHIK, 2000), isto é, a norma $L_{1}$ de um vetor $z$ de tamanho $n$ é dada por $\sum_{r=1}^{n}\left|Z_{r}\right|$.

Para verificar se uma dada configuração atende às restrições operacionais do problema $(I(F))$, é necessário a execução de um fluxo de carga, que deve ser eficiente computacionalmente em virtude da grande quantidade de configurações que devem ser analisadas na busca pela configuração "ótima". Para isso, torna-se necessário a utilização de estruturas de dados eficientes computacionalmente, para representação da topologia elétrica dos SDRs, bem como de eficientes algoritmos para cálculo de fluxo de carga. Nesse contexto importa destacar que para facilitar o cálculo de fluxo de potência, em problemas de reconfiguração de redes, as cargas podem ser modeladas como corrente constante e pode-se empregar métodos para calculo de fluxo de potência monofásicos de varredura direta/inversa. Dentre os métodos de varredura direta/inversa existentes na literatura, para o problema em questão destaca-se o soma de correntes, que para ser aplicado as barras da rede devem estar ordenadas segundo um modelo conhecido como Pai-Filho (MPF). Dessa forma, pode-se calcular o fluxo de corrente partindo dos nós terminais (nós folhas) em direção à subestação (nó raiz); enquanto as tensões podem ser obtidas de forma encadeada partindo da subestação até as barras terminais.

Para tornar ainda mais simples a formulação de problemas de reconfiguração de redes em SDRs através de AEs, em (MANSOUR et al., 2009) e (SANTOS et al., 2010) foi proposta a utilização da RNP e de seus operadores. Quando aplicados, esses operadores produzem exclusivamente configurações factíveis, ou seja, esses operadores realizam modificações em uma floresta gerando novas florestas que correspondem a configurações factíveis do SDR. Dessa forma, utilizando a RNP e seus operadores, o problema descrito na Equação 2.2 pode ser reescrito como segue:

$$
\begin{array}{ll}
\text { Min. } & E(F)+|\Omega I(F)| \\
\text { s.a. : } & H(F)=0
\end{array}
$$

$F$ ser dado pelos operadores da RNP. 
A RNP de um SDR possui, naturalmente, as barras de cada árvore (alimentador) ordenadas segundo o MPF. Com isso, evita-se a utilização de um algoritmo de busca (CORMEN, 2002) para obter tal modelo. Assim, o fluxo de carga de varredura direta/inversa com RNP é mais eficiente que fluxos de carga convencionais para tratamento de problemas de reconfiguração de redes em SDRs (SANTOS et al., 2008). Além disso, o uso de MPF garante que as restrições de igualdade, $(H(F))$ na Equação 2.3, sejam satisfeitas. Assim, fazendo uso da propriedade da RNP de permitir o armazenamento dos nós de acordo com o MPF, pode-se escrever o problema de reconfiguração de redes em SDR da seguinte forma:

$$
\begin{array}{ll}
\text { Min. } & E(F)+|\Omega I(F)| \\
\text { s.a. : } & \text { Utilizar MPF com RNP } \\
& F \text { ser dado pelos operadores da RNP. }
\end{array}
$$

A utilização da RNP e seus operadores, juntamente com o fluxo de carga pelo MPF, tornam a modelagem matemática do problema mais simples, isso é facilmente percebido comparando a Equação 2.4 com a Equação 2.1. Além disso, com esta formulação são geradas exclusivamente configurações factíveis. Assim, somente as restrições de queda de tensão, carregamento na rede e nos transformadores são consideradas na formulação matemática do problema.

\subsection{Fluxo de Carga para SDRs}

O estudo de fluxo de carga em uma rede de energia elétrica consiste na obtenção das condições de operação da mesma (tensões complexas nas barras, fluxos de potência nas linhas e transformadores), em função da topologia da rede e dos seus níveis de demanda e geração de potência.

Métodos convencionais para o cálculo de fluxo de carga em redes de transmissão de energia elétrica, tais como o método de Newton-Raphon, Desacoplado Rápido e versões modificadas dos mesmos (MONTICELLI, 1983; MONTICELLI; GARCIA; SAAVEDRA, 1990), podem apresentar um mal desempenho quando aplicados em sistemas de distribuição. Principalmente para redes radiais com grande número de barras. Isso ocorre devido às características particulares dos $\mathrm{SDRs}$, dentre as quais podemos citar: baixa relação $\mathrm{X} / \mathrm{R}$ (reatância/resistência) dos parâmetros dos alimentadores, trechos com impedâncias relativamente baixas ${ }^{1}$ associados a trechos com impedâncias altas e grande número de barras de carga distribuídas. Em razão dessas características, as matrizes associadas aos SDRs são mal-condicionadas, dificultando o cálculo de fluxo de carga através dos méto-

\footnotetext{
${ }^{1}$ Representação de chaves seccionadoras e trechos pequenos de linhas entre cargas muito próximas.
} 
dos tradicionais supracitados (DAS; NAGI; KOTHARI, 1994), que exigem a fatoração de matrizes, pois, afetam a convergência daqueles métodos exigindo um grande número de iterações, podendo causar, até mesmo, divergência do processo iterativo.

Face ao exposto, neste capítulo serão apresentados dois métodos tradicionais para resolução do problema de fluxo de potência para SDRs juntamente com os seus respectivos algoritmos de solução, que são mais indicados para tratamento de problemas de reconfiguração de redes em SDRs.

\subsubsection{Método de Varredura Direta/Inversa}

Os métodos de varredura direta/inversa são bastante empregados em SDR(ou fracamente malhados). A rede, nestes métodos, é representada por um grafo acíclico (árvore), cujo nó raiz corresponde à subestação (ver Figura 2.3).

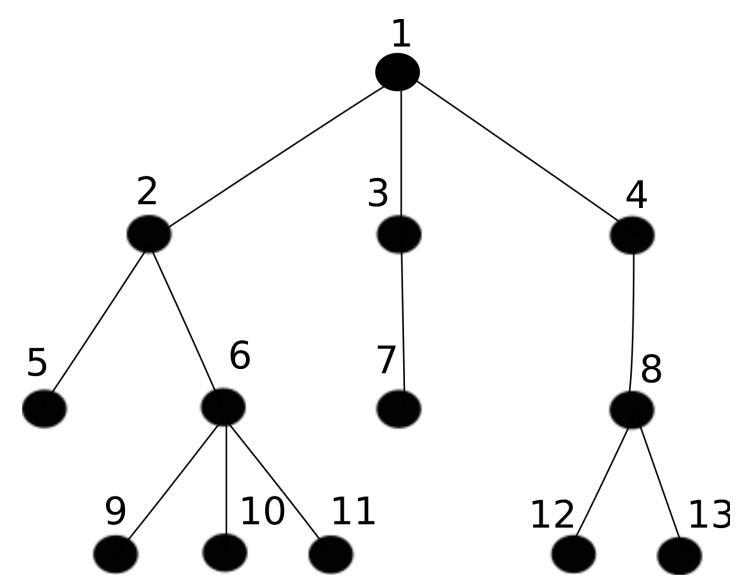

Figura 2.3: Exemplo de um SDR representado por um grafo.

Os métodos de varredura direta/inversa recebem esse nome devido ao fato de apresentarem um processo iterativo que faz um percurso das barras extremas em direção à subestação e vice-versa. Nestes métodos, primeiramente realiza-se a etapa de varredura inversa backward, que partindo das barras extremas (nós folhas) e usando um valor inicial das tensões nodais, consiste em calcular as correntes ou fluxos de potência nas linhas até a subestação (nó raiz). Após esta etapa, realiza-se a etapa de varredura direta forward, que a partir do resultado da injeção de corrente ou potência da subestação, e do valor conhecido da tensão nessa barra, consiste em calcular as tensões das barras da rede, até as barras extremas. Esse processo se repete até que algum critério de convergência seja satisfeito. Segundo SRINIVAS (2000), são duas as versões clássicas de métodos de varredura direta/inversa:

- Método de Soma de Correntes SHIRMOHAMMADI et al. (1988);

- Método de Soma de Potências BARAN; WU (1989b); CESPEDES (1990). 


\subsubsection{Método de Soma de Correntes}

O método de soma de correntes SHIRMOHAMMADI et al. (1988) foi desenvolvido inicialmente para SDRs, podendo ser aplicado a sistemas de distribuição fracamente malhados. Tal método é conceitualmente simples e apresenta desempenho eficiente. Para um sistema de distribuição radial com $n$ nós e $b$ ramos $(b=n-1)$, dado a tensão do nó raiz e assumindo a tensão igual a 1 (um) p.u. com ângulo de 0 (zero) graus para todas as demais barras do SDR, o método de resolução consiste em três passos:

1. Cálculo da corrente nodal: na iteração $k$, as injeções de corrente complexa nodais são calculadas segundo a expressão:

$$
I_{i}^{(k)}=\left(S_{i} / V_{i}^{(k-1)}\right)^{*}-Y_{i}^{s h} V_{i}^{k-1}, i=1,2, \ldots, n,
$$

em que $V_{i}^{(k-1)}$ é a tensão na barra $i$, calculada durante a iteração $(k-1)$ e $S_{i}$ é a injeção de potência complexa especificada na barra $i . Y_{i}^{s h}$ é a soma de todos os elementos shunt da barra $i$; e $n$ é o número total de barras da representação radial do sistema.

2. Backward: Na iteração $k$, a partir das linhas conectadas às barras extremas do grafo (barras com maiores profundidades) e movendo-se até as linhas conectadas à barra raiz (com profundidade zero), calcula-se a corrente $\left(J_{L}\right)$ na linha $L$, que liga uma barra $L 2$ à sua barra antecessora $L 1$, conforme ilustrado na Figura 2.4, da seguinte forma:

$$
J_{L}^{(k)}=-I_{L 2}^{(k)}+\sum(\text { Corrente nas linhas que saem do nó L2), }
$$

onde $L=p, p-1, \ldots, 1, I_{L 2}^{(k)}$ é a injeção de corrente no nó $L 2$ e $p$ é o número de linhas que o sistema possui;

3. Forward: as tensões complexas das barras são atualizadas, iniciando pelas barras que estão conectadas à barra raiz (subestação) e seguindo até as barras extremas. Seja $L$ a linha que liga uma barra $L 2$ à sua barra antecessora $L 1$, a tensão de $L 2$ é calculada usando a atualização da tensão na iteração $k$ de $L 1$ e o fluxo de corrente na linha calculado no passo 3 :

$$
V_{L 2}^{(k)}=V_{L 1}^{(k)}-Z_{L} J_{L}^{(k)}, L=1,2, \ldots, p,
$$

onde $Z_{L}$ é a impedância série da linha $L$;

4. Os passos 2, 3 e 4 são repetidos até que seja alcançado o critério de convergência. 


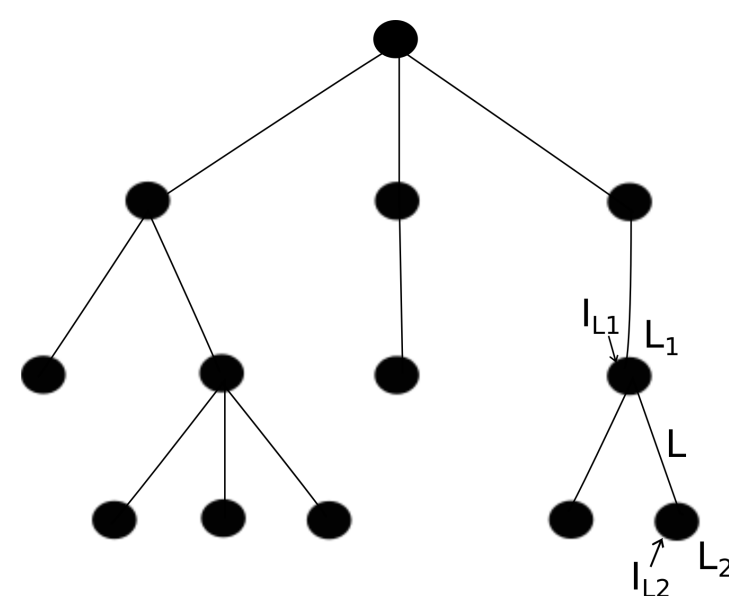

Figura 2.4: Passo backward sweep.

Adota-se como critério de convergência o maior erro de potência ativa e reativa nas barras do sistema, tal que este erro seja menor que um valor preestabelecido $\epsilon$. Conforme descrito nos passos acima, em cada iteração é calculada a injeção de corrente e, posteriormente, as tensões das barras do sistema. Assim, a potência complexa injetada na barra $i$ (ou a potência complexa líquida na barra $i$ ) na iteração $k, S_{i}^{(k)}$, é calculada utilizando a expressão 2.8 .

$$
S_{i}^{(k)}=V_{i}^{(k)} I_{i}^{(k) *}-Y_{i}\left|V_{i}^{(k)}\right|^{2}, i=1,2, \ldots, n
$$

O erro de potência ativa e reativa na barra i é calculado da seguinte forma:

$$
\begin{aligned}
& \Delta P_{i}^{(k)}=\operatorname{Re}\left[S_{i}^{(k)}-S_{i}\right] \\
& \Delta Q_{i}^{(k)}=\operatorname{Im}\left[S_{i}^{(k)}-S_{i}\right] .
\end{aligned}
$$

\subsubsection{Método de Soma de Potências}

O método da soma de potências (BARAN; WU, 1989b; CESPEDES, 1990) é o método mais difundido na literatura. Tal método é relativamente simples do ponto de vista conceitual e apresenta um desempenho eficiente na resolução de problemas de fluxo de carga radial (BRANDINI, 2000).

Para o cálculo dos fluxos de potência nos ramos da rede, adota-se as equações para o cálculo de fluxos em redes radiais desenvolvidos por BARAN; WU (1989b) A figura 2.5 ilustra um alimentador sem ramificações. Cada nó possui uma determinada potência complexa $S_{L}=P_{L}+j Q_{L}$ (considera-se neste caso as cargas com potência constante). Os arcos que ligam esses nós possuem uma impedância $z_{l}=r_{l}+j x_{l}$.

Na etapa Backward são utilizadas as seguintes equações de fluxo de carga: 
0

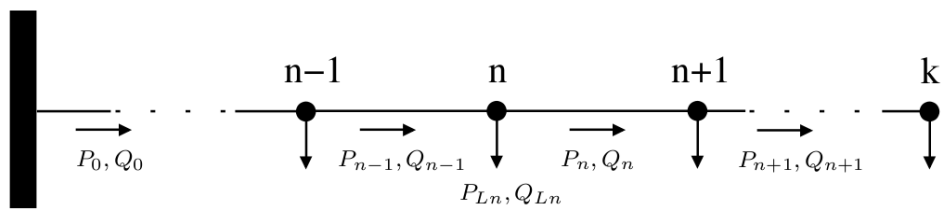

Figura 2.5: Alimentador de uma rede de distribuição.

$$
\begin{gathered}
P_{n-1}=P_{n}+r_{n} \frac{P_{n}^{\prime 2}+Q_{n}^{\prime 2}}{V_{n}^{2}}+P_{L n} \\
Q_{n-1}=Q_{n}+x_{n} \frac{P_{n}^{\prime 2}+Q_{n}^{\prime 2}}{V_{n}^{2}}+Q_{L n},
\end{gathered}
$$

onde:

- $P_{n-1}$ é o fluxo de potência ativa entre os nós n-1 e $n$;

- $Q_{n-1}$ é o fluxo de potência reativa entre os nós n-1 e $n$;

- $P_{n}$ é o fluxo de potência ativa entre os nós $n$ e $n+1$;

- $Q_{n}$ é o fluxo de potência reativa entre os nós $n$ e $n+1$;

- $P_{L n}$ é a injeção de potência ativa líquida na barra $n$;

- $Q_{L n}$ é a injeção de potência reativa líquida na barra $n$;

- $P_{n}^{\prime}=P_{n}+P_{L n}$

- $Q_{n}^{\prime}=Q_{n}+Q_{L n}$.

Na etapa Forward, a equação 2.12 é utilizada para atualizar a magnitude das tensões nas barras. Já a equação 2.13, adaptado de HAQUE (1996), é utilizada para atualizar o ângulo das tensões nas barras.

$$
\begin{gathered}
V_{n+1}^{2}=V_{n}^{2}-2\left(r_{n} P_{n}+x_{n} Q_{n}\right)+\left(r_{n}^{2}+x_{n}^{2}\right) \frac{P_{n}^{2}+Q_{n}^{2}}{V_{n}^{2}}, \\
\delta_{n+1}=\delta_{n}-\tan ^{-1}\left(\frac{k_{1}}{k_{2}}\right)
\end{gathered}
$$

onde,

- $V_{n}$ é a tensão na barra $n$;

- $\delta_{n}$ é o ângulo na barra $n$;

- $r_{n}$ é a resistência em série na linha que conecta a barra $n$; 
- $x_{n}$ é a reatância em série na linha que conecta $n$;

- $k_{1}=\frac{P_{n} x_{n}-Q_{n} r_{n}}{V_{n}}$

- $k_{2}=V_{n}-\frac{P_{n} x_{n}-Q_{n} r_{n}}{V_{n}}$.

O cálculo do fluxo de carga através deste método é composto pelos seguintes passos:

1. Assumir que as tensões iniciais em todas as barras são iguais à tensão da subestação (nó raiz);

2. Backward: calcular os fluxos de potência ativa e reativa para cada linha usando as equações 2.10 e 2.11;

3. Forward: calcular a tensão e o ângulo de cada barra utilizando as equações 2.12 e 2.13 ;

4. Como critério de convergência, verificar a variação da magnitude e da fase das tensões nodais na iteração atual com a iteração anterior. Se a diferença for maior ou igual a uma tolerância próxima de zero, repita o processo a partir do item 2; caso contrário, encerram-se os cálculos.

\subsection{Modelagem da Carga}

As cargas oferecem grandes dificuldades para sua modelagem, visto que representam agregados de consumidores com diferentes características e nem sempre previsíveis. Além da diversidade de elementos que as compõem, as variações com o tempo são um fator adicional na dificuldade de modelagem. Portanto, deve-se encarar a carga como uma representação esquemática na qual se faz referência ao fato de serem variáveis e apresentarem duas componentes, potências ativa e reativa (CARVALHO, 2006).

Nos estudos de fluxo de potência, a modelagem da carga assume um papel importante nos resultados obtidos, possuindo influência decisiva na qualidade dos resultados, podendo conduzir a valores imprecisos, com prejuízo significativo para o sistema elétrico, à medida que a representação das cargas não condiz com a realidade do estado de regime permanente (SOUZA BARBOSA, 1995).

Qualquer carga depende da tensão aplicada e da frequência da tensão de suprimento. Entretanto, no contexto deste trabalho a modelagem da carga será realizada considerando apenas a sua dependência da tensão aplicada. Existem vários modelos para representar o comportamento da carga em função da tensão aplicada, dentre os quais se destacam (KAGAN; OLIVEIRA; ROBBA, 2005): carga de impedância constante com a tensão; carga de potência constante com a tensão e carga de corrente constante com a tensão. A seguir, serão descritos brevemente cada um destes modelos, sendo que, para melhor ilustração de cada modelo, será utilizado o seguinte SDR: 


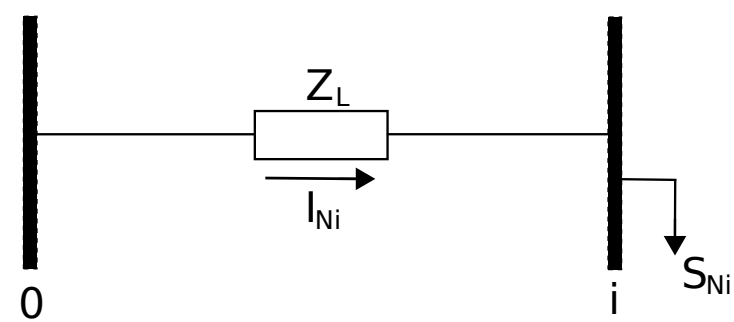

Figura 2.6: Sistema de Distribuição Radial com duas barras.

\subsubsection{Carga de impedância constante com a tensão}

O modelo da carga de impedância constante com a tensão possui característica de ter sua impedância invariante independentemente do valor da tensão aplicada, e é obtida a partir da potência ativa e reativa absorvida pela carga quando alimentada com tensão nominal ou de referência. Com isso, quando aplicado uma tensão nominal $\dot{V}_{N i}=V_{N i} \angle \theta_{1}$ sobre a carga $i$ da Figura 2.6, temos:

$$
\dot{S}_{N i}=S_{N i} \angle \alpha_{i}=P_{i}+j Q_{i}
$$

assim,a potência absorvida pela carga suprida por tensão nominal resulta para a impedância:

$$
\dot{Z}_{\text {cons }}=\frac{\dot{V}_{N i}^{2}}{\dot{S}_{N i}^{*}}=\frac{\dot{V}_{N i}^{2}}{S_{N i}} \angle \alpha_{i}=R+j X
$$

Por exemplo, aplicando uma tensão $\dot{V}_{i 2}=V_{i 2} \angle \theta_{i 2}$ sobre a carga $i$, o valor da potência absorvida será:

$$
\dot{S}_{i 2}=\dot{V}_{i 2} \dot{I}^{*}=\dot{V}_{i 2} \frac{\dot{V}_{N i}^{2}}{\dot{Z}_{\text {cons }}^{*}}=\frac{V_{i 2}^{2}}{\frac{V_{N i}^{2}}{\dot{S}_{N i}}}=\left(\frac{V_{i 2}}{V_{N i}}\right)^{2} \dot{S}_{N i}
$$

Observa-se que a impedância $\dot{Z}_{\text {cons }}$ se mantém constante, e que a potência absorvida pela carga varia quadraticamente com a tensão aplicada.

\subsubsection{Carga de potência constante com a tensão}

O modelo da carga de potência constante com a tensão possui característica de ter sua potência ativa e reativa invariante, ou seja, independentemente do valor da tensão aplicada, os valores de potência se mantém constante, isto é, são iguais a seus valores nominais. Portanto baseado no sistema da Figura 2.6 temos que a potência absorvida por uma carga monofásica, com tensão nominal $\dot{V}_{N i}=V_{N i} \angle \theta_{i}$ :

$$
\dot{S}_{N i}=S_{N i} \angle \alpha_{i}=P_{i}+j Q_{i}
$$


é constante para qualquer valor de tensão.

Por exemplo, aplicando uma tensão $\dot{V}_{i 2}=V_{i 2} \angle \theta_{i 2}$ sobre a carga $i$, o valor da corrente será dado por:

$$
\dot{I}_{i 2}=\frac{\dot{S}_{N i}^{*}}{\dot{V}_{i 2}^{*}}=\frac{S_{N i} \angle-\alpha_{i}}{V_{i 2} \angle-\theta_{i 2}}=\frac{S_{N i}}{V_{i 2}} \angle \theta_{i 2}-\alpha_{i}
$$

Observa-se que a potência absorvida $\dot{S}_{N i}$ se mantém constante, e que a corrente absorvida é inversamente proporcional à tensão aplicada.

\subsubsection{Carga de corrente constante com a tensão}

Neste modelo, a intensidade de corrente absorvida e o ângulo de defasagem entre a tensão e a corrente são invariantes, isto é, não variam quando o valor da tensão varia em torno do valor nominal. Vale destacar que, para esse modelo, os valores da intensidade de corrente e do ângulo de defasagem são aqueles obtidos para a carga suprida com tensão nominal. Assim, quando aplicado uma tensão nominal $\dot{V}_{N i}=V_{N i} \angle \theta_{i}$ sobre a carga $i$ da Figura 2.6, temos:

$$
\dot{S}_{N i}=S_{N i} \angle \alpha_{i}=P_{i}+j Q_{i}
$$

Portanto, a corrente absorvida por essa carga é:

$$
\dot{I}_{N i}=\frac{\dot{S}_{N i}^{*}}{\dot{V}_{N i}^{*}}=\frac{S_{N i} \angle-\alpha_{i}}{V_{N i} \angle-\theta_{i}}=\frac{S_{N i}}{V_{N i}} \angle \theta_{i}-\alpha_{i}=I_{N i} \angle \theta_{i}-\alpha_{i}
$$

Agora, quando aplicado uma tensão $\dot{V}_{i 2}=V_{i 2} \angle \theta_{i 2}$ qualquer sobre a carga $i$, o valor da corrente será:

$$
\dot{I}_{i 2}=I_{N i} \angle \theta_{i 2}-\alpha_{i}
$$

Ou seja, o módulo da corrente $I_{N i}$ e o ângulo de defasagem $\alpha_{i}$ permanecem constantes. Com isso, a potência absorvida será:

$$
\begin{gathered}
\dot{S}_{i 2}=\dot{V}_{i 2} \dot{I}_{i 2}^{*}=V_{i 2} \angle \theta_{i 2} I_{N i} \angle-\left(\theta_{i 2}-\alpha_{i}\right) \\
\dot{S}_{i 2}=V_{i 2} I_{N i} \angle \alpha_{i}
\end{gathered}
$$

ou seja, a potência absorvida pela carga varia linearmente com a tensão aplicada.

Quando o estudo de fluxo de carga é realizado assumindo-se carga modelada por corrente constante com a tensão, o processo de solução torna-se direto, isto é, sem iteração. Isto ocorre quando se despreza a rotação de fase da tensão, que permite o cálculo da queda de tensão, nos trechos dos alimentadores, através de números reais. Nesse caso é dito que o fluxo de carga foi executado com representação real da rede. O fluxo de carga assumindo-se carga modelada por corrente constante com a tensão será iterativo quando 
não se despreza a rotação de fase da tensão. Nessa situação, realiza-se o cálculo da queda de tensão, nos trechos dos alimentadores, através de números complexos (representação complexa da rede).

Importa destacar que estudos demonstram que os resultados obtidos através da solução direta, que se baseia em aproximações, estão muito próximos aos valores exatos.

\subsection{Cálculo do número de manobras}

Para avaliar a qualidade de uma determinada configuração, são necessários dois procedimentos: a execução de um fluxo de carga e o cálculo do número de manobras necessárias para implementar essa nova configuração, determinando assim a sua adequação para o problema de reconfiguração de redes em pauta. Em geral, determina-se o número de manobras a partir de comparações entre vetores binários que armazenam o estado das chaves (aberta ou fechada) de cada configuração. O custo computacional deste procedimento é relativamente alto, pois requer a criação de um vetor de estado atual das chaves para cada nova configuração gerada e realiza-se uma comparação deste com o vetor da configuração inicial. O tamanho de cada vetor é equivalente ao número de chaves $(m)$ do SDR.

Face ao exposto, em (SANTOS, 2009) foi proposto um algoritmo que determina o número de manobras de forma mais eficiente. Para esta formulação são utilizados dois vetores: um com o estado das chaves na configuração inicial e outro, de tamanho $G_{\max }$ (número máximo de gerações), que armazena a quantidade de chaves alteradas em relação à configuração inicial.

Na ocorrência de uma falta, o procedimento de isolar o setor em falta e conectar os setores a jusante do mesmo ao SDR exige manobras de chaves que nem sempre ocorrerão aos pares. Para ilustrar esse procedimento, o SDR apresentado na Figura 2.2 foi reproduzido na Figura 2.7, onde o setor 10 sofreu uma falta. Neste caso, deve-se isolar o setor em falta, que pode ser realizado abrindo-se as chaves A e B, realizando assim 2 manobras. Com este procedimento, os setores 11, 12 e 13 ficaram desconectados do SDR. Para reconectá-los novamente, é necessário fechar uma chave (dentre as chaves C, D ou E) que os conectam a algum alimentador, isto custará 1 manobra de chave. Deste modo, na primeira alteração de topologia foram necessárias 3 manobras de chaves.

Após o procedimento descrito acima, as chaves alteradas ocorrerão em pares, isto é, quando uma chave é aberta, outra deve ser fechada. Considerando o estado das chaves em 3 configurações específicas, torna-se possível determinar o número de manobras para originar uma determinada configuração:

1. Configuração inicial $(o)^{2}$;

\footnotetext{
${ }^{2} \mathrm{Na}$ configuração initial o setor em falta se encontra isolado e a energia restabelecida ao setores a
} 


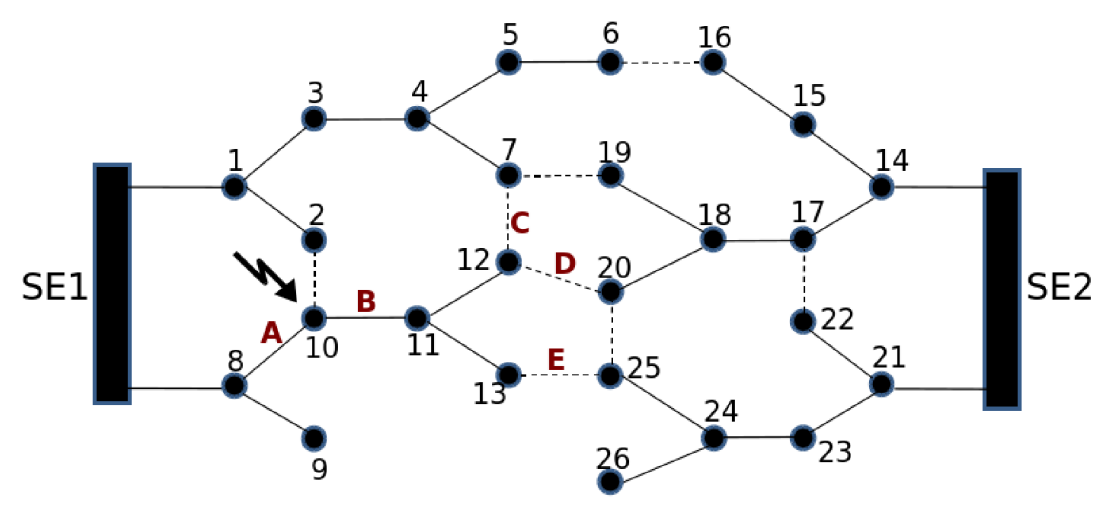

Figura 2.7: Operações de manobras necessárias para isolar o setor em falta.

2. Configuração alterada $(x)$;

3. Configuração final $(y)$.

Considerando que uma configuração $y$ originou-se de alterações em uma configuração $x$, têm-se 3 possibilidade para calcular o número de chaves alteradas da configuração $y$;

1. Os estados das duas chaves alteradas em $y$, em relação a $x$, são diferentes dos estados dessas chaves em $o$. Deste modo, o número de chaves alteradas de y será o número de chaves alteradas de $x$ mais 2 ;

Tabela 2.2: Manobras de chaves - caso 1.

\begin{tabular}{|c|c|c|c|}
\cline { 2 - 4 } \multicolumn{1}{c|}{} & \multicolumn{3}{c|}{ Configurações } \\
\hline Chaves & $o$ & $x$ & $y$ \\
\hline 1 & 1 & 1 & $\mathbf{0}$ \\
\hline 2 & 1 & 0 & 0 \\
\hline 3 & 0 & 1 & 1 \\
\hline 4 & 0 & 0 & $\mathbf{1}$ \\
\hline 5 & 1 & 1 & 1 \\
\hline
\end{tabular}

2. Os estados das duas chaves alteradas em $y$, em relação a $x$, são iguais aos estados dessas chaves em $o$. Deste modo, o número de chaves alteradas de y será o número de chaves alteradas de $x$ menos 2 ; 
Tabela 2.3: Manobras de chaves - caso 2.

\begin{tabular}{|c|c|c|c|}
\cline { 2 - 4 } \multicolumn{1}{c|}{} & \multicolumn{3}{c|}{ Configurações } \\
\hline Chaves & $o$ & $x$ & $y$ \\
\hline 1 & 1 & 1 & 1 \\
\hline 2 & 1 & 0 & $\mathbf{1}$ \\
\hline 3 & 0 & 1 & $\mathbf{0}$ \\
\hline 4 & 0 & 0 & 0 \\
\hline 5 & 1 & 1 & 1 \\
\hline
\end{tabular}

3. O estado de uma das chaves alteradas em $y$, em relação a $x$, é igual ao estado dessa chave em $o$ e, o estado da outra chave alterada é diferente. Deste modo, o número de chaves alteradas de $y$ será igual ao número de chaves alteradas de $x$.

Tabela 2.4: Manobras de chaves - caso 3.

\begin{tabular}{|c|c|c|c|}
\cline { 2 - 4 } \multicolumn{1}{c|}{} & \multicolumn{3}{c|}{ Configurações } \\
\hline Chaves & $o$ & $x$ & $y$ \\
\hline 1 & 1 & 1 & 1 \\
\hline 2 & 1 & 0 & $\mathbf{1}$ \\
\hline 3 & 0 & 1 & 1 \\
\hline 4 & 0 & 0 & 0 \\
\hline 5 & 1 & 1 & $\mathbf{0}$ \\
\hline
\end{tabular}

Em todos os casos acima, são necessárias 2 mudanças de chaves em $x$ para originar $y$, porém não garante que essas mudanças sejam efetivas, ou seja, em relação à configuração inicial $o$. Por esse motivo, não se pode simplesmente dizer que o número de manobras necessárias para implantar y é o número de manobras para implantar $x$ mais 2 .

\subsection{Conclusões}

Conforme apresentado neste capítulo, AEs são métodos de otimização que têm se mostrado bastante eficientes para tratamento dos problemas de reconfiguração de redes restabelecimento de energia e redução de perdas. Entretanto, para possibilitarem a análise de SDRs de grande porte de forma eficiente, torna-se necessário a utilização de estruturas de dados que possibilitem a análise, de cada configuração gerada, de forma eficiente computacionalmente. Nesse sentido, destacou-se a utilização da estrutura de dados RNP e de seus operadores.

Na seção 2.4 demonstra-se que, fazendo uso da RNP e de seus operadores, a formulação matemática dos problemas de reconfiguração de redes tratados neste trabalho torna-se bastante simples, em razão das seguintes vantagens da RNP (conforme apresentado na seção 1.5 do capítulo 1): (i) A RNP e seus operadores produzem exclusivamente 
configurações factíveis; (ii) Em comparação com outras estruturas de dados, a RNP pode gerar mais configurações factíveis, num mesmo período de tempo, tendo em vista que a mesma apresenta uma complexidade computacional de ordem $O \sqrt{n_{s}}$ (SANTOS, 2009), onde $n_{s}$ é o número de vértices no grafo (ou setores do sistema); (iii) Cada configuração gerada pela RNP e seus operadores possui todos os nós ordenados de acordo com uma relação conhecida como Modelo Pai-Filho (MPF), possibilitando, assim, a execução de um algoritmo de fluxo de carga de varredura direta/inversa de forma mais eficiente.

A estrutura de dados RNP será apresentada detalhadamente no capítulo 3. 


\section{Capítulo 3}

\section{Representação Nó-Profundidade}

\subsection{Introdução}

Para garantir eficiência computacional para as metodologias propostas neste trabalho, a topologia elétrica dos SDR será representada através da estrutura de dados denominada Representação Nó-Profundidade (RNP).

Face ao exposto, a RNP e seus operadores serão apresentados neste capítulo, bem como o procedimento para cálculo de fluxo de carga de varredura inversa/direta através da utilização da RNP.

\subsection{Representação Nó-Profundidade}

A RNP, proposta por DELBEM et al. (2004), baseia-se nos conceitos de nó e profundidade de nó em um grafo acíclico e conexo (árvore). Basicamente, a RNP é composta por uma lista linear contendo os nós da árvore e suas respectivas profundidades. Essa lista é formada por pares $\left(n_{x}, p_{x}\right)$, onde $n_{x}$ representa o nó da árvore e $p_{x}$ a profundidade do nó. A ordem em que os pares são dispostos na lista é importante.

Computacionalmente, esta lista é formada por uma matriz de dimensão $2 \mathrm{x} n$, onde $n$ é o número de nós de uma determinada árvore. De tal forma que, cada par $\left(n_{x}, p_{x}\right)$ é armazenado em uma determinada coluna da matriz, onde $p_{x}$ e $n_{x}$ são armazenados na primeira e na segunda linha respectivamente (Figura 3.1b). Para armazenar um nó e a sua respectiva profundidade na RNP, utiliza-se um algoritmo de busca em profundidade (CORMEN, 2002). Desta maneira, começando a busca a partir do nó raiz da árvore, é produzida uma lista de pares $\left(n_{x}, p_{x}\right)$ em uma sequência apropriada enquanto um nó $n_{x}$ é visitado.

Para o entendimento de como uma árvore é armazenada na RNP, será realizada uma análise da Figura 3.1b, que apresenta a RNP para a árvore geradora representada por linhas espessas no grafo da Figura 3.1a. Inicialmente é armazenado o nó raiz da árvore, 
no caso o nó 1 , com profundidade igual a 0 . Logo, realiza-se uma busca em profundidade na árvore, através dos ramos conectados ao nó raiz, para armazenar os demais nós juntamente com suas respectivas profundidades, as quais são calculadas em relação ao nó raiz.

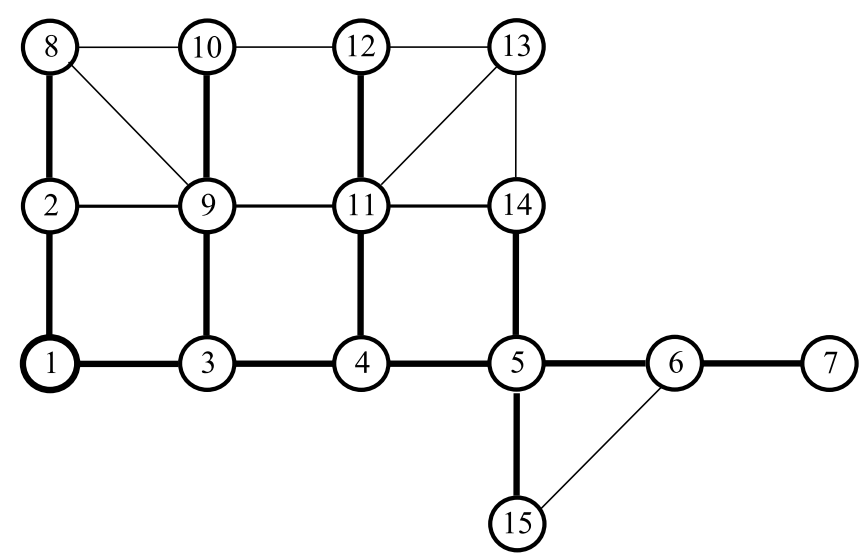

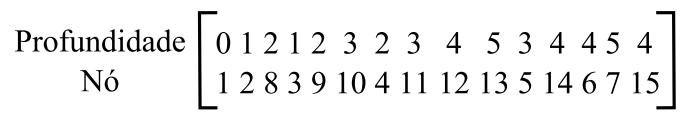

(b) Representação Nó-Profundidade

(a) Grafo

Figura 3.1: Exemplo de um grafo e sua RNP

A codificação para uma floresta é composta pela união das codificações de todas as árvores da mesma. Assim, a estrutura de dados da floresta pode ser facilmente implementada utilizando uma lista de ponteiros, onde cada ponteiro indica a RNP de uma árvore da floresta.

\subsubsection{Operadores da RNP}

Para facilitar a manipulação da floresta armazenada em RNPs, criaram-se dois operadores bastante similares, chamados de PAO (do inglês, Preserve Ancestor Operator) e CAO (do inglês, Change Ancestor Operator) (DELBEM et al., 2004) e (SANTOS, 2009). Ambos os operadores geram uma floresta $F^{\prime}$ de um grafo $G$ quando esses são aplicados a outra floresta $F$ de $G$. Os resultados produzidos pela aplicação de ambos operadores são similares. Dada uma floresta com duas árvores ou mais, a aplicação de um dos operadores a essa floresta é equivalente a transferir uma subárvore (parte podada) de uma árvore $A_{d e}$ (árvore origem) para uma árvore $A_{\text {para }}$ (árvore destino). Entretanto, no operador PAO a raiz da sub-árvore podada será a raiz dessa subárvore em $A_{\text {para }}$; já no operador CAO, um novo nó (diferente da raiz) é escolhido para ser a nova raiz da sub-árvore em $A_{\text {para }}$ (DELBEM et al., 2004).

O operador PAO requer a definição prévia de dois nós: o nó de poda $p$ na árvore $A_{d e}$, que indica a raiz da sub-árvore que será podada; e o nó adjacente $a$, que é o nó da árvore $A_{\text {para }}$, onde a sub-árvore será inserida. Além desses dois nós, o operador CAO requer ainda o nó $r$, que será a nova raiz da sub-árvore que será transferida. 


\subsubsection{Operador PAO}

Para descrição do operador PAO, considera-se que os nós $p$ e $a$ sejam previamente escolhidos. A RNP é implementada utilizando-se matrizes, sendo conhecidos os índices de $p\left(i_{p}\right)$ e $a\left(i_{a}\right)$ (Figura 3.2a) nas matrizes $A_{d e}$ e $A_{\text {para }}$, respectivamente.

$\mathrm{O}$ operador PAO pode ser descrito através dos seguintes passos (Figura 3.2):

1. Determinam-se as posições $\left(i_{p}, i_{l}\right)$ dos índices na árvore $A_{d e}$, correspondente à subárvore enraizada no nó $p$. Conhecido $i_{p}$, é necessário encontrar apenas $i_{l}$, que corresponde ao índice do último nó na sub-árvore que tem o nó $p$ como raiz. O conjunto $\left(i_{p}, i_{l}\right)$ corresponde ao nó $p$, em $i_{p}$, e consecutivos nós $x$ na segunda linha da matriz $A_{d e}$, tal que $i_{x}>i_{p}$ e $p_{x}>p_{p}$ (entre as linhas tracejadas na Figura 3.2a), $p_{x}$ é a profundidade do nó $x$;

2. Copiam-se os dados do conjunto $\left(i_{p}, i_{l}\right)$, da árvore $A_{d e}$, em uma matriz temporária $A_{t m p}$ (contendo os dados da sub-árvore que está sendo transferida); ver Figura 3.2b. A profundidade de cada nó $x$, do conjunto $\left(i_{p}, i_{l}\right)$, é atualizada utilizando a seguinte equação: $p_{x}=p_{x}-p_{p}+p_{a}+1$, onde: $p_{x}, p_{p}$ e $p_{a}$ são as profundidades dos nós $x, p$ e $a$, respectivamente;

3. Cria-se a matriz $A_{p a r a^{\prime}}$, contendo os nós de $A_{\text {para }}$ e inserindo depois a matriz $A_{t m p}$ na posição $i_{a}+1$ de $A_{\text {para }}$, isto é, gera-se uma nova árvore que conecta a sub-árvore $A_{\text {tmp }}$ na árvore $A_{\text {para }^{\prime}}$ (Figura 3.2c);

4. Constrói-se uma matriz $A_{d e^{\prime}}$, que possua os nós de $A_{d e}$, sem os nós de $A_{t m p}$;

5. Atualiza-se a floresta, fazendo com que a estrutura de dados que antes apontava para $A_{d e}$ e $A_{\text {para }}$, aponte agora para $A_{d e^{\prime}}$ e $A_{\text {para }}$.

\subsubsection{Operador CAO}

Para a descrição do operador CAO, considera-se que um conjunto de nós seja previamente determinado: o nó de poda $p$, o novo nó raiz $r$ e o nó adjacente $a$. Os nós $p$ e $r$ pertencem à árvore $A_{d e}$, e o nó a à $A_{\text {para }}$;

As diferenças do operador PAO para o CAO estão nos passos 2 e 3 do procedimento do operador PAO (apresentados na seção anterior), isto é, a formação da sub-árvore cortada e como a mesma é armazenada em um vetor temporário tmp são diferentes. Os passos 2 e 3, para o operador CAO, são descritos na sequência. As Figuras 3.3a, 3.3b, 3.3c e 3.3d ilustram um exemplo destes passos para as mesmas arvorés $A_{d e}$ e $A_{\text {para }}$ (Figura 3.2) utilizadas para análise do operador PAO.

O procedimento de cópia da subárvore para o operador CAO pode ser dividida em dois passos: 

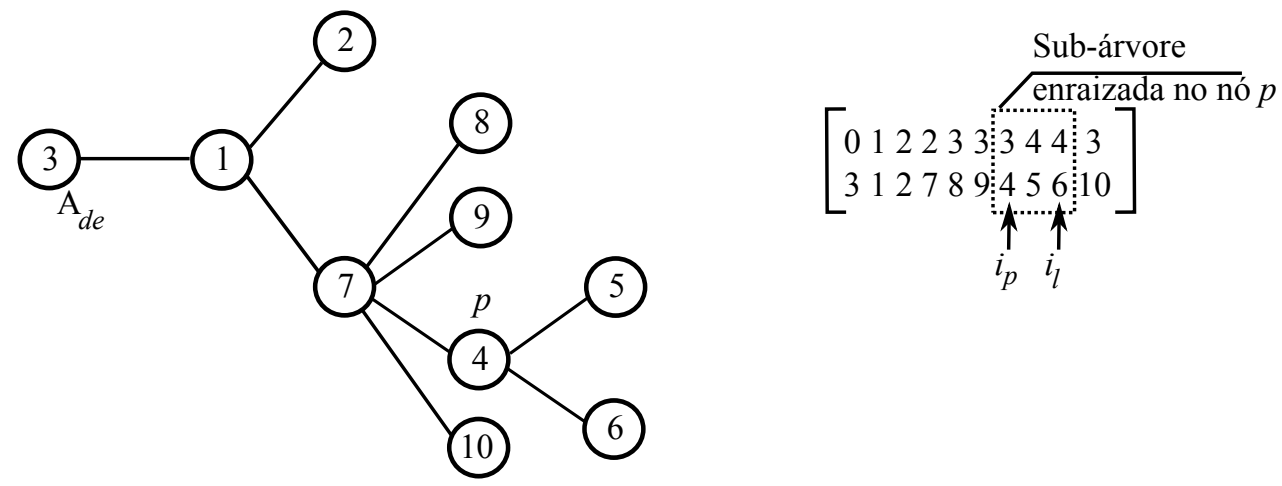

$\stackrel{a}{11}_{\mathrm{A}_{\text {para }}}$

$\left[\begin{array}{c}0 \\ 11 \\ \uparrow \\ i_{a}\end{array}\right]$

(a) $\mathrm{A}_{d e}, \mathrm{~A}_{\text {para }}$ e suas respectivas RNPs.

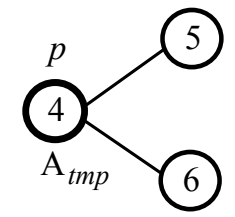

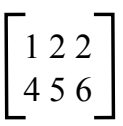

(b) $\mathrm{A}_{\text {tmp }}$ e sua RNP.

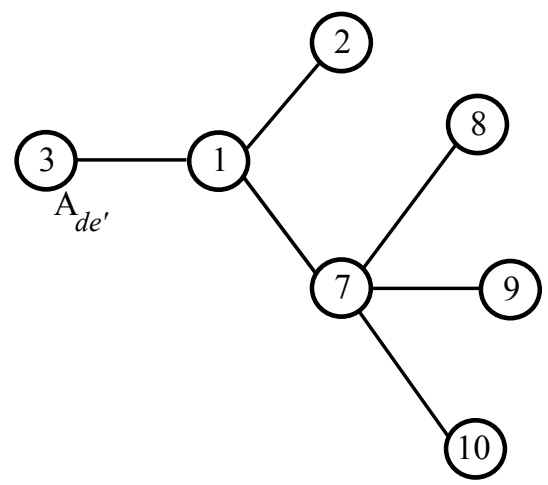

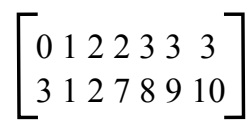

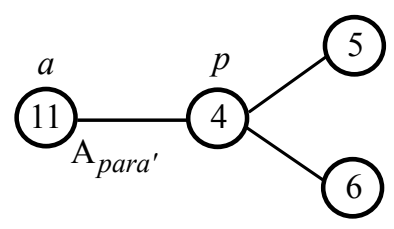

$\left[\begin{array}{cccc}0 & 1 & 2 & 2 \\ 11 & 4 & 5 & 6\end{array}\right]$

(c) $\mathrm{A}_{d e^{\prime}}, \mathrm{A}_{\text {para }}$ e suas respectivas RNPs.

Figura 3.2: Ilustração dos passos do operador PAO 
O primeiro é similar ao passo 2 do operador PAO, com a diferença de que, no operador CAO, troca-se o índice $i_{p}$ por $i_{r}$

No segundo passo consideram-se os nós de $r$ até $p$ de $A_{d e}$, isto é $r_{0}, r_{1}, r_{2}, \ldots, r_{n}$, onde $r_{0}=r$ e $r_{n}=p$, como raízes de sub-árvores (ver os nós destacados na Figura 3.3a). O algoritmo para o segundo passo deve copiar a sub-árvore enraizada em $r_{i}(i=1,2, \ldots, n)$, sem a sub-árvore enraizada em $r_{i-1}$ (veja Figura 3.3b), e armazene o resultado das subárvores na matriz temporária $A_{t m p 1}$ (veja Figura 3.3c). Em seguida, o operador CAO cria a matriz $A_{\text {para }}$, contendo os nós de $A_{\text {para }}$ e inserindo depois a matriz $A_{t m p 1}$ na posição $i_{a}+1$ de $A_{\text {para }}$. Ou seja, cria-se uma nova árvore que conecta a sub-árvore $A_{t m p 1}$ na árvore $A_{\text {para }}$ (ver Figura 3.3d).

Observe que no terceiro passo do operador PAO cria-se a $A_{\text {para }}$ a partir de $A_{\text {para }}$ e $A_{t m p}$. No operador CAO, cria-se a matriz $A_{p a r a^{\prime}}$ a partir de $A_{\text {para }}$ e $A_{t m p 1}$.

\subsubsection{Determinação dos nós (vértices) $p, r$ e $a$}

O algoritmo para determinação eficiente dos nós (vértices) $p, r$ e $a$ utiliza duas estruturas auxiliares: a matriz $\Pi_{x}$ e o array $\pi$. A matriz $\Pi_{x}$ contém a identificação do vértice, sua posição na estrutura RNP, sua floresta e sua árvore. Sempre que um vértice tem sua posição alterada pelos operadores PAO e CAO, uma nova coluna com as informações atualizadas é inserida na matriz. O array $\pi$ armazena, em cada posição, o ancestral da floresta representada naquela posição (DELBEM et al., 2004). A seguir, ilustram-se no algoritmo 1 , os passos para se obter os vértices $p, r$ e $a$ :

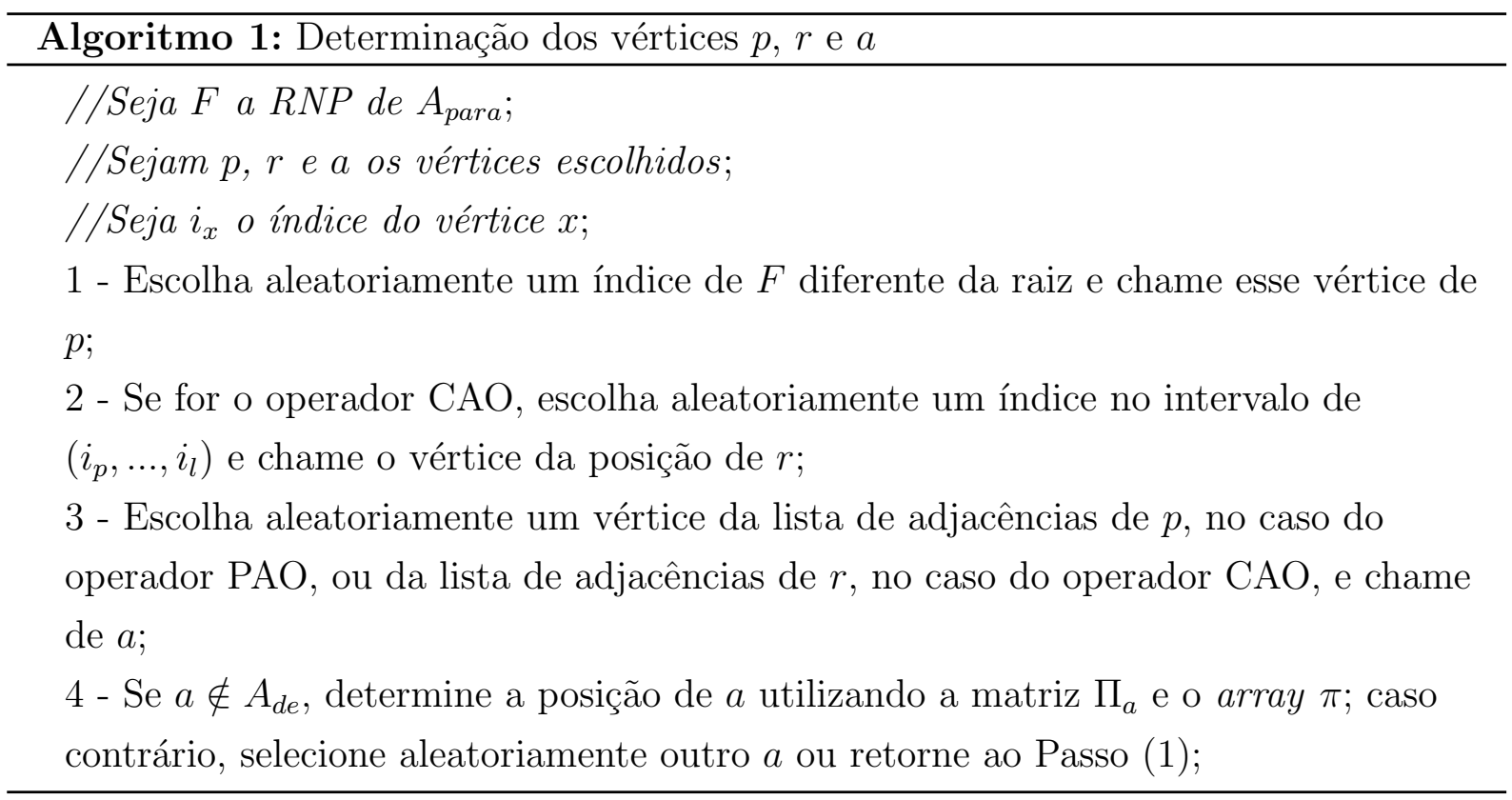

\subsubsection{Localização de um nó (vértice) na RNP}

Seja $F_{0}$ uma floresta do grafo $G$ codificada pela RNP e $A_{i}$ a i-ésima árvore em $F_{0}$ e $F_{j}$ a j-ésima floresta gerada depois de $F_{0}$. A localização de um vértice em $F_{0}$ utiliza uma 


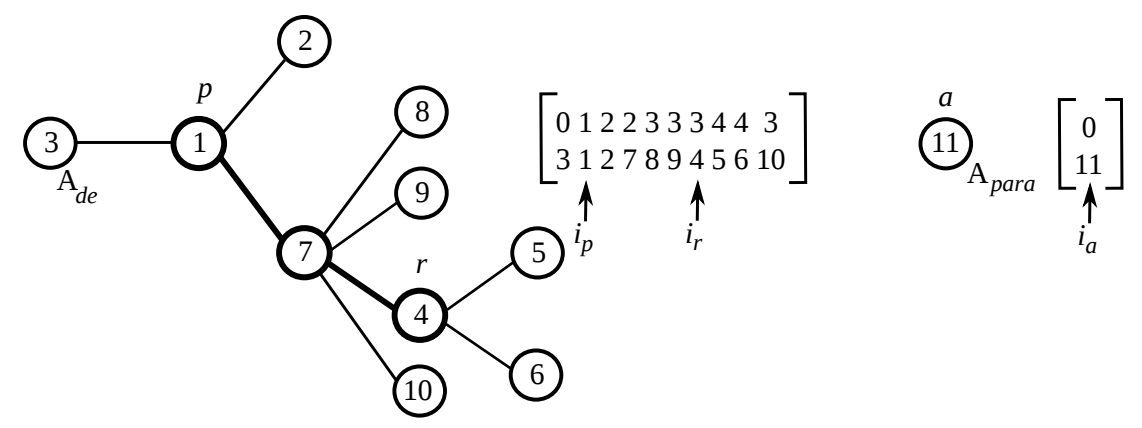

(a) RNP de $\mathrm{A}_{d e}$ e escolha do vértice a.
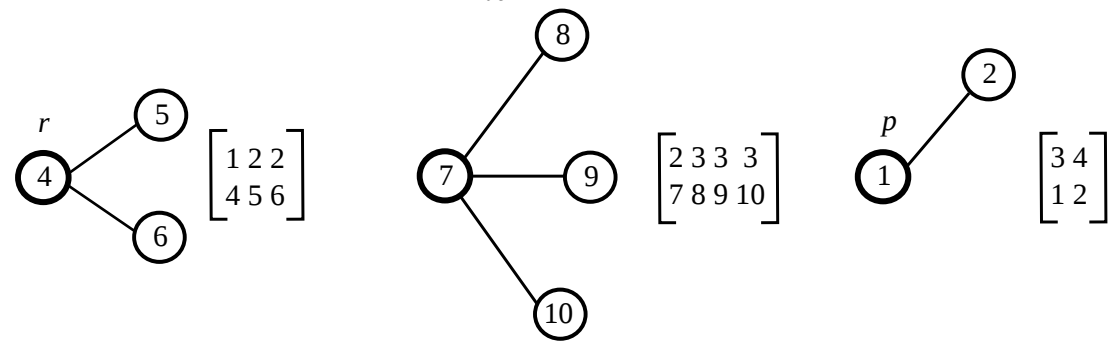

(b) Subárvores enraizadas nos nós do caminho de $r$ a $p$.

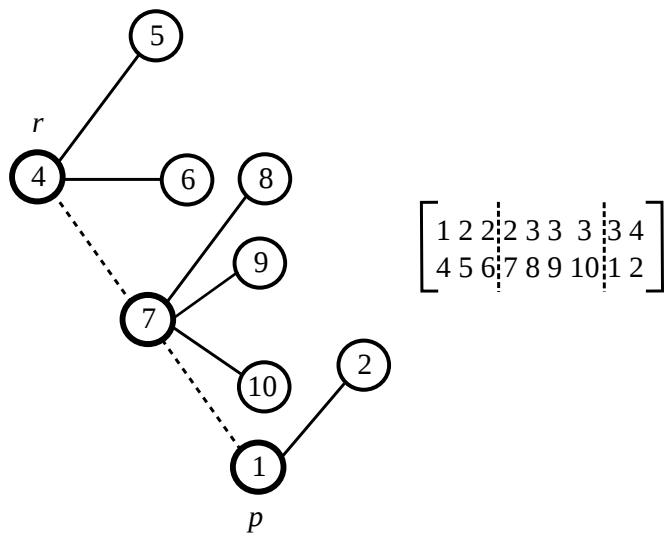

(c) RNP da subárvore podada $\mathrm{A}_{t m p 1}$.

$3_{\mathrm{A}_{d e^{\prime}}}^{a}\left[\begin{array}{l}0 \\ 3\end{array}\right]$

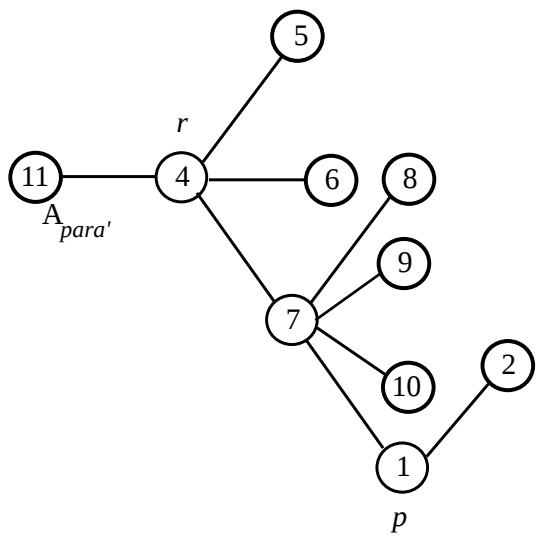

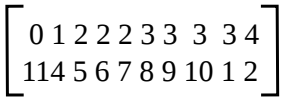

(d) Árvore $\mathrm{A}_{\text {para' }}$ e sua RNP.

Figura 3.3: Ilustração dos passos do operador CAO. 
matriz auxiliar $\Pi_{x}$, para cada vértice $x$ de $G$. Para floresta original $F_{0}$ de $G, \Pi_{x}$ possui só uma coluna:

$$
\Pi_{x}=\left[\begin{array}{c}
0 \\
i_{0} \\
j_{0} \\
k_{0}
\end{array}\right]
$$

onde $i_{0}$ é o índice da árvore que contém $x, j_{0}$ é o índice correspondente a $x$ na árvore $A_{i_{0}}$ e $k_{0}$ é a profundidade de $x$ na árvore $A_{i_{0}}$. Suponha que uma floresta $F_{\text {posterior }}$ é obtida a partir de $F_{\text {anterior }}$, e que o vértice $x$ pertence à subárvore transferida para uma nova árvore em $F_{\text {posterior. }}$ Então, $x$ deve ter uma posição em $F_{\text {posterior }}$ que é diferente da sua posição em $F_{\text {anterior }}$. Com o objetivo de armazenar essa mudança, insere-se uma nova coluna em $\Pi_{x}$ com os valores de sua nova posição. A matriz alterada resulta em:

$$
\Pi_{x}=\left[\begin{array}{ccccc}
0 & \ldots & \text { anterior } & \ldots & \text { posterior } \\
i_{0} & \ldots & i_{\text {anterior }} & \ldots & i_{\text {posterior }} \\
j_{0} & \ldots & j_{\text {anterior }} & \ldots & j_{\text {posterior }} \\
k_{0} & \ldots & k_{\text {anterior }} & \ldots & k_{\text {posterior }}
\end{array}\right] \text {, }
$$

A atualização de colunas deve ser efetuada pelo menos para os vértices da subárvore podada. No pior caso, todos os vértices de $A_{d e}$ e $A_{\text {para }}$ precisam ter suas matrizes atualizadas. Na primeira linha de $\Pi_{x}$ é armazenado um identificador da floresta, que teve o vértice $x$ alterado para uma nova posição. O último predecessor $F_{\text {anterior }}$ de $F_{\text {posterior }}$ pode ser determinado a partir do array $\pi$ (vetor que armazena a relação de ancestralidade (DELBEM et al., 2004). Assim, para localizar a posição de um vértice $x$ em $F_{i}$, primeiro busca-se em $\Pi_{x}$, se $F_{i}$ existe; caso contrário, localiza-se em $\pi$, o predecessor de $F_{i}$ chamado de $F_{k}$, com $k<i$, e consequentemente, busca-se $F_{k}$ em $\Pi_{x}$. Se a busca novamente retornar um valor nulo, o processo recomeça buscando do predecessor de $F_{k}$ até que seja encontrada uma coluna para $x$ em alguma floresta. A busca em $\Pi_{x}$ pode ser efetuada usando um método de busca para o conjunto de dados ordenados como, por exemplo, a busca binária (CORMEN, 2002). Uma vez identificada a coluna com o predecessor do vértice, é necessário apenas ler os índices armazenados na mesma coluna.

\subsection{Conclusões}

Este Capítulo apresentou uma estrutura de dados eficiente para armazenar e manipular grafos, a representação Nó-Profundidade (RNP). Em nosso contexto, essa representação armazena a configuração dos alimentadores de um SDR. Juntamente com a RNP, 
descreveram-se dois Operadores, PAO e CAO, utilizados para modificar de maneira eficiente a topologia da rede armazenada em RNPs. Tais operadores são capazes de gerar novas configurações sempre radiais e conexas, em pequeno tempo de processamento. Foi também apresentado como determinar o conjunto de nós requeridos pelos operadores, bem como uma maneira de encontrá-los quando armazenados em computador. 


\section{Capítulo 4}

\section{Algoritmos Evolutivos para Otimização Multi-Objetivo}

\subsection{Introdução}

Um problema de otimização combinatória multi-objetivo consiste em minimizar (ou maximizar) simultaneamente um conjunto de objetivos, satisfazendo um conjunto de restrições. Para estes problemas não existe uma única solução que seja ótima com relação a todos os objetivos, mas um conjunto de boas soluções não dominadas, que é chamado de conjunto Pareto Ótimo (ou também de Fronteira de Pareto Ótimo) (DEB, 2001). Adiantando que uma solução domina outra solução, quando é melhor que a outra em pelo menos um objetivo e não pior em todos os demais objetivos.

Neste Capítulo é introduzida, inicialmente, uma definição básica sobre os AEs, com destaque para a abordagem evolutiva Evolução Diferencial, tendo em vista que uma das propostas deste trabalho é a investigação da utilização da Evolução Diferencial junto com o método AEMT. Em seguida são apresentados os principais aspectos da otimização multi-objetivo e algumas das principais técnicas de AEMO.

\subsection{Algoritmos Evolutivos}

AEs são uma classe de algoritmos de otimização que simulam o processo de evolução natural. Desde os anos 70, várias metodologias de resolução foram propostas, a maioria pertencente a uma destas três classes: algoritmos genéticos, programação evolutiva e estratégias evolutivas.

Fazendo uma analogia com o processo da evolução natural, as soluções candidatas são denominadas indivíduos, também referidos na literatura como cromossomos, cadeia de valores de parâmetros ou cadeias binárias (DEB, 2001). Uma das características principais destas técnicas é o uso de um conjunto de soluções candidatas (população), que é 
manipulado em cada iteração de modo a melhorar a aptidão média dos indivíduos que formam essa população em relação ao ambiente em que está. Os indivíduos da população são avaliados e as soluções com maior aptidão são selecionadas para a reprodução formando uma nova geração. Com o decorrer das gerações, as soluções mais adequadas acabam dominando a população, resultando em um aumento na qualidade das soluções.

A seguir são apresentados os conceitos associados a estas técnicas e sua relação com a metáfora inspiradora da evolução natural:

- Indivíduos: representam organismos genéticos que farão parte do processo evolutivo;

- Seleção: os indivíduos mais adaptados sobrevivem e se perpetuam;

- Recombinação: é o mecanismo natural para que uma espécie seja perpetuada, o qual compreende a transferência de material genético dos ancestrais para seus descendentes;

- Mutação: é uma modificação aleatória do material genético dos indivíduos, ou seja, é a alteração de pequenas percentagens nos bits dos cromossomos, sendo uma outra forma do algoritmo genético explorar a região de busca. Este operador pode introduzir características que não dependem da população original aumentando a diversidade da população, podendo evitar que o algoritmo convirja prematuramente.

Embora existam as várias classes de AEs, é possível descrever um algoritmo básico comum a todas, conforme ilustra o algoritmo 2.

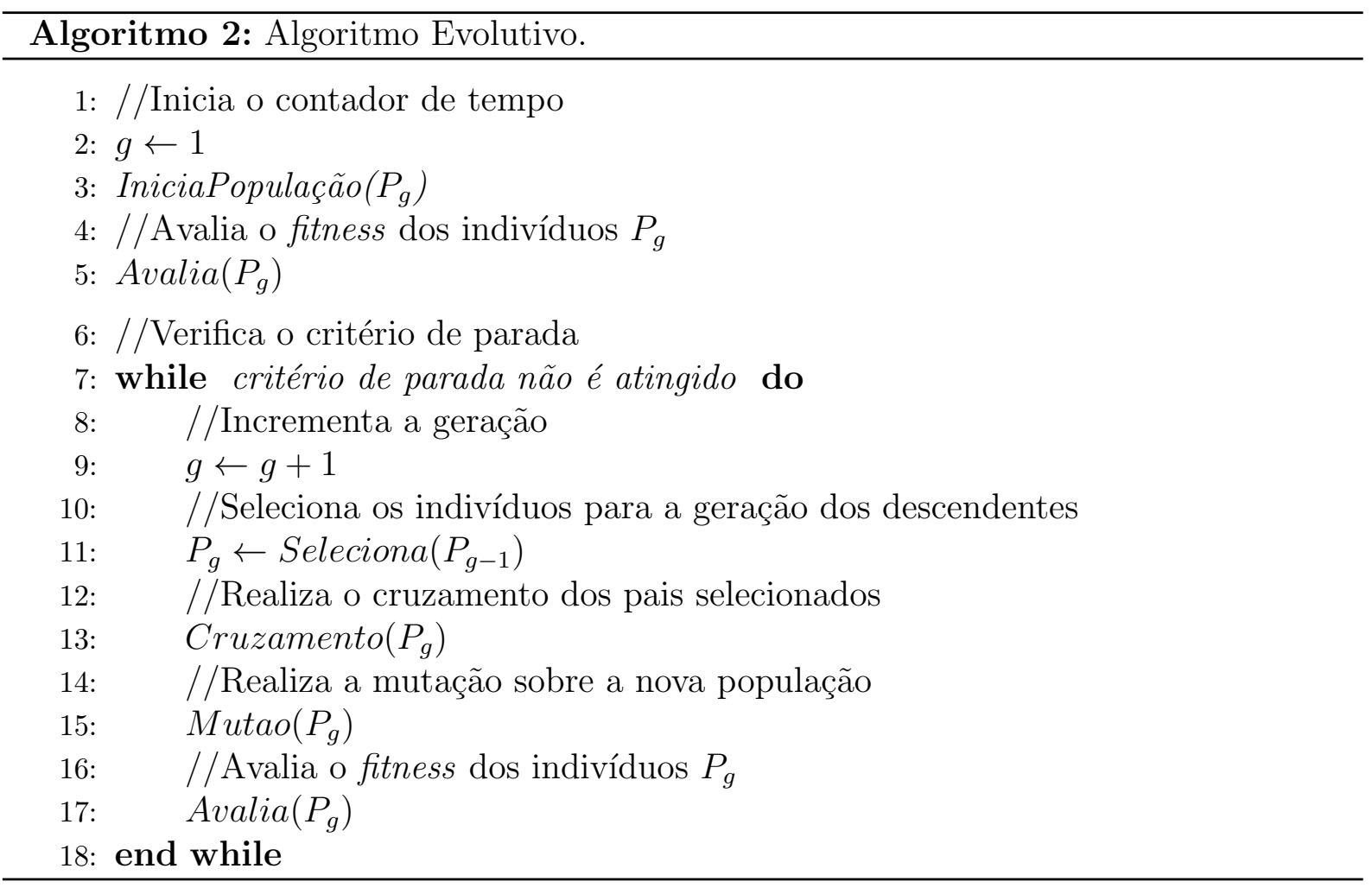




\subsubsection{Evolução Diferencial}

Dentre os algoritmos evolucionários, destaca-se o algoritmo DE desenvolvido por STORN; PRICE (1997), visando a busca por melhores resultados com uma abordagem um pouco diferente da utilizada nos algoritmos genéticos e nas estratégias de evolução. Os processos de seleção e cruzamento são implementados com aritmética de ponto flutuande. Esta característica permite que este algoritmo seja diretamente aplicado na otimização de espaços contínuos. A escolha do DE para otimização numérica está baseada nas seguintes características (CHENG; HWANG, 2001):

1. É um algoritmo de busca estocástica, originado dos mecanismos de seleção natural;

2. Dificilmente torna-se preso em ótimos locais, pois busca a solução ótima global manipulando uma população de soluções, ou seja, buscando simultaneamente a solução em diferentes regiões do espaço de busca;

3. Permite que os parâmetros de entrada e saída sejam manipulados como números ordinários reais (pontos flutuantes) sem processamento extra e, portanto, utiliza eficientemente os recursos do computador;

4. É eficaz trabalhando com uma população pequena.

Segundo STORN; PRICE (1997) o DE é uma nova heurística para minimização de funções não-lineares e não-diferenciáveis no espaço contínuo. Os autores comprovaram que a evolução diferencial, em muitas instâncias, foi o melhor algoritmo evolutivo, quando comparado com: simulated annealing adaptativo (INGBER, 1993); Nelder e Mead com Annealing (PRESS et al., 1992); estratégia evolutiva (SCHWEFEL, 1993) e AG breeder (MüHLENBEIN; SCHLIERKAMP-VOOSEN, 1993). Essas comparações foram realizadas para abordagens de minimização em relação ao número de avaliações necessárias para localizar o mínimo global das funções teste utilizadas no experimento.

Ainda em (STORN; PRICE, 1997) foi observado que, diferentemente da maioria dos AEs, onde muitos parâmetros precisam ser ajustados, na evolução diferencial apenas três parâmetros precisam ser selecionados (tamanho da população, constante de cruzamento e coeficiente de variação diferencial), tornando-se um método mais simples e eficiente.

\subsubsection{Funcionamento}

Basicamente o funcionamento do DE consiste na geração de uma população inicial escolhida aleatoriamente, composta por $N_{p}$ indivíduos chamados vetores, cobrindo todo o espaço de busca. Geralmente, esta população é criada por uma distribuição de probabilidade uniforme, quando não há nenhum conhecimento sobre o problema. Assim, a população segue uma evolução natural, porém o número de indivíduos permanece fixo durante todo o processo do algoritmo. 
Além do número de indivíduos $N_{p}$ da população, o DE necessita de mais dois parâmetros iniciais: o fator escalar $F$, da equação de mutação diferencial, e do escalar $C_{r}$ que indica a probabilidade de cruzamento de um indivíduo da população durante a fase de recombinação.

A idéia principal da evolução diferencial é gerar novos indivíduos, denotados vetores modificados, pela adição da diferença vetorial ponderada pelo fator escalar $F$, entre dois indivíduos aleatórios da população, a um terceiro indivíduo. Esta operação é chamada de mutação.

Na etapa de mutação, para cada indivíduo corrente $X_{\alpha}^{G}$ da população, conhecido como vetor alvo, é gerado um vetor modificado $v_{i}^{G+1}$, de acordo com a equação 4.1 .

$$
v_{i}^{(G+1)}=X_{\alpha}^{G}+F\left(X_{\beta}^{G}-X_{\gamma}^{G}\right)
$$

Para a obtenção do vetor modificado $v_{i}^{G+1}$, considere os vetores $X_{\alpha}^{G}, X_{\beta}^{G}$ e $X_{\gamma}^{G}$ distintos entre si e escolhidos aleatoriamente em uma população com $N_{p}$ indivíduos. Os índices aleatórios $\alpha, \beta, \gamma \in\left\{1, \ldots, N_{p}\right\}$ são inteiros distintos entre si. Utilizando o par de vetores $\left(X_{\beta}^{G}, X_{\gamma}^{G}\right)$ da $G$-ésima geração, define-se o vetor de diferença $\left(X_{\beta}^{G}-X_{\gamma}^{G}\right)$. Esta diferença é multiplicada pelo escalar $F$, sendo denotada diferença vetorial ponderada, ou apenas, diferença ponderada e será usada para perturbar o terceiro vetor $X_{\alpha}^{G}$. A figura 4.1 ilustra um exemplo bidimensional composto pelos diferentes vetores que geram o vetor modificado $v_{i}^{G+1}$. Vale destacar que, segundo STORN; PRICE (1997), o escalar F é um número real positivo pertencente ao intervalo $[0,2]$ que controla a amplitude da diferença vetorial. Indiretamente, essa amplitude controla a taxa em que a população corrente evolui e a sua distribuição no espaço de busca.

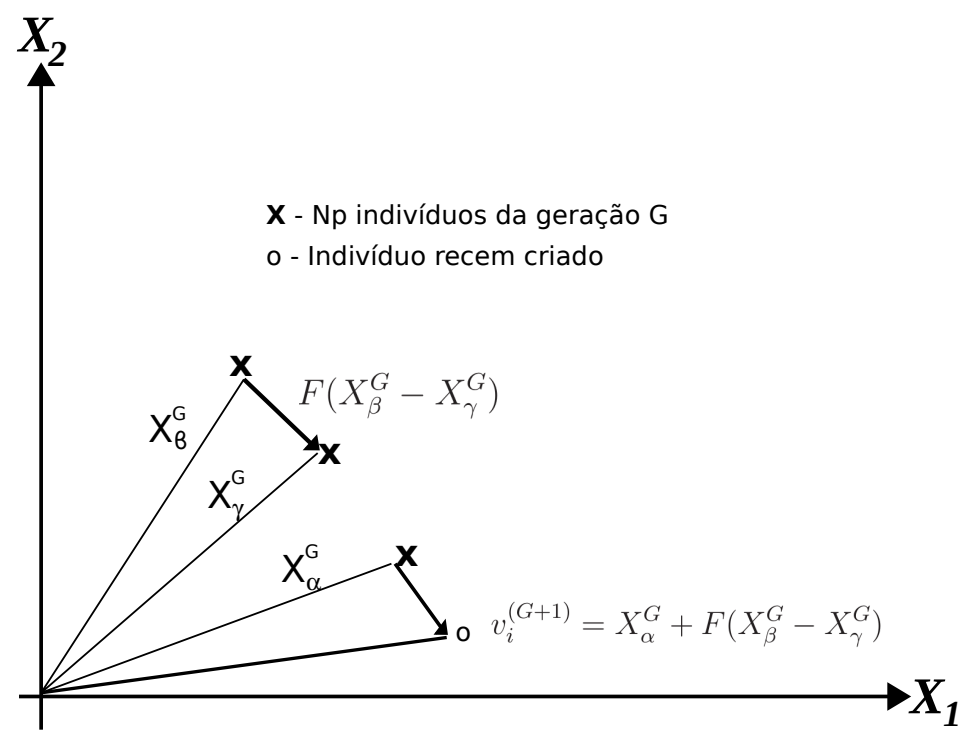

Figura 4.1: Processo para gerar um vetor modificado $v_{i}^{G+1}$ de uma função bidimensional. 
Após a etapa de mutação, os componentes do vetor modificado são misturados com os componentes de um indivíduo escolhido aleatoriamente na população, para resultar o chamado vetor experimental $U^{G+1}$. Para isso, utilizando o vetor alvo e o vetor modificado, as componentes do vetor experimental $U^{G+1}$ são escolhidas pela seguinte comparação:

$$
\mathrm{U}(\mathrm{i})^{\mathrm{G}+1}=\left\{\begin{array}{l}
v(i)^{G+1}, \quad \text { se } \operatorname{rand}_{i} \leq C_{r} \\
X(i)^{G}, \quad \text { se } \operatorname{rand}_{i}>C_{r}, i=1, . . n
\end{array}\right.
$$

sendo $v(i)^{G+1}$ a $i$-ésima componente do vetor modificado $v_{i}^{G+1}, X_{\alpha}(i)^{G}$ a $i$-ésima componente do vetor alvo $X_{\alpha}^{G}, \operatorname{rand}_{i}$ um número gerado aleatoriamente no intervalo [0,1] e $C_{r}$ que representa a probabilidade do vetor experimental herdar os valores das variáveis do vetor modificado. Esta etapa de misturar os parâmentros é freqüentemente conhecida como cruzamento.

A próxima etapa é o processo de seleção, no qual verifica-se se o custo do vetor experimental é menor que o custo do vetor alvo. Em caso afirmativo, o vetor experimental será o vetor alvo da próxima geração. O procedimento é finalizado através de algum critério de parada como, por exemplo, um número máximo de avaliações.

Quando comparado com outros algoritmos evolucionários, o DE apresenta um desempenho muito melhor, apesar de ser um algoritmo muito simples e de fácil implementação. Tal desempenho está diretamente relacionado com a sua habilidade em manter a diversidade e fazer uma busca local de boa qualidade. Por essas características o DE tem despertado nas últimas décadas um grande interesse no mundo acadêmico e industrial.

\subsection{Problemas de Otimização Multi-Objetivo}

Muitos problemas reais envolvem a otimização de vários objetivos ao mesmo tempo que, em geral, são conflitantes. Isto caracteriza um problema de otimização multi-objetivo (MOOP, do inglês Multi-Objective Optimization Problem). Um MOOP possui um conjunto de funções objetivo a serem otimizadas (maximizar ou minimizar). Além disso, possui restrições que devem ser satisfeitas para que uma solução seja factível ao problema. O enunciado geral de um MOOP é o seguinte DEB (2001):

$$
\begin{array}{rll}
\text { Maximizar/Minimizar } & f_{m}(x), & m=1,2, . ., N_{o b j} \\
\text { sujeito a: } & g_{j}(x) \leq 0, & j=1,2, \ldots, N R_{d e s} \\
& h_{k}(x)=0, & k=1,2, . ., N R_{\text {igu }} \\
& x_{i}^{(\text {inf })} \leq x_{i} \leq x_{i}^{(\text {sup })}, & i=1,2, . ., N_{\text {var }}
\end{array}
$$


Onde $x$ é um vetor de $N_{v a r}$ variáveis de decisão, $x=\left(x_{1}, x_{2}, \ldots, x_{N_{v a r}}\right)^{T}$, também denominado de solução. Os valores $x_{i}^{(i n f)}$ e $x_{i}^{(\text {sup })}$ representam os limites inferior e superior, respectivamente, para a variável $x_{i}$. Esses limites definem o espaço de variáveis de decisão ou espaço de decisão $S_{d e c}$. As $N R_{\text {des }}$ desigualdades $\left(g_{j}\right)$ e as $N R_{\text {igu }}$ igualdades $\left(h_{k}\right)$ são chamadas de funções de restrição. Uma solução $x$ factível satisfaz as $N R_{i g u}+N R_{\text {des }}$ funções de restrição e os $2 N_{\text {var }}$ limites. Caso contrário, a solução não será factível. O conjunto de todas as soluções factíveis formam a região factível ou espaço de busca $S_{\text {fact }}$.

Cada função $f_{m}(x)$ pode ser maximizada ou minimizada. Porém, para trabalhar com os algoritmos de otimização, é necessário converter todas as funções para serem apenas de maximização ou minimização. O vetor de funções objetivo $f(x)=$ $\left[f_{1}(x), f_{2}(x), \ldots, f_{N_{o b j}}(x)\right]$ compõe um espaço multidimensional chamado espaço de objetivos $S_{o b j}$. Para cada solução $x$, no espaço de decisão, existe uma $f(x)$ em $S_{o b j}$. Esta é uma diferença fundamental em relação à otimização de objetivos simples, cujo espaço de objetivos é unidimensional.

\subsubsection{Conceitos Básicos}

As funções objetivo empregadas nos MOOPs são em geral conflitantes entre si. Uma função objetivo $f_{1}$ é conflitante com outra função $f_{2}$ quando não é possível melhorar o valor de $f_{1}$ sem piorar o valor de $f_{2}$. Um exemplo prático de objetivos conflitantes explorado em (DEB, 2001) é a tomada de decisão a partir de dois critérios (custo e conforto) para a compra de um automóvel. Vale destacar que, quanto mais confortável o automóvel, maior será o custo. Na Figura 4.2 são ilustrados algumas alternativas de escolha.

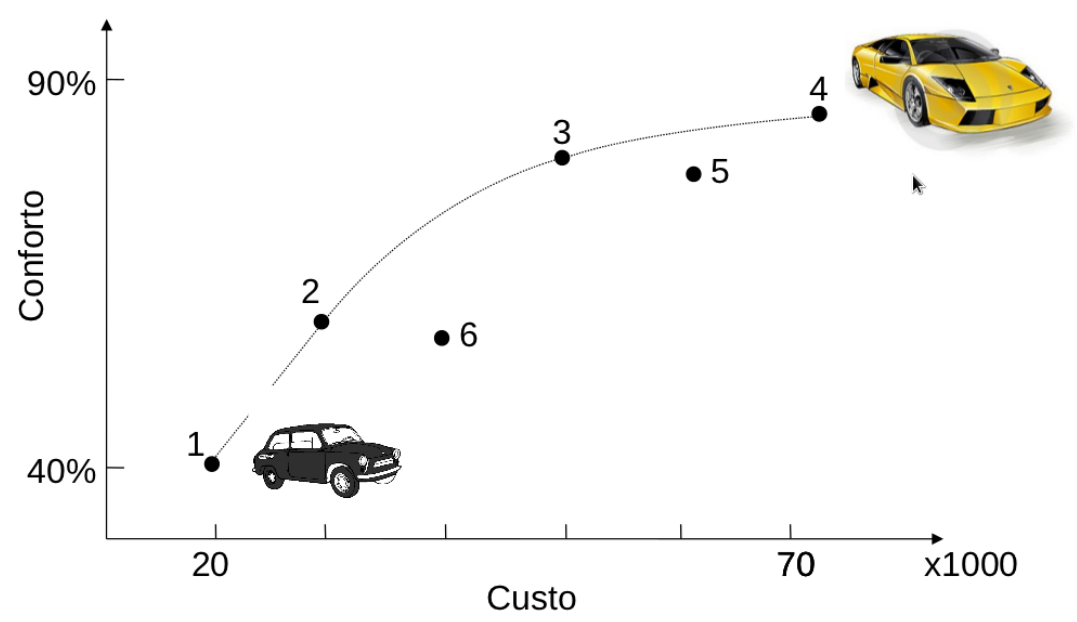

Figura 4.2: Curva Conforto X Custo do automóvel.

Com isso, busca-se minimizar o custo total e maximizar o conforto. Pela Figura 4.2 tem-se 6 opções de compra. Intuitivamente, descarta-se a opção 5, pois possui o mesmo 
conforto que a opção 3, porém com maior custo. Analisando somente as soluções 1 e 6 , não se pode afirmar qual das duas é melhor, pois a solução 6 tem maior conforto que a 1 , porém maior custo. Ao analisar as soluções 2 e 6 , observa-se que a solução 6 também deve ser descartada, pois possui menor conforto e maior custo em relação a solução 2. Tem-se então 4 opções, 1,2,3 e 4, como boas alternativas para a compra. Dentre essas soluções, não se pode afirmar qual é a melhor, pois quando uma tem maior conforto, também tem maior custo, e vice versa. Diz-se que uma solução domina outra solução, quando é melhor que a outra em pelo menos 1 objetivo e não pior em todos os outros objetivos. Da Figura 4.2, tem-se que a solução 3 domina a solução 5 e, a solução 2 domina a solução 6 . Portanto, as soluções 5 e 6 são dominadas e, as soluções 1,2,3 e 4 são não dominadas por nenhuma outra. Temos então o conjunto das soluções não dominadas 1,2,3 e 4, e o conjunto das soluções dominadas 5,6 .

Em um MOOP emprega-se o conceito de dominânca de Pareto para comparar duas soluções factíveis de um problema. Dadas duas soluções $x$ e $y$, diz-se que $x$ domina $y$ (denotado como $x \prec y$ ) se as seguintes condição forem satisfeitas:

1. A solução $x$ é não pior que $y$ em todos os objetivos;

2. A solução $x$ é melhor que $y$ em pelo menos um objetivo.

Desta forma, existe um conjunto de soluções que possuem vantagens em conforto mas que não são melhores em custo e vice-versa. Ou seja, existe um conjunto de alternativas ótimas que são não dominadas entre si nos objetivos de custo e conforto. Em um MOOP, o conjunto de soluções não dominadas é chamado de conjunto Pareto-ótimo, que representa as soluções ótimas do problema. A fronteira de Pareto é o conjunto dos valores das funções objetivo das soluções do conjunto Pareto-ótimo.

\subsubsection{Diferenças entre Otimização Mono-Objetivo e Multi- Objetivo}

Em (DEB, 2001) identificam-se três importantes aspectos que diferenciam a otimização multi-objetivo e a otimização mono-objetivo, estes sendo:

1. Nos problemas de otimização mono-objetivo tem-se como objetivo encontrar uma solução ótima global (máximo ou mínimo). Se a função objetivo desses problemas for multimodal, poderia existir mais de um ótimo global (CHUANG; HSU, 2010). Neste caso, todos os ótimos são equivalentes. Na otimização multi-objetivo encontrar o conjunto de soluções da fronteira de Pareto é tão importante quanto preservar a diversidade neste conjunto. Desta forma, um algoritmo eficiente para a otimização multi-objetivo deve considerar estes dois aspectos; 
2. Nos problemas de otimização multi-objetivo trabalha-se com os espaços das variáveis e dos objetivos. Já nos problemas com um objetivo trabalha-se unicamente no espaço das variáveis, já que procura-se apenas uma solução no espaço dos objetivos. Desta forma, manter a diversidade nos espaços das variáveis e dos objetivos torna a solução dos problemas multi-objetivo mais complicada, pois a proximidade de duas soluções no espaço das variáveis não implica proximidade no espaço dos objetivos;

3. Os métodos tradicionais de otimização mono-objetivo estão baseados em uma função simples a qual se pondera uma determinada função objetivo com as restrições violadas. Pode-se também tratar cada objetivo separadamente, utilizando a função objetivo proposta e as restrições violadas como outras funções objetivos. Portanto, um problema de otimização multi-objetivo pode ser convertido, mediante técnicas e manipulações algébricas, em um problema de otimização mono-objetivo.

\subsection{Algoritmos Evolutivos para Otimização Multi- Objetivo}

Os AEs são promissores para serem empregados em MOOP, em razão de apresentarem as seguintes características: trabalham com mais de uma função simultaneamente; não precisam de informações adicionais e são capazes de escapar de ótimos locais. Neste contexto, nas próximas seções serão apresentados alguns AEMO disponíveis na literatura.

\subsubsection{NSGA-II: Elitist Non-Dominanted Sorting Genetic Al- gorithm}

Proposto por DEB et al. (2002), o algoritmo Elitist Non-Dominanted Sorting Genetic Algorithm (NSGA-II) baseia-se na ordenação eletista por dominância chamada de Pareto ranking. Esse procedimento consiste em classificar as soluções de um conjunto $M$ em diversas fronteiras $\left(\mathcal{F}_{1}, \mathcal{F}_{2}, \ldots, \mathcal{F}_{k}\right.$, onde $k$ é o número de fronteiras) conforme o grau de dominância de cada solução. Deste modo, a fronteira $\mathcal{F}_{1}$ contém as soluções não dominadas de todo o conjunto de soluções $M, \mathcal{F}_{2}$ contêm as soluções não dominadas de $M-\mathcal{F}_{1}$, $\mathcal{F}_{3}$ contêm as soluções não dominadas de $M-\left(\mathcal{F}_{1} \cup \mathcal{F}_{2}\right)$ e assim sucessivamente.

O procedimento de ordenação por não dominância proposto por DEB et al. (2002) é descrito no algoritmo 3. Para cada solução $i$, contida em $P$, são calculados dois valores:

- $n d_{i}$, o número de soluções que dominam a solução $i$;

- $U_{i}$, o conjunto de soluções que são dominadas pela solução $i$.

As linhas 1-15 do Algoritmo 3 calculam tais valores para as soluções em $M$. Além disso, as soluções com $n d_{i}=0$ estão contidas na fronteira $\mathcal{F}_{1}$. Em seguida, as linhas 
17-29 percorrem o conjunto de soluções dominadas $U_{i}$, para cada solução $i$ em $\mathcal{F}_{1}$. O contador $n d_{j}$, de cada solução $j$ em $U_{i}$, é decrementado em 1 . Se $n d_{j}=0$, então a solução $j$ pertence à próxima fronteira, neste caso, $\mathcal{F}_{2}$. A iteração das linhas 17-29 é repetida até que todas as soluções estejam classificadas em uma fronteira. A Figura 4.3 ilustra este procedimento aplicado às soluções que minimizam $f_{1}$ e $f_{2}$.

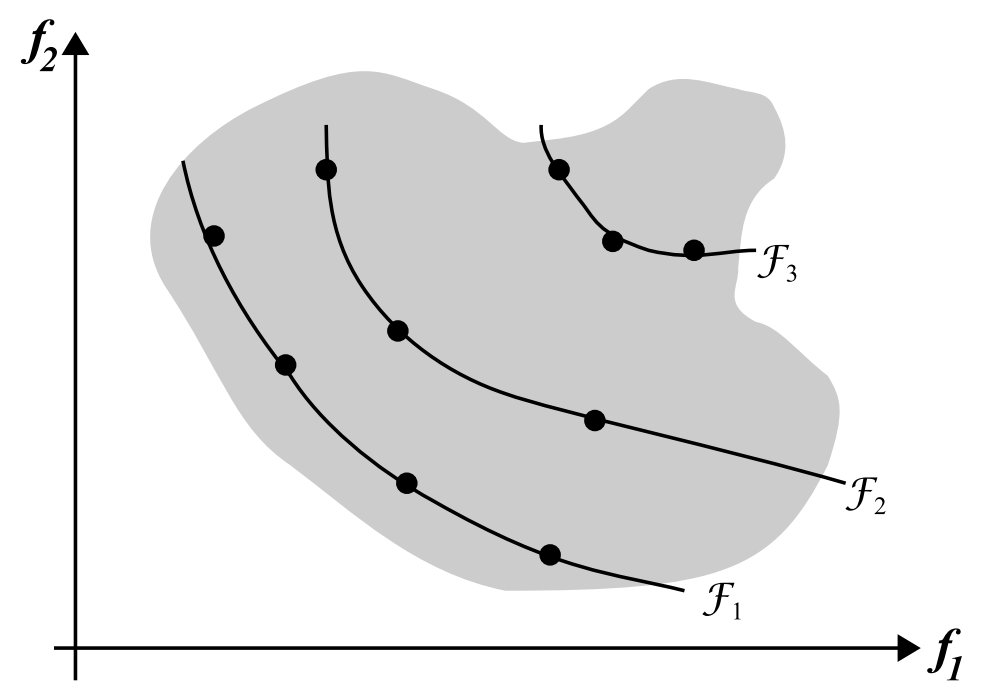

Figura 4.3: Ordenação por não dominância (Deb, 2001).

O algoritmo NSGA-II trabalha com duas populações, denotadas por $P$ e $Q$, ambas de tamanho $N_{\text {ind }}$. As populações $P$ e $Q$ em cada iteração $t=1,2, \ldots, N_{\text {iter }}$ são denotadas por $P_{t}$ e $Q_{t}$, respectivamente. Na primeira geração, os indivíduos iniciais da população $P_{1}$ geram as soluções em $Q_{1}$, através da aplicação dos operadores genéticos. Em seguida, estabelece-se um processo competitivo para preencher $N_{i n d}$ vagas para a solução $P_{t+1}$, entre $2 * N_{\text {ind }}$ indivíduos contido em $R_{t}=P_{t} \cup Q_{t}$. Esta operação é realizada utilizando a ordenação por não dominância em $R_{t}$, encaminhando as soluções não dominadas contidas nas fronteiras diretamente para a próxima geração (elitismo).

Para garantir a diversidade na fronteira, o NSGA-II emprega uma estimativa de densidade das soluções que rodeiam cada indivíduo da população. Assim, calcula-se a média da distância das duas soluções adjacentes a cada indivíduo para todos os objetivos. Esse valor é denominado distância de multidão. O Algoritmo 4 descreve os passos para calcular tal valor, onde crowdist $_{n}$ é o valor da distância de multidão do $n$-ésimo indivíduo do conjunto $M$ (denotado como $\left.M_{n}\right)$ e $f_{m}\left(M_{n}\right)$ é o valor da $m$-ésima função objetivo para o $n$-ésimo indivíduo.

O fitness de cada solução $i$ é determinado pelos seguintes valores:

1. $\operatorname{rank}_{i}=k$, o valor de ranking $i$ é igual ao número da fronteira $\mathcal{F}_{k}$ à qual $i$ pertence;

2. crowdist $_{i}$, o valor de distância de multidão de $i$. 

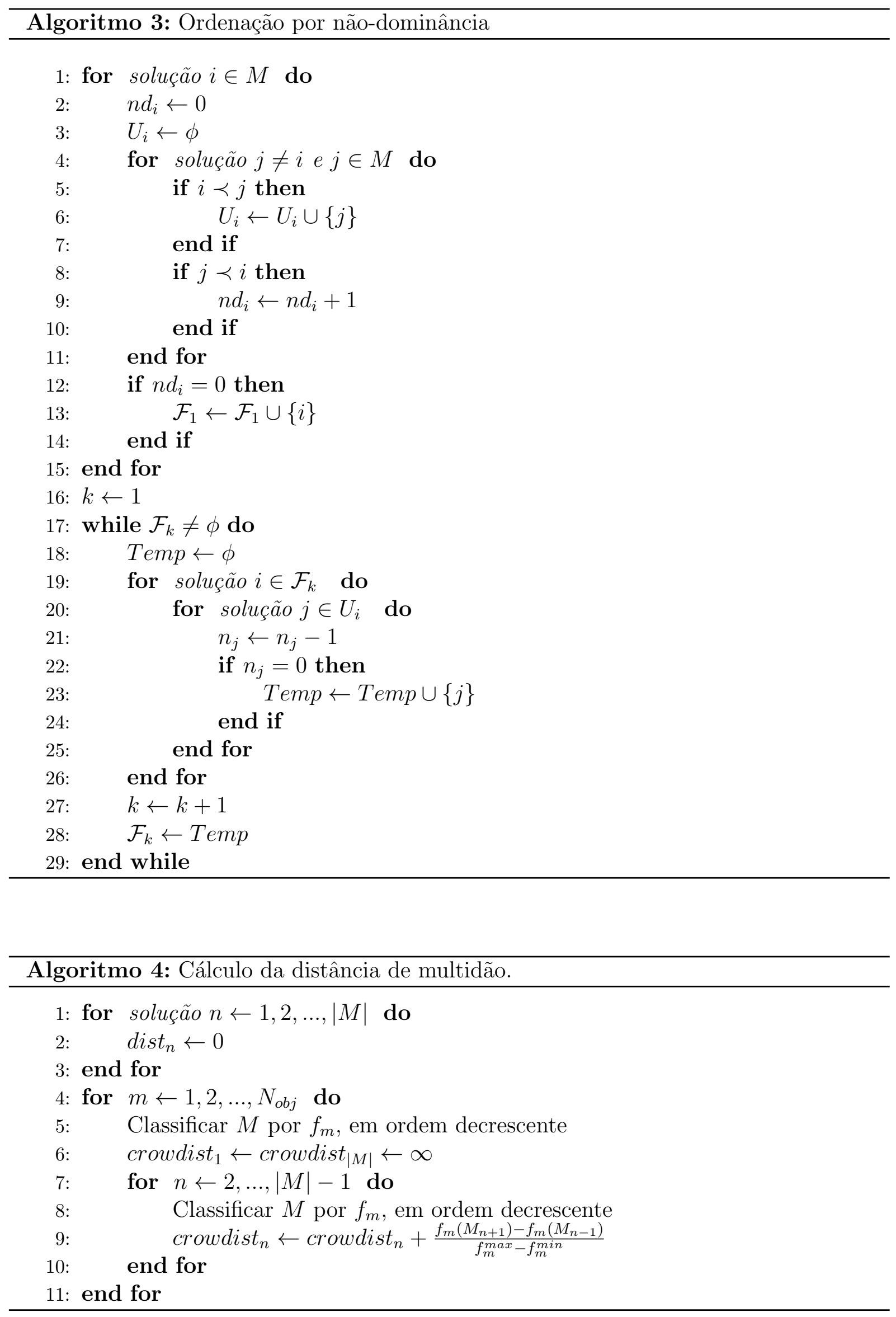
O NSGA-II emprega um processo de seleção por torneio, que é guiado por um novo operador denominado crowded-comparison operator $\left(\prec_{c}\right)$. Em tal abordagem, duas soluções são comparadas para escolher qual delas vai gerar descendentes na nova população. Uma solução $i$ é escolhida sobre uma solução $j$ se:

1. $i$ possui um ranking menor que $j$, ou seja, rank $_{i}<r a n k_{j}$;

2. Se ambas as soluções possuem o mesmo ranking e $i$ possui um maior valor de distância de multidão, ou seja, $\operatorname{rank}_{i}=\operatorname{rank}_{j}$ e corwdist $_{i}>$ crowdist $_{j}$.

O cálculo da distância de mutidão permite que as soluções melhores espalhadas passem a ocupar as útlimas vagas disponíveis de $P_{t+1}$, garantindo a diversidade das soluções. A população $Q_{t+1}$ é gerada utilizando os operadores de seleção por torneio, recombinação e mutação em $P_{t+1}$. O NSGA-II continua por $N_{i t e r}$ iterações e as soluções finais encontramse em $P_{N_{i t e r}} \cup Q_{N_{i t e r}}$. A sequência de passos do NSGA-II é descrita no Algoritmo 5. A Figura 4.4 ilustra o esquema para uma iteração do NSGA-II.

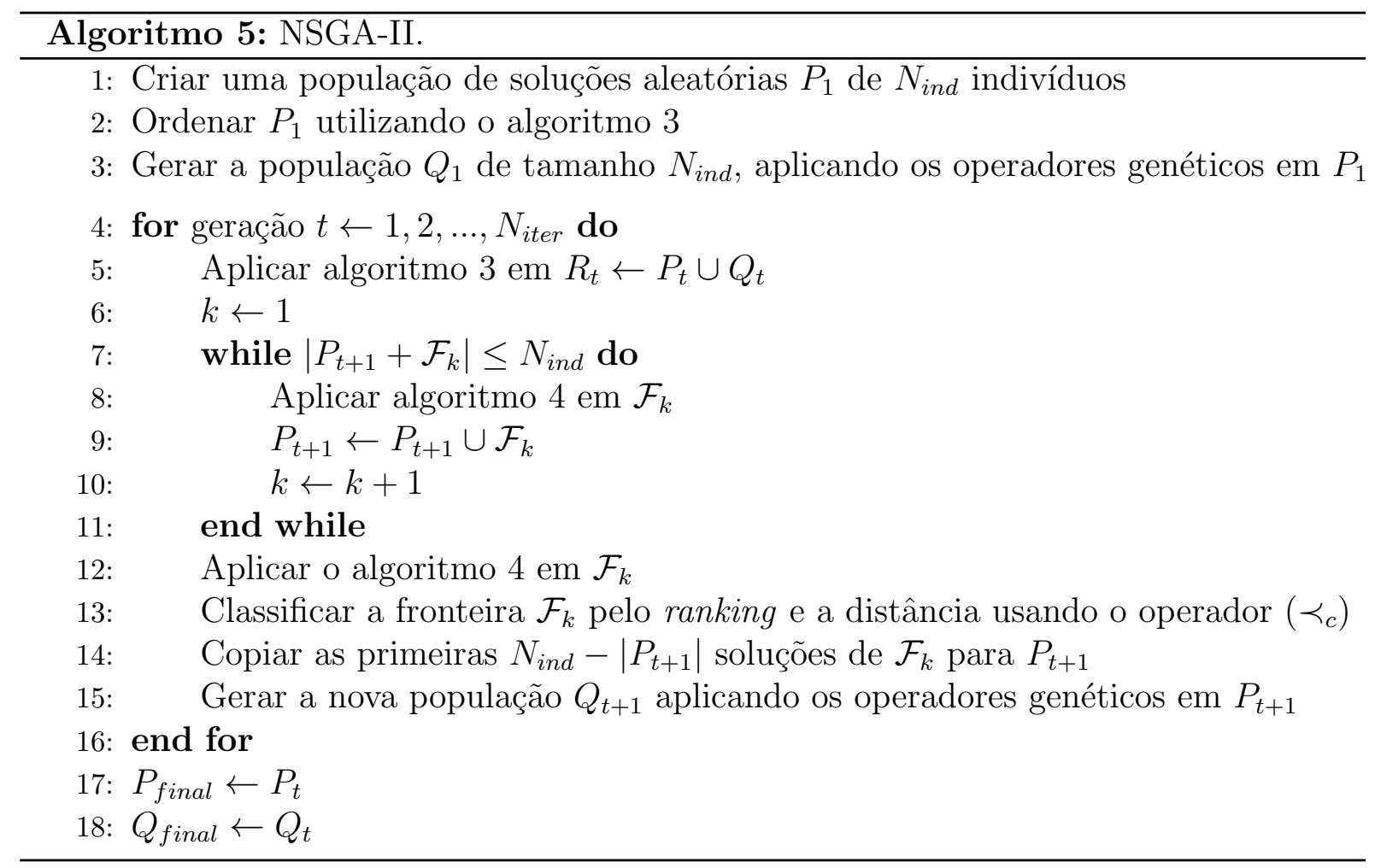

\subsubsection{SPEA2: Strength Pareto Evolutionary Algorithm}

Proposto por (ZITZLER; LAUMANNS; THIELE, 2001), o SPEA2 emprega também duas populações $P$ e $Q$. Na população $Q$, chamada de população externa, são armazenadas apenas as soluções não-dominadas encontradas pelo algoritmo. O tamanho da população 


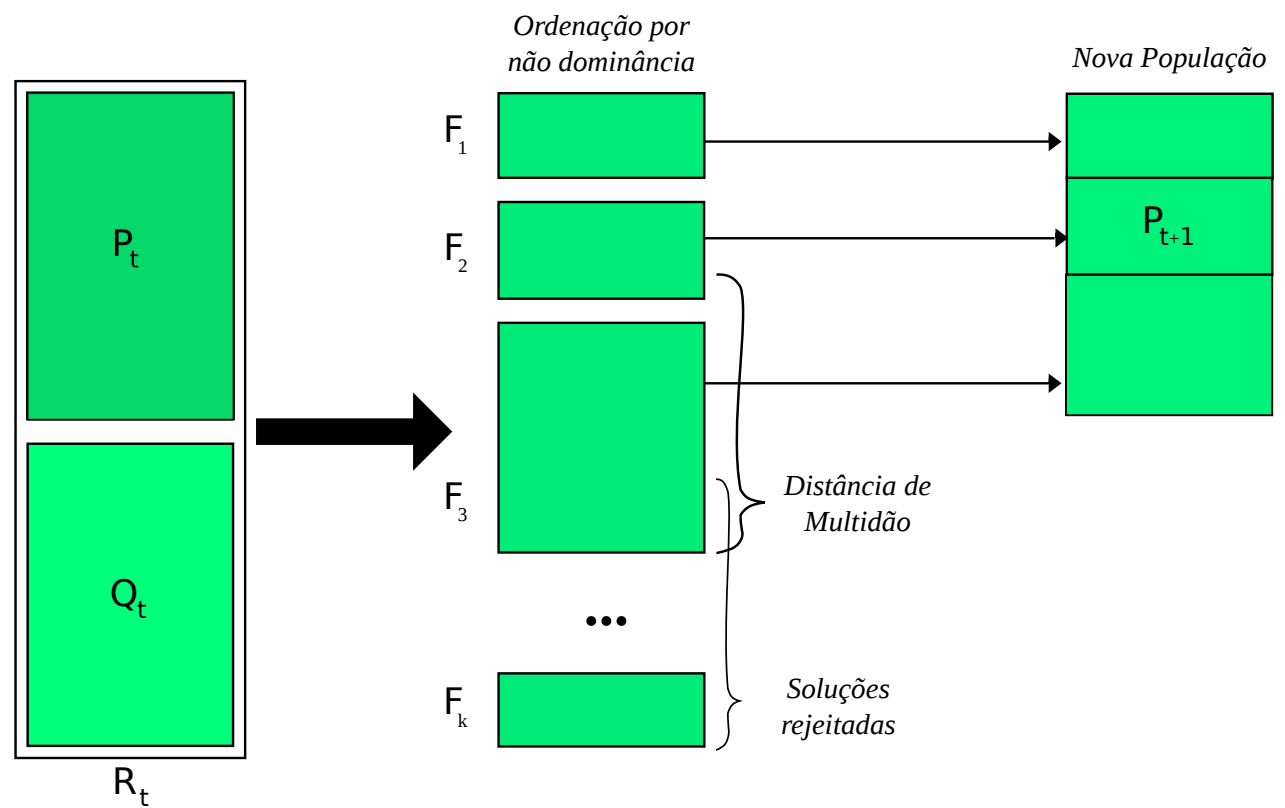

Figura 4.4: Esquema para uma iteração do NSGA-II (Deb, 2001).

$Q$, denotado como $N_{\text {ext }}$, é fornecido como parâmetro. As populações $P$ e $Q$, em cada iteração $t=1,2, \ldots N_{\text {iter }}$, são denotadas como $P_{t}$ e $Q_{t}$, respectivamente.

No SPEA2 inicialmente é criada uma população aleatória $P_{1}$ e uma população externa $Q_{1}$ inicialmente vazia. Em cada iteração $t$, a função de aptidão é calculada para cada solução $i$ em $R_{t}=P_{t} \cup Q_{t}$. No cálculo da função de aptidão, são usados os conceitos de dominância e de densidade, que será definida a seguir. O objetivo é minimizar o valor da função de aptidão. Quanto menor o valor da função de aptidão de um indivíduo, melhor é a adaptação do indivíduo. A força do indivíduo (denotado por $s t r e n g t h{ }_{i}$ ) é dada pelo número de soluções que ele domina:

$$
\text { strength }_{i}=\left|j, j \in R_{t},\right| i \prec j \mid \text {. }
$$

O valor $s t r e n g t h$, representa o número de soluções em $R_{t}$ que são dominadas pela solução $i$. Assim, soluções que não-dominam nenhuma outra possui o valor de strength $_{i}$ igual a zero. Calcula-se também o valor de aptidão bruto do indivíduo, denotado por $r a w_{i}$, que é a soma das forças de todos os indivíduos que o dominam:

$$
\operatorname{raw}_{i}=\sum_{j \in R_{t}, j \prec i} \text { strenght }_{j}
$$

O valor rawi $_{i}$ representa o somatório dos valores strenght $t_{j}$ das soluções $j \in R_{t}$ que dominam $i$. Assim, as soluções não-dominadas tem um valor rawi igual a zero; enquanto que as soluções com um rawi alto são dominadas por muitas soluções em $R_{t}$.

A densidade do indivíduo é uma função decrescente em relação ao $k$-ésimo vizinho mais próximo. A inclusão de um fator de densidade se deve ao fato de que, nos casos em 
que existem muitas soluções não-dominadas, strenght $t_{i}$ se aproxima de zero para todas as soluções. Nesse caso, é necessário haver um mecanismo para privilegiar soluções dentre as não-dominadas.

Para cada indivíduo $i$ em $R_{t}$, as distâncias Euclidianas (no espaço dos objetivos) entre $i$ e todos os indivíduos $j \in R_{t}$ são calculadas pela equação 4.6 e armazenadas em uma lista.

$$
\operatorname{dens}_{i}=\frac{1}{d i s t_{i j}^{k}+2} .
$$

Depois de ordenada a lista em ordem crescente, $k$-ésimo elemento representa o termo $d i s t_{i j}^{k}$. É sugerido para $k$ o valor $\sqrt{\left|R_{t}\right|}$.

Finalmente, a aptidão final para cada solução $i$ em $R_{t}$, denotada por $F_{i}$, é dada por:

$$
F_{i}=\operatorname{raw}_{i}+\text { dens }_{i}
$$

\subsubsection{Seleção e truncamento}

No método de seleção, o primeiro passo é copiar todos os indivíduos não-dominados de $P_{t}$ e de $Q_{t}$ para a população externa da próxima geração $Q_{t+1}$. Nesse caso, podem ocorrer 3 possibilidades:

1. O número de indivíduos no conjunto não-dominado é exatamente o mesmo da população externa $\left(\left|Q_{t+1}\right|=N_{e x t}\right)$;

2. O número de indivíduos no conjunto não-dominado é menor que o tamanho da população externa $\left(\left|Q_{t+1}\right|<N_{e x t}\right)$;

3. O número de indivíduos no conjunto não-dominado excede o tamanho da população externa $\left(\left|Q_{t+1}\right|>N_{\text {ext }}\right)$;

No primeiro caso, o processo de seleção está completo. No segundo caso, os melhores $N_{e x t}-\left|Q_{t+1}\right|$ indivíduos dominados, incluindo a população regular e a população externa na geração anterior, são copiados para a nova população externa. No terceiro caso, um algoritmo de corte é utilizado.

O objetivo do algoritmo de corte do SPEA2 é restringir o tamanho de $Q_{t+1}$ a $N_{\text {ext }}$ soluções. Em cada iteração, é removida a solução cuja distância para seu vizinho mais próximo seja a menor dentre as distâncias existentes. No caso de empate, calcula-se a segunda menor distânca, e assim sucessivamente. Formalmente, uma solução $i^{\prime}$ é eliminada de $Q_{t+1}$ se as seguintes condições forem satisfeitas:

1. dist $_{i^{\prime} j^{\prime}}^{1}<d i s t_{i j}^{1} \quad \mid \quad i^{\prime}, j^{\prime}, i \neq i^{\prime}, j \in Q_{t+1}$ ou; 
2. $\operatorname{dist}_{i^{\prime} j^{\prime}}^{l}=\operatorname{dist}_{i j}^{l}$ e dist $t_{i^{\prime} j^{\prime}}^{k}<d i s t_{i j}^{k} \quad \mid i^{\prime}, j^{\prime}, i \neq i^{\prime}, j \in Q_{t+1}, \quad l<k<N_{e x t}, \quad 1<$ $l<k$.

onde $d i s t_{i^{\prime} j^{\prime}}^{1}$, dist $t_{i^{\prime} j^{\prime}}^{k}$ e $d i s t_{i^{\prime} j^{\prime}}^{l}$ representam as distâncias de $i^{\prime}$ em relação a seu primeiro, $k$-ésimo e $l$-ésimo vizinho mais próximo (denotado por $j^{\prime}$ ). Com isso, são eliminadas soluções em $Q_{t+1}$ até reduzir o seu tamanho para $N_{\text {ext }}$.

A Figura 4.5 ilustra um conjunto de soluções pertencentes à população externa $Q_{t+1}$. Depois de aplicar o algoritmo de corte, algumas soluções são eliminadas, conforme ilustrado na fiugura. Além disso, o algoritmo de corte garante que as soluções extremas para cada objetivo sejam mantidas.
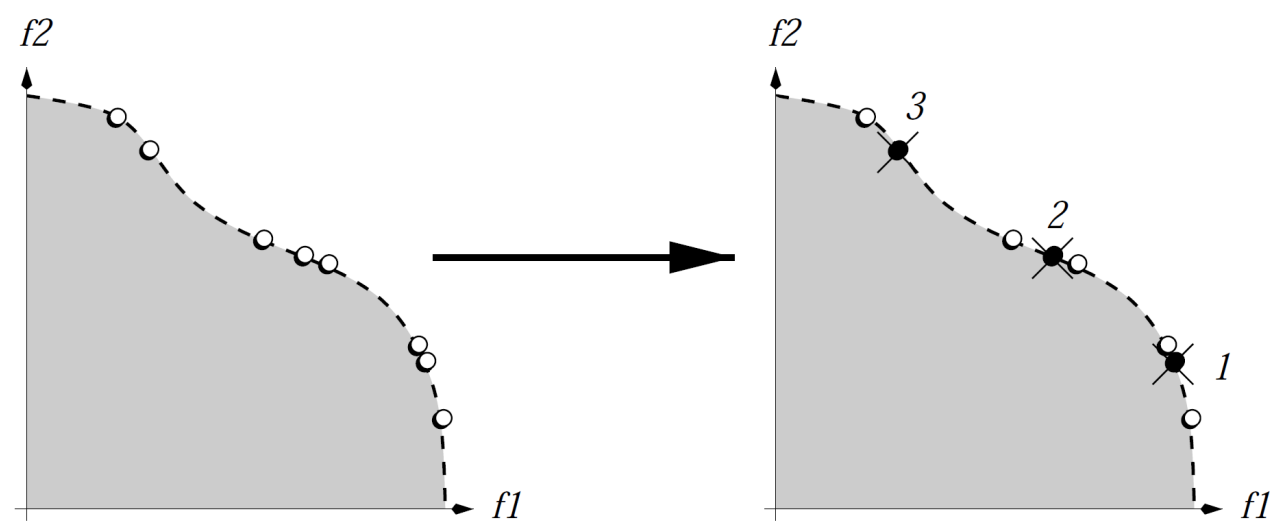

Figura 4.5: Algoritmo de Corte no modelo SPEA2 (ZITZLER et al., 2001).

\subsubsection{Algoritmo Evolutivo Multi-Objetivo em Tabelas}

O Algoritmo Evolutivo Multi-Objetivo em Tabelas (AEMT), segundo SANTOS (2009) e R. BENAYOUN J. DE MONTGOLFIER; LARITCHEV (1971), trabalha com várias subpopulações em paralelo armazenadas em tabela, onde os melhores indivíduos para cada característica do problema são armazenados em suas respectivas subpopulações. Uma importante característica do AEMT é o uso de uma subpopulação para armazenar indivíduos avaliados por uma função agregação, também conhecido como soma ponderada (DEB, 2001); (COELLO, 1998). O indivíduo selecionado para reprodução pode ser proveniente de qualquer subpopulação ou tabela. Essa estratégia de seleção aumenta a diversidade entre os indivíduos que reproduzem de forma que as características de um indivíduo de uma subpopulação possam migrar para as demais subpopulações da tabela. Em conseqüência, aumenta-se a possibilidade do algoritmo escapar de ótimos locais, aproximando-se de soluções com avaliações próximas de um ótimo global na fronteira Pareto-ótima.

Alguns parâmetros são importantes para o desempenho do AEMT:

1. O tamanho de cada subpopulação $S_{p i}$, que indica o número máximo de indivíduos que podem permanecer em cada subpopulação $P_{i}$ de uma geração para outra; 
2. O número máximo de gerações $\left(g_{\max }\right)$.

Soluções geradas pelo AEMT podem ser armazenadas ou descartadas, dependendo do grau de adaptação do indivíduo a cada objetivo do problema (característica do problema em uma subpopulação $P_{i}$ ).

No processo de seleção de sobreviventes, um novo indivíduo é acrescentado a uma subpopulação $P_{i}$ se sua adequação ao objetivo de $P_{i}$ for melhor que pelo menos um indivíduo da mesma. O mesmo indivíduo pode ser incluído em mais de uma tabela de acordo com esse critério de seleção. Importa destacar que, como a população é estacionária, os novos indivíduos substituem os piores.

\subsection{Métricas de desempenho}

A comparação de desempenho de um ou vários métodos de otimização multi-objetivo é uma tarefa complexa. Segundo DEB (2001) duas metas da otimização multi-objetivo são: convergência e diversidade das soluções encontradas. Para tanto, segundo DEB (2001) existem diversas métricas que ajudam na análise destas metas com destaque para as métricas:

- Taxa de Erro;

- Distância Geracional;

- Métrica de Cobertura;

- Espaçamento;

- Espalhamento;

Entretanto, atualmente uma métrica bastante usada na avaliação de algoritmos multiobjetivos é o indicador de hipervolume (HV) DEB (2001). No HV, calcula-se o volume da região coberta entre os pontos das soluções na fronteira de Pareto $P$ e um ponto de referência $W$. Para cada solução $i$ pertencente a $P$, é construído um hipercubo $v_{i}$ com referência a um ponto $W$. O ponto de referência pode ser encontrado construindo-se um vetor com os piores valores da função objetivo. O resultado da métrica é a união de todos os hipercubos encontrados. Quanto maior o valor do HV melhor, pois um alto valor de $\mathrm{HV}$ indica que houve um elevado espalhamento entre as soluções de $P$ e indica que houve também uma melhor convergência. O HV é calculado da seguinte maneira:

$$
H V=\sum_{i \in P} v_{i}
$$




\subsection{Conclusões}

Neste capítulo foram apresentados conceitos de algoritmos evolutivos, com destaque para a abordagem evolutiva Evolução Diferencial, tendo em vista que uma das propostas deste trabalho é a investigação da utilização da Evolução Diferencial. Além disso, foram discutidos técnicas de otimização multio-bjetivo bem como os principais algoritmos evolutivos multi-objetivo, como o NSGA-II, SPEA2 e o AEMT. No próximo Capítulo serão apresentados detalhadamente os métodos AEMT e NSNP, que são AEMOs que tratam de problemas de reconfiguração de redes em SDRs com o uso da RNP e serão utilizados como base para o desenvolvimento deste trabalho. 


\section{Capítulo 5}

\section{AEMO para Reconfiguração de Redes em SDR}

\subsection{Introdução}

Conforme mencionado no capítulo 1, os métodos apresentados em (SANTOS, 2009) e (MANSOUR et al., 2009) fazem uso da estrutura de dados denominada RNP e de seus operadores genéticos apresentados no capítulo 3. A diferença entre esses métodos é o AEMO utilizado. O método proposto em (SANTOS, 2009) faz uso da RNP e de um AEMO que trabalha em paralelo com várias subpopulações armazenadas em tabelas, daí a razão de o mesmo ter sido chamado de AEMT (Algoritmo Evolutivo Multi-objetivo em Tabelas). Por outro lado, o método proposto em (MANSOUR et al., 2009) baseia-se na combinação da RNP com uma versão modificada do NSGA-II. Em razão disso, esse método passou a ser chamado de NSNP (NSGA-II com RNP). Para avaliar de forma eficiente computacionalmente a qualidade das configurações geradas durante o processo evolutivo, os métodos AEMT e NSNP fazem uso de um fluxo de carga baseado na RNP e do procedimento de cálculo do número de manobras apresentado na seção 2.7 do capítulo 2. Face ao exposto, antes de apresentar os métodos AEMT e NSNP, apresentar-se-á como se da o cálculo de fluxo de potência através da estrutura de dados RNP.

\subsection{Extensão da RNP para fluxo de carga}

Como os métodos AEMT e NSNP fazem uso da RNP, é necessário realizar uma modificação no fluxo de carga, para que o mesmo trabalhe com a RNP. Os detalhes dessa modificação serão discutidos a seguir.

Usualmente, nos trabalhos desenvolvidos para tratamento de problemas de reconfiguração de redes em SDRs, para execução do fluxo de potência as barras de carga de um setor são modeladas como se estivessem concentradas em um único ponto. Esse procedimento 
reduz o grau de confiabilidade dos resultados obtidos.

Procurando reproduzir um SDR real com a maior fidelidade possível para a exeução de um fluxo de potência, em SANTOS (2009) utilizou-se a RNP em dois níveis diferentes: a RNP do alimentador e a RNP do setor. Considere os 2 alimentadores da Figura 5.1. As barras em cinza pertencem ao alimentador 1 e as barras em preto ao alimentador 2 . Nas Figuras 5.1 e 5.2, os retângulos são barras em subestações, círculos são barras do SDR (barras de carga, extremidade de chaves, ponto de conexão de duas ou mais linhas), linhas pontilhadas são chaves seccionadoras NF, linhas cheias são linhas do SDR e linhas interrompidas são chaves seccionadoras NA.

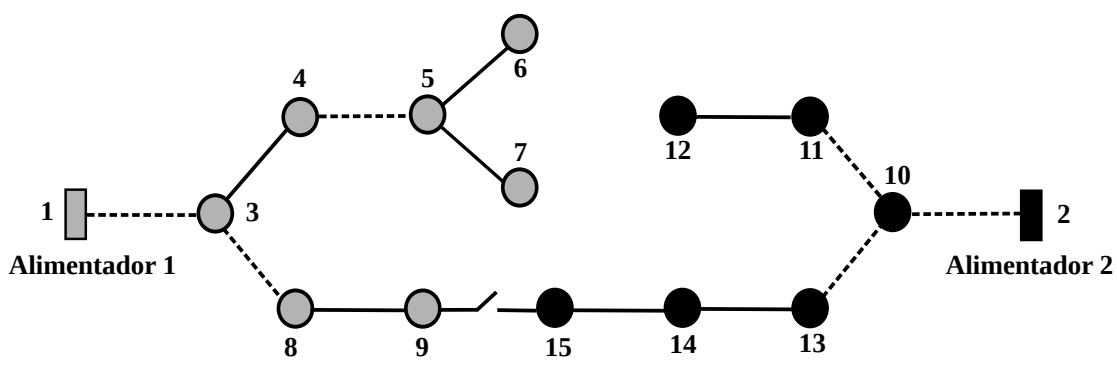

Figura 5.1: SDR com dois alimentadores.

A Figura 5.2 mostra o agrupamento das barras e linhas não separadas por chaves na Figura 5.1, desta forma, tem-se um grafo em que todas as arestas são chaves seccionadoras, conforme a Figura 5.3.

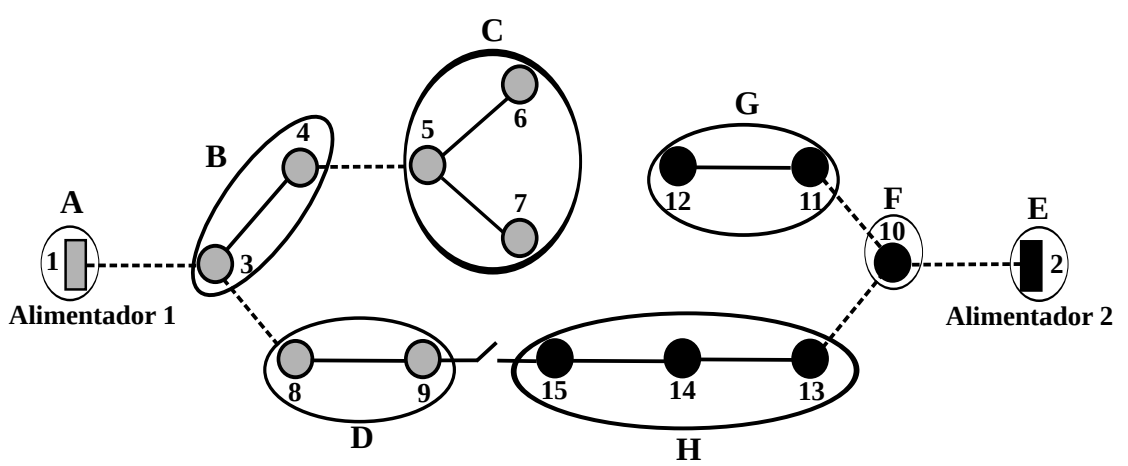

Figura 5.2: Agrupamento das linhas e barras em setores.

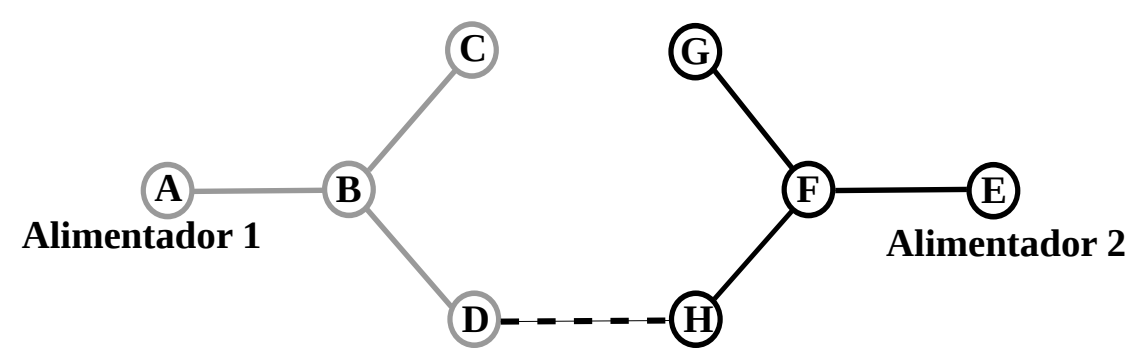

Figura 5.3: Grafo representando setores do SDR da Figura 5.2. 
A Figura 5.3 possui 2 RNPs, uma para o alimentador 1 (cor cinza) e outra para o alimentador 2 (cor preta), denominadas RNP do alimentador. As chaves seccionadoras NF são as arestas em cinza e preto e a chave NA é a aresta tracejada. Assim, temos uma estrutura $T_{1}$ que armazena o endereço de memória da RNP do alimentador 1 , e a estrutura $T_{2}$ armazena o endereço de memória da RNP do alimentador 2:

$$
\begin{aligned}
& T_{1}=\left[\begin{array}{llll}
0 & 1 & 2 & 2 \\
A & B & C & D
\end{array}\right], \\
& T_{2}=\left[\begin{array}{llll}
0 & 1 & 2 & 2 \\
E & F & G & H
\end{array}\right] .
\end{aligned}
$$

A partir da Figura 5.2 cada trecho de linhas e barras não separadas por chaves pode ser analisado como uma árvore de grafo, isto é, é possível também associar RNP's aos setores. Cada setor pode ter mais de um nó raiz, dependendo do sentido em que está sendo alimentado. Assim, pode haver mais de uma árvore representando cada setor. Para finalidade de fluxo de carga, acrescenta-se a cada uma dessas árvores o nó adjacente ao seu nó raiz. A figura 5.4 mostra o setor D da figura 5.2 com os seus respectivos nós adjacentes

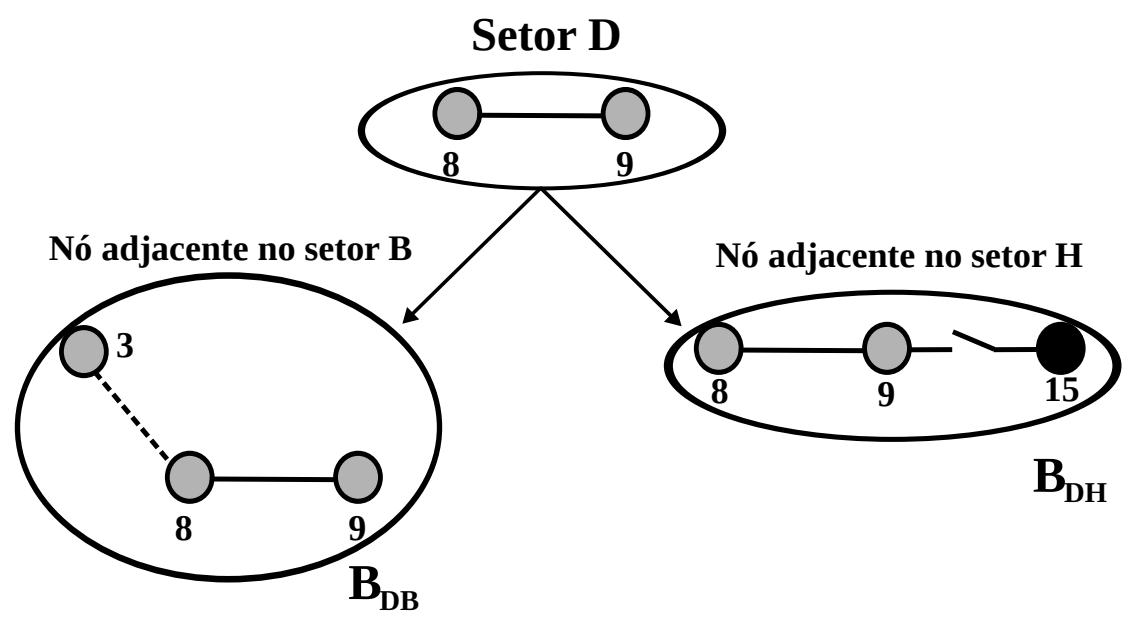

Figura 5.4: Árvore do setor D, com os nós adjacentes aos setores B e H.

A RNP do setor pode ser representada de forma semelhante à RNP do alimentador, onde as árvores foram armazenadas em estruturas denotadas por $T_{i}$. Para a RNP do setor, denota-se $B_{s r}$, onde $s$ representa o setor em análise e $r$ o setor pelo qual a energia chega ao setor $s$. Conforme pode ser visto na Figura 5.4, para o mesmo setor $s$ pode existir mais de um setor $r$.

Para a Figura 5.4, o fluxo de corrente pode chegar ao setor $D$ por dois caminhos diferentes, através do setor $B$ ou do setor $H$. Assim, têm-se $B_{s r}=B_{D B}$ para o setor $B$ e $B_{s r}=B_{D H}$ para o setor $H$. Com isso, para o setor $D$ podemos ter duas RNPs de setores: 


$$
\begin{aligned}
B_{D B} & =\left[\begin{array}{lll}
0 & 1 & 2 \\
3 & 8 & 9
\end{array}\right], \\
B_{D H} & =\left[\begin{array}{ccc}
0 & 1 & 2 \\
15 & 9 & 8
\end{array}\right] .
\end{aligned}
$$

Para descobrir qual das configurações acima deve ser utilizada, é necessário realizar uma análise da RNP do alimentador. Deste modo, analisando o alimentador 1, descobre-se que o setor $D$ está conectado ao setor $B$, conforme abaixo:

$$
T_{1}=\left[\begin{array}{llll}
0 & \mathbf{1} & 2 & \mathbf{2} \\
A & \mathbf{B} & C & \mathbf{D}
\end{array}\right]
$$

Portanto, no exemplo da Figura 5.4, o $r$ correto é o setor $B$.

Importa destacar que a determinação de todas as RNPs de cada setor pode ser executada por um procedimento off-line, deixando todas as estruturas prontas para serem utilizadas pelo fluxo de carga on-line.

\subsubsection{Método de Soma de Correntes com RNP}

Conforme mencionado no capítulo 3, o método de fluxo de carga utilizado neste trabalho é o de Soma de Correntes junto com o modelo de carga corrente constante. Isto em razão das características específicas dos SDRs e da necessidade de avaliar as configurações geradas em um curto tempo de processamento.

Conforme já apresentado no capítulo 2, o algoritmo do método Soma de Correntes é composto por duas sub-rotinas:

- Subrotina CORRENTES: obtém as correntes a jusante por meio do processo backward para todas as barras de um alimentador;

- Subrotina TENSÕES: utiliza as correntes a jusante para obter as tensões nas barras do mesmo alimentador, por meio do processo forward.

A sub-rotina CORRENTES percorre os nós (barras) do sistema, partindo dos nós terminais até o nó raiz (ver Algoritmo 6). Vale destacar que a ordem dos nós visitados é a ordem que está definida nas RNPs do alimentador e do setor. A carga de uma barra $m$ é denominada $I(m)$ e a sua corrente jusante é denominada $J(m)$.

Na sub-rotina TENSOES (ver Algoritmo 7) a ordem dos nós visitados é no sentido do nó raiz para os nós terminais. Essa ordem já está determinada nas RNPs do alimentador e do setor. Os dados necessários para obter as tensões em cada barra são a corrente na barra $I(n)$, a tensão a montante da barra $n, V(m)$, e a impedância $Z_{m n}$ entre as barras $m$ e $n$. 

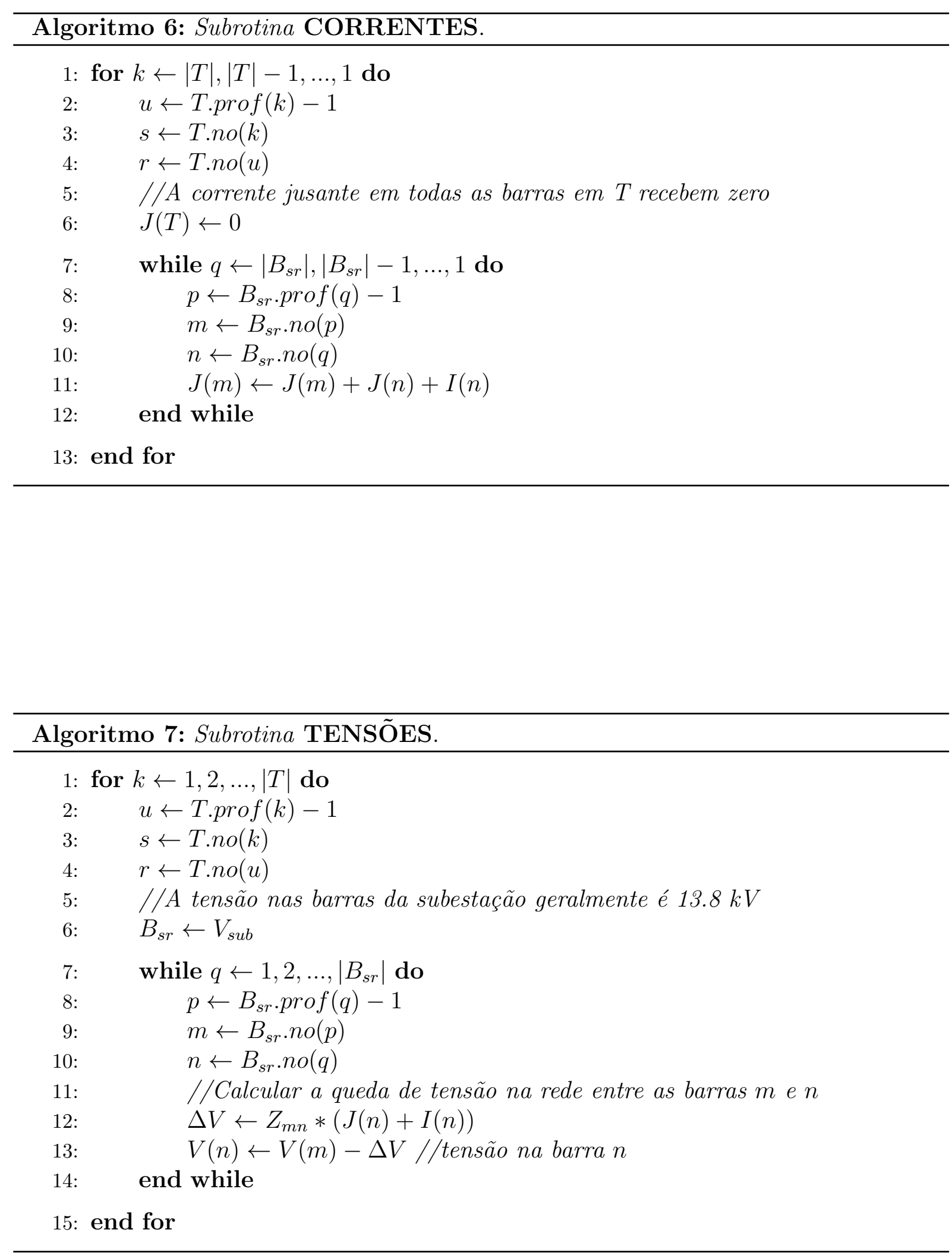
Os dados retornados pelas subrotinas apresentadas acima são utilizados pelo algoritmo principal do fluxo de carga utilizando a RNP, este descrito no Algoritmo 8. Como os operadores PAO e CAO modificam pares de árvores de uma floresta, para cada nova floresta apenas 2 alimentadores são alterados. Assim, as sub-rotinas CORRENTES e TENSOES são aplicadas somente a esses alimentadores, pois o fluxo de carga para os outros alimentadores não se altera.

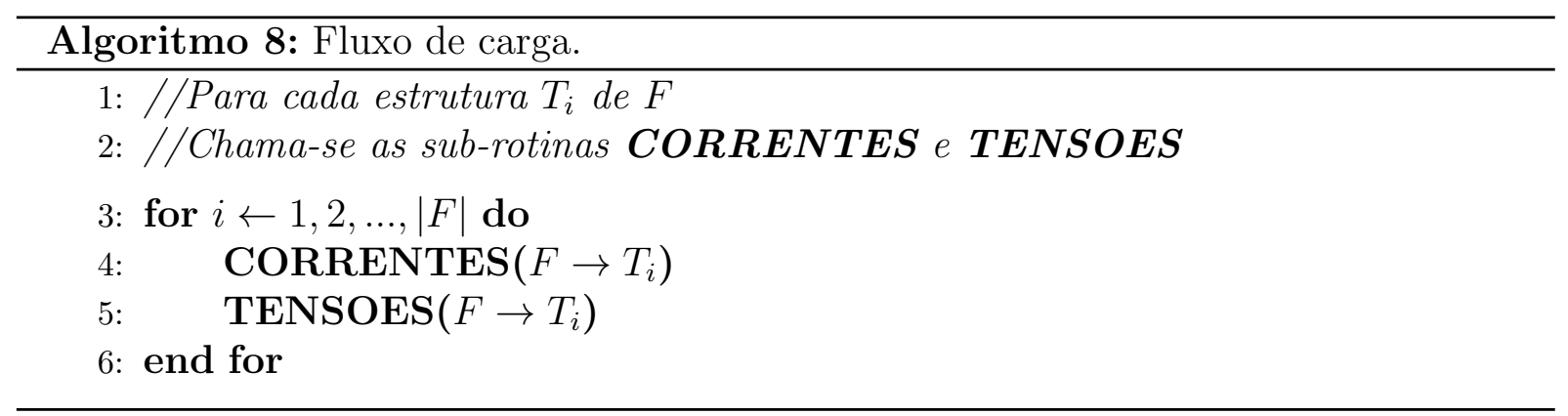

\subsection{AEMT com o uso da RNP}

Como mencionado anteriormente, o AEMT trabalha com várias subpopulações armazenadas em tabelas. Cada subpopulação é definida a seguir:

- $S_{p i}$ : é o tamanho da tabela de subpopulação $P_{i}$, indicando a quantidade de indivíduos que podem ser armazenados em $P_{i}$, com $i=1, \ldots, 5$. Portanto, as cinco tabelas de subpopulações $P_{i}$ são: $P_{1}$ - indivíduos com menor perda ôhmica; $P_{2}$ - indivíduos com menor perfil de tensão; $P_{3}$ - indivíduos com menor carregamento da rede; $P_{4}$ - indivíduos com menor carregamento da subestação; $P_{5}$ - indivíduos com menores valores da função agregação.

A função agregação (ver Equação 5.1) é composta pelos valores de perdas ôhmicas, número de operações de manobras e restrições operacionais (perfil de tensão, carregamento da rede e da susbestação):

$$
f(x)=x_{1}+x_{2}+\delta_{1} x_{3}+\delta_{2} x_{4}+\delta_{3} x_{5}
$$

onde, $x_{1}, x_{2}, x_{3}, x_{4}$ e $x_{5}$ correspondem, respectivamente, à somatória das perdas ôhmicas em kW, número de chaveamentos, máximo carregamento da rede em p.u., ao máximo carregamento das subestações em p.u., à máxima queda de tensão em p.u., ; $\delta_{i}$ é a penalização de cada objetivo $x_{i}$, sendo: 


$$
\delta_{\mathrm{i}}=\left\{\begin{array}{l}
100, \text { se, uma restrição foi violada para pelo menos uma barra } \\
0, \text { caso contrário, }
\end{array}\right.
$$

para $i=1,2,3$.

Segundo SANTOS (2009), o AEMT é robusto em relação a variações dos pesos $w_{i i}$. Esses valores devem ser suficientemente altos a fim de penalizar soluções infactíveis (pesos variando de 10 a 100 são em geral adequados).

Para geração de novos indivíduos, o AEMT faz uso dos operadores PAO e CAO da RNP (ver Capítulo 3), que são selecionados segundo uma determinada probabilidade, que é alterada conforme o sucesso do operador escolhido. Inicialmente ambos os Operadores $\mathrm{PAO}$ e CAO possuem a mesma taxa de probabilidade (por exemplo, $T_{P A O}=T_{C A O}=$ $50 \%)$. Suponha que o Operador PAO tenha sido escolhido para gerar um novo indivíduo. Se o indivíduo gerado tiver sucesso, ou seja, for acrescentado a uma ou mais subpopulações, aumenta-se $T_{P A O}$ para $51 \%$ e, como conseqüência, $T_{C A O}$ é reduzido para $49 \%$ e, assim por diante. Esse ajuste dinâmico do processo de escolha dos Operadores melhora o desempenho do algoritmo consideravelmente, conforme mostrado em (SANTOS, 2009).

O pseudocódigo do AEMT é apresentado no Algoritmo 9. Vale ressaltar que, diferentemente do NSGA-II e SPEA2 (ver Capítulo 4) que geram vários indivíduos por iteração, no AEMT apenas 1 indivíduo é gerado por iteração.

Vale destacar que esta abordagem pode ser aplicada tanto no problema de redução de perdas como restabelecimento de energia em SDRs de grande porte após a ocorrência de uma ou múltiplas faltas.

Para o problema de restabelecimento de energia em SDRs, devido a radialidade do sistema, após a ocorrência de uma ou mais faltas, as áreas fora de serviço representam subárvores de grafo. Assim, os operadores da RNP (ver Capítulo 3) podem ser aplicados para conectá-la(s) a outra árvore (alimentador), quando possível. Cada aplicação de um dos operadores gera um indivíduo novo na população, isto é, uma floresta que representa um SDR sem o(s) setor(es) em falta (isolados) e com a área fora de serviço re-conectada a algum ponto energizado do sistema. Esse indivíduo pode violar uma ou mais restrições operacionais do sistema, potencialmente inviabilizando o uso dessa configuração na prática. Assim, é necessário encontrar uma nova configuração que melhore a qualidade do sistema.

\subsubsection{Resultados Obtidos com o AEMT}

Em (SANTOS, 2009), o AEMT foi avaliado utilizando o SDR da cidade de São Carlos (SDR-SC), em operação em 1994, com 3.860 barras e 632 chaves (509 chaves NF e 123 chaves NA). Além disso, foram realizados testes utilizando outras três redes sintetizadas a partir do SDR-SC. As redes sintetizadas possuem tamanhos (número de barras e chaves) 


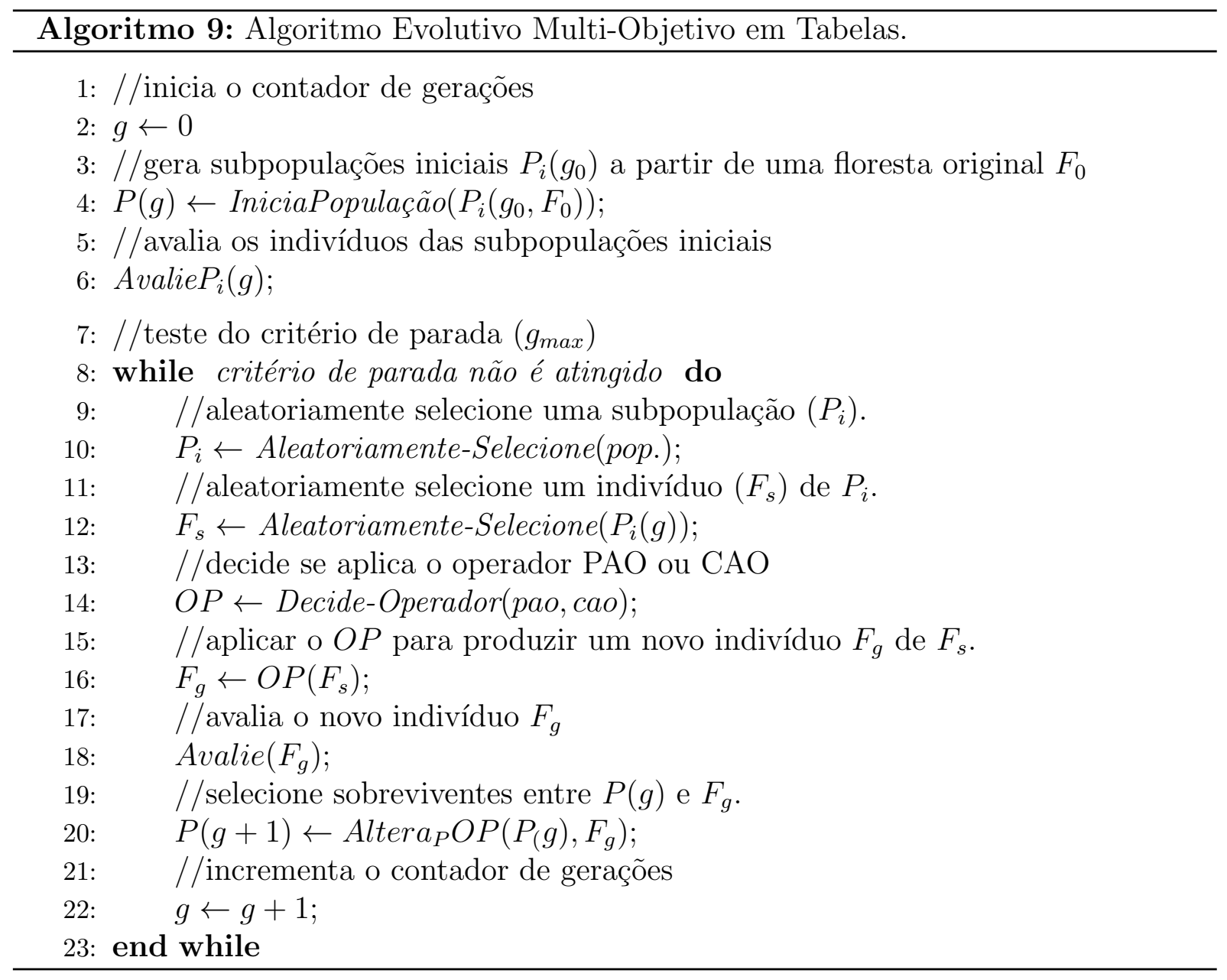


que são aproximadamente duas, quatro e oito vezes o tamanho do SDR-SC. Com isso, o AEMT foi avaliado inclusive para uma rede com 30.880 barras, 4.264 setores, 5.166 chaves (4.072 chaves NF e 1.094 chaves NA), 24 subestações e 184 alimentadores.

Segundo (SANTOS, 2009), quanto maior o tamanho da rede, maior o número de configurações possíveis. Em conseqüência, aumenta-se a possibilidade de existirem um número maior de soluções que atendam as restrições do problema. Por outro lado, obter resultados adequados para esse tipo de problema é difícil, pois o número de configurações infactíveis também aumenta com o tamanho da rede. Portanto, com base nos resultados obtidos para o problema de restabelecimento de energia para o SDR-SC e para as redes sintetizadas mostram que o AEMT é capaz de vencer tais dificuldades e explorar adequadamente o espaço das soluções factíveis, encontrando configurações de alta qualidade em curto intervalo de tempo.

Em (SANTOS, 2009) também são apresentados resultados do AEMT para o problema de redução de perdas ôhmicas, em que os resultados obtidos pelo o AEMT foram comparados com resultados encontrados pelo NSGA-II e SPEA2 adaptados com a RNP. O NSGA-II e o SPEA2 encontram fronteiras de Pareto com um número maior de soluções. Por outro lado, foi possível observar que o AEMT possui uma forte característica de concentrar as soluções nos extremos da fronteira. Ainda em (SANTOS, 2009) destaca-se que o tempo de computação requerido pelo AEMT é menor que das outras duas técnicas multi-objetivo, mas não de forma expressiva.

\subsection{NSNP - NSGA-II com o uso da RNP}

Como mencionado na seção anterior, em (SANTOS, 2009) foi desenvolvido o AEMT para tratar do problema de reconfiguração de redes em SDR, porém, o AEMT não apresenta um bom mapeamento do problema, pois não gera de forma eficiente uma Fronteira de Pareto, diminuindo assim o número de configurações possíveis de serem implementadas em um SDR.

Neste contexto, em (MANSOUR et al., 2009) é proposto a substituição do método AEMT por outra técnica de MOEA, que permita a geração de uma Fronteira de Pareto de forma a conseguir encontrar configurações melhores que as obtidas pelo AEMT.

O algoritmo proposto, NSNP, foi baseado no trabalho proposto por (SANTOS, 2009), e na técnica NSGA-II (DEB et al., 2002), para obtenção de planos de restabelecimento de energia em SDR de grande porte.

O NSGA-II é a técnica de MOEA mais utilizada na literatura e já foi aplicada para resolver o problema de restabelecimento em SDR (KUMAR; DAS; SHARMA, 2008). Porém, o NSGA-II não apresenta bons resultados quando aplicado em problemas com um grande número de funções objetivo (geralmente acima de três objetivos), conforme abordado em (DEB; SUNDAR, 2006). Deste modo, para lidar com o problema de restab- 
elecimento de energia em SDR, MANSOUR et al. (2009) realizaram algumas modificações no NSGA-II. Tais modificações serão descritas nas próximas seções.

\subsubsection{Formulação Matemática}

Os AEs convencionais, ou mono-objetivos, quando aplicados para o problema multiobjetivo de restabelecimento de energia em SDR fazem uso de uma função agregação e perdem eficiência quando aplicados em SDR de grande porte (KUMAR; DAS; SHARMA, 2008).

Para contornar esse problema, em SANTOS (2009) desenvolveu-se um AE para reconfiguração de SDR que faz uso da RNP e de seus operadores. Destaca-se o fato de tais operadores gerarem apenas configurações factíveis.

A abordagem proposta por MANSOUR et al. (2009) também faz uso da RNP e dos seus operadores, entretanto baseia-se no NSGA-II. Assim, são necessárias algumas modificações na formulação matemática discutida anteriormente (ver Capítulo 2 seção 2.4)

Na nova formulação matemática proposta por MANSOUR et al. (2009) consideram-se duas funções objetivo: a primeira é o número de operações de chaveamento, que deve ser o menor possível para garantir um rápido restabelecimento de energia; e a segunda é uma função agregação que contempla os demais objetivos e restrições do problema de restabelecimento (perdas resistivas, restrições operacionais dentre outros). Dessa forma, o problema descrito na Equação 2.4 é reescrito como segue:

$$
\begin{array}{cl}
\text { Min. } & E=\left[e_{1}(F)\left|\Omega I^{\prime}(F)\right|\right] \\
\text { s.a. } & \\
& \text { Utilizar MPF com RNP } \\
& \text { F ser dado pelos operadores da RNP, }
\end{array}
$$

onde $E$ é um vetor de duas funções objetivo: $e_{1}(F)$ é o número de operações de chaveamento; e $\left|\Omega I^{\prime}(F)\right|$ é a função agregação composta pelas restrições operacionais (queda de tensão, carregamento da rede e carregamento do sistema) e pelas perdas resistivas. A penalidade $\Omega$ é a mesma matriz diagonal discutida no Capítulo 2 seção 2.4.

Conforme mencionado em (DEB; SUNDAR, 2006), o NSGA-II não apresenta um bom desempenho para problemas com mais de três funções objetivo. Para tanto, a nova formulação matemática, proposta por MANSOUR et al. (2009) (equação 5.2), utiliza apenas duas funções objetivo. Quando utilizado três funções objetivos, a metodologia apresentou um desempenho inferior para tratar do problema em pauta. 


\subsubsection{NSNP - Pseudocódigo}

Como mencionado anteriormente, o NSNP baseia-se na RNP e no NSGA-II. Porém, devido à utilização da RNP, são necessárias algumas modificações no NSGA-II tradicional, apresentado no Capítulo 4, pois no NSNP as populações $P$ e $Q$ são geradas pelos operadores da RNP. Lembrando que no NSGA-II tradicional, aquelas populações são geradas por operadores genéticos tradicionais.

Inicialmente, o operador PAO é utilizado para conectar a área fora de serviço a algum alimentador, gerando assim o primeiro indivíduo da população $P_{1}$. Este indivíduo representa uma configuração factível e através dele são gerados os demais $N_{\text {ind }}-1$ indivíduos restantes da população $P_{1}$. Os demais passos são similares ao algoritmo 5 (ver Seção 4.4.1), com exceção da geração das populações, conforme discutido anteriormente.

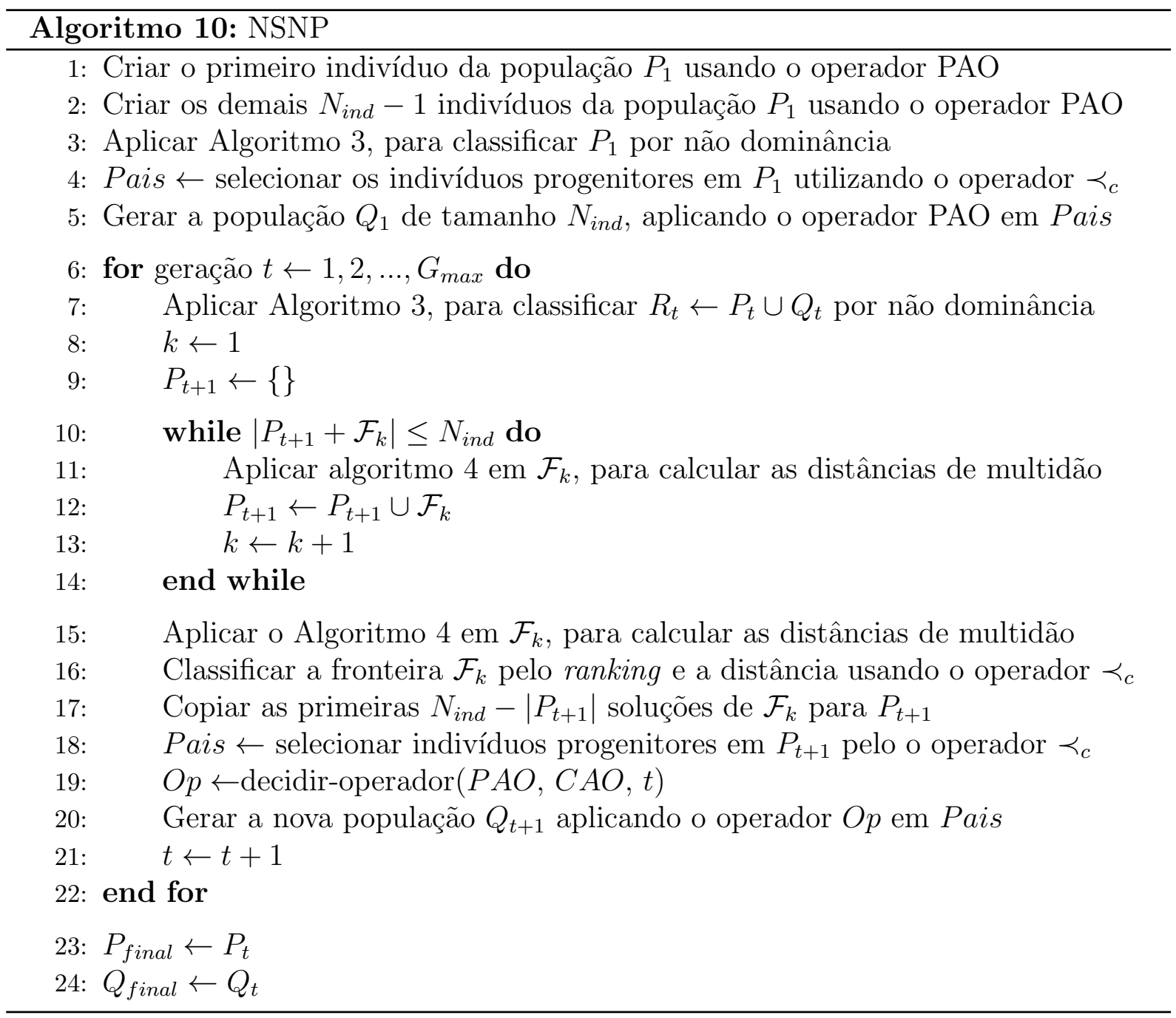

\subsubsection{Resultados Obtidos com o NSNP}

Em (MANSOUR et al., 2009) o NSNP foi avaliado utilizando o SDR-SC, que possui 3.860 barras e 632 chaves (509 chaves NF e 123 chaves NA) que corresponde ao SDR da 
cidade de São Carlos em operação em 1994.

Ainda em (MANSOUR et al., 2009) é apresentado um comparativo entre o NSNP e o AEMT para o problema de restabelecimento de energia. Os resultados indicam que o NSNP possibilita uma maior redução do número de manobras, porém com um aumento de perdas ôhmicas. De uma forma mais geral, pode-se dizer que, em razão de basearse no NSGA-II, o NSNP apresenta um melhor mapeamento do problema, em razão de possibilitar a obtenção das Fronteiras de Pareto.

\subsection{Conclusões}

Detalhes dos métodos AEMT e NSNP, bem como a modificação do algoritmo para o cálculo do fluxo de carga em SDRs para uso da RNP, foram apresentados neste capítulo. No próximo capítulo serão apresentadas as metodologias propostas para reconfiguração de redes em SDR, que possibilitam o tratamento dos problemas de redução de perdas e restabelecimento de energia em SDR de grande porte. 


\section{Capítulo 6}

\section{Metodologias Propostas}

\subsection{Introdução}

Neste Capítulo são apresentadas as metodologias propostas neste trabalho, para tratamento dos problemas de redução de perdas ôhmicas e restabelecimento de energia em SDRs de grande porte. A primeira metodologia proposta é uma combinação dos métodos AEMT, NSNP e SPEA2. A segunda metodologia baseia-se no algoritmo de evolução diferencial e no AEMT.

\subsection{AEMT com Soluções Não Dominadas e Strength Pareto}

O nova metodologia proposta, Algoritmo Evolutivo Multi-Objetivo em Tabelas com Soluções Não Dominadas e Strength Pareto (AEMT-SP), combina as principais características dos métodos AEMT, NSNP e SPEA2, além do uso da RNP e seus operadores.

A ideia desta metodologia é corrigir o problema de falta de diversidade das soluções geradas pelo método AEMT, que ocorre em razão de o AEMT não utilizar o conceito de classificação por camadas (ranking), ou seja, não separa as soluções entre dominadas e não dominadas, como no método NSGA-II. Com isso, uma fronteira de Pareto gerada pelo AEMT possui poucas soluções que ficam concentradas nos extremos da fronteira.

Face ao exposto, o AEMT-SP também é baseado na ideia de tabelas de subpopulações. Entretanto, o AEMT-SP utiliza novas tabelas de subpopulações, definidas como tabelas de sobpopulações não dominadas, que usa uma técnica de não dominância entre as soluções a fim de garantir a diversidade entre as mesmas. Esta técnica de não dominância é a mesma utilizada pelo método NSNP. Vale destacar que essas novas tabelas armazenam os indivíduos de acordo com o grau de dominância entre as soluções. Outra importante característica desta metodologia é a inclusão de uma tabela de força dos indivíduos (strength), similiar ao método SPEA2 apresentado na seção 4.4.2. Com a inclusão 
desta tabela, espera-se garantir uma melhor convergência e distribuição das soluções na fronteira de pareto. Para tanto, o valor armazenado nesta tabela é o valor de aptidão bruto (raw) de cada indívuo, que é obtido de acordo com equação 4.5 da seção 4.4.2. Com isso, defini-se como melhor solução aquela que possui o valor de aptidão bruto igual a zero, ou seja, não é dominada por nenhuma outra solução contida na tabela.

As tabelas de subpopulações relacionadas aos objetivos e restrições operacionais são preenchidas conforme proposto no método AEMT (SANTOS, 2009), ou seja, um novo indivíduo gerado $\left(I_{N e w}\right)$ será inserido em uma tabela de subpopulação $P_{i}$, caso esta tabela ainda não esteja totalmente preenchida, ou se $I_{N e w}$ é melhor do que a pior solução em $P_{i}$.

As tabelas de subpopulações não dominadas, definidas neste trabalho como $F_{1}, F_{2}$ e $F_{3}$, são preenchidas de acordo com o grau de dominância de cada solução, ou seja, soluções que não são dominadas por nenhuma outra solução são armazenadas em uma tabela $F_{1}$; soluções que são domindas somente por soluções armazenadas em $F_{1}$ são armazenadas em uma tabela $F_{2}$; e soluções que são dominadas apenas pelas soluções armazenadas em $F_{1}$ e $F_{2}$ são armazenadas em uma tabela $F_{3}$. A partir de ensaios experimentais, foi possível observar um melhor desempenho da metodologia proposta com a utilização de três tabelas de subpopulações não dominadas $\left(F_{1}, F_{2}\right.$ e $\left.F_{3}\right)$ quando comparado com inclusão de apenas uma $\left(F_{1}\right)$ ou duas tabelas $\left(F_{1}\right.$ e $\left.F_{2}\right)$. Importa destacar também que, a função de distância de multidão, proposta em (DEB et al., 2002) e (DEB, 2001), foi utilizada a fim de assegurar a diversidade entre as soluções contidas nas tabelas de subpopulação não dominadas. A tabela $F_{\text {str }}$ (Strength Pareto) é preenchida com o valor de aptidão bruto de cada indivíduo, sendo que ao atingir sua capacidade máxima a pior solução, isto é, aquela que possui o maior valor de raw, é eliminada.

A seguir são apresentados alguns dos parâmetros importantes para o desempenho do AEMT-SP:

- $G_{m a x}$ : é o número máximo de indivíduos gerados pelo AEMT-SP. É também utilizado como critério de parada;

- $S_{p i}$ : é o tamanho da tabela de subpopulação $P_{i}$, indicando a quantidade de indivíduos que podem ser armazenados em $P_{i}$, com $i=1, \ldots, 5$. Portanto, as cinco tabelas de subpopulações $P_{i}$ são: $P_{1}$ - indivíduos com menores perdas ôhmicas; $P_{2}$ - indivíduos com menores quedas de tensão; $P_{3}$ - indivíduos com menores carregamentos da rede; $P_{4}$ - indivíduos com menores carregamentos das subestações; e $P_{5}$ - indivíduos com menores valores da função agregação. Essa função é composta pelos valores de perdas ôhmicas, número de operações de manobras e restrições operacionais (perfil de tensão, carregamento da rede e da susbestação), conforme apresentado na equação 5.1 do capítulo 5 .

- $S_{f i}$ : é o tamanho da tabela de subpopulação com soluções não dominadas $F_{i}$, com $i=1,2,3$. 
- $S_{f s t r}$ : é o tamanho da tabela Strength Pareto.

Importa destacar que o AEMT-SP faz uso de duas funções como critério de entrada para as tabelas de subpopulações não dominadas e strength pareto:

1. Número de operações de manobras;

2. Função Agregação (ver Equação 5.1 do capítulo 5).

Com isso, dada uma solução $I_{N e w}$, é verificado se o número de operações de manobras e o valor da função ponderação de $I_{N e w}$ é menor ou igual $(\leq)$ que alguma solução contida em $F_{1}$, ou seja, se a solução dada por $I_{N e w}$ domina alguma solução em $F_{1}$. Se esta solução for dominada por alguma solução contida em $F_{1}$, realizada-se novamente esta verificação, mas agora em $F_{2}$, e assim sucessivamente. A Figura 6.1 fornece um exemplo das fronteiras de pareto obtidas a partir das tabelas de subpopulações não dominadas $F_{1}, F_{2}$ e $F_{3}$. O pseudocódigo do AEMT-SP é apresentado no Algoritmo 11.

O armazenamento das soluções na tabela de strength pareto é realizado da seguinte forma: calcula-se o valor de aptidão bruto de $I_{N e w}$ em relação a todas as soluções contidas nesta tabela e, em seguida, verifica-se se o valor de aptidão bruto de $I_{N e w}$ é menor que o valor de aptidão bruto da pior solução da tabela. Em caso positivo, troca-se a pior solução na tabela por $I_{\text {New }}$, caso contrário, a tabela não é alterada.

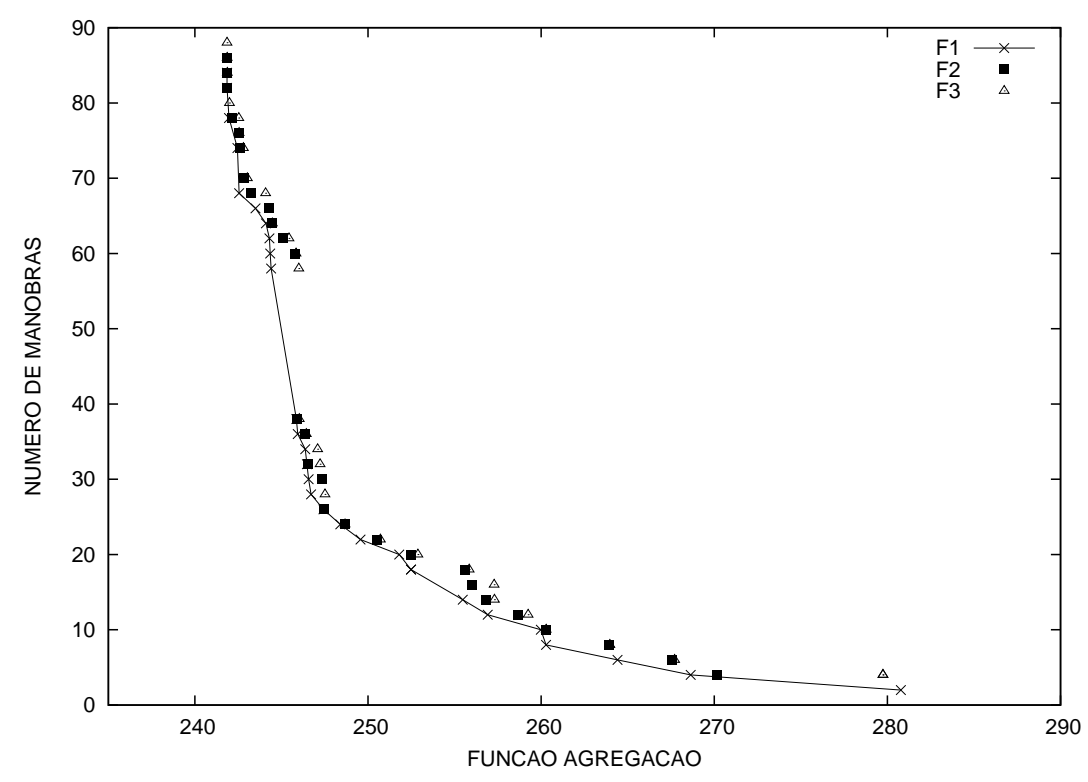

Figura 6.1: Fronteiras de pareto obtidas através das tabelas $F_{1}, F_{2}$ e $F_{3}$.

De modo similar ao AEMT, o AEMT-SP pode ser aplicado para os problemas de redução de perdas e restabelecimento de energia após a ocorrência de uma ou múltiplas faltas em SDRs de grande porte. 


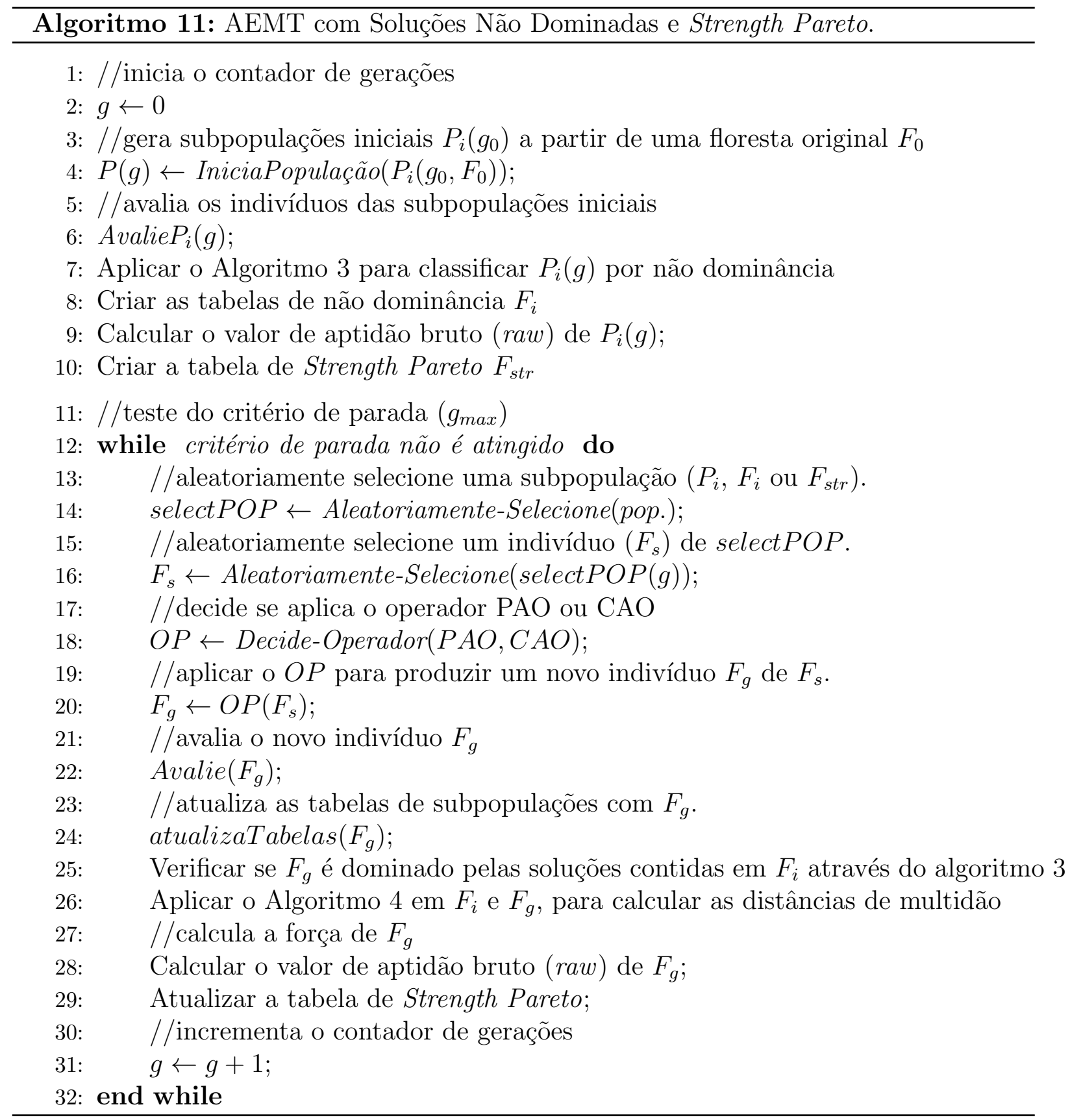




\subsection{Evolução Diferencial Multi-Objetivo em Tabelas}

Nesta seção é apresentada a metodologia Evolução Diferencial Multi-Objetivo em Tabelas (EDMT), que se baseia no algoritmo de evolução diferencial clássico apresentado na seção 4.2.1 do capítulo 4. O uso do DE está diretamente relacionado aos bons desempenhos apresentados quando comparado com outras abordagens evolutivas, conforme apresentado em (STORN; PRICE, 1997). Além disso, em (STORN; PRICE, 1997) outros importantes aspectos são abordados, sendo eles: simplicidade do algoritmo devido aos poucos parâmetros utilizados, eficiência na obtenção de boas soluções e capacidade para sair de regiões de mínimo e máximo local.

A metodologia EDMT fundamenta-se nos conceitos de lista de movimentos, proposto por PRADO et al. (2010a) e PRADO et al. (2010b), no operador de recombinação baseado no histórico evolutivo dos indivíduos, proposto por LIMA (2009), e no método AEMT-SP apresentado na seção 6.2. O funcionamento do EDMT baseia-se na mesma idéia de funcionamento do DE clássico apresentado na seção 4.2.1, em que geram-se novos indivíduos (os vetores modificados), pela adição da diferença vetorial ponderada pelo fator escalar $F$ entre dois indivíduos aleatórios da população a um terceiro indivíduo, também selecionado aleatoriamente. Esta operação é chamada de mutação. Em seguida, os indivíduos do vetor modificado são misturados com os componentes de um indivíduo selecionado aleatoriamente na população. Este processo de combinação é chamado de cruzamento. Afim de garantir um melhor desempenho da característica multi-objetivo, esta metodologia faz uso também das tabelas de soluções não dominadas e da tabela de strength pareto.

\subsubsection{Operador de Recombinação baseado no Histórico Evolu- tivo}

Nesta seção, apresenta-se o operador de recombinação para RNP (EHR, do inglês Evolutionary History Recombination) proposto por LIMA (2009) e que é utilizado como base para o processo de mutação diferencial da metodologia EDMT proposta. O EHR baseia-se no histórico evolutivo dos operadores PAO e CAO da RNP apresentados no capítulo 3 , isto é, na sequência de vértices $(p, a)$ e $(p, r, a)$ aplicados para a geração de novos indivíduos. O histórico de cada indivíduo pode ser recuperado por meio da matriz $\Pi_{v x}$ (que armazena a localização do vértice $v_{x}$ de cada indivíduo) e do array $\pi$ (que armazena o índice do ancestral de cada indivíduo), que foram apresentados no capítulo 3. A Figura 6.2 ilustra um exemplo de histórico de evolução por meio das aplicações dos operadores PAO e CAO. Nessa Figura a partir da floresta $F 0$, com a aplicação do operador PAO utilizando os vértices $p=F$ e $a=B$ obtém-se a árvore $F 1$ (lado esquerdo). As florestas F2 e F3 (lado direito) são geradas, respectivamente, a partir da aplicação do 
operador CAO sobre $F 0$ (com os vértices $p=E, r=D$ e $a=H$ ) e $F 2$ (com os vértices $p=G, r=J$ e $a=A$ ) respectivamente.

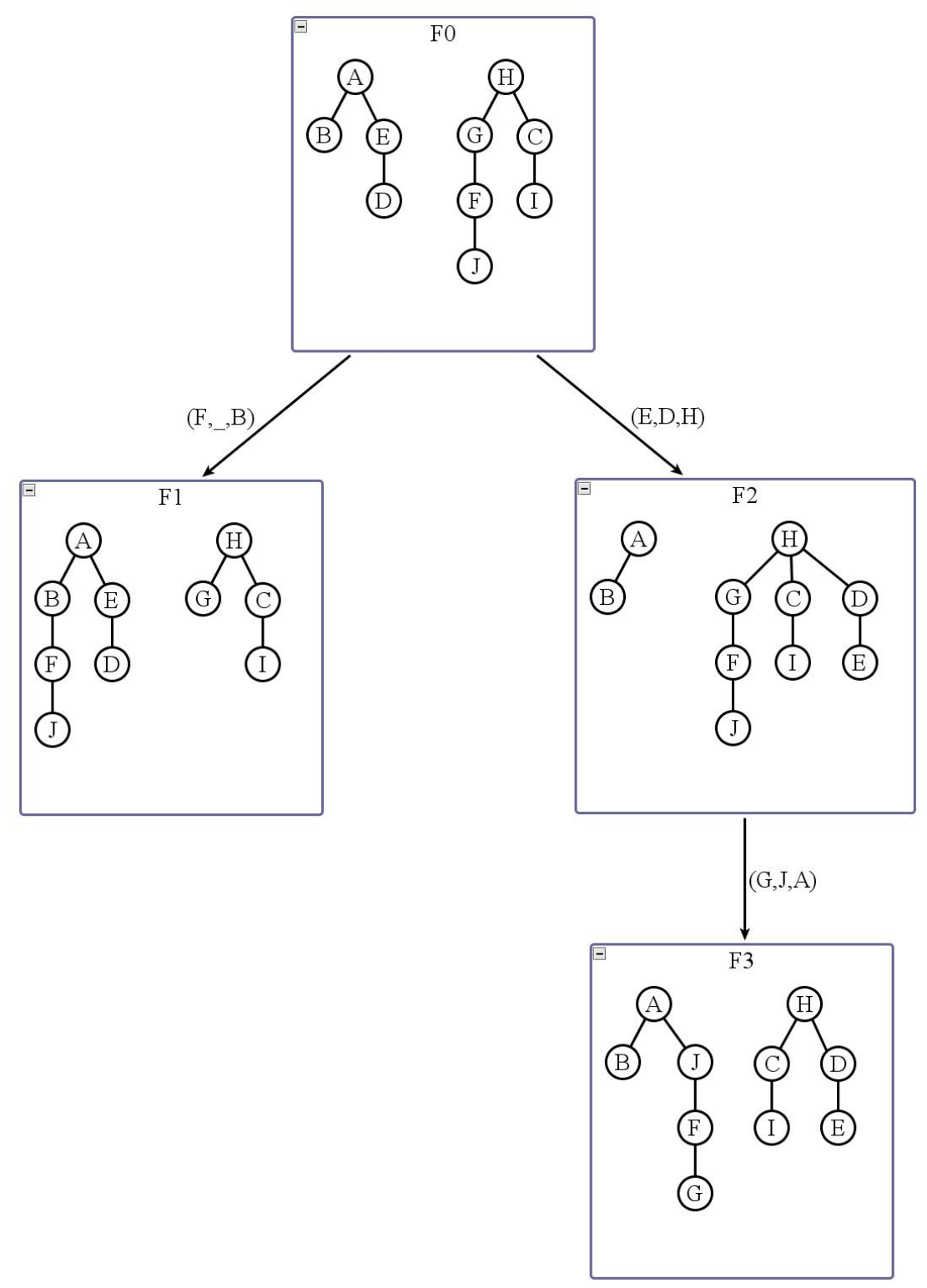

Figura 6.2: Histórico de aplicações dos operadores PAO e CAO.

Entretanto, para facilitar a utilização do EHR, é proposto em LIMA (2009) uma modificação no array $\pi$, para que o mesmo possa armazenar, além do índice do ancestral, a trinca de vértices $(a, r$ e $p$ ) que foram utilizados na aplicação de PAO ou CAO. Vale destacar que, quando um indivíduo é gerado através da aplicação do operador PAO, o valor contido em $r$ será nulo. Com isso, o EHR pode então ser definido através do Algoritmo 12. 


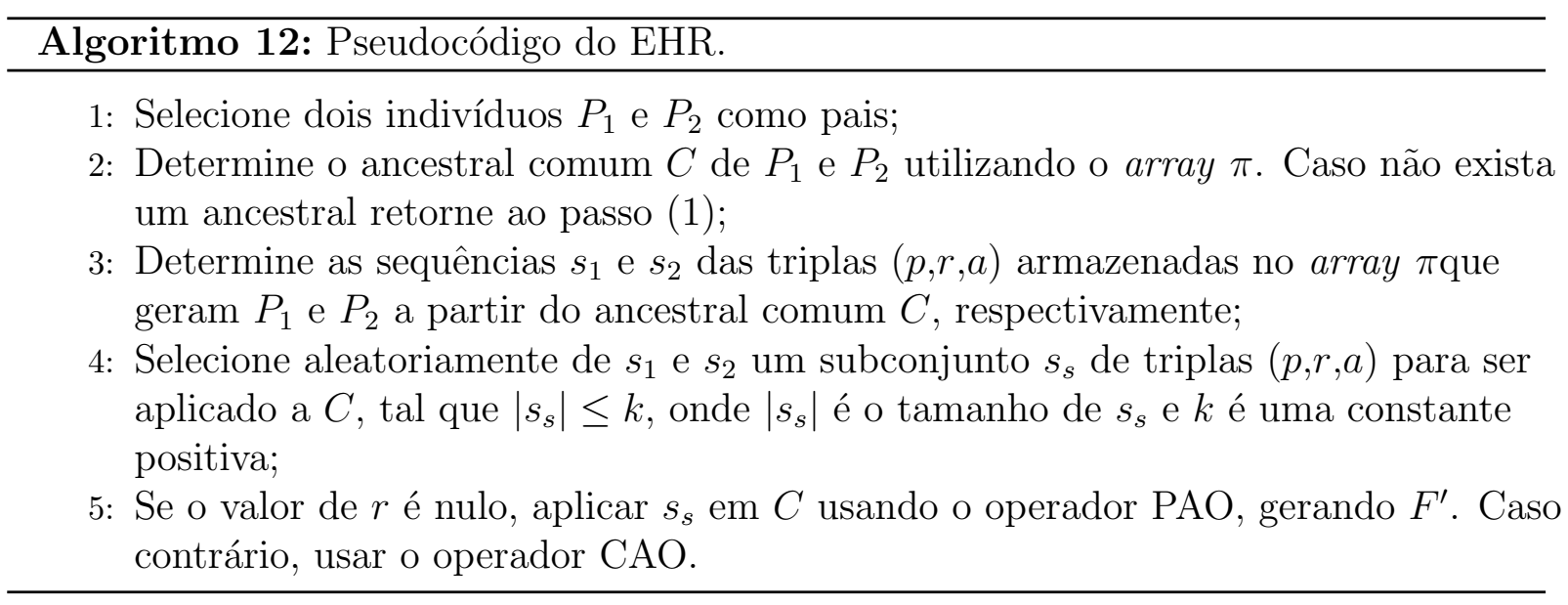

\subsubsection{Exemplo Ilustrativo}

Para ilustrar melhor o funcionamento do EHR, considere o SDR dado na Figura 6.3, que é composto por 3 alimentadores. Cada alimentador é identificado pelo número de sua barra origem (ou nó raiz), isto é, da barra da Subestação. A RNP de cada um desses alimentadores é ilustrada na Figura 6.4.

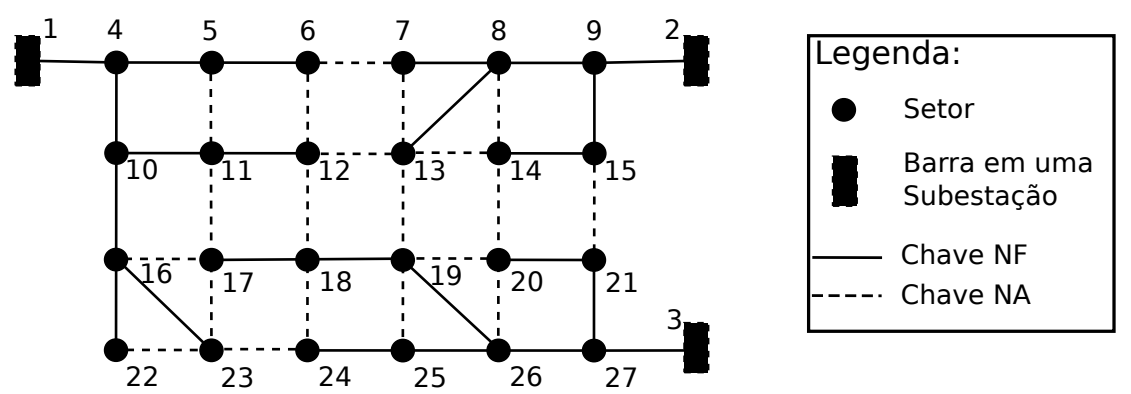

Figura 6.3: SDR com três alimentadores modelados por um grafo com três árvores.

$$
\begin{aligned}
& \mathrm{T} 1=\left|\begin{array}{c}
\text { Profundidade } \\
\text { Nó }
\end{array}\right|=\left|\begin{array}{llllcccccc}
0 & 1 & 2 & 3 & 2 & 3 & 4 & 3 & 4 & 4 \\
1 & 4 & 5 & 6 & 10 & 11 & 12 & 16 & 22 & 23
\end{array}\right| \\
& \begin{aligned}
\mathrm{T} 2 & =\left|\begin{array}{c}
\text { Profundidade } \\
\text { Nó }
\end{array}\right|=\left|\begin{array}{llcccccccc}
0 & 1 & 2 & 3 & 2 & 3 & 3 \\
2 & 9 & 15 & 14 & 8 & 7 & 13
\end{array}\right| \\
\mathrm{T} 3 & =\left|\begin{array}{c}
\text { Profundidade } \\
\text { Nó }
\end{array}\right|=\mid \begin{array}{cccccccccc}
0 & 1 & 2 & 3 & 2 & 3 & 4 & 5 & 3 & 4 \\
3 & 27 & 21 & 20 & 26 & 19 & 18 & 17 & 25 & 24
\end{array}
\end{aligned}
\end{aligned}
$$

Figura 6.4: RNP dos três alimentadores da Figura 6.3.

As Figuras 6.5 e 6.6 ilustram dois indivíduos gerados a partir da aplicação dos operadores PAO e CAO.

Este dois indivíduos possuem um ancestral em comum (ver Figura 6.7), que é a floresta do SDR ilustrado na Figura 6.3. Para gerar o indivíduo da Figura 6.5 foi necessário a modificação no par de vértices (11 e 17), e para gerar o inidivíduo da Figura 6.6 foi necessário a modificação na tripla de vértices $(21,20$ e 14). A partir da combinação 

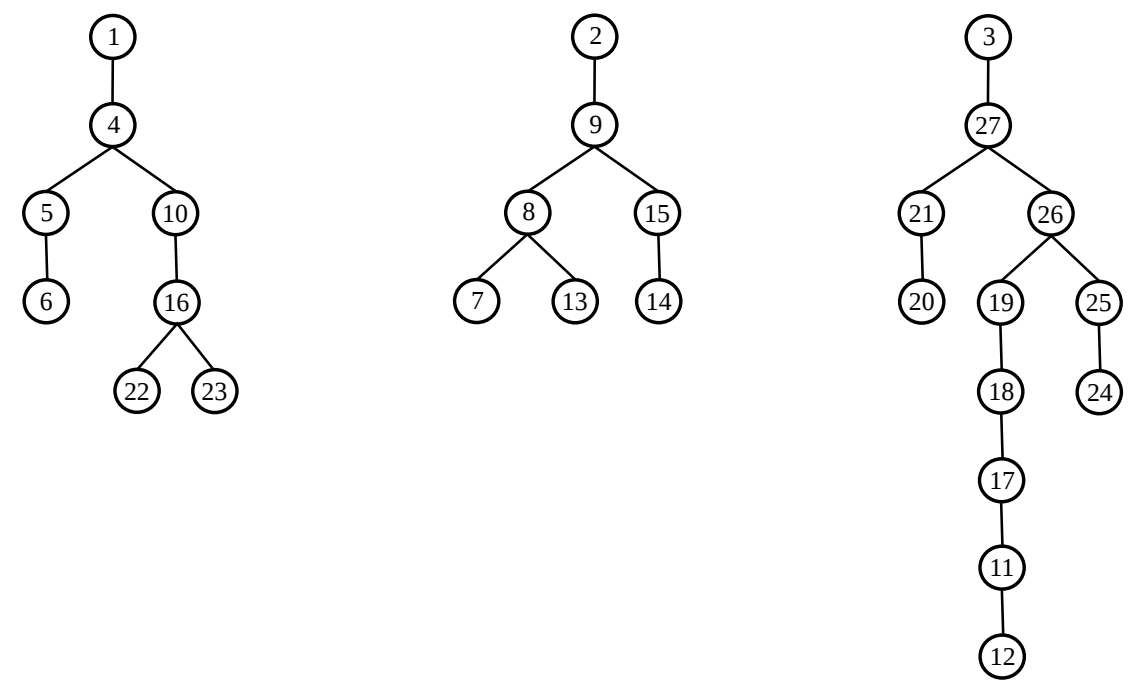

Figura 6.5: Inidivíduo gerado com o operador PAO na configuração da Figura 6.3.
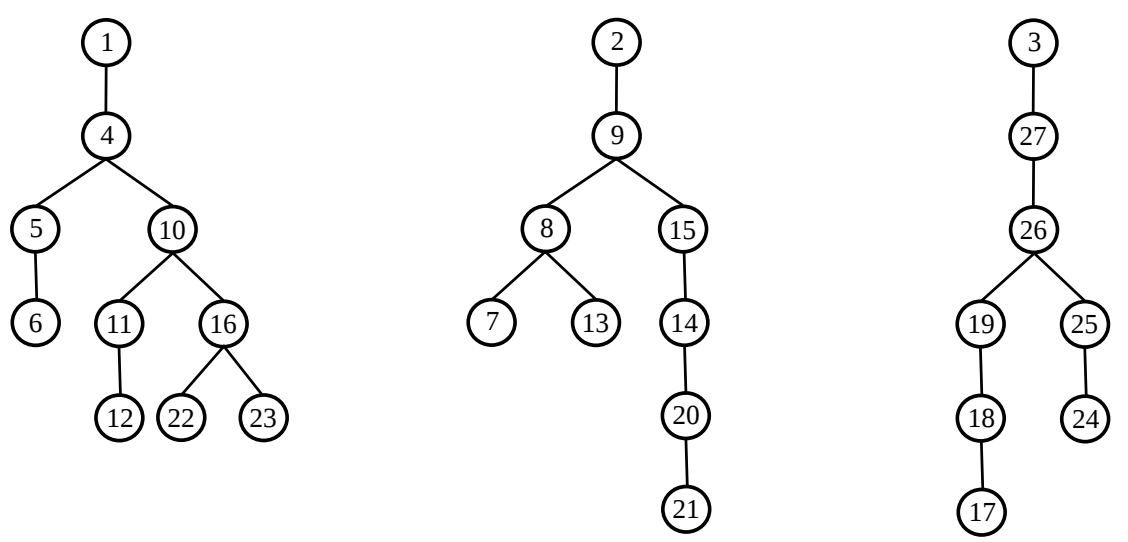

Figura 6.6: Inidivíduo gerado com o operador CAO na configuração da Figura 6.3. 
destas duas modificações, é possível obter um novo indivíduo a partir do operador EHR, conforme ilustrado na Figura 6.8.
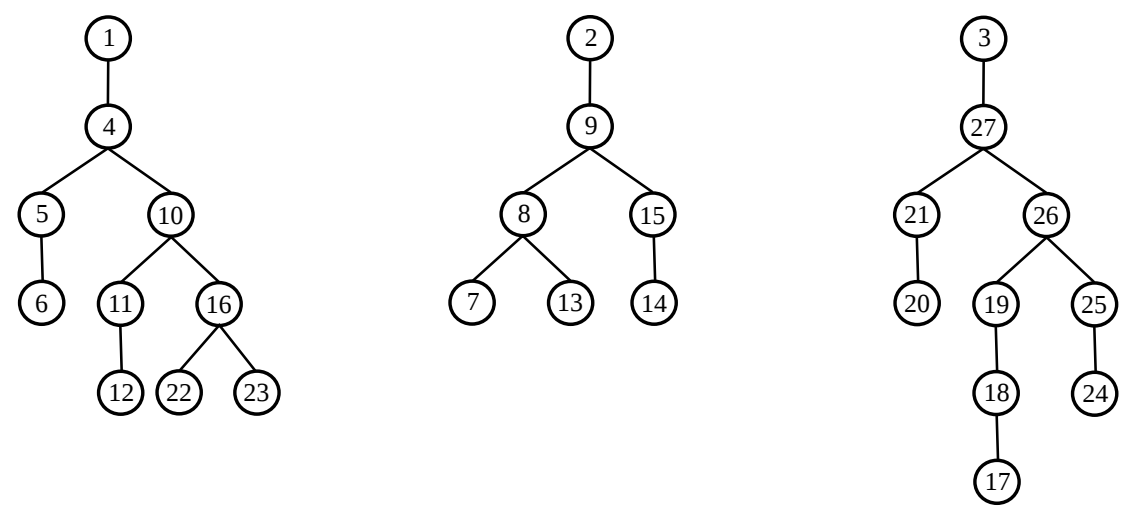

Figura 6.7: Ancestral comum dos indivíduos das Figuras 6.5 e 6.6.
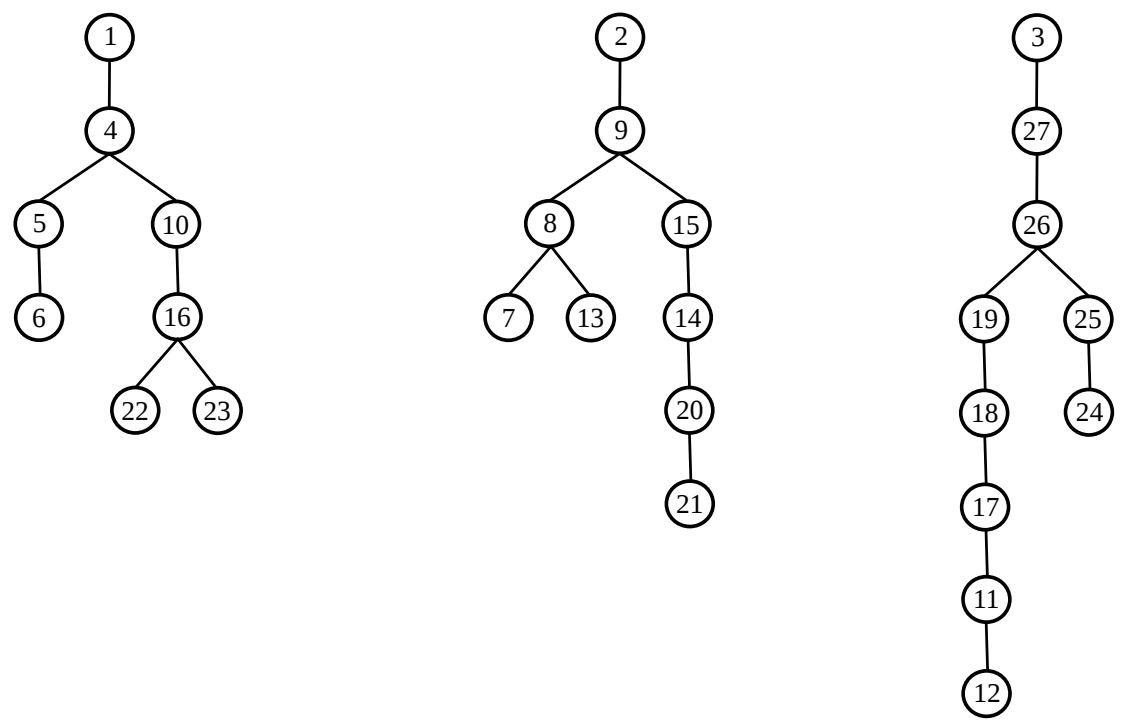

Figura 6.8: Novo indivíduo gerado pelo operador EHR.

\subsubsection{Mutação Diferencial por Lista de Movimentos}

Segundo PRADO et al. (2010a) o algoritmo de Evolução Diferencial é, originalmente, aplicável à otimização contínua devido ao seu mecanismo de busca ser baseado nas perturbações criadas a partir do vetor diferença. Essa definição de mutação diferencial está estritamente ligada ao espaço Euclidiano, uma vez que os vetores são variáveis contínuas. Uma diferença análoga não é diretamente obtida no domínio das variáveis discretas, o que faz com que, uma extensão das técnicas de Evolução Diferencial para esse contexto, não seja uma tarefa simples à primeira vista.

Para tanto, em (PRADO et al., 2010a) e (PRADO et al., 2010b) é proposto um método de otimização da evolução diferencial discreta, em que a diferença entre dois vetores distintos deve ser definida no espaço das variáveis discretas. A idéia por trás desta 
abordagem é definir a diferença entre duas soluções candidatas como sendo uma lista de movimentos no espaço de busca. Essa lista é definida como PRADO et al. (2010a):

Definição 1. A lista de movimentos $M_{i j}$ é uma lista contendo uma sequência de movimentos válidos $m_{k}$, tais que a aplicação destes movimentos, à solução $s_{i} \in S$, leva ̀̀ solução $s_{j} \in S$.

Com isso, a diferença entre duas soluções é definida como sendo esta lista de movimentos:

$$
M_{i j} \quad=s_{i} \ominus s_{j}
$$

onde $\ominus$ é um operador de subtração binário especial que retorna a lista de movimentos $M_{i j}$ que representa o "caminho" da solução $s_{i}$ até a solução $s_{j}$. Esta lista captura a diferença entre essas duas soluções.

A multiplicação da lista de movimentos por um escalar deve ser também definida. Em (PRADO et al., 2010a) e (PRADO et al., 2010b) duas alternativas são dadas:

Definição 2. A multiplicação da lista de movimentos $M_{i j}$ por um escalar $F \in[0,1]$, retorna a lista $M_{i j}^{\prime}$ com os primeiros $\left(F \times\left|M_{i j}\right|\right)$ movimentos de $M_{i j}$, onde $\left|M_{i j}\right|$ é o tamanho da lista

Definição 3. A multiplicação da lista de movimentos $M_{i j}$ por um escalar $F \in[0,1]$, retorna a lista $M_{i j}^{\prime}$ com os $\left(F \times\left|M_{i j}\right|\right)$ movimentos escolhidos aleatoriamente de $M_{i j}$, onde $\left|M_{i j}\right|$ é o tamanho da lista

Portanto, a multiplicação da lista de movimentos por um escalar pode ser denotada, usando o operador de multiplicação binário especial $\otimes$, por:

$$
M_{i j}^{\prime} \quad=F \otimes M_{i j}
$$

Finalmente, a aplicação da lista de movimentos a uma dada solução é definida como se segue:

Definição 4. A aplicação da sequência de movimentos da lista $M_{i j}^{\prime}$ na solução $s_{k}$, retorna uma nova solução $s_{k}^{\prime}$

A definição 4 pode ser escrita como:

$$
s_{k}^{\prime} \quad=s_{k} \oplus M_{i j}^{\prime}
$$


Com estas definições, pode-se escrever a equação do vetor modificado como:

$$
\begin{array}{r}
v^{i}=X_{\alpha} \oplus F \otimes\left(X_{\beta} \ominus X_{\gamma}\right) \\
v^{i}=X_{\alpha} \oplus F \otimes M_{\beta \gamma} \\
v^{i}=X_{\alpha} \oplus M_{\beta \gamma}^{\prime}
\end{array}
$$

que é a versão discreta da equação 4.1 apresentada no capítulo 4 .

Face ao exposto, importa destacar que o EDMT faz uso da lista de movimentos discutida anteriormente. Para obter essa lista de movimentos, o EDMT faz uso do operador EHR (ver seção 6.3.1), uma vez que o mesmo fornece um histórico evolutivo dos operadores PAO e CAO. Com isso, a lista de movimentos será dada pelo histórico de modificações dos dois indivíduos selecionados aleatoriamente na população até o ancestral comum. Para tanto, a lista de movimentos é preenchida partindo dos indivíduos $X_{\beta}$ e $X_{\gamma}$. Para melhor representar esta etapa, na Figura 6.9, cada vértice representa um indivíduo (configuração factível de um SDR). Ainda na Figura 6.9 é ilustrado o conjunto de modificações geradas, a partir do Ancestral Comum (AC) até os indivíduos $X_{2}$ e $Y_{2}$. Com isso, a lista de movimentos será composta pelo conjunto de vértices necessários para gerar os indivíduos $X_{2}$ e $Y_{2}$ a partir de AC. A seguir, será apresentado um pequeno exemplo da construção da lista de movimentos do EDMT, para ilustrar melhor o seu funcionamento.

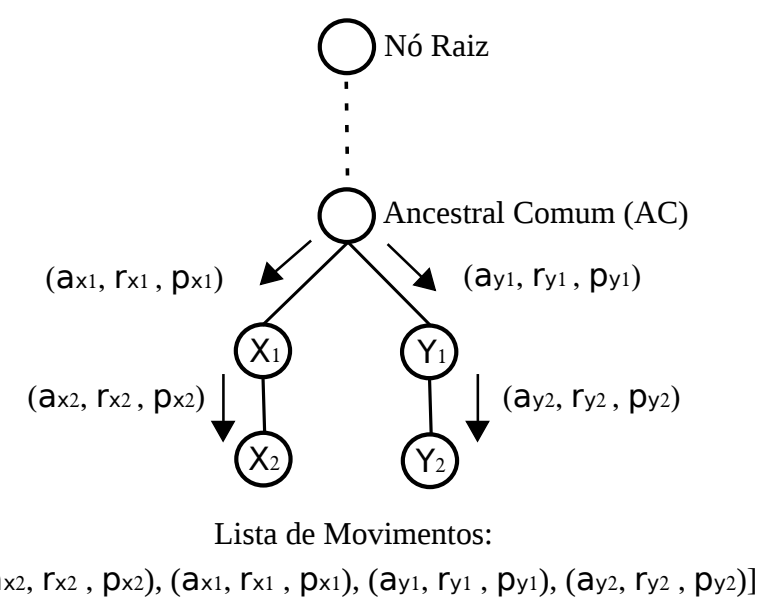

Figura 6.9: Lista de movimentos de $X_{2}$ até $Y_{2}$.

\subsubsection{Exemplo Ilustrativo}

Para esse exemplo foi considerado novamente o SDR ilustrado na Figura 6.3. Inicialmente três indivíduos $X_{\alpha}, X_{\beta}$ e $X_{\gamma}$ são selecionados aleatoriamente na população. Estes indivíduos estão representados respectivamente nas Figuras 6.10, 6.11 e 6.12. Vale destacar que o ancestral comum dos indivíduos $X_{\beta}$ e $X_{\gamma}$ é o indivíduo representado na Figura 6.7. 

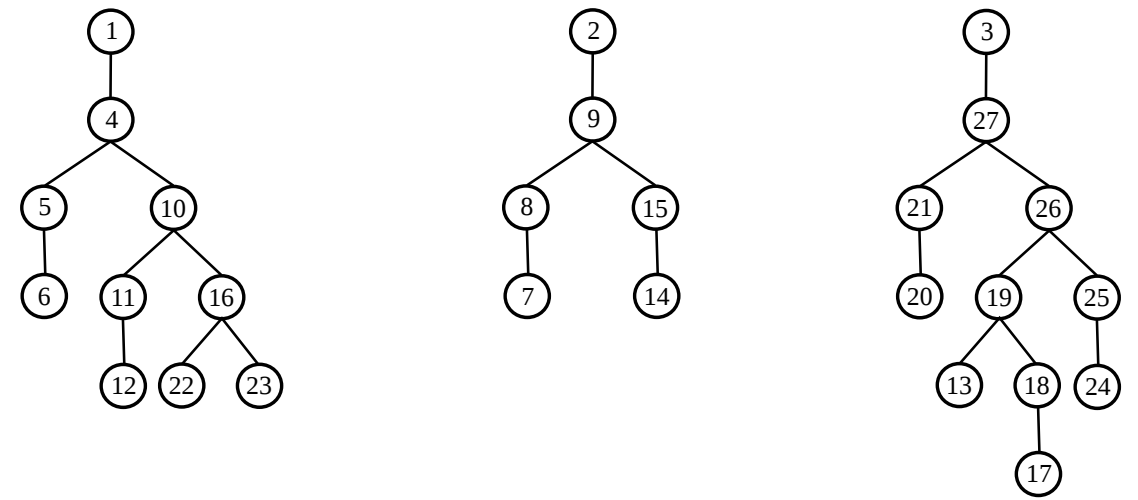

Figura 6.10: Indivíduo $X_{\alpha}$ selecionado aleatoriamente na população.
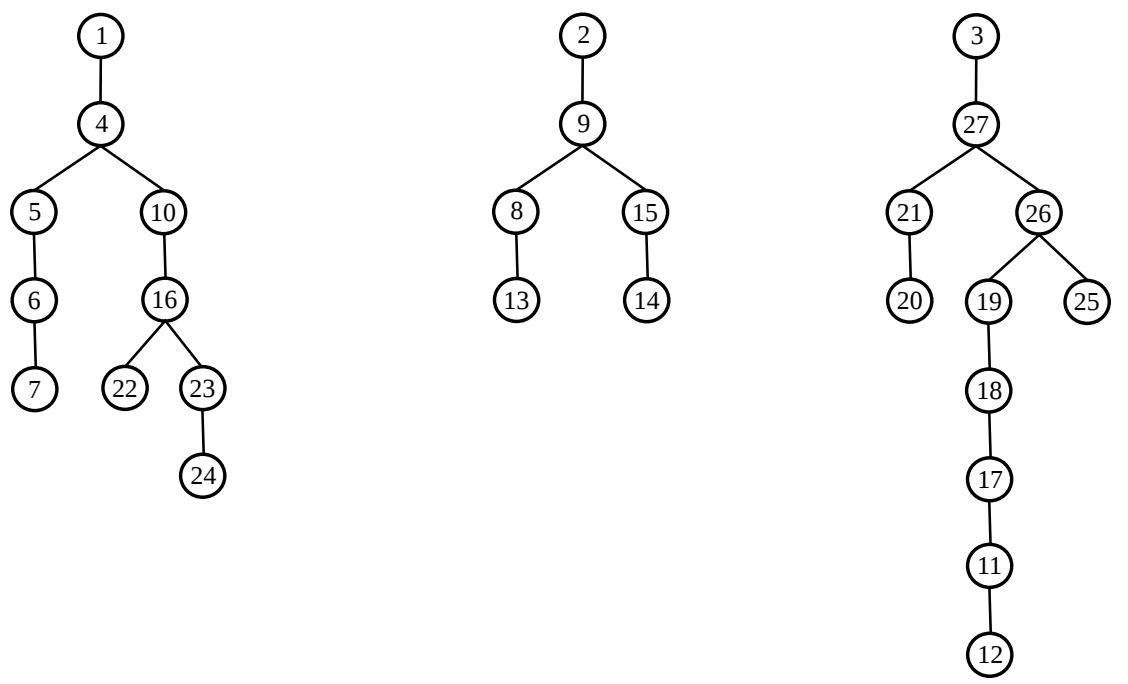

Figura 6.11: Indivíduo $X_{\beta}$ selecionado aleatoriamente na população.
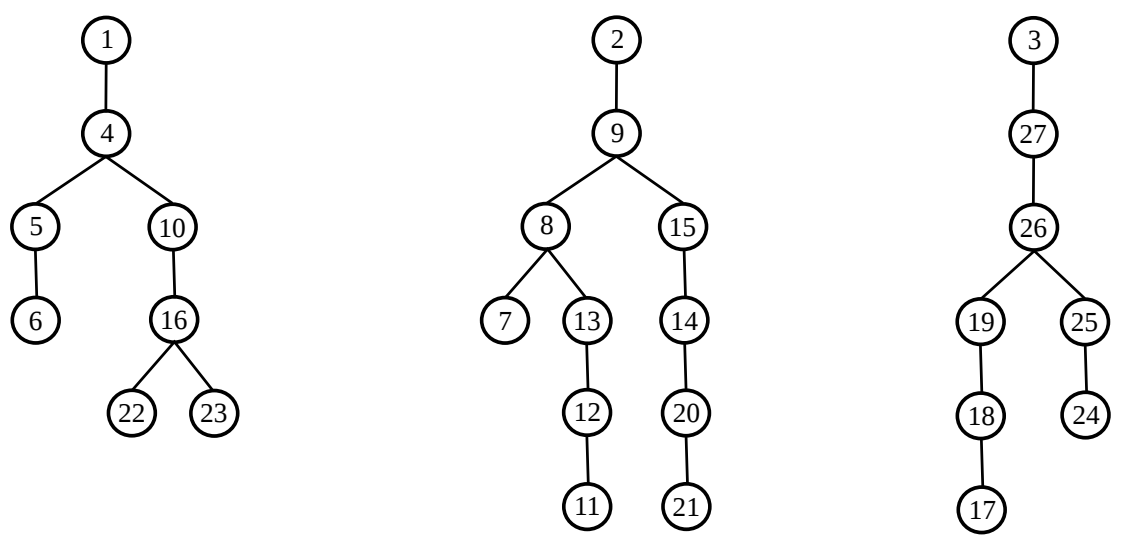

Figura 6.12: Indivíduo $X_{\gamma}$ selecionado aleatoriamente na população. 
A próxima etapa consiste em definir as duas listas de movimentos, definidas por $M_{A C \beta}$ e $M_{A C \gamma}$, que levam do $\mathrm{AC}$ até os indivíduos $X_{\beta}$ e $X_{\gamma}$. As listas de movimentos $M_{A C \beta}$ e $M_{A C \gamma}$ estão ilustradas, respectivamente, nas Figuras 6.13 e 6.14 .

$$
[(11,17),(7,6),(24,23)]
$$

Figura 6.13: Lista de Movimentos $M_{A C \beta}$.

$$
[(21,20,14),(11,12,13)]
$$

Figura 6.14: Lista de Movimentos $M_{A C \gamma}$.

A partir de $M_{A C \beta}$ e $M_{A C \gamma}$, cria-se a lista de movimentos $M_{E D M T}$, que é a união de $M_{A C \beta}$ e $M_{A C \gamma}$, conforme ilustrado na Figura 6.15. Importa destacar que, a partir de ensaios experimentais, observou-se um melhor desempenho quando a lista de movimentos $M_{E D M T}$ é preenchida partindo incialmente das modificações necessárias para gerar o indivíduo $X_{\beta}$, na ordem invertida da lista $M_{A C \beta}$, seguido das modificações necessárias para gerar o indivíduo $X_{\gamma}$, conforme a sequência da lista $M_{A C \gamma}$.

$$
[(24,23),(7,6),(11,17),(21,20,14),(11,12,13)]
$$

Figura 6.15: Lista de Movimentos $M_{E D M T}$.

A próxima etapa consiste na multiplicação da lista $M_{E D M T}$ pelo escalar $F$ por $M_{E D M T}$, gerando a lista de movimentos $M_{E D M T}^{\prime}$. Para esse exemplo, considerou-se $F=0.6$, gerando a lista $M_{E D M T}^{\prime}$ contendo os 3 primeiros movimentos da lista $M_{E D M T}$, conforme ilustrado na Figura 6.16. Isto em razão de $\left|M_{E D M T}\right|=5$.

$$
[(24,23),(7,6),(11,17)]
$$

Figura 6.16: Lista de Movimentos $M_{E D M T}^{\prime}$.

Finalmente, a partir da definição 4 e da equação 6.5, aplicam-se os movimentos da lista de movimentos $M_{E D M T}^{\prime}$ ao indivíduo $X_{\alpha}$, gerando o vetor modificado $v^{i}$, conforme ilustrado na Figura 6.17.

$$
\begin{array}{r}
v^{i}=X_{\alpha} \oplus F \otimes M_{E D M T} \\
v^{i}=X_{\alpha} \oplus M_{E D M T}^{\prime}
\end{array}
$$



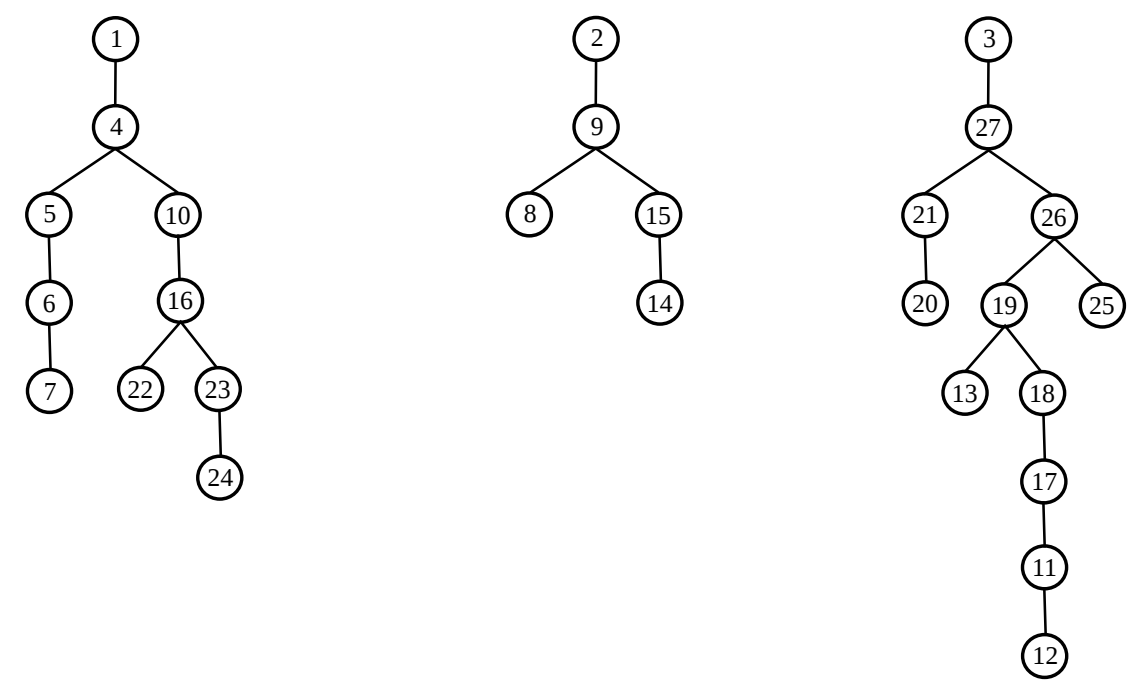

Figura 6.17: Vetor modificado $v^{i}$ resultante.

\subsubsection{Funcionamento}

Inicialmente são definidos os parâmetros que são importantes para o desempenho do EDMT:

- $G_{\text {max }}$ : é o número máximo de utilização dos operadores PAO e CAO no EDMT. É também utilizado como critério de parada;

- $S_{p i}$ : é o tamanho da tabela de subpopulação $P_{i}$, indicando a quantidade de indivíduos que podem ser armazenados em $P_{i}$, com $i=1, \ldots, 5$. Portanto, as cinco tabelas de subpopulações $P_{i}$ são: $P_{1}$ - indivíduos com as menores perdas ôhmicas; $P_{2}$ indivíduos com as menores quedas de tensão; $P_{3}$ - indivíduos com os menores carregamentos da rede; $P_{4}$ - indivíduos com os menores carregamentos da subestação; e $P_{5}$ - indivíduos com os menores valores da função agregação. A função agregação é composta pelos valores de perdas ôhmicas, número de operações de chaveamento e restrições operacionais (perfil de tensão, carregamento da rede e da susbestação);

- $S_{f i}$ : é o tamanho da tabela de subpopulação com soluções não dominadas $F_{i}$, com $i=1,2,3$

- $S_{f s t r}$ : é o tamanho da tabela Strength Pareto $F_{\text {str }}$;

- escalar $F$;

- taxa de cruzamento $C_{r}$;

- div: é o tamanho da diversidade inicial. Cria uma quantidade suficiente de histórico de indivíduos para o uso da lista de movimentos e do operador EHR. Os indivíduos são gerados apenas com o uso dos operadores PAO e CAO. 
A seguir, é apresentado um exemplo para melhor ilustrar o funcionamento da metodologia proposta.

A primeira etapa consiste na operação de mutação. Para isso, os indivíduos $X_{4}, Y_{5}, K_{2}$ e $W_{2}$ são selecionados aleatoriamente da população, conforme ilustrado na Figura 6.18.

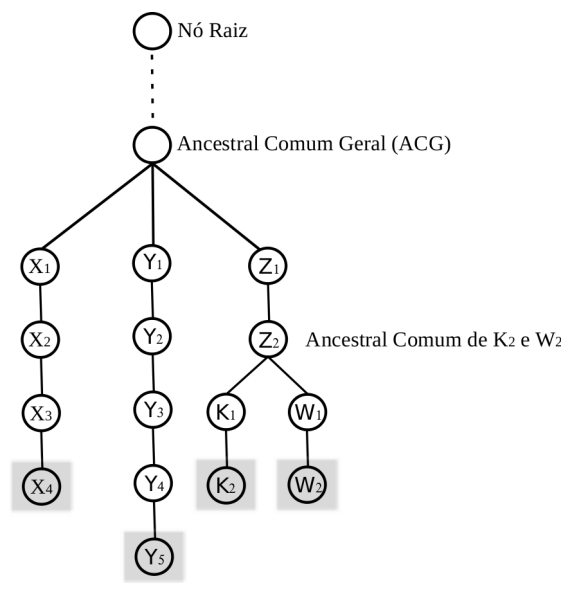

Figura 6.18: Indivíduos $X_{4}, Y_{5}, K_{2}$ e $W_{2}$ selecionados aleatoriamente da população.

Durante a operação de mutação é obtida a lista de movimentos $M_{E D M T}$, que é a união das listas de movimentos $M_{A C K_{2}}$ e $M_{A C W_{2}}$, que são os movimentos de $Z_{2}$ para $K_{2}$ e de $Z_{2}$ para $W_{2}$, sendo $Z_{2}$ o AC de $K_{2}$ e $W_{2}$. Em seguida, $M_{E D M T}$ é multiplicada com o escalar $F$ e o resultado é aplicado ao indivíduo $Y_{5}$, conforme ilustrado na figura 6.19:

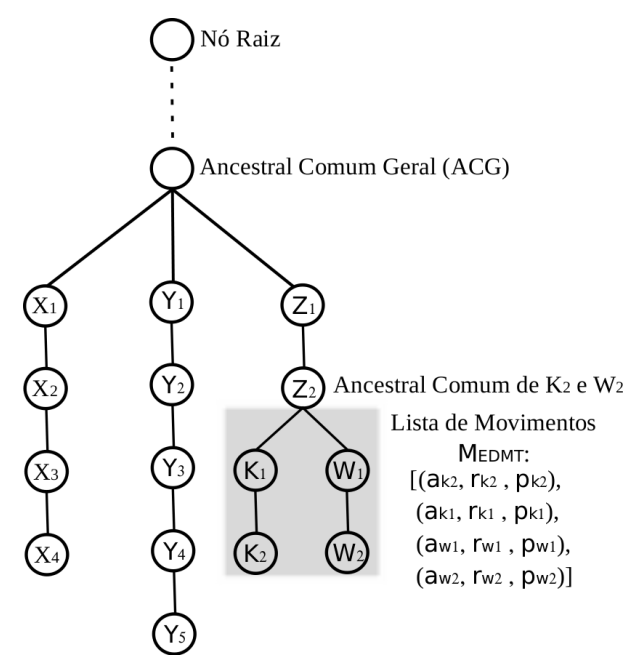

(a) Lista de Movimentos obtida a partir (b) Aplicação da Lista de do indivíduo $K_{2}$ até o indivíduo $W_{2}$. Movimentos em $Y_{5}$ gerando o novo indivíduo $Y_{6}$.

Figura 6.19: Mutação Diferencial.

A próxima etapa consiste na aplicação do operador de cruzamento, em que aplica-se uma combinação entre os indivíduos ancestrais de $X_{4}$ e $Y_{6}$ até o ACG, resultando no vetor experimental $U$. Para tanto, os indivíduos são selecionados de acordo com taxa $C_{r} \in[0,1]$, 
que defini a probabilidade dos ancestrais de $X_{4}$ até o ACG, ganharem dos ancestrais de $Y_{5}$ até $\mathrm{ACG}$, isto é, de serem copiados no vetor experimental $U$. Com isso, caso o valor sorteado for menor que a taxa $C_{r}$, seleciona-se um dos ancestrais de $X_{4}$, caso contrario, seleciona-se um dos ancestrais de $Y_{5}$. Importa destacar que o ponto de corte não pode ser superior à quantidade de ancestrais de $X_{4}$ até ACG e o tamanho máximo do vetor experimental $U$ é igual à quantidade de ancestrais de $X_{4}$ até o ACG. A figura 6.20 ilustra o funcionamento do cruzamento proposto.

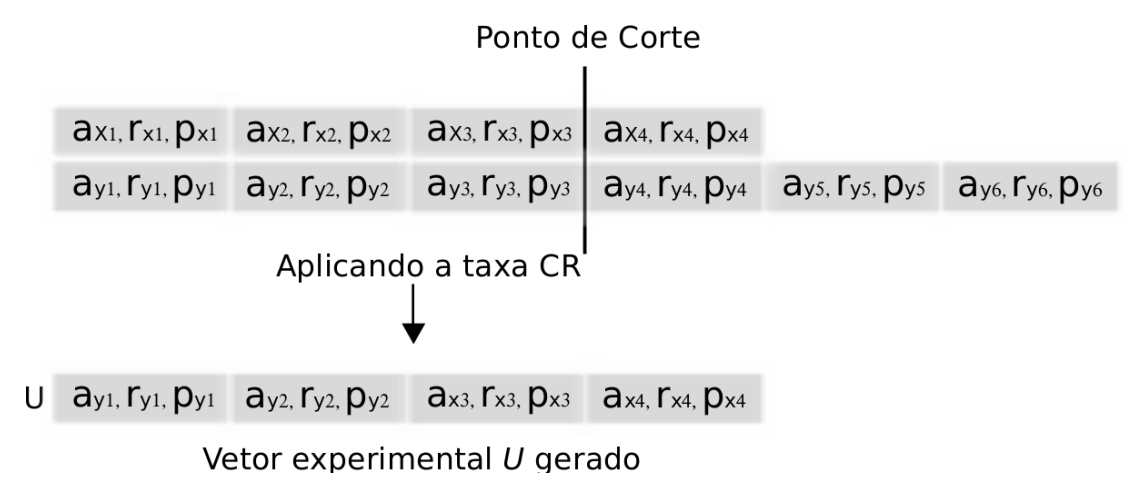

Figura 6.20: Cruzamento entre os indivíduos ancestrais de $X_{4}$ e $Y_{6}$ até o ACG.

Como resultado final do cruzamento, os vértices $\left(\left(a_{y 1}, r_{y 1}, p_{y 1}\right),\left(a_{y 2}, r_{y 2}, p_{y 2}\right),\left(a_{x 3}\right.\right.$, $\left.\left.r_{x 3}, p_{x 3}\right),\left(a_{x 4}, r_{x 4}, p_{x 4}\right)\right)$ presentes no vetor experimental $U$ são aplicados no ACG, gerando assim, um novo indivíduo. 


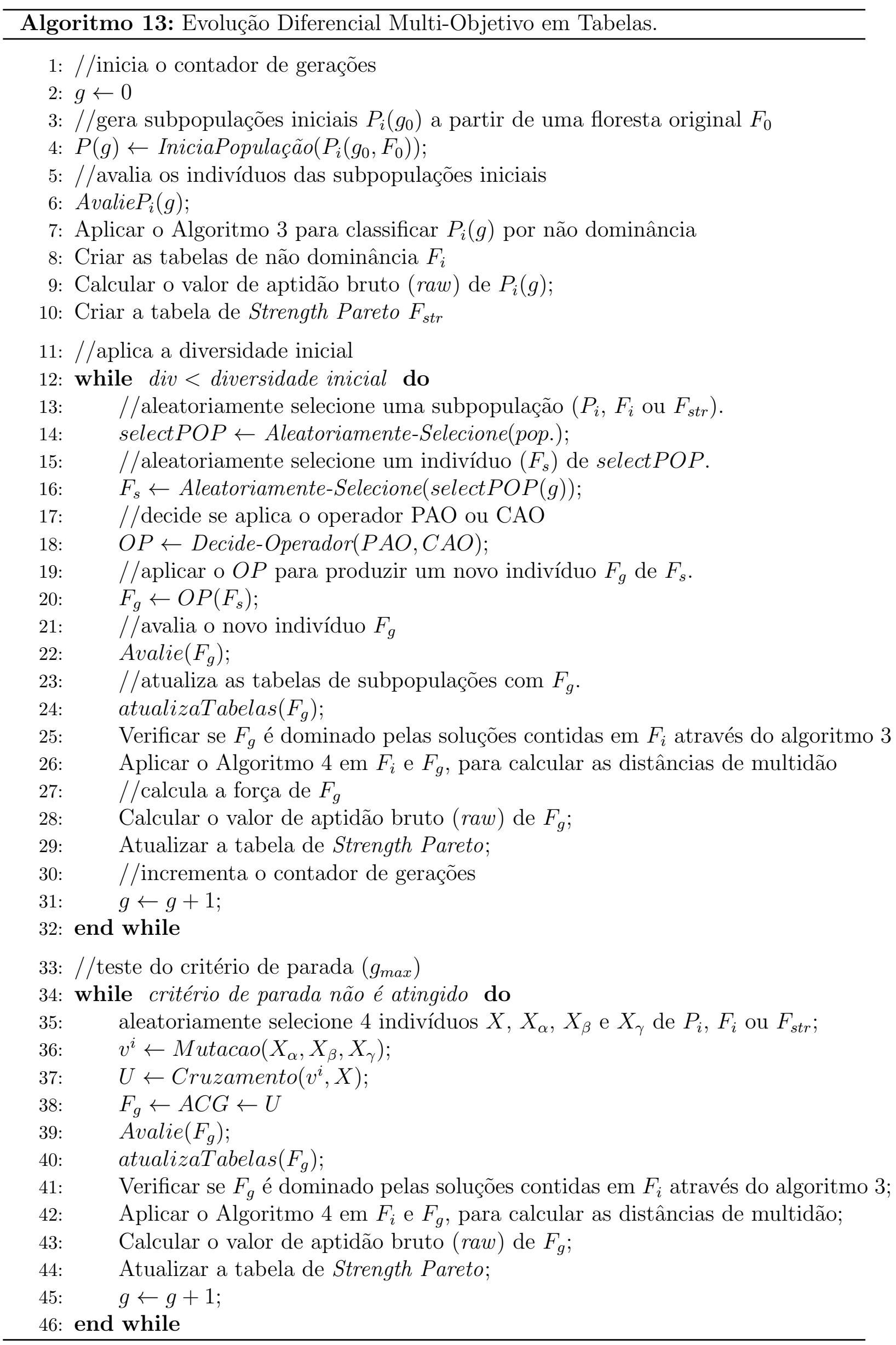




\subsection{Conclusões}

Este capítulo apresentou as metodologias AEMT-SP e EDMT propostas neste trabalho. No próximo capítulo serão apresentadas simulações computacionais usando cada metodologia para os problemas de redução de perdas e restabelecimento de energia para uma única falta e múltiplas faltas em SDR de grande porte. 


\section{Capítulo 7}

\section{Resultados Experimentais}

Resultados de simulações computacionais são apresentados neste Capítulo. As simulações foram realizadas no SDR real da cidade de São Carlos (SDR-SC) em operação no ano de 1994. O SDR-SC é constituído de 3.860 barras, 533 setores, 632 chaves sendo 509 chaves NF e 123 chaves NA, 3 subestações (Bela Vista, São Carlos e Paraíso) e 23 alimentadores. A subestação Bela Vista possui 2 transformadores de 25MVA; a subestação São Carlos tem 2 transformadores de 25MVA e a subestação Paraíso tem 1 transformador de 25MVA. Para verificar se as metodologias propostas podem ser aplicadas em SDRs maiores que o SDR-SC, não incorrendo no problema de explosão combinatorial, simulações foram realizadas para reconfiguração de redes utilizando o SDR-SC aumentado, ou seja, com tamanho duplicado, quadruplicado e octuplicado.

As simulações apresentadas concentram-se nos problemas de redução de perdas ôhmicas e restabelecimento de energia após a ocorrência de uma única falta e múltiplas faltas. Optou-se pela exploração destes dois problemas devido a maior complexidade computacional e, em especial, pela necessidade de resposta em tempo real, quando se trata do problema de restabelecimento de energia.

As metodologias propostas foram implementadas utilizando um computador com processador Core 2 Quad 2,4GHz, 8Gbytes de memória RAM, Sistema Operacional Linux Ubuntu versão 10.04, e compilador de linguagem C gcc-4.4.

Os sistemas utilizados nos testes apresentam as seguintes características:

- Sistema 1 (S1 = SDR-SC): 3.860 barras, 532 setores, 632 chaves (509 NF e 123 NA), 3 subestações e 23 alimentadores;

- Sistema 2 (S2): 7.720 barras, 1.064 setores, 1.277 chaves (1018 NF e 259 NA), 6 subestações e 46 alimentadores;

- Sistema 3 (S3): 15.440 barras, 2.128 setores, 2.577 chaves (2.036 NF e 541 NA), 12 subestações e 92 alimentadores; 
- Sistema 4 (S4): 30.880 barras, 4.264 setores, 5.166 chaves (4.072 NF e 1.094 NA), 24 subestações e 184 alimentadores;

Mais detalhes sobre estes sistemas podem ser encotrados em (SANTOS, 2009) e (COLAB, 2012).

Com o intuito de analisar de forma particular e efetiva a influência de cada uma das metodologias propostas no tratamento dos problemas de redução de perdas ôhmicas e restabelecimento de energia, são apresentados os resultados individualizados para cada um destes problemas para os sistemas 1, 2, 3 e 4. Os resultados obtidos pelas metodologias propostas serão comparados com a metodologia AEMT proposta em (SANTOS, 2009). Para avaliar o desempenho multi-objetivo de cada uma das metodologias, será utilizado a métrica de desempenho Hipervolume, apresentada no capítulo 4.

Vale destacar que nos testes que serão apresentados nesta tese, as três metodologias serão empregadas para obtenção de configurações radiais, que possibilitem o restabelecimento de energia para todas as cargas que não estão nos setores atingidos pelas faltas respeitando todas as restrições operacionais (queda de tensão de no máximo $10 \%$ e carregamentos da rede e das subestações de no máximo 100\%). Dessa forma, o número de manobras dos planos de restabelecimento de energia que serão obtidos por essas metodologias pode ser ainda menor se: (i) forem aceitas configurações possuindo algumas violações não significativas das restrições operacionais; e/ou (ii)for considerada a possibilidade de corte de cargas.

\subsection{Simulações para o problema de Restabelecimento de Energia}

Nesta seção as metodologias AEMT-SP, EDMT e AEMT serão aplicadas nos sistemas 1, 2, 3 e 4 para tratamento do problema de restabelecimento de energia considerando a ocorrência de uma única falta. Além disso, será estudado o desempenho das três metodologias na ocorrência de múltiplas faltas no sistema 4. Para tanto, os parâmetros utilizados nas simulações pelas três metodologias foram:

1. AEMT-SP: $S_{p 1, \ldots, p 5}=5, G_{\max }=70.000, S_{f 1}=20, S_{f 2}=40, S_{f 3}=20$ e $S_{f s t r}=30$;

2. EDMT: $S_{p 1, \ldots, p 5}=5, G_{\max }=70.000, S_{f 1}=30, S_{f 2}=50, S_{f 3}=60, S_{f s t r}=30$, $F=0.6$ e div $=10.000$;

3. AEMT: $S_{p 1, \ldots, p 5}=5$ e $G_{\max }=70.000$;

Importa destacar que, para as três metodologias comparadas, o indivíduo considerado como a melhor solução é aquele que apresenta o menor número de operações de manobras 
e não viola as restrições operacionais, sendo os limites definidos nesse trabalho como: queda de tensão de no máximo $10 \%$ e carregamentos da rede e das subestações de no máximo $100 \%$.

Além disso, a tabela de subpopulação de função agregação das três metodologias é composta pela somatória das perdas ôhmicas em kW, número de chaveamentos, máximo carregamento da rede em p.u., máximo carregamento das subestações em p.u. e máxima queda de tensão em p.u., conforme apresentado na equação 5.1 do capítulo 5 .

\subsubsection{Simulações para falta única}

As simulações foram realizadas considerando a ocorrência de uma falta na saída do maior alimentador dos sistemas 1, 2, 3 e 4. Com isso, ocorrerá a interrupção do fornecimento de energia para todos os consumidores destes alimentadores.

O número de manobras de chaveamento que será apresentado nas próximas tabelas não contabiliza as manobras necessárias para isolar os setores em falta. Ou seja, são as manobras necessárias para restaurar a energia, para todas os setores não atingidos pelas faltas, depois de os setores em falta terem sido isolados. Para os casos de uma única falta, analisados nesta seção, foram necessárias 3 manobras de chaveamento para isolar os setores em falta, de cada um dos quatro sistemas testados. A partir de os setores em falta isolados, as três metodologias testadas encontraram as mesmas primeiras configurações factíveis para os sistemas testados. Essas configurações são apresentadas na Tabela 7.1 e exigem apenas 2 manobras de chaveamento (sem considerar as 3 necessárias para isolar os setores em falta). Conforme pode ser observado nessa tabela, as primeiras configurações são factíveis (radiais e restabelecem energia para todas os setores não atingidos pelas faltas), mas não são soluções factíveis, pois todas desrespeitam a restrição de carregamento da rede $(139,59 \%)$.

Tabela 7.1: Características da $1^{a}$ configuração factível para os sistemas 1, 2, 3 e 4.

\begin{tabular}{lcccc}
\hline \hline & Sistema 1 & Sistema 2 & Sistema 3 & Sistema 4 \\
\hline Número de Manobras & 2 & 2 & 2 & 2 \\
Perdas Ôhmicas [KW] & 414,94 & 696,37 & 1259,05 & 2384,43 \\
Queda de Tensão [\%] & 5,01 & 5,01 & 5,01 & 5,01 \\
Carregamento da Rede [\%] & $\mathbf{1 3 9 , 5 9}$ & $\mathbf{1 3 9 , 5 9}$ & $\mathbf{1 3 9 , 5 9}$ & $\mathbf{1 3 9 , 5 9}$ \\
Carregamento da Subestação [\%] & 53,34 & 53,34 & 53,34 & 53,34 \\
\hline \hline
\end{tabular}

A Tabela 7.2 apresenta uma análise dos resultados obtidos através das metodologias AEMT-SP, EDMT e AEMT aplicados aos Sistemas 1, 2, 3 e 4. Os resultados apresentados referem-se aos valores de operações de manobras (valor mínimo, máximo, médio e desvio padrão). Estes valores foram obtidos com base nos resultados de 50 simulações realizadas com as três metodologias. Importa destacar que esses valores foram obtidos a partir da 
tabela de função agregação.

Tabela 7.2: Número de manobras obtidas para os Sistemas 1, 2, 3 e 4.

\begin{tabular}{l|r|ccc}
\hline \hline \multirow{2}{*}{} & & \multicolumn{3}{c}{ Número de Manobras } \\
\cline { 3 - 5 } \multicolumn{1}{c}{ Sistema 1} & EDMT & AEMT-SP & AEMT \\
\hline \multirow{5}{*}{ Sistema 2} & Mínimo & 4 & 4 & 18 \\
& Média & 7 & 6 & 21 \\
& Máximo & 12 & 10 & 26 \\
& Desvio Padrão & 2,09 & 2,11 & 2,27 \\
\hline \multirow{4}{*}{ Sistema 3 3ínimo } & 4 & 4 & 24 \\
& Média & 8 & 11 & 37 \\
& Máximo & 16 & 42 & 62 \\
& Desvio Padrão & 3,43 & 7,95 & 6,84 \\
\hline \multirow{5}{*}{ Sistema 4} & Mínimo & 4 & 4 & 58 \\
& Média & 13 & 21 & 84 \\
& Máximo & 32 & 68 & 132 \\
& Desvio Padrão & 7,05 & 14,41 & 15,18 \\
\hline \hline
\end{tabular}

Como pode ser observado na Tabela 7.2, a metodologia EDMT obteve os melhores resultados em relação ao número de operações de manobras, encontrando configurações com o valor mínimo (4 manobras) para os Sistemas 1, 2, 3 e 4, com destaque para o valor médio de operações de manobras, que manteve-se inferior para os quatro sistemas quando comparado com as metodologias AEMT-SP e AEMT.

As Tabelas 7.3, 7.4, 7.5 e 7.6 sintetizam os resultados de perdas ôhmicas e das restrições operacionais obtidos pelas três metodologias para os sistemas 1, 2, 3 e 4. A partir da tabela de função agregação, foram calculados os valores médios e os desvios padrão com base nos resultados de 50 simulações realizadas com as três metodologias. Importa destacar que o tempo de processamento da metodologia EDMT ficou inferior em relação às metodologias AEMT-SP e AEMT para os quatro sistemas avaliados.

No que segue, temos as Figuras 7.1, 7.2, 7.3 e 7.4 que ilustram as fronteiras de Pareto obtidas pelas metodologias EDMT, AEMT-SP e AEMT, aplicados ao problema de restabelecimento de energia para os Sistemas 1, 2, 3 e 4. Na tabela 7.7 é possível verificar os valores de hipervolume obtidos para as Figuras 7.1, 7.2, 7.3 e 7.4. Na mesma tabela é apresentado o valor do ponto de referência $W$, utilizado para cada uma das metodologias. Com base nos resultados do hipervolume, é possível verificar um melhor desempenho da metodologia EDMT, em relação as outras duas metodologias, em que o valor de hipervolume encontrado foi superior para os Sistemas 1, 2, 3 e 4, indicando uma melhor convergência e melhor distribuição das soluções na fronteira. 
Tabela 7.3: Simulações para uma falta no Sistema 1.

\begin{tabular}{lcccccc}
\hline \hline & \multicolumn{2}{c}{ EDMT } & \multicolumn{2}{c}{ AEMT-SP } & \multicolumn{2}{c}{ AEMT } \\
& Média & DP* & Média & DP* & Média & DP* \\
\hline Perdas Ôhmicas [KW] & 379,49 & 36,94 & 370,54 & 36,68 & 299,13 & 7,38 \\
Queda de Tensão [\%] & 4,28 & 0,86 & 4,15 & 0,86 & 3,25 & 0,003 \\
Carregamento da Rede [\%] & 84,81 & 7,08 & 80,52 & 5,82 & 77,79 & 3,22 \\
Carregamento da Subestação [\%] & 54,10 & 2,44 & 53,24 & 2,21 & 55,15 & 7,38 \\
Tempo de Processamento (s) & 10,67 & 1,22 & 14,68 & 1,27 & 14,38 & 1,32 \\
\hline \hline
\end{tabular}

*Desvio Padrão

Tabela 7.4: Simulações para uma falta no Sistema 2.

\begin{tabular}{lcccccc}
\hline \hline & \multicolumn{2}{c}{ EDMT } & \multicolumn{2}{c}{ AEMT-SP } & \multicolumn{2}{c}{ AEMT } \\
& Média & DP* & Média & DP* & Média & DP* \\
\hline Perdas Ôhmicas [KW] & 642,12 & 35,16 & 645,77 & 38,99 & 551,55 & 10,02 \\
Queda de Tensão [\%] & 3,96 & 0,76 & 4,11 & 0,85 & 3,27 & 0,07 \\
Carregamento da Rede [\%] & 85,90 & 7,03 & 83,27 & 5,79 & 77,15 & 5,25 \\
Carregamento da Subestação [\%] & 54,70 & 1,65 & 55,47 & 1,75 & 54,55 & 10,02 \\
Tempo de Processamento (s) & 12,65 & 1,55 & 18,89 & 0,99 & 20,63 & 3,25 \\
\hline \hline
\end{tabular}

*Desvio Padrão

Tabela 7.5: Simulações para uma falta no Sistema 3.

\begin{tabular}{lcccccc}
\hline \hline & \multicolumn{2}{c}{ EDMT } & \multicolumn{2}{c}{ AEMT-SP } & \multicolumn{2}{c}{ AEMT } \\
& Média & DP* & Média & DP* & Média & DP* \\
\hline Perdas Ôhmicas [KW] & 1195,96 & 41,72 & 1170,02 & 44,11 & 1014,24 & 27,83 \\
Queda de Tensão [\%] & 4,16 & 0,88 & 3,86 & 0,72 & 5,75 & 2,42 \\
Carregamento da Rede [\%] & 88,18 & 7,70 & 86,70 & 9,31 & 92,44 & 8,15 \\
Carregamento da Subestação [\%] & 55,37 & 2,11 & 44,82 & 2,24 & 70,01 & 23,83 \\
Tempo de Processamento (s) & 15,30 & 1,68 & 16,13 & 0,71 & 21,66 & 2,42 \\
\hline \hline
\end{tabular}

*Desvio Padrão

Tabela 7.6: Simulações para uma falta no Sistema 4.

\begin{tabular}{lcccccc}
\hline \hline & \multicolumn{2}{c}{ EDMT } & \multicolumn{2}{c}{ AEMT-SP } & \multicolumn{2}{c}{ AEMT } \\
& Média & DP* & Média & DP* & Média & DP* \\
\hline Perdas Ohmicas [KW] & 2301,60 & 46,40 & 2284,91 & 59,36 & 2006,35 & 34,86 \\
Queda de Tensão [\%] & 3,83 & 0,77 & 4,06 & 0,65 & 3,86 & 1,14 \\
Carregamento da Rede [\%] & 88,03 & 7,39 & 87,30 & 8,82 & 95,97 & 4,50 \\
Carregamento da Subestação [\%] & 55,39 & 2,16 & 56,44 & 2,62 & 75,36 & 34,86 \\
Tempo de Processamento (s) & 15,63 & 1,98 & 19,68 & 0,55 & 18,55 & 0,78 \\
\hline \hline
\end{tabular}

*Desvio Padrão 
De acordo com as fronteiras de Pareto geradas, é possível observar que para o problema de restabelecimento de energia, a metodologia EDMT possui um melhor mapeamento das soluções na fronteira, alcançando soluções com menor número de operações de manobras, quando comparado com as metodologias AEMT-SP e AEMT.

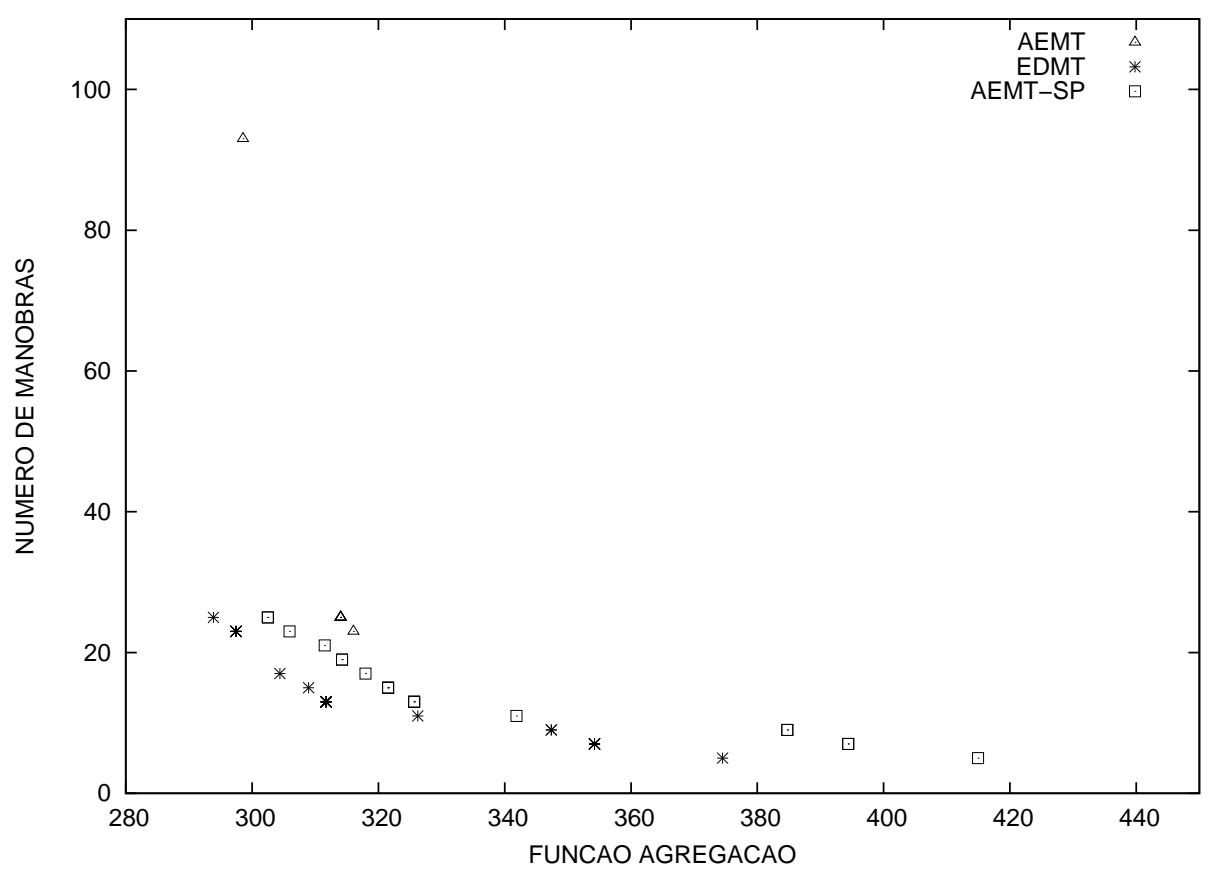

Figura 7.1: Fronteiras de Pareto obtidas para o sistema 1.

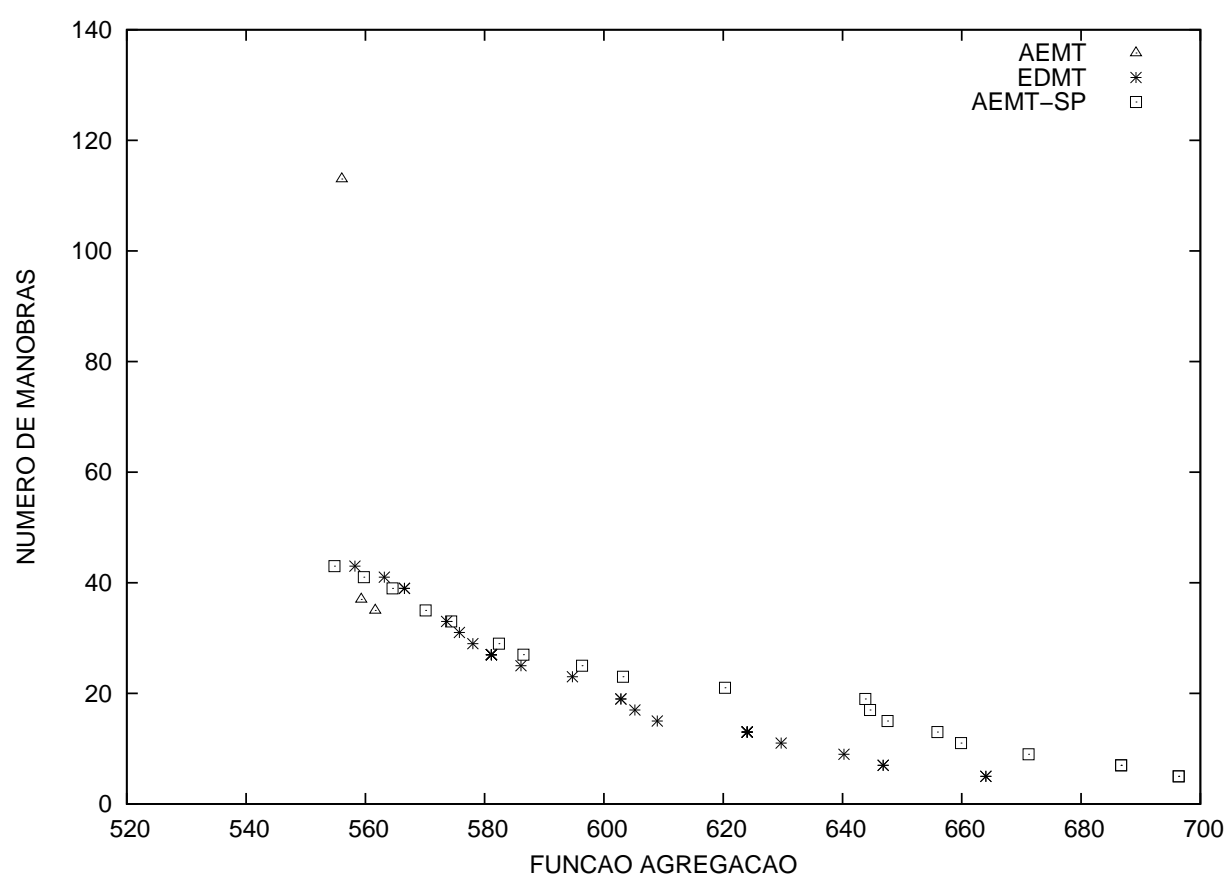

Figura 7.2: Fronteiras de Pareto obtidas para o sistema 2. 


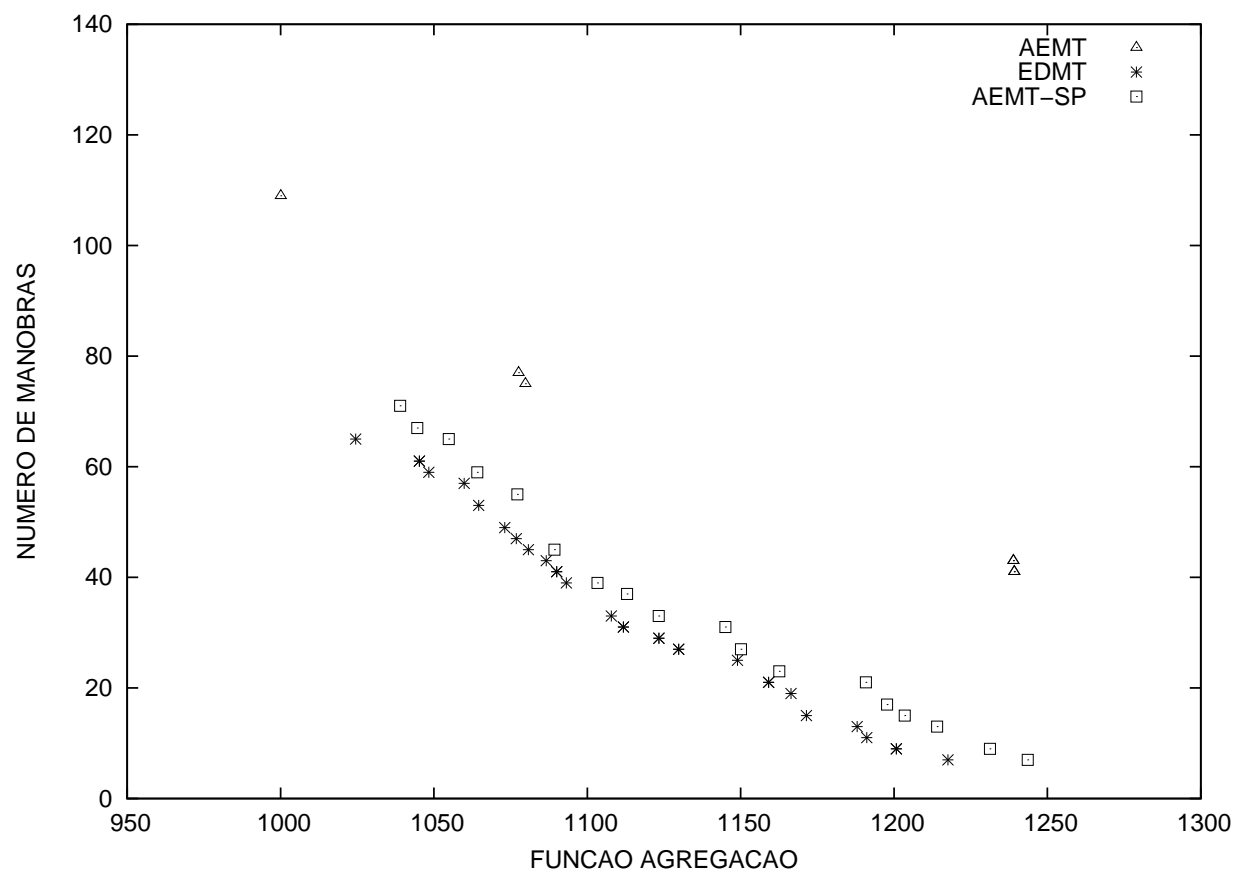

Figura 7.3: Fronteiras de Pareto obtidas para o sistema 3.

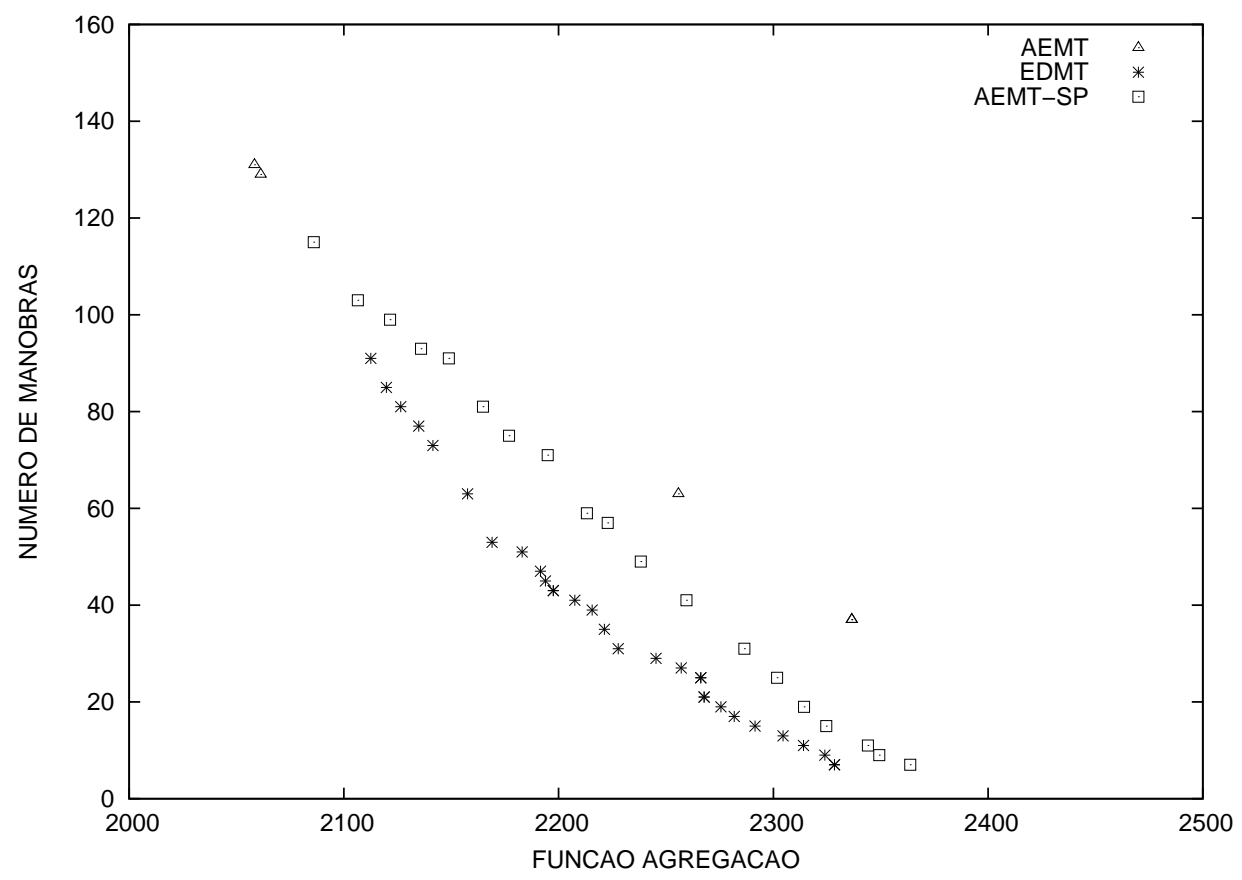

Figura 7.4: Fronteiras de Pareto obtidas para o sistema 4. 
Tabela 7.7: Valores obtidos de hipervolume para as três metodologias.

\begin{tabular}{|c|c|c|c|c|}
\hline & \multicolumn{3}{|c|}{ Metodologias } \\
\hline & & EDMT & AEMT-SP & $\overline{\mathrm{AEMT}}$ \\
\hline \multirow{2}{*}{ Sistema 1} & Hipervolume & 15802,61 & 14672,83 & 12089,21 \\
\hline & $W$ & $450 / 110$ & $450 / 110$ & $450 / 110$ \\
\hline \multirow{2}{*}{ Sistema 2} & Hipervolume & 20483,31 & 20097,68 & 16227,60 \\
\hline & $W$ & $750 / 120$ & $750 / 120$ & $750 / 120$ \\
\hline \multirow{2}{*}{ Sistema 3} & Hipervolume & 44633,52 & 42489,54 & 26427,08 \\
\hline & $W$ & $1400 / 140$ & $1400 / 140$ & $1400 / 140$ \\
\hline \multirow{2}{*}{ Sistema 4} & Hipervolume & 71108,14 & 69573,38 & 56134,76 \\
\hline & $W$ & $2500 / 210$ & $2500 / 210$ & $2500 / 210$ \\
\hline
\end{tabular}

\subsubsection{Subpopulações de pares de manobras e heurística}

Conforme observado nos resultados anteriores, com o aumento do número de manobras, em especial nos Sistemas 3 e 4, fica mais difícil encontrar boas soluções. Para tanto, em (SANTOS et al., 2010) foram incluídas, no AEMT, 5 novas tabelas de subpopulações de pares de manobras, definidas da seguinte forma:

$P_{5+i}$, com $\mathrm{p}=1, \ldots, 5$ - armazenam as soluções (ou configurações) que exigem apenas "p" pares de manobras, sem considerar as manobras necessárias para isolar os setores em falta. As melhores soluções dessas tabelas são aquelas que apresentarem o menor valor de $X(F)+V(F)$, isto é, da soma do carregamento da rede pela maior queda de tensão da rede da correspondente solução (essas definições foram apresentadas no capítulo 2). Todas essas tabelas de subpopulações de pares de manobras apresentam o tamanho 5 $\left(S_{p 5+i}\right)$, isto é, 5 é a quantidade máxima de indivíduos que podem ser armazenados nessas tabelas. Essas novas tabelas melhoraram de forma significativa o desempenho do AEMT para tratamento do problema de restabelecimento de energia. Em razão disso, elas serão incorporadas nas metodologias EDMT e AEMT-SP propostas neste trabalho.

Além das novas tabelas de pares de manobras, com o objetivo de melhorar os resultados obtidos na tabela 7.2, propõe-se a utilização de uma herística para priorizar a aplicação dos operadores da RNP em alimentadores com valores elevados de queda de tensão e carregamento da rede, isto é, para priorizar as manobras em regiões que realmente precisam ser re-configuradas. A ideia é restringir o espaço de busca e, consequentemente, obter soluções com um menor número de manobras e que não violem os limites operacionais do sistema. De acordo com a heurística proposta, cria-se uma lista ordenada de alimentadores para aplicação dos operadores da RNP. O alimentador que possuir a maior queda de tensão será o primeiro dessa lista, e assim por diante. Quando dois ou mais alimentadores tiverem valores similares de máxima queda de tensão, com precisão de $10^{-2}$, os alimentadores com maiores carregamentos de rede serão os primeiros na lista. Quando dois ou mais alimentadores apresentarem valores similares para máxima queda de tensão 
e carregamento da rede, com precisão de $10^{-2}$, a escolha pelos primeiros alimentadores da lista será aleatória.

A Tabela 7.8 apresenta os resultados obtidos com a inclusão das tabelas de subpopulações de pares de manobras e heurística nas metodologia EDMT e AEMT-SP, e a metodologia AEMT com a inclusão de tabelas de subpopulações de pares de manobras (conforme proposto em (SANTOS et al., 2010). Os resultados apresentados referem-se aos valores de operações de manobras (valor mínimo, máximo, médio e desvio padrão), com base nos resultados de 50 simulações realizadas com todas as metodologias propostas. Importa destacar que, os resultados apresentados foram obtidos das tabelas de pares de manobras.

Tabela 7.8: Número de manobras obtidas com o uso da heurística.

\begin{tabular}{l|r|ccc}
\hline \hline \multirow{2}{*}{} & & \multicolumn{3}{c}{ Número de Manobras } \\
\cline { 3 - 5 } \multicolumn{1}{c}{ Sistema 1 } & Mínimo & 4 & 4 & 4 \\
& Média & 5 & 6 & 10 \\
& Máximo & 8 & 12 & 26 \\
& Desvio Padrão & 1,13 & 2,18 & 5,48 \\
\hline \multirow{4}{*}{ Sistema 2} & Mínimo & 4 & 4 & 6 \\
& Média & 5 & 6 & 14 \\
& Máximo & 10 & 14 & 44 \\
& Desvio Padrão & 1,39 & 2,02 & 7,51 \\
\hline \multirow{4}{*}{ Sistema 3 3 3} & Mínimo & 4 & 4 & 8 \\
& Média & 6 & 7 & 22 \\
& Máximo & 10 & 18 & 104 \\
& Desvio Padrão & 1,69 & 3,24 & 20,11 \\
\hline \multirow{5}{*}{ Sistema 4 } & Mínimo & 4 & 4 & 8 \\
& Média & 6 & 6 & 33 \\
& Máximo & 12 & 16 & 178 \\
& Desvio Padrão & 1,49 & 2,04 & 36,81 \\
\hline \hline
\end{tabular}

Como pode ser observado na Tabela 7.8, as metodologias EDMT e AEMT-SP obtiveram uma melhora significativa nos resultados em relação aos resultados apresentados na Tabela 7.2 e ao método AEMT com tabelas de pares de manobras, principalmente para os sistemas maiores (S3 e S4). Esta melhora está diretamente relacionada com a inclusão das tabelas de subpopulações de pares de manobras e aplicação de uma heurística para priorizar manobras entre os alimentadores com maior queda de tensão e maior carregamento da rede. Com isso, é possível verificar uma grande flexibilidade das metodologias propostas, uma vez que, foi possível alcançar outras regiões no espaço de soluções, sem a necessidade de aplicar mudanças complexas na estrutura das metodologias propostas.

As Tabelas 7.9, 7.10, 7.11 e 7.12 sintetizam os resultados de perdas ôhmicas e das restrições operacionais obtidos pelas metodologias EDMT, AEMT-SP e AEMT, para os 
sistemas 1, 2, 3 e 4 . Os valor médio e o desvio padrão foram obtidos com base nos resultados de 50 simulações realizadas com as três metodologias.

Tabela 7.9: Simulações com heurística para uma falta no Sistema 1.

\begin{tabular}{lcccccc}
\hline \hline & \multicolumn{2}{c}{ EDMT } & \multicolumn{2}{c}{ AEMT-SP } & \multicolumn{2}{c}{ AEMT } \\
& Média & DP* & Média & DP* & Média & DP* \\
\hline Perdas Ôhmicas [KW] & 395,45 & 21,99 & 387,54 & 31,05 & 353,86 & 36,09 \\
Queda de Tensão [\%] & 4,72 & 0,63 & 4,58 & 0,77 & 3,82 & 0,79 \\
Carregamento da Rede [\%] & 80,86 & 2,85 & 83,74 & 5,61 & 74,47 & 8,45 \\
Carregamento da Subestação [\%] & 54,71 & 1,38 & 55,32 & 2,76 & 53,36 & 1,57 \\
Tempo de Processamento (s) & 11,19 & 0,91 & 18,85 & 1,88 & 12,88 & 1,25 \\
\hline \hline
\end{tabular}

*Desvio Padrão

Tabela 7.10: Simulações com heurística para uma falta no Sistema 2.

\begin{tabular}{lcccccc}
\hline \hline & \multicolumn{2}{c}{ EDMT } & \multicolumn{2}{c}{ AEMT-SP } & \multicolumn{2}{c}{ AEMT } \\
& Média & DP* & Média & DP* & Média & DP* \\
\hline Perdas Ôhmicas [KW] & 671,92 & 23,41 & 667,75 & 30,17 & 636,31 & 45,73 \\
Queda de Tensão [\%] & 4,58 & 0,68 & 4,40 & 0,74 & 3,74 & 0,70 \\
Carregamento da Rede [\%] & 82,29 & 5,20 & 85,26 & 5,96 & 75,28 & 10,41 \\
Carregamento da Subestação [\%] & 54,93 & 0,90 & 55,44 & 1,92 & 54,45 & 1,76 \\
Tempo de Processamento (s) & 15,86 & 1,23 & 24,85 & 0,68 & 13,76 & 1,66 \\
\hline \hline
\end{tabular}

*Desvio Padrão

Tabela 7.11: Simulações com heurística para uma falta no Sistema 3.

\begin{tabular}{lcccccc}
\hline \hline & \multicolumn{2}{c}{ EDMT } & \multicolumn{2}{c}{ AEMT-SP } & \multicolumn{2}{c}{ AEMT } \\
& Média & DP* & Média & DP* & Média & DP* \\
\hline Perdas Ôhmicas [KW] & 1236,95 & 26,84 & 1227,39 & 30,48 & 1191,67 & 69,57 \\
Queda de Tensão [\%] & 4,62 & 0,72 & 4,31 & 0,71 & 3,91 & 0,80 \\
Carregamento da Rede [\%] & 83,15 & 6,29 & 85,25 & 6,44 & 83,01 & 9,58 \\
Carregamento da Subestação [\%] & 55,24 & 1,27 & 55,18 & 1,44 & 57,17 & 4,86 \\
Tempo de Processamento (s) & 19,98 & 1,44 & 27,76 & 0,71 & 14,99 & 0,40 \\
\hline \hline
\end{tabular}

*Desvio Padrão

No que segue, temos as Figuras 7.5, 7.6, 7.7 e 7.8 que ilustram as fronteiras de Pareto obtidas pelas metodologias EDMT, AEMT-SP e AEMT aplicadas nos Sistemas 1, 2, 3 e 4.

Na tabela 7.13 é possível verificar os valores de hipervolume obtidos para as Figuras 7.5, 7.6, 7.7 e 7.8. Na mesma tabela é apresentado o valor do ponto de referência $W$ utilizado para cada uma das metodologias. Com base nos resultados do hipervolume, é 
Tabela 7.12: Simulações com heurística para uma falta no Sistema 4.

\begin{tabular}{lcccccc}
\hline \hline & \multicolumn{2}{c}{ EDMT } & \multicolumn{2}{c}{ AEMT-SP } & \multicolumn{2}{c}{ AEMT } \\
& Média & DP* & Média & DP* & Média & DP* \\
\hline Perdas Ôhmicas [KW] & 2364,91 & 28,21 & 2364,90 & 21,42 & 2301,26 & 90,91 \\
Queda de Tensão [\%] & 4,71 & 0,69 & 4,70 & 0,55 & 3,79 & 0,75 \\
Carregamento da Rede [\%] & 82,16 & 4,27 & 82,63 & 5,02 & 84,62 & 10,54 \\
Carregamento da Subestação [\%] & 55,17 & 1,22 & 55,08 & 0,84 & 56,85 & 5,28 \\
Tempo de Processamento (s) & 19,55 & 1,33 & 28,32 & 0,69 & 15,52 & 0,52 \\
\hline \hline
\end{tabular}

*Desvio Padrão

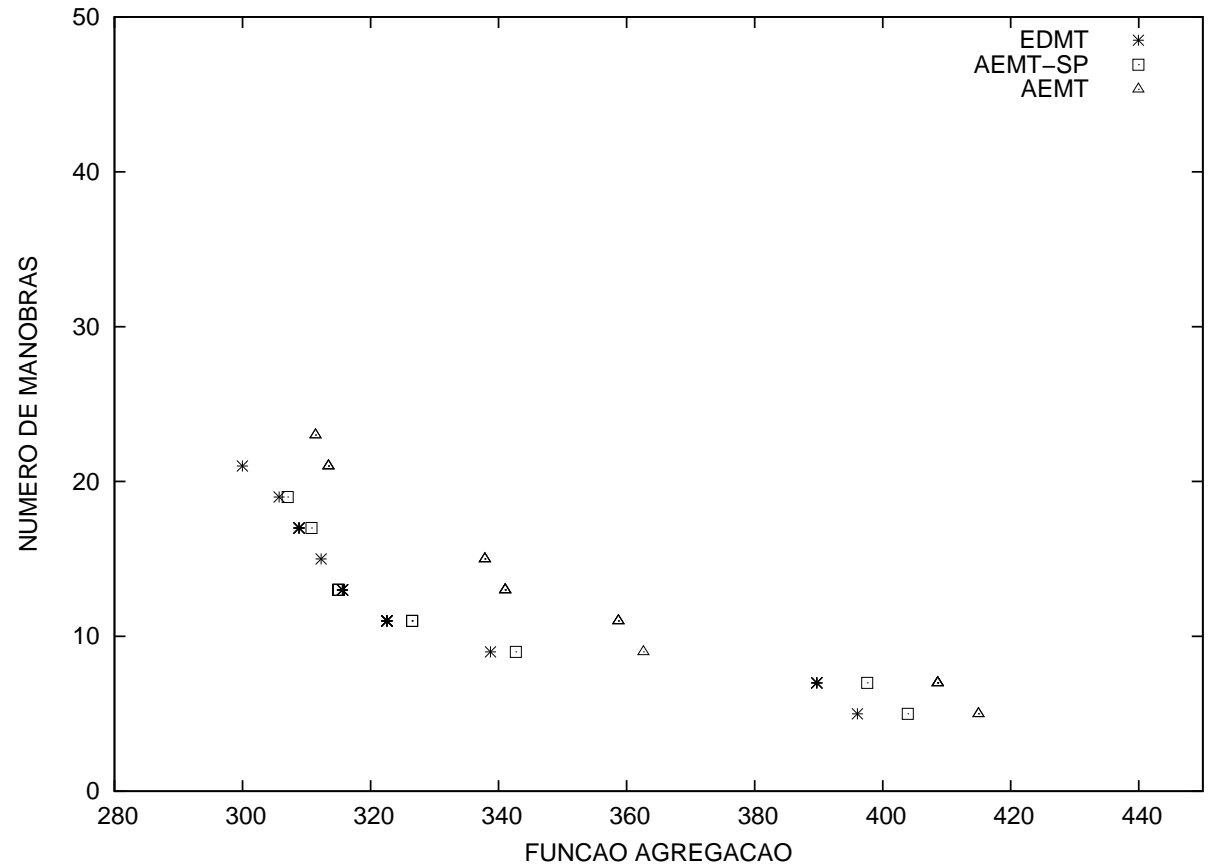

Figura 7.5: Fronteiras de Pareto obtidas para o sistema 1. 


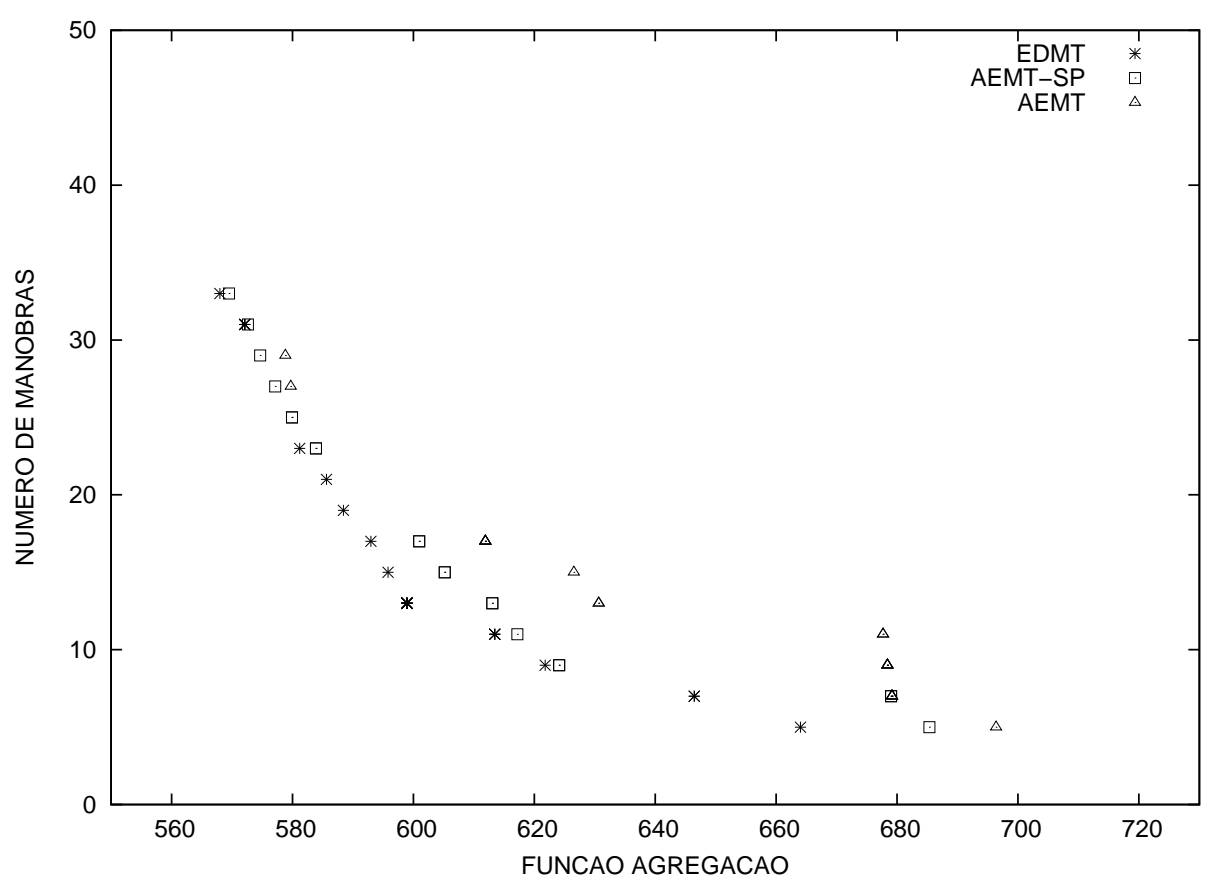

Figura 7.6: Fronteiras de Pareto obtidas para o sistema 2.

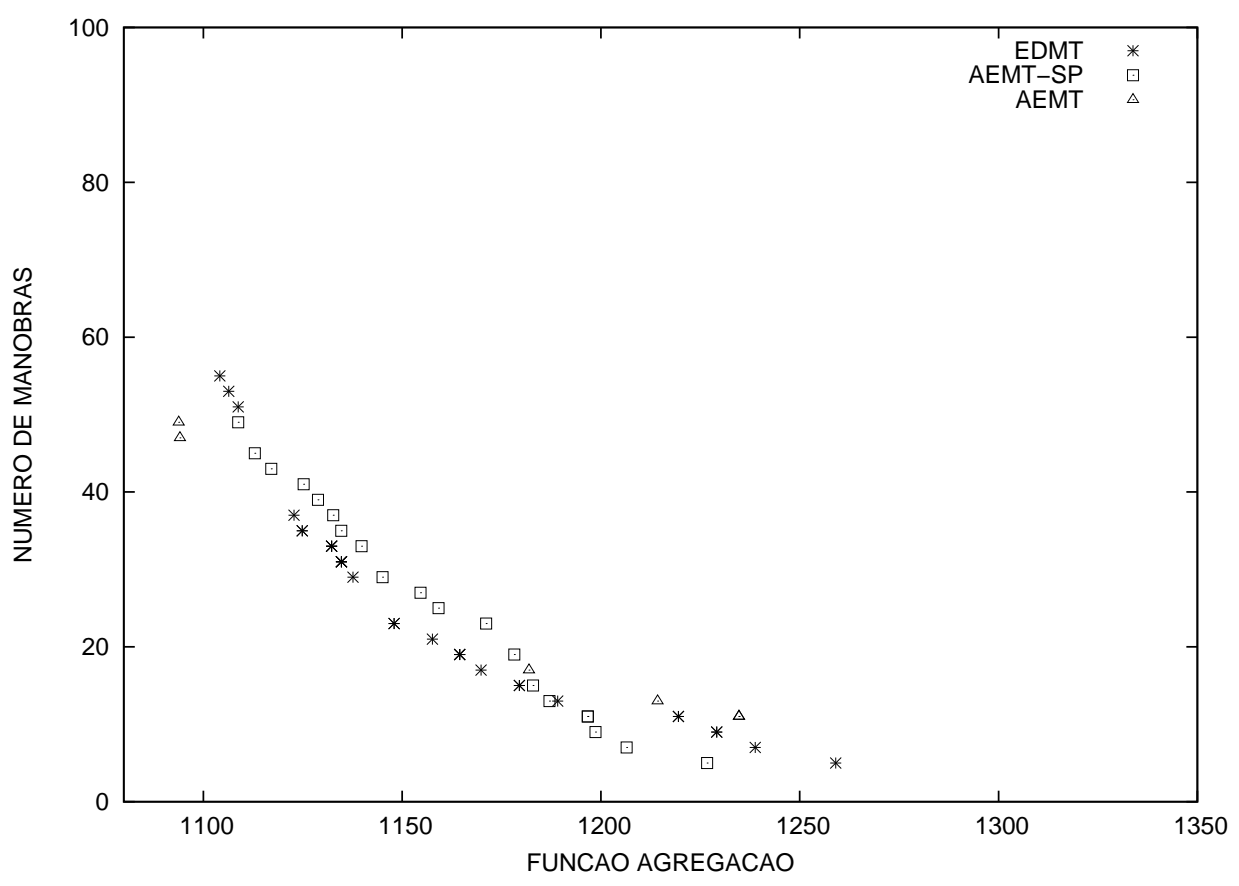

Figura 7.7: Fronteiras de Pareto obtidas para o sistema 3. 


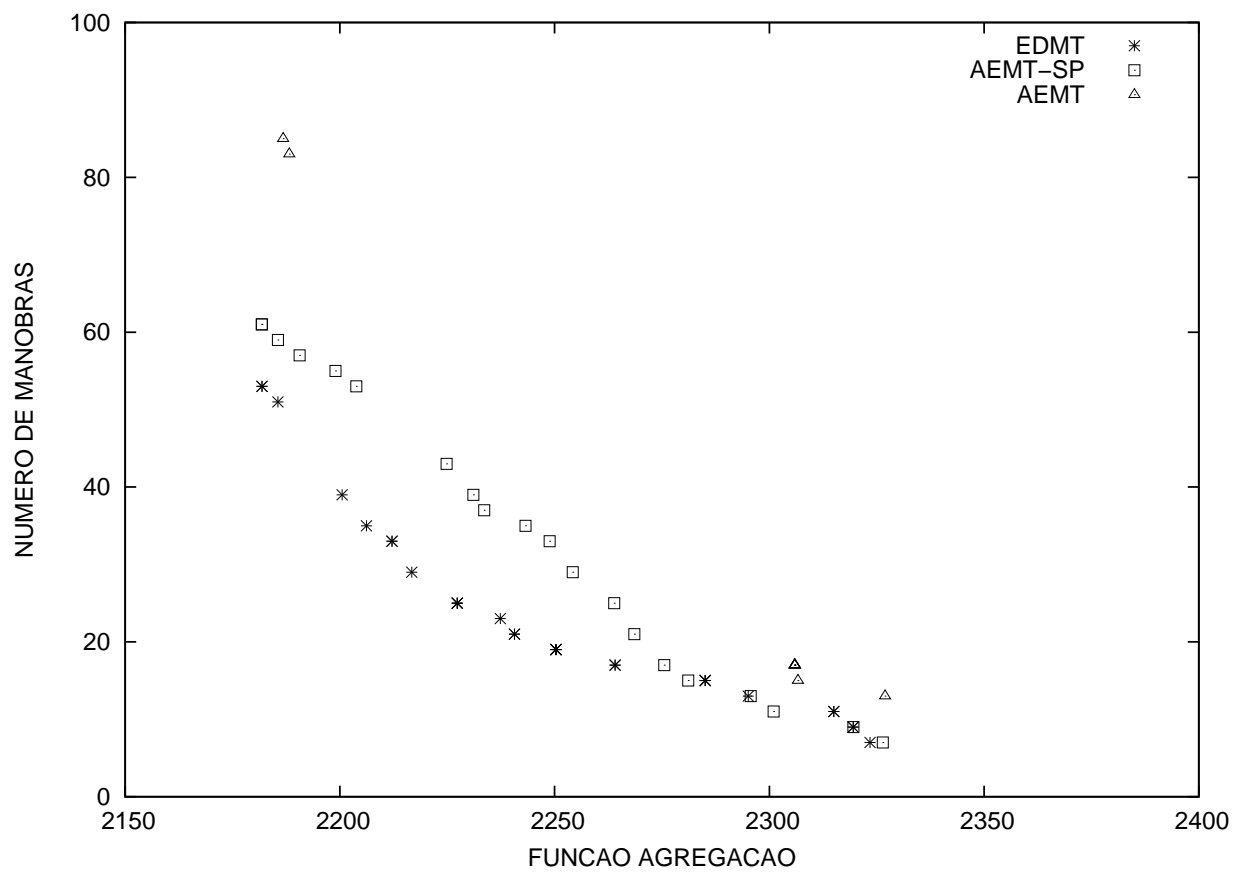

Figura 7.8: Fronteiras de Pareto obtidas para o sistema 4.

possível verificar um melhor desempenho da metodologia EDMT em relação às metodologias AEMT-SP e AEMT, em que o valor de hipervolume encontrado foi superior para os Sistemas 1, 2, 3 e 4, indicando uma melhor convergência e melhor distribuição das soluçõs na fronteira.

Tabela 7.13: Valores obtidos de hipervolume para as três metodologias.

\begin{tabular}{l|c|ccc}
\hline \hline \multicolumn{2}{c}{} & \multicolumn{3}{c}{ Metodologias } \\
\cline { 3 - 5 } \multicolumn{2}{c}{} & EDMT & AEMT-SP & AEMT \\
\hline \multirow{2}{*}{ Sistema 1 } & Hipervolume & 6171,72 & 5908,30 & 5416,42 \\
& $W$ & $450 / 50$ & $450 / 50$ & $450 / 50$ \\
\hline \multirow{2}{*}{ Sistema 2 } & Hipervolume & 7284,79 & 7038,43 & 6338,60 \\
& $W$ & $750 / 50$ & $750 / 50$ & $750 / 50$ \\
\hline \multirow{2}{*}{ Sistema 3 } & Hipervolume & 14144,61 & 13991,37 & 12880,69 \\
& $W$ & $1300 / 90$ & $1300 / 90$ & $1300 / 90$ \\
\hline \multirow{2}{*}{ Sistema 44 } & Hipervolume & 15607,06 & 14448,83 & 8032,35 \\
& $W$ & $2400 / 90$ & $2400 / 90$ & $2400 / 90$ \\
\hline \hline
\end{tabular}

\subsubsection{Simulações com múltiplas faltas}

Nesta seção, o desempenho das metodologias EDMT e AEMT-SP, com as tabelas de pares de manobras e a heurística proposta, será avaliado e comparado com o desempenho do AEMT, proposto em (SANTOS et al., 2010), para o problema de restabelecimento de energia no caso de múltiplas faltas. O objetivo é verificar o desempenho dessas metodolo- 
gias para um problema mais complexo. Foram consideradas então 8 faltas, em 8 alimentadores distintos do Sistema 4. Para isolar todos os setores em falta, foram necessárias 19 manobras de chaveamento. A partir de os setores em falta isolados, as três metodologias testadas encontraram a mesma primeira configuração factível, que requer um total de 11 manobras de chaveamento (sem considerar as 19 necessárias para isolar os setores em falta). As demais características dessa configuração são apresentadas na Tabela 7.14. Conforme pode ser observado nessa tabela, essa configuração não é uma solução factível, pois não satisfaz as restrições de queda de tensão e de carregamento da rede.

Tabela 7.14: Características da $1^{a}$ configuração factível encontrada para múltiplas faltas.

\begin{tabular}{lc}
\hline \hline Manobras & 11 \\
Perdas Ôhmicas [KW] & 3048,37 \\
Queda de Tensão [\%] & $\mathbf{1 3 , 4 2}$ \\
Carregamento da Rede [\%] & $\mathbf{1 5 0 , 0 8}$ \\
Carregamento da Subestação [\%] & 63,00 \\
\hline \hline
\end{tabular}

Como pode ser observado na Tabela 7.15, as metodologias EDMT, AEMT-SP e AEMT foram capazes de encontrar soluções factíveis para o problema de múltiplas faltas. Importa destacar que a metodologia EDMT, obteve melhores resultados quando comparado com as metodologias AEMT-SP e AEMT, alcançando um número médio de 18 operações de manobras enquanto que as metodologias AEMT-SP e AEMT alcançaram em média 33 e 100 operações de manobras, respectivamente. Já para o pior caso, a metodologia EDMT obteve 47 operações de manobras enquanto que as metodologias AEMT-SP e AEMT alcançaram 123 e 73 operações de manobras, respectivamente.

Tabela 7.15: Número de manobras obtidas para o problema de múltiplas faltas.

\begin{tabular}{c|r|ccc}
\hline \hline & \multicolumn{1}{c}{ EDMT } & AEMT-SP & AEMT \\
\hline \multirow{2}{*}{ Manobras } & Mínimo & 13 & 13 & 21 \\
& Média & 18 & 33 & 100 \\
& Máximo. & 47 & 123 & 273 \\
& Desv. Pad. & 5,63 & 28,87 & 68,31 \\
\hline \multirow{2}{*}{ Perdas Ôhmicas $[\mathrm{KW}]$} & Média & 2642,11 & 2577,20 & 2435,88 \\
& Desv. Pad. & 72,4 & 101,46 & 159,66 \\
\hline \multirow{2}{*}{ Queda de Tensão [\%] } & Média & 4,76 & 4,42 & 4,19 \\
& Desv. Pad. & 0,61 & 1,07 & 0,61 \\
\hline \multirow{2}{*}{ Carregamento da Rede [\%] } & Média & 97,82 & 97,47 & 96,13 \\
& Desv. Pad. & 4,12 & 4,62 & 4,55 \\
\hline \multirow{2}{*}{ Carregamento da Subestação [\%] } & Média & 54,51 & 56,68 & 60,88 \\
& Desv. Pad. & 2,97 & 2,75 & 6,78 \\
\hline \multirow{2}{*}{ Tempo de Processamento (s) } & Média & 23,53 & 28,83 & 17,26 \\
& Desv. Pad. & 1,88 & 1,47 & 0,88 \\
\hline \hline
\end{tabular}


Finalmente a Figura 7.9 ilustra as fronteiras de Pareto obtidas pelas metodologias EDMT, AEMT-SP e AEMT para o problema de múltiplas faltas no Sistema 4. Na tabela 7.16 é possível verificar os valores de hipervolume obtidos para a Figura 7.9. Na mesma tabela é apresentado o valor do ponto de referência $W$ utilizado para cada uma das metodologias. Com base nos resultados do hipervolume, é possível verificar novamente um melhor desempenho da metodologia EDMT, em relação às metodologias AEMT-SP e AEMT, em que o valor de hipervolume encontrado foi superior, indicando uma melhor convergência e melhor distribuição das soluções na fronteira.

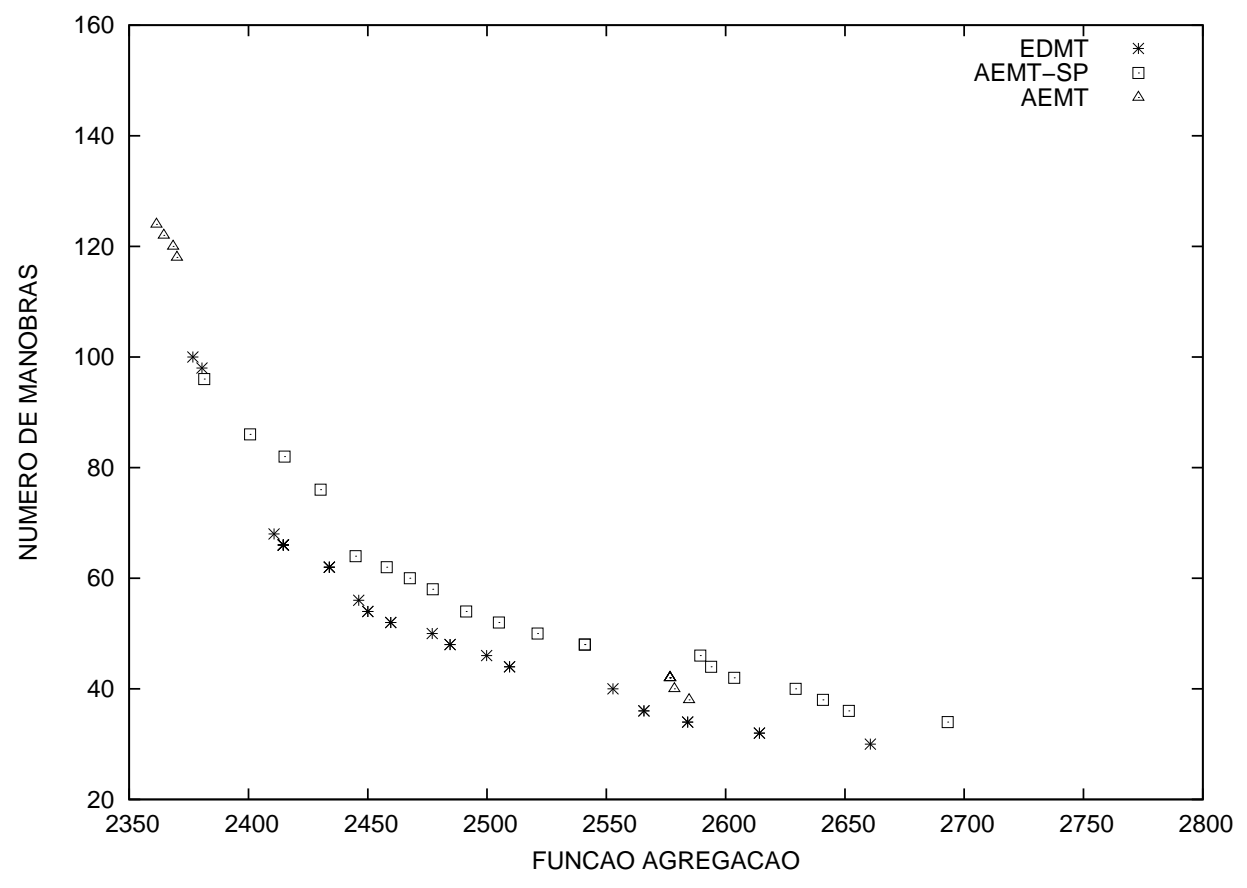

Figura 7.9: Fronteiras de Pareto obtidas para múltiplas faltas.

Tabela 7.16: Valores obtidos de hipervolume para o sistema 4 com múltiplas faltas.

\begin{tabular}{c|ccc}
\hline \hline \multirow{2}{c}{} & \multicolumn{3}{c}{ Metodologias } \\
\cline { 2 - 4 } & EDMT & AEMT-SP & AEMT \\
\hline Hipervolume & 35971,51 & 33401,73 & 23072,66 \\
$W$ & $2700 / 160$ & $2700 / 160$ & $2700 / 160$ \\
\hline \hline
\end{tabular}

Os resultados apresentados nesta seção demonstram que a metodologia EDMT apresenta um desempenho superior ao das metodologias AEMT-SP e AEMT, para tratamento do problema de múltiplas faltas. Isto em razão dos planos de restabelecimentos encontrados pela EDMT exigirem, em média, 18 operações de chaveamento para restabelecimento de energia em todos os setores não atingidos pelas faltas, respeitando todas as restrições operacionais do sistema. Por outro lado, os planos encontrados pelas metodologias AEMT-SP e AEMT requerem, em média, 33 e 100 operações de chaveamento, respectivamente. Com base nesses resultados, pode-se observar que, sistemas maiores possuem um 
número de soluções factíveis maior do que sistemas relativamente menores e, felizmente, a metodologia EDMT consegue encontrar algumas dessas soluções.

Planos de restabelecimento com 18 operações de chaveamento podem ser considerados inviáveis na prática, mas vale lembrar que estão sendo consideradas 8 faltas simultâneas em um sistema com 30.880 barras. De qualquer forma, deve-se destacar que outras configurações encontradas pela metodologia EDMT, com um número menor de operações de chaveamento que violam as restrições operacionais, poderiam ser utilizadas considerando um procedimento de corte de cargas ou, simplesmente, aceitando essas violações (desde que não sejam significativas).

\subsection{Simulações para o problema de Redução de Per- das Ôhmicas}

Nesta seção serão apresentados os resultados obtidos pelas metodologias EDMT, AEMT-SP e AEMT para o problema de redução de perdas ôhmicas nos sistemas 1, 2, 3, e 4.

Para tanto, os parâmetros utilizados nas simulações pelas metodologias AEMT-SP, EDMT e AEMT foram:

1. AEMT-SP: $S_{p 1, \ldots, p 5}=5, G_{\max }=100.000, S_{f 1}=20, S_{f 2}=40, S_{f 3}=40$ e $S_{f s t r}=35$;

2. EDMT: $S_{p 1, \ldots, p 5}=5, G_{\max }=100.000, S_{f 1}=30, S_{f 2}=50, S_{f 3}=60, S_{f s t r}=35$, $F=0.6$ e $d i v=50.000$;

3. AEMT: $S_{p 1, \ldots, p 5}=5$ e $G_{\max }=100.000$;

Vale destacar que para o tratamento do problema de redução de perdas ôhmicas não serão considerados as tabelas de pares de manobras, nem mesmo a heurística proposta neste trabalho.

A Tabela 7.17 ilustra os valores das configurações iniciais dos sitemas 1, 2, 3 e 4, sem a aplicação da reconfiguração de redes para redução de perdas ôhmicas.

Tabela 7.17: Valores da topologia inicial dos Sistemas 1, 2, 3 e 4.

\begin{tabular}{lcccc}
\hline \hline & Sistema 1 & Sistema 2 & Sistema 3 & Sistema 4 \\
\hline Perdas Ohmicas [KW] & 281,27 & 562,69 & 1125,377 & 2250,75 \\
Queda de Tensão [\%] & 3,25 & 3,25 & 3,25 & 3,25 \\
Carregamento da Rede [\%] & 67,12 & 67,12 & 67,12 & 67,12 \\
Carregamento da Subestação [\%] & 55,34 & 55,34 & 53,34 & 55,34 \\
\hline \hline
\end{tabular}

A Tabela 7.18 apresenta os resultados obtidos através das metodologias EDMT, AEMT-SP e AEMT, aplicadas aos Sistemas 1, 2, 3 e 4. Os resultados apresentados 
referem-se à porcentagem (\%) de redução de perdas ôhmicas (valor máximo, mínimo, médio e desvio padrão). Os valores apresentados da Tabela 7.18 foram calculados a partir da tabela de perdas ôhmicas, com base nos resultados de 50 simulações realizadas com as três metodologias.

Tabela 7.18: Simulações para redução de perdas ôhmicas nos Sistemas 1, 2, 3 e 4.

\begin{tabular}{|c|c|c|c|c|}
\hline & \multicolumn{3}{|c|}{ " Redução de Perdas Ôhmicas [\%] } \\
\hline & & EDMT & AEMT-SP & AEMT \\
\hline \multirow{4}{*}{ Sistema 1} & Mínimo & 15,55 & 15,48 & 13,95 \\
\hline & Média & 16,39 & 16,47 & 16,12 \\
\hline & Máximo. & 16,86 & 16,94 & 16,92 \\
\hline & Desvio Padrão & 0,33 & 0,31 & 0,84 \\
\hline \multirow{4}{*}{ Sistema 2} & Mínimo & 14,20 & 14,41 & 14,21 \\
\hline & Média & 15,69 & 15,84 & 15,71 \\
\hline & Máximo & 16,69 & 16,76 & 16,69 \\
\hline & Desvio Padrão & 0,65 & 0,60 & 0,59 \\
\hline \multirow{4}{*}{ Sistema 3} & Mínimo & 19,56 & 20,27 & 13,16 \\
\hline & Média & 21,97 & 22,36 & 18,37 \\
\hline & Máximo & 23,99 & 24,34 & 22,50 \\
\hline & Desvio Padrão & 0,97 & 0,95 & 2,47 \\
\hline \multirow{4}{*}{ Sistema 4} & Mínimo & 20,84 & 20,33 & 17,65 \\
\hline & Média & 23,25 & 23,15 & 20,70 \\
\hline & Máximo & 25,77 & 25,65 & 24,15 \\
\hline & Desvio Padrão & 0,93 & 1,19 & 1,82 \\
\hline
\end{tabular}

Conforme pode ser observado na Tabela 7.18, para todos os sistemas testados as metodologias propostas EDMT e AEMT-SP obtiveram resultados melhores (com maior redução de perdas) que a metodologia AEMT. Analisando os resultados obtidos pelas metodologias EDMT e AEMT-SP, verifica-se que a AEMT-SP obteve resultados melhores para os Sistemas 1, 2 e 3. Entretanto, para o maior Sistema testado (Sistema 4), a EDMT obteve os melhores resultados.

As Tabelas 7.19, 7.20, 7.21 e 7.22 sintetizam os resultados de perdas ôhmicas e restrições operacionais obtidos pelas metodologias EDMT, AEMT-SP e AEMT. Como pode ser observado nas tabelas 7.21 e 7.22, a metodologia AEMT não consegue alcançar bons resultados, além de violar a restrição operacional de Carregamento da Rede (para os Sistemas 3 e 4), enquanto que as metodologias EDMT e AEMT-SP conseguiram uma maior redução de perdas de ôhmicas sem violar restrição operacional alguma.

Nas Figuras 7.10, 7.11, 7.12 e 7.13 são ilustradas as fronteiras de Pareto obtidas pelas metodologias EDMT, AEMT-SP e AEMT, aplicadas ao problema de redução de perdas ôhmicas para os Sistemas 1, 2, 3 e 4. De acordo com as figuras 7.10, 7.11, 7.12 e 7.13 não é possível definir claramente, através de uma inspeção visual qual das metodologias obteve uma melhor convergência e melhor distribuição das soluções na fronteira, em especial, 
Tabela 7.19: Resultados das simulações para o Sistema 1.

\begin{tabular}{lcccccc}
\hline \hline & \multicolumn{2}{c}{ EDMT } & \multicolumn{2}{c}{ AEMT-SP } & \multicolumn{2}{c}{ AEMT } \\
& Média & DP* & Média & DP* & Média & DP* \\
\hline Perdas Ôhmicas [KW] & 235,14 & 0,93 & 234,91 & 0,88 & 235,92 & 2,35 \\
Queda de Tensão [\%] & 3,17 & 0,002 & 3,17 & 0,001 & 3,17 & 0,001 \\
Carregamento da Rede [\%] & 60,27 & 2,24 & 60,12 & 1,43 & 60,16 & 1,97 \\
Carregamento da Subestação [\%] & 56,32 & 0,32 & 56,42 & 0,36 & 56,16 & 0,59 \\
Tempo de Processamento (s) & 19,11 & 1,56 & 33,33 & 3,02 & 30,10 & 3,51 \\
\hline \hline
\end{tabular}

*Desvio Padrão

Tabela 7.20: Resultados das simulações para o Sistema 2.

\begin{tabular}{lcccccc}
\hline \hline & \multicolumn{2}{c}{ EDMT } & \multicolumn{2}{c}{ AEMT-SP } & \multicolumn{2}{c}{ AEMT } \\
& Média & DP* & Média & DP* & Média & DP* \\
\hline Perdas Ôhmicas [KW] & 474,44 & 3,66 & 473,50 & 3,39 & 474,27 & 3,44 \\
Queda de Tensão [\%] & 3,17 & 0,001 & 3,17 & 0,001 & 3,17 & 0,001 \\
Carregamento da Rede [\%] & 60,73 & 1,89 & 60,95 & 2,14 & 60,76 & 2,13 \\
Carregamento da Subestação [\%] & 56,48 & 0,57 & 56,50 & 0,53 & 56,56 & 0,54 \\
Tempo de Processamento (s) & 25,19 & 1,83 & 29,63 & 2,26 & 34,28 & 3,75 \\
\hline \hline
\end{tabular}

*Desvio Padrão

Tabela 7.21: Resultados das simulações para o Sistema 3.

\begin{tabular}{lcccccc}
\hline \hline & \multicolumn{2}{c}{ EDMT } & \multicolumn{2}{c}{ AEMT-SP } & \multicolumn{2}{c}{ AEMT } \\
& Média & DP* & Média & DP* & Média & DP* \\
\hline Perdas Ôhmicas [KW] & 878,07 & 10,95 & 873,70 & 10,80 & 918,58 & 27,53 \\
Queda de Tensão [\%] & 4,60 & 1,96 & 3,73 & 1,18 & 9,15 & 4,40 \\
Carregamento da Rede [\%] & 91,19 & 12,76 & 91,76 & 12,87 & $\mathbf{1 8 8 , 2 7}$ & 37,73 \\
Carregamento da Subestação [\%] & 76,31 & 11,40 & 49,56 & 1,29 & 97,61 & 22,63 \\
Tempo de Processamento (s) & 28,92 & 2,29 & 29,62 & 0,97 & 34,01 & 3,79 \\
\hline \hline
\end{tabular}

*Desvio Padrão

Tabela 7.22: Resultados das simulações para o Sistema 4.

\begin{tabular}{lcccccc}
\hline \hline & \multicolumn{2}{c}{ EDMT } & \multicolumn{2}{c}{ AEMT-SP } & \multicolumn{2}{c}{ AEMT } \\
& Média & DP* & Média & DP* & Média & DP* \\
\hline Perdas Ôhmicas [KW] & 1728,41 & 20,11 & 1729,35 & 27,12 & 1784,80 & 40,81 \\
Queda de Tensão [\%] & 3,60 & 0,86 & 3,79 & 0,82 & 4,56 & 1,37 \\
Carregamento da Rede [\%] & 96,44 & 5,49 & 98,49 & 1,79 & $\mathbf{1 7 6 , 9 0}$ & 37,90 \\
Carregamento da Subestação [\%] & 87,41 & 9,92 & 86,10 & 8,64 & $\mathbf{1 0 2 , 0 2}$ & 14,98 \\
Tempo de Processamento (s) & 30,18 & 1,23 & 35,25 & 0,77 & 27,41 & 1,47 \\
\hline \hline
\end{tabular}

*Desvio Padrão 
comparando-se os pontos plotados entre as metodologias EDMT e AEMT-SP. Para tanto, foi necessário a aplicação da métrica de desempenho de hipervolume. Na tabela 7.23 é possível verificar os valores de hipervolume obtidos para as Figuras 7.10, 7.11, 7.12 e 7.13. Na mesma tabela é apresentado o valor do ponto de referência $W$ utilizado para cada uma das metodologias. Com base nos resultados do hipervolume, é possível verificar novamente um melhor desempenho da metodologia EDMT, em relação às demais metodologias, em que o valor de hipervolume encontrado foi superior para os Sistemas 1, 2, 3 e 4, indicando uma melhor convergência e melhor distribuição das soluções na fronteira.

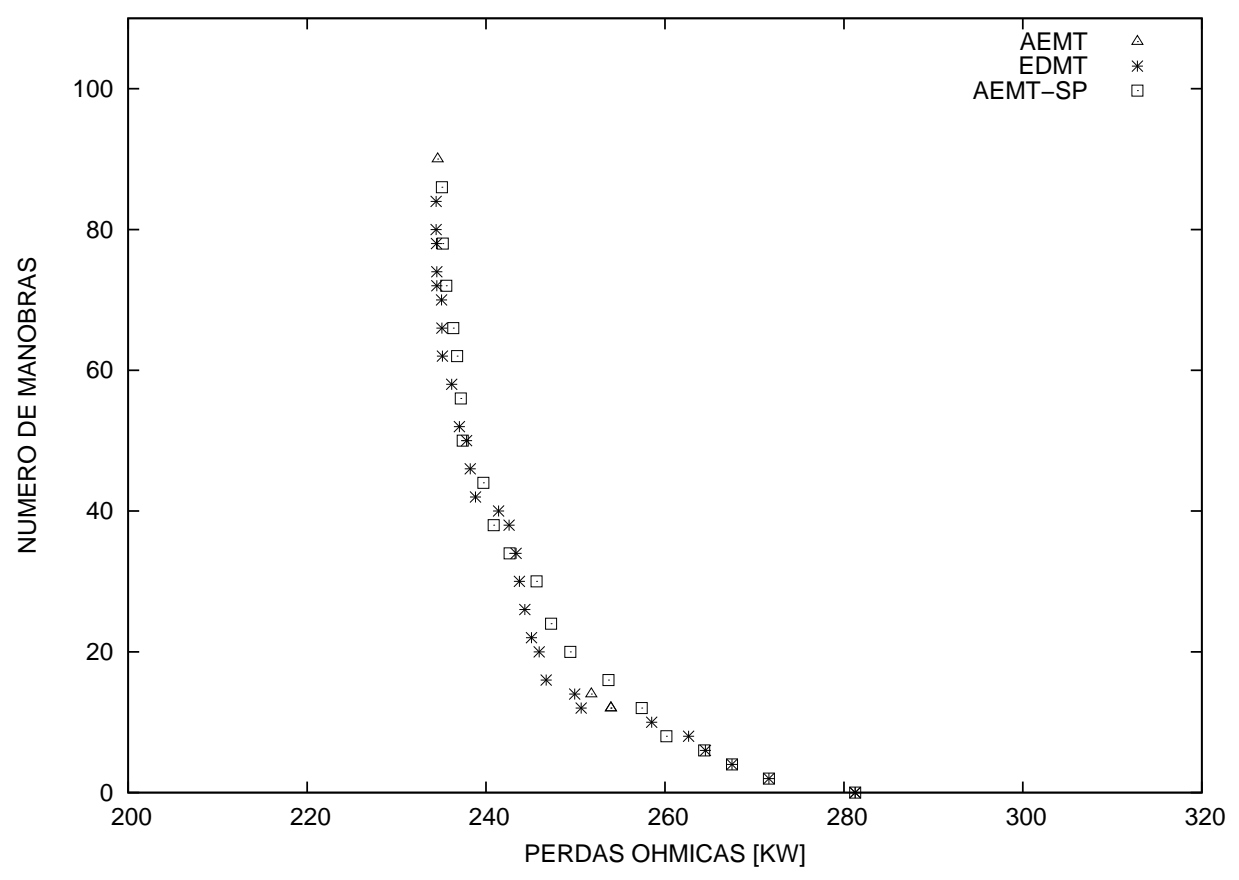

Figura 7.10: Fronteiras de Pareto obtidas para o sistema 1.

Tabela 7.23: Valores obtidos de hipervolume.

\begin{tabular}{l|c|ccc}
\hline \hline \multicolumn{2}{c}{} & \multicolumn{3}{c}{ Metodologias } \\
\cline { 3 - 5 } \multicolumn{2}{c}{} & EDMT & AEMT-SP & AEMT \\
\hline \multirow{2}{*}{ Sistema 1 } & Hipervolume & 11923,91 & 11779,02 & 9966,04 \\
& $W$ & $350 / 110$ & $350 / 110$ & $350 / 110$ \\
\hline \multirow{2}{*}{ Sistema 2 } & Hipervolume & 21097,43 & 19996,05 & 18110,25 \\
& $W$ & $600 / 200$ & $600 / 200$ & $600 / 200$ \\
\hline \multirow{2}{*}{ Sistema 3 } & Hipervolume & 86058,49 & 82711,04 & 76529,27 \\
& $W$ & $1150 / 450$ & $1150 / 450$ & $1150 / 450$ \\
\hline \multirow{2}{*}{ Sistema 4 } & Hipervolume & 304408,41 & 277211,93 & 233326,03 \\
& $W$ & $2300 / 850$ & $2300 / 850$ & $2300 / 850$ \\
\hline \hline
\end{tabular}




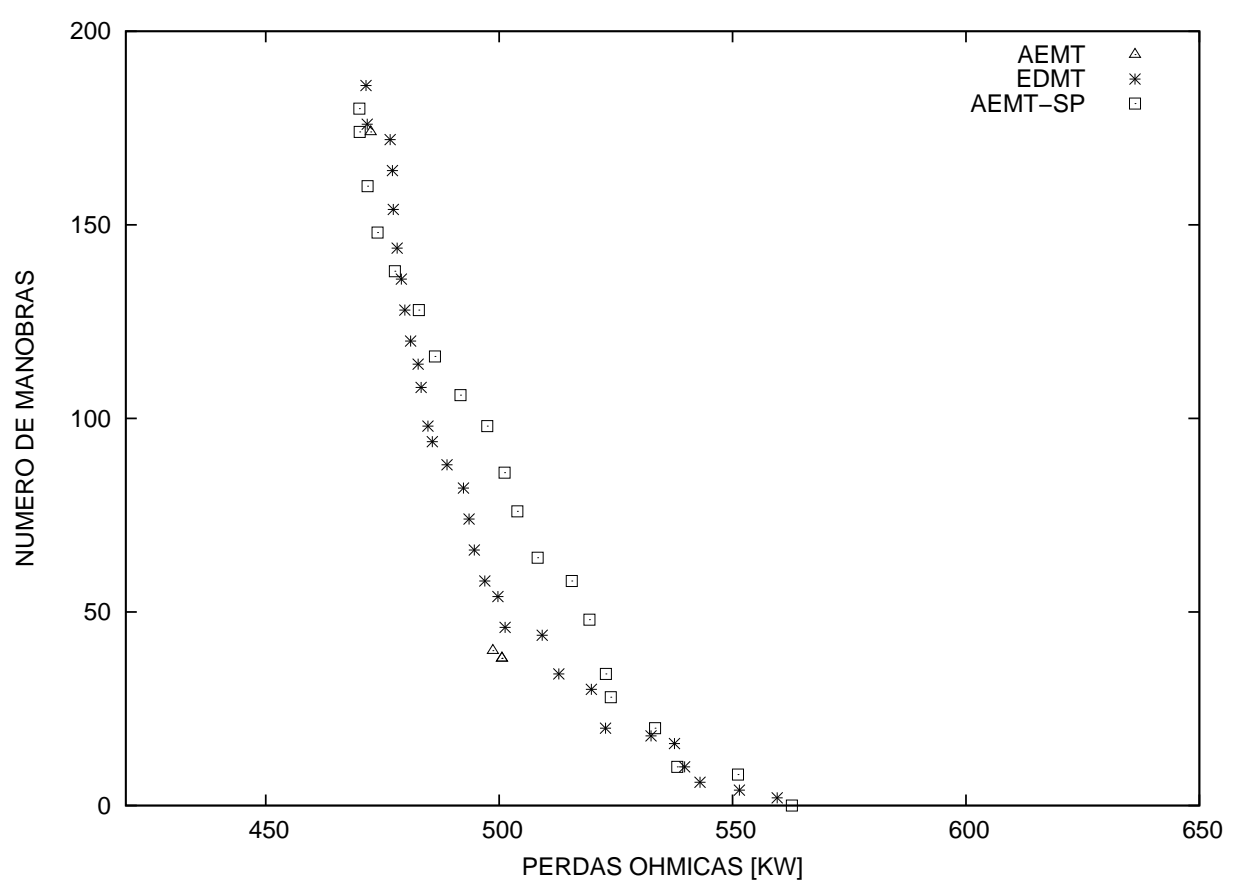

Figura 7.11: Fronteiras de Pareto obtidas para o sistema 2.

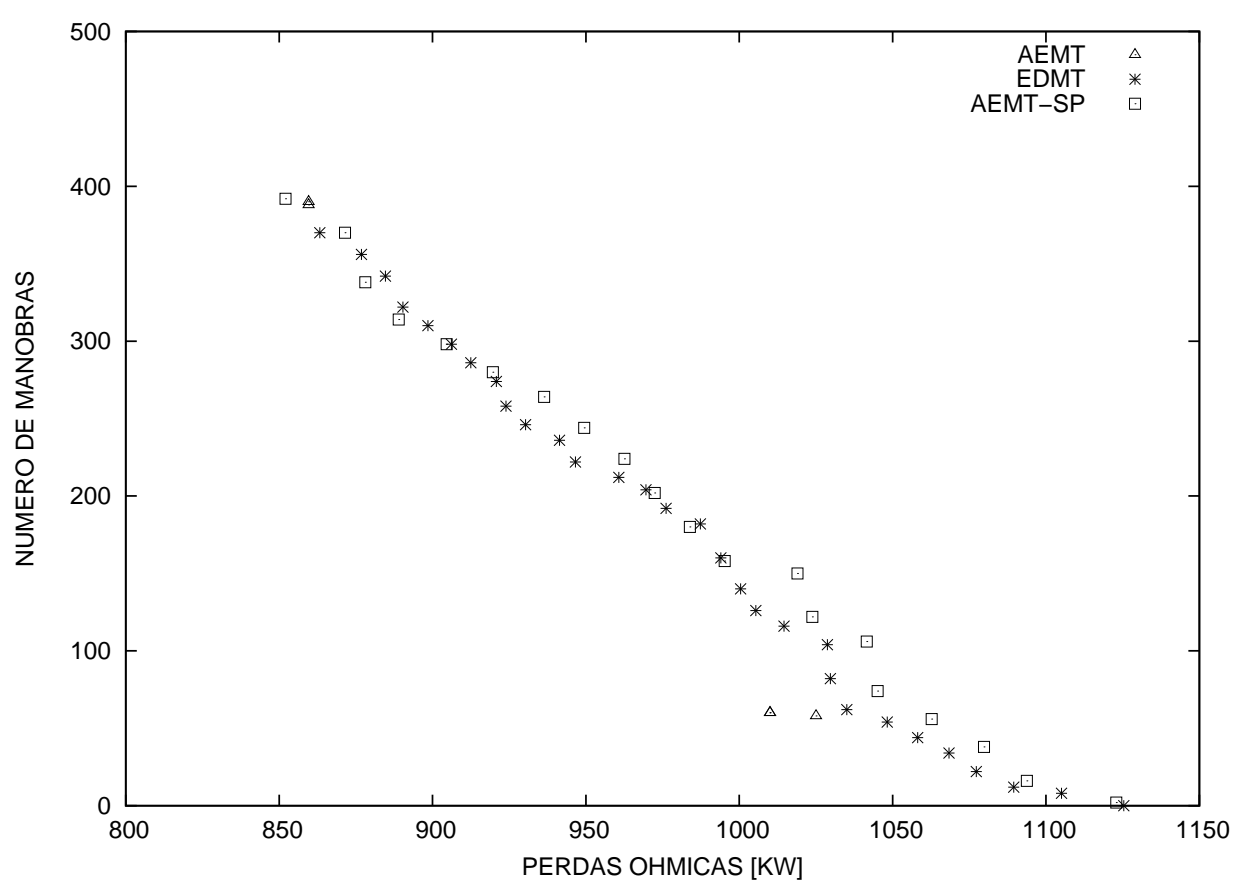

Figura 7.12: Fronteiras de Pareto obtidas para o sistema 3. 


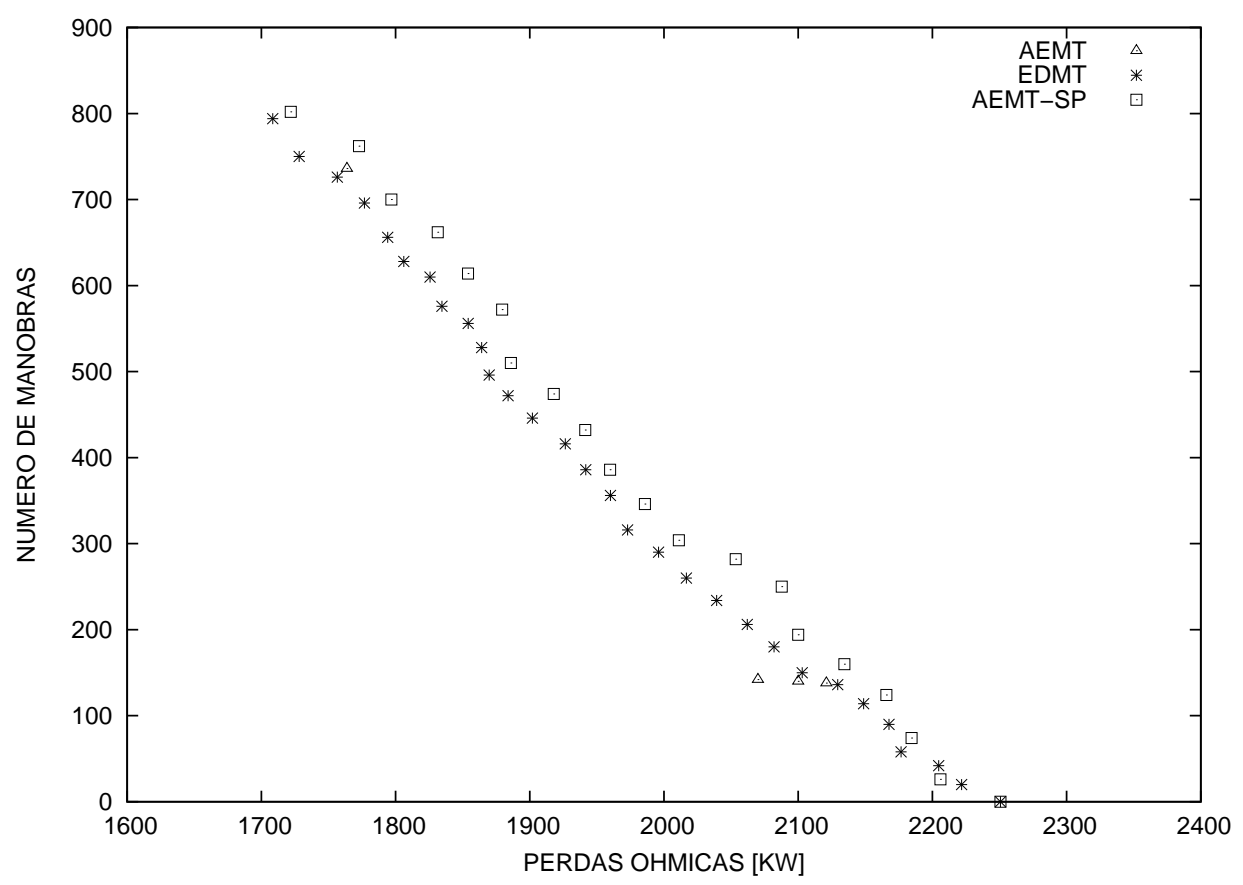

Figura 7.13: Fronteiras de Pareto obtidas para o sistema 4.

\subsection{Conclusões}

De uma forma geral, considerando todas as simulações apresentadas neste capítulo, pode-se concluir que as metodologias propostas, EDMT e AEMT-SP, são mais eficientes que a metodologia AEMT. Vale ressaltar que através das metodologias propostas foi possível obter soluções factíveis para sistemas de grande porte, mais especificamente, para sistemas com até 30.880 barras.

Para o problema de restabelecimento de energia para uma única falta e faltas múltiplas, foi proposto a inclusão de novas tabelas de subpopulação de pares de manobras e aplicação de uma heurística que prioriza as manobras entre os alimentadores com maior queda de tensão e maior carregamento da rede. Com isso, tornou-se possível restringir o espaço de busca, facilitando a obtenção de soluções factíveis com um menor número de manobras. Importa destacar que para o problema de restabelecimento de energia, a EDMT se mostrou mais eficiente que a AEMT-SP, principalmente para o caso mais complicado de múltiplas faltas.

Para o problema de redução de perdas ôhmicas, as metodologias propostas conseguiram uma redução significativa de perdas ôhmicas em relação às perdas iniciais dos Sistemas testados. Para os Sistemas 1,2 e 3, a metodologia AEMT-SP obteve uma maior redução de perdas quando comparado com a metodologia EDMT. Entretanto, para o Sistema 4, a metodologia EDMT foi superior em relação a metodologia AEMT-SP, alcançando uma maior redução de perdas ôhmicas. 



\section{Capítulo 8}

\section{Conclusões e Trabalhos Futuros}

\subsection{Conclusões}

Este Capítulo sintetiza os principais resultados obtidos e apresenta algumas considerações sobre perspectivas de pesquisas futuras relativas a este trabalho. Tomando por base as metodologias NSNP (MANSOUR et al., 2009) e AEMT (SANTOS et al., 2010), diversos estudos foram realizados e diversas combinações de AEMO foram analisadas, na tentativa de obtenção de metodologias eficientes para tratamento dos problemas de reconfiguração de redes redução de perdas ôhmicas e restabelecimento de energia após a ocorrência de uma e múltiplas faltas permanentes.

Esses estudos deram origem a diversos resultados parciais, isto é, diversas metodologias que já se mostravam mais eficientes que as metodologias NSNP e AEMT, mas que poderiam ser ainda melhoradas. Essas metodologias são apresentadas em artigos publicados em anais de congressos nacionais e internacionais, citados no capítulo 9, e deram origem às metodologias AEMT-SP e EDMT que foram apresentadas no capítulo 6.

Importa destacar que este trabalho utilizou como base as metodologias NSNP e AEMT, em razão de essas metodologias possibilitarem o tratamento dos problemas de redução de perdas ôhmicas e restabelecimento de energia em SDRs de grande porte (com milhares de barras, linhas e chaves), sem a exigência de simplificação alguma, seja na modelagem do problema seja na quantidade de equipamentos da rede elétrica a serem considerados. Entretanto, o desempenho dessas metodologias não é o mesmo quando a dimensão do sistema aumenta ou quando considera-se, no caso do problema de restabelecimento de energia, um número maior de faltas simultâneas. Eis a razão da proposição deste trabalho, o desenvolvimento de metodologias que permitem o tratamento dos problemas de perdas ôhmicas e restabelecimento de energia, em SDRs de grande porte sem a exigência de simplificação alguma, e que mantenha o desempenho independentemente do tamanho do sistema e do número de faltas simultâneas.

Sistemas de Distribuição do mundo real possuem grande quantidade de barras e chaves. 
Assim, técnicas que consigam lidar com modelagens complexas envolvendo a maior quantidade possível de componentes de um SDR podem ser interessantes para obtenção de planos de restabelecimento de melhor qualidade.

O uso da estrutura de dados RNP é base de desenvolvimento das metodologias propostas, uma vez que essa codificação e seus operadores geram exclusivamente configurações factíveis e possibilitam uma avaliação maia rápida das configurações geradas. Com isso, evitam-se rotinas para identificar e corrigir infactibilidades das configurações, que aumentam consideravelmente o tempo de processamento e estão presentes em várias abordagens encontradas na literatura.

As duas metodologias propostas, AEMT-SP e EDMT, foram avaliadas utilizando o SDR da cidade de São Carlos (SDR-SC), em operação em 1994, com 3.860 barras e 632 chaves (509 chaves NF e 123 chaves NA) Além disso, foram realizadas simulações utilizando outros três sistemas construídos a partir do SDR-SC. Esses sistemas possuem dimensões (número de barras e chaves) que são duas, quatro e oito vezes a dimensão do SDR-SC. Com isso, as metodologias AEMT-SP e EDMT foram avaliadas inclusive para uma rede com 30.880 barras, 4.264 setores, 5.166 chaves (4.072 chaves NF e 1.094 chaves NA), 24 subestações e 184 alimentadores.

Considerando que o SDR real alimentava uma cidade de quase 200.000 habitantes, a maior rede sintetizada corresponderia a uma SDR para uma cidade de cerca de 1,5 milhões de habitantes. Quanto maior o tamanho da rede, maior o número de configurações possíveis. Em consequência, aumenta-se à possibilidade de existir um número maior de soluções que atendam as restrições do problema. Por outro lado, obter resultados adequados para esse tipo de problema é difícil, pois o número de soluções infactíveis também aumenta com o tamanho da rede. Outros aspectos como funções não-lineares, descontínuas, com vários ótimos locais e envolvendo múltiplos objetivos conflitantes tornam o problema ainda mais complexo.

Os resultados obtidos nas simulações com o AEMT-SP e EDMT, para os sistemas 1, 2, 3 e 4, mostram que tais metodologias são capazes de vencer tais dificuldades e explorar adequadamente o espaço das soluções factíveis, encontrando configurações de alta qualidade em curto intervalo de tempo. Importa mencionar o bom desempenho das duas metodologias propostas no tratamento dos problemas de redução de perdas ôhmicas e restabelecimento de energia em sistemas com mais de 30.000 barras, em que a qualidade das soluções foram sempre melhores que os resultados obtidos pela metodologia AEMT, indicando um melhor mapeamento dos problemas tratados com um baixo tempo de processamento.

As principais contribuições deste trabalho podem ser sintetizadas como segue:

1. Integração das principais caracteristicas dos métodos NSGA-II e SPEA2 no método AEMT. Com isso, foi possível melhorar as características multiobjetivo do AEMT, além de ober melhores resultados; 
2. Desenvolvimento de uma heurística que prioriza as manobras entre os alimentadores com maior queda de tensão e maior carregamento da rede para o problema de restabelecimento de energia. O objetivo é restringir o espaço de busca para obtenção de soluções com um menor número de manobras e que não violem os limites operacionais;

3. Estudo do problema de restabelecimento de energia para múltiplas faltas em um SDR com mais de 30 mil barras;

4. Adaptação do operador EHR (LIMA, 2009) para utilizar não somente as aplicações PAO, mas também as aplicações CAO;

5. Desenvolvimento de um operador baseado no operador de mutação do algoritmo de evolução diferencial. Para esse desenvolvimento, utilizou-se o operador EHR e o conceito de lista de movimentos;

6. Desenvolvimento de um algoritmo de evolução diferencial multi-objetivo baseado na RNP.

\subsection{Perspectivas Futuras}

Por fim, listam-se a seguir algumas perspectivas de trabalhos futuros:

1. Considerar aspectos práticos para o tratamento do problema de restabecimento de energia, sendo eles: a sequência dos chaveamentos, consumidores prioritários, priorização de chaves automáticas, presença de geração distribuída e vários níveis de carregamento da rede;

2. Trabalhar com um conjunto de funções agregação nas tabelas de subpopulações das metodologias propostas, aumentando assim o número de subpopulações e a diversidade de soluções na fronteira de Pareto;

3. Análise de outras abordagens evolutivas, como os algoritmos evolutivos de segunda geração, em especial, o algoritmo de estimação de distribuição.

4. Adaptar as metodologias propostas para trabalhar com a RNPG (Representação NóProfundidade Grau) (DELBEM; DE LIMA; TELLES, 2012), que estende a RNP e possui garantia teórica de complexidade de tempo sublinear. 



\section{Capítulo 9}

\section{Publicações Originadas desta Pesquisa}

\subsection{Artigos Submetidos}

1. Sanches, D. S. ; London, J.B. A.; Delbem A.C.B. Multi-objective Evolutionary Algorithm for Single and Multiple Fault Service Restoration in Large-scale Distribution Systems. In: IEEE Transactions on Power Systems.

2. Sanches, D. S. ; Gois, M. M., Delbem A.C.B. ; London, J.B. A.Multi-objective Evolutionary Algorithm with non-dominated solutions and Strength Pareto subpopulation tables for Service Restoration in Distribution Systems. In: IEEE Power Engineering Society General Meeting, 2013.

\subsection{Artigos Aceitos para Publicação}

1. Sanches, D. S. ; Delbem A.C.B. ; London, J.B. A. Combining Subpopulation Tables, Non-dominated Solutions and Strength Pareto of MOEAs to treat Service Restoration Problem in Large-Scale Distribution Systems. In: IEEE Grenoble PowerTech 2013.

2. Gois M.M.; Sanches, D. S.; Martins J.; London, J.B. A. ; Delbem A.C.B. Multiobjective Evolutionary Algorithm with Node-Depth Encoding and Strength Pareto for Service Restoration in Large-scale Distribution Systems. In: 7th International Conference on Evolutionary Multi-Criterion Optimization. EMO 2013. 


\subsection{Artigos Publicados}

1. Sanches, D. S. ; Marques, L. T. ; Borges, H. ; A.C.B. Delbem ; London , J.B. A. Análise Comparativa entre algoritmos evolutivos multi-objetivos aplicados ao problema de redução de perdas em sistemas de distribuição de grande porte. In: XIX Congresso Brasileiro de Automática, 2012, Campina Grande. Anais, 2012.

2. Sanches, D. S. ; Marquez, R. C. ; Silva, M. ; Delbem A.C.B. ; London, J.B. A. Integrando relevantes aspectos de algoritmos evolutivos multi-objetivos para tratamento do problema de restabelecimento de energia em sistemas de distribuição de grande porte. In: XIX Congresso Brasileiro de Automática, 2012, Campina Grande. Anais, 2012.

3. Sanches, D. S. ; Santos, A. C. ; Lima, T. W. ; Delbem A.C.B. ; London , J.B. A. Node-Depth Encoding with Recombination for Multi-Objective Evolutionary Algorithm to Solve Loss Reduction Problem in Large-scale Distribution Systems. In: IEEE Power Engineering Society General Meeting, 2012, San Diego. Anais, 2012.

4. Sanches, D. S. ; London , J.B. A. ; Delbem A.C.B. ; Santos, A. C. Integrating Relevant Aspects of MOEAs Applied to Service Restoration in Distribution Systems. In: IEEE Power Engineering Society General Meeting, 2012, San Diego. Anais., 2012 .

5. Sanches, D. S. ; Mansour, M. R. ; London , J.B. A. ; Delbem A.C.B. ; Santos, A. C. . Integrating Relevant Aspects of MOEAs to Solve Loss Reduction Problem in Large-scale Distribution Systems. In: IEEE Trondheim PowerTech 2011, 2011. Anais, 2011.

6. Fantin, C. A. ; Sanches, D. S. ; London Jr., J.B. A. ; Delbem A.C.B. ; Santos, A. C. . Reconfiguração de Redes Para Melhoria do Perfil de Tensão e Redução de Perdas em Sistemas de Distribuição de Grande Porte. In: IX Conferência Brasileira sobre Qualidade da Energias Elétrica, 2011, Cuiabá. Anais, 2011.

7. Fantin, C. A. ; Sanches, D. S.; Marquez, R. A. C.; Santos, A. C. ; Delbem, A. C. B. ; London, Jr., J. B. A. . Metodologia para Redução de Perdas de Energia Elétrica e Melhoria do Perfil de tensão em Sistemas de Distribuição de Energia. In: 9th Latin-American Congress: Electricity Generation and Transmission, 2011, Mar del Plata. Anais, 2011 


\section{Referências Bibliográficas}

AHUJA R., M. T.; ORLIN, J. Network Flows: theory, algorithms and applications. [S.l.]: Prentice Hall, Englewood Cliffs, 1993.

AOKI, K.; NARA, K.; ITOH, M.; SATOH, T.; KUWABARA, H. A new algorithm for service restoration in distribution systems. Power Delivery, IEEE Transactions on, [S.l.], v.4, n.3, p.1832-1839, Jul 1989.

AOKI, K.; NARA, K.; SATOH, T.; KITAGAWA, M.; YAMANAKA, K. New approximate optimization method for distribution system planning. Power Systems, IEEE Transactions on, [S.l.], v.5, n.1, p.126 -132, feb 1990.

AUGUGLIARO, A.; DUSONCHET, L.; SANSEVERINO, E. R. Multiobjective service restoration in distribution networks using an evolutionary approach and fuzzy sets. International Journal of Electrical Power \& Energy Systems, [S.l.], v.22, p.103$110,2000$.

BARAN, M.; WU, F. Network reconfiguration in distribution systems for loss reduction and load balancing. Power Delivery, IEEE Transactions on, [S.l.], v.4, n.2, p.1401 -1407, apr 1989.

BARAN, M.; WU, F. Optimal sizing of capacitors placed on a radial distribution system. Power Delivery, IEEE Transactions on, [S.1.], v.4, n.1, p.735-743, Jan 1989.

BRANDINI, A. C. Análise crítica de algoritmos de fluxo de carga usados em sistemas de distribuição radial. 2000. Dissertação de Mestrado - FEIS-UNESP.

BUENO, E. A. Redução de Perdas Técnicas através de Reconfigurações de Redes de Distribuição de Energia Elétrica sob Demandas Variáveis. 2005. Tese de Doutorado - FEEC/UNICAMP.

CARvalho, M. R. Estudo Comparativo de Fluxo de Poténcia para Sistemas de Distribuição Radial. 2006. Dissertação de Mestrado - EESC-USP.

CESPEDES, R. New method for the analysis of distribution networks. Power Delivery, IEEE Transactions on, [S.1.], v.5, n.1, p.391-396, Jan 1990. 
CHEN, C.; LIN, C.; WU, C.; KANG, M. Feeder reconfiguration for distribution system contingencies by object oriented programming. Power Engineering Society Summer Meeting, 2000. IEEE, [S.l.], v.1, p.431-436 vol. 1, 2000.

CHENG, S.-L.; HWANG, C. Optimal approximation of linear systems by a differential evolution algorithm. Systems, Man and Cybernetics, Part A: Systems and Humans, IEEE Transactions on, [S.1.], v.31, n.6, p.698 -707, nov 2001.

CHUANG, C.-Y.; HSU, W.-L. Multivariate multi-model approach for globally multimodal problems. In: GENETIC AND EVOLUTIONARY COMPUTATION, 12., 2010, New York, NY, USA. Proceedings... ACM, 2010. p.311-318. (GECCO '10).

CIVANLAR, S.; GRAINGER, J.; YIN, H.; LEE, S. Distribution feeder reconfiguration for loss reduction. Power Delivery, IEEE Transactions on, [S.l.], v.3, n.3, p.1217 -1223 , jul 1988.

COELLO, C. A. C. A Comprehensive Survey of Evolutionary-Based Multiobjective Optimization Techniques. Knowledge and Information Systems, [S.l.], v.1, p.269-308, 1998.

COLAB. Código Fonte. Disponível Online: http://lcr.icmc.usp.br/colab /browser/projetos/mean. [S.l.: s.n.], 2012.

CORMEN, T. H. Algoritmos: teoria e prática. [S.l.]: Campus, 2002.

COSTA, M. F. N. da. Computação Evolutiva para Minimização de Perdas Resistivas em Sistemas de Distribuição de Energia Elétrica. 1999. Tese de Doutorado - FEEC/UNICAMP.

DAS, D.; NAGI, H. S.; KOTHARI, D. P. Novel Method for Solving Radial Distribution Networks. Generation, Transmission and Distribution, IEE Proceedings-, [S.l.], v.141, n.4, p.291-298, Jul 1994.

DEB, K. Multi-objective optimization using evolutionary altorithms. New York: Wiley, 2001.

DEB, K.; PRATAP, A.; AGARWAL, S.; MEYARIVAN, T. A fast and elitist multiobjective genetic algorithm: nsga-ii. Evolutionary Computation, IEEE Transactions on, [S.l.], v.6, n.2, p.182 -197, apr 2002.

DEB, K.; SUNDAR, J. Reference point based multi-objective optimization using evolutionary algorithms. In: GECCO '06: PROCEEDINGS OF THE 8TH ANNUAL CONFERENCE ON GENETIC AND EVOLUTIONARY COMPUTATION, 2006, New York, NY, USA. Anais... ACM, 2006. p.635-642. 
Delbem, A. C. B.; CARvalho, A. C. P. L. F. de; POliCAStro, C. A.; Pinto, A. K. O.; HONDA, K.; GARCIA, A. C. Node-Depth Encoding for Evolutionary Algorithms Applied to Network Design. In: ACM, 2004. Anais... [S.l.: s.n.], 2004. p.678687.

DELBEM, A. C. B.; DE LIMA, T.; TELlES, G. P. Efficient Forest Data Structure for Evolutionary Algorithms Applied to Network Design. Evolutionary Computation, IEEE Transactions on, [S.l.], v.PP, n.99, p.1, 2012.

DELBEM, A.; CARVALHO, A. de; BRETAS, N. Main chain representation for evolutionary algorithms applied to distribution system reconfiguration. Power Systems, IEEE Transactions on, [S.l.], v.20, n.1, p.425-436, Feb. 2005.

DIMITRIJEVIC, S.; RAJAKOVIC, N. An innovative approach for solving the restoration problem in distribution networks. Electric Power Systems Research, [S.l.], v.81, n.10, p.1961 - 1972, 2011.

FERREIRA, F. A. L. Metodologia para Reconfiguração de Redes de Distribuição Trifásicas Assimétricas e Não Balanceadas com Geração Distribuída. 2010. Dissertação de Mestrado - PUCRS.

FUKUYAMA, Y.; CHIANG, H.-D.; MIU, K. Parallel genetic algorithm for service restoration in electric power distribution systems. International Journal of Electrical Power \&amp; Energy Systems, [S.1.], v.18, n.2, p.111-119, 1996.

GARCIA, V. J. Metaheurísticas multiobjetivo para o problema de restauração do serviço em redes de distribuição de energia elétrica. 2005. Tese de Doutorado - FEEC/UNICAMP.

GARCIA, V. J.; FRANCA, P. M. Multiobjective service restoration in electric distribution networks using a local search based heuristic. European Journal of Operational Research, [S.l.], v.189, n.3, p.694-705, 2008.

GOLDBERG, D. E. Genetic Algorithms in Search, Optimization and Machine Learning. Boston, MA, USA: Addison-Wesley Longman Publishing Co., Inc., 1989.

GOMES, F.; CARNEIRO S., J.; PEREIRA, J.; VINAGRE, M.; GARCIA, P.; OLIVEIRA, E.; ARAUJO, L. A new distribution system reconfiguration approach using optimal power flow technique and sensitivity analysis for loss reduction. Power Engineering Society General Meeting, 2005. IEEE, [S.l.], p.897-901 Vol. 1, June 2005.

GRADSHTEYN, I. S.; RYZHIK, I. M. Tables os Integrals, Series, and Products. San Diego: Academic Press, 2000. 
HAQUE, M. Efficient load flow method for distribution systems with radial or mesh configuration. Generation, Transmission and Distribution, IEE Proceedings-, [S.l.], v.143, n.1, p.33 -38, jan 1996.

HONG, Y.-Y.; HO, S.-Y. Determination of network configuration considering multiobjective in distribution systems using genetic algorithms. Power Systems, IEEE Transactions on, [S.l.], v.20, n.2, p.1062 - 1069, may 2005.

HSIAO, Y.-T. Multiobjective evolution programming method for feeder reconfiguration. Power Systems, IEEE Transactions on, [S.l.], v.19, n.1, p.594 - 599, feb. 2004.

INAGAKI, J.; NAKAJIMA, J.; HASEYAMA, M. A multiobjective service restoration method for power distribution systems. Circuits and Systems, 2006. ISCAS 2006. Proceedings. 2006 IEEE International Symposium on, [S.1.], p.4 pp.-, May 2006.

INGBER, L. Simulated annealing: practice versus theory. Mathl. Comput. Modelling, [S.l.], v.18, p.29-57, 1993.

JENSEN, M. Reducing the run-time complexity of multiobjective EAs: the nsga-ii and other algorithms. Evolutionary Computation, IEEE Transactions on, [S.l.], v.7, n.5, p.503-515, Oct. 2003.

J.Z.; ZHU. Optimal reconfiguration of electrical distribution network using the refined genetic algorithm. Electric Power Systems Research, [S.l.], v.62, n.1, p.37-42, 2002.

KAGAN, N. Configuração de Redes de Distribuição através de Algoritmos Genéticos e Tomada de Decisão Fuzzy. 1999.

KAGAN, N.; OLIVEIRA, C. C. B. de; ROBBA, E. J. Introdução aos Sistemas de Distribuição de Energia Elétrica. São Paulo: Edgard Blucher, 2005.

KASHEM, M.; GANAPATHY, V.; JASMON, G. A geometrical approach for network reconfiguration based loss minimization in distribution systems. International Journal of Electrical Power and Energy Systems, [S.1.], v.23, n.4, p.295 - 304, 2001.

KLEINBERG, M.; MIU, K.; CHIANG, H.-D. Service restoration of power distribution systems incorporating load curtailment. In: CIRCUITS AND SYSTEMS, 2009. ISCAS 2009. IEEE INTERNATIONAL SYMPOSIUM ON, 2009. Anais... [S.l.: s.n.], 2009. p.1709-1712.

KUMAR, Y.; DAS, B.; SHARMA, J. Multiobjective, Multiconstraint Service Restoration of Electric Power Distribution System With Priority Customers. Power Delivery, IEEE Transactions on, [S.1.], v.23, n.1, p.261-270, Jan. 2008. 
LIMA, T. W. de. Estruturas de Dados Eficientes para Algoritmos Evolutivos Aplicados a Projeto de Redes. 2009. Tese de Doutorado - ICMC/USP.

MANSOUR, M.; SANTOS, A.; LONDON, J.; DELBEM, A.; BRETAS, N. Energy restoration in distribution systems using multi-objective evolutionary algorithm and an efficient data structure. In: POWERTECH, 2009 IEEE BUCHAREST, 2009. Anais. . . [S.l.: s.n.], 2009. p.1 -7 .

MANTOVAnI, J.; CASARI, F.; ROMERO, R. Reconfiguração de Sistemas de Distribuição Radiais Utilizando o Critério de Queda de Tensão. SBA Controle e Automação, [S.1.], v.11, p.150-159, may 2000.

MERLIN, A.; BACK, H. Search for a minimal-loss operating spanning tree configuration in an urban power distribution system. Proc. 5th Power System Computation Conference, [S.l.], p.1-18, 1975.

MONTICELLI, A.; GARCIA, A.; SAAVEDRA, O. Fast decoupled load flow: hypothesis, derivations, and testing. Power Systems, IEEE Transactions on, [S.l.], v.5, n.4, p.1425-1431, Nov 1990.

MONTICELli, A. J. Fluxo de Carga em Redes de Energia Elétrica. São Paulo: Edgard Blucher, 1983.

MORELATO, A.; MONTICELLI, A. Heuristic search approach to distribution system restoration. Power Delivery, IEEE Transactions on, [S.l.], v.4, n.4, p.2235 -2241, oct 1989 .

MüHLENBEIN, H.; SCHLIERKAMP-VOOSEN, D. Predictive Models for the Breeder Genetic Algorithm - I. Continuous Parameter Optimization. EVOLUTIONARY COMPUTATION, [S.l.], v.1, p.25-49, 1993.

NARA, K.; SHIOSE, A.; KITAGAWA, M.; ISHIHARA, T. Implementation of genetic algorithm for distribution systems loss minimum re-configuration. Power Systems, IEEE Transactions on, [S.1.], v.7, n.3, p.1044 -1051, aug 1992.

PEREIRA, B. R. Alocação Otimizada de Bancos de Capacitores em Sistemas de Distribuição de Energia Elétrica Através de Metaheurísticas Multiobjetivo. 2009. Dissertação de Mestrado - FEIS-UNESP.

PRADO, R. S.; SILVA, R. C. P.; GUIMARÃES, F. G.; NETO, O. M. Uma Nova Abordagem para a Evolução Diferencial em Otimização Discreta. In: CONGRESSO BRASILEIRO DE AUTOMÁTICA, 2010. CBA 2010, 2010. Anais. . . [S.l.: s.n.], 2010. p. $830-836$. 
PRADO, R. S.; SILVA, R. C. P.; GUIMARÃES, F. G.; NETO, O. M. A New Differential Evolution Based Metaheuristic for Discrete Optimization. International Journal of Natural Computing Research, [S.l.], v.1, n.2, p.15-32, 2010.

PRESS, W. H.; TEUKOLSKY, S. A.; VeTterlinG, W. T.; FLANNERY, B. P. Numerical recipes in $\mathbf{C}$ (2nd ed.): the art of scientific computing. New York, NY, USA: Cambridge University Press, 1992.

QUEIROZ, L. M. O. de. Estimação e Análise das Perdas Técnicas na Distribuição de Energia Elétrica. 2010. Tese de Doutorado - FEEC/UNICAMP.

R. BENAYOUN J. DE MONTGOLFIER, J. T.; LARITCHEV, O. Linear programming with multiple objective functions: step method (stem). Mathematical Programming, [S.l.], v.1, p.366-375, Dec 1971.

RAO, R. S.; RAVINDRA, K.; SATISH, K.; NARASIMHAM, S. V. L. Power Loss Minimization in Distribution System Using Network Reconfiguration in the Presence of Distributed Generation. Power Systems, IEEE Transactions on, [S.l.], v.PP, n.99, p.1 -9, 2012.

SANTOS, A. C. dos. Algoritmo Evolutivo Computacionalmente Eficiente para Reconfiguração de Sistemas de Distribuição. 2009. Tese de Doutorado EESC/USP.

SAnTOS, A. C.; NANni, M.; MANSOUR, M. R.; DELBEM, A. C. B.; LONDON, J. B. A.; BRETAS, N. G. A power flow method computationally efficient for large-scale distribution systems. Transmission and Distribution Conference and Exposition: Latin America, 2008 IEEE/PES, [S.l.], p.1-6, Aug. 2008.

SANTOS, A.; DELBEM, A.; LONDON, J.; BRETAS, N. Node-Depth Encoding and Multiobjective Evolutionary Algorithm Applied to Large-Scale Distribution System Reconfiguration. Power Systems, IEEE Transactions on, [S.l.], v.25, n.3, p.1254-1265, aug. 2010.

SARFI, R.; SALAMA, M.; CHIKHANI, A. Distribution system reconfiguration for loss reduction: an algorithm based on network portioning theory. IEEE Power Industry Computer Application Conference, [S.1.], p.503-509, may 1995.

SCHWEFEL, H.-P. P. Evolution and Optimum Seeking: the sixth generation. New York, NY, USA: John Wiley \& Sons, Inc., 1993.

SHIN, D. J.; KIM, J. O.; KIM, T. K.; CHOO, J. B.; SINGH, C. Optimal service restoration and reconfiguration of network using Genetic-Tabu algorithm. Electric power systems research, [S.1.], v.20, p.422-436, Feb 2004. 
SHIRMOHAMMADI, D. Service restoration in distribution networks via network reconfiguration. Power Delivery, IEEE Transactions on, [S.l.], v.7, n.2, p.952 -958, apr 1992.

SHIRMOHAMMADI, D.; HONG, H. Reconfiguration of electric distribution networks for resistive line losses reduction. Power Delivery, IEEE Transactions on, [S.l.], v.4, n.2, p.1492-1498, apr 1989.

SHIRMOHAMMADI, D.; HONG, H.; SEMLYEN, A.; LUO, G. A compensation-based power flow method for weakly meshed distribution and transmission networks. Power Systems, IEEE Transactions on, [S.1.], v.3, n.2, p.753-762, May 1988.

SOUZA BARBOSA, A. de. Fluxo de Potência em Sistemas de Distribuição: aplicações práticas. 1995. Dissertação de Mestrado — UFPB.

SRINIVAS, M. Distribution load flows: a brief review. Power Engineering Society Winter Meeting, 2000. IEEE, [S.l.], v.2, p.942-945 vol.2, 2000.

STORN, R.; PRICE, K. Differential Evolution - A Simple and Efficient Heuristic for global Optimization over Continuous Spaces. Journal of Global Optimization, [S.l.], v.11, p.341-359, 1997.

STROGATZ, S. H. Exploring complex networks. Nature, [S.l.], v.410, p.268-276, 2001.

TOUNE, S.; FUDO, H.; GENJI, T.; FUKUYAMA, Y.; NAKANISHI, Y. Comparative study of modern heuristic algorithms to service restoration in distribution systems. Power Delivery, IEEE Transactions on, [S.l.], v.17, n.1, p.173-181, Jan 2002.

VITORINO, R.; JORGE, H.; NEVES, L. Network reconfiguration using a genetic approach for loss and reliability optimization in distribution systems. In: POWER ENGINEERING, ENERGY AND ELECTRICAL DRIVES, 2009. POWERENG '09. INTERNATIONAL CONFERENCE ON, 2009. Anais. . . [S.l.: s.n.], 2009. p.84 -89.

WU, W.-C.; TSAI, M.-S. Application of Enhanced Integer Coded Particle Swarm Optimization for Distribution System Feeder Reconfiguration. Power Systems, IEEE Transactions on, [S.l.], v.26, n.3, p.1591 -1599, aug. 2011.

ZITZLER, E.; LAUMANNS, M.; THIELE, L. SPEA2: improving the strength pareto evolutionary algorithm. Tech Report, [S.l.], 2001. 